\title{
Profiles of general practice in Europe : an international study of variation in the tasks of general practitioners
}

Citation for published version (APA):

Boerma, W. G. W. (2003). Profiles of general practice in Europe : an international study of variation in the tasks of general practitioners. [Doctoral Thesis, Maastricht University]. NIVEL. https://doi.org/10.26481/dis.20030917wb

Document status and date:

Published: 01/01/2003

DOI:

10.26481/dis.20030917wb

Document Version:

Publisher's PDF, also known as Version of record

\section{Please check the document version of this publication:}

- A submitted manuscript is the version of the article upon submission and before peer-review. There can be important differences between the submitted version and the official published version of record.

People interested in the research are advised to contact the author for the final version of the publication, or visit the DOI to the publisher's website.

- The final author version and the galley proof are versions of the publication after peer review.

- The final published version features the final layout of the paper including the volume, issue and page numbers.

Link to publication

\footnotetext{
General rights rights.

- You may freely distribute the URL identifying the publication in the public portal. please follow below link for the End User Agreement:

www.umlib.nl/taverne-license

Take down policy

If you believe that this document breaches copyright please contact us at:

repository@maastrichtuniversity.nl

providing details and we will investigate your claim.
}

Copyright and moral rights for the publications made accessible in the public portal are retained by the authors and/or other copyright owners and it is a condition of accessing publications that users recognise and abide by the legal requirements associated with these

- Users may download and print one copy of any publication from the public portal for the purpose of private study or research.

- You may not further distribute the material or use it for any profit-making activity or commercial gain

If the publication is distributed under the terms of Article $25 \mathrm{fa}$ of the Dutch Copyright Act, indicated by the "Taverne" license above, 


\section{Profiles of General Practice in Europe}

An international study of variation in the tasks of general practitioners

Wienke G.W. Boerma 
ISBN 90-6905-626-7

http://www.nivel.nl

nivel@nivel.nl

Telephone +31302729700

Fax +31302729729

(C)2003 NIVEL, Postbus 1568, 3500 BN Utrecht, The Netherlands

Cover design: Lisette Jansen

Word processing / layout: Christel van Aalst

Translation: $\quad$ Vertaalkantoor drs. H. Kerkhoven; Elaine Bohlken

Printing: $\quad$ Twin Design

All rights reserved. No part of this publication may be reproduced, stored in a retrieval system or transmitted, in any form or by any means, electronic, mechanical, photocopying, recording or otherwise, without the prior written permission of NIVEL. Exceptions are allowed in respect of any fair dealing for the purpose of research, private study or review. 


\title{
Profiles of General Practice in Europe
}

\author{
An international study of variation \\ in the tasks of general practitioners
}

\section{PROEFSCHRIFT}

ter verkrijging van de graad van doctor aan de Universiteit Maastricht, op gezag van de Rector Magnificus Prof. Dr. A.C. Nieuwenhuijzen Kruseman, volgens het besluit van het College van Decanen, in het openbaar te verdedigen op woensdag 17 september 2003 om 14.00 uur

door

Wijnand Gerard Willem (Wienke) Boerma 


\section{Promotores:}

Prof. dr. J. van der Zee

Prof. dr. P.P. Groenewegen (Universiteit Utrecht)

Beoordelingscommissie:

Prof. dr. J.A.M. Maarse (voorzitter)

Prof. dr. R.P.T.M. Grol

Prof. dr. J.A. Knottnerus

Prof. dr. M. McKee (London School of Hygiene and Tropical Medicine, UK)

Prof. dr. B. Starfield (Johns Hopkins Bloomberg School of Public Health, Baltimore, USA)

The study presented in this book was funded by the European Commission in the BIOMED 1 programme (grant no. BMH1-CT92-1636) and implemented by NIVEL in collaboration with coordinators in the participating countries. 
TO NIVEL 



\section{Contents}

1 Problem, method and questions of the study 11

Introduction 12

Problem and research questions 13

Influences on the provision of GPs' services 15

Study design and methods $\quad 32$

Contents 43

2 Service profiles of general practitioners in Europe 45

Introduction $\quad 46$

Method 46

$\begin{array}{ll}\text { Results } & 49\end{array}$

Discussion $\quad 55$

3 General practice in urban and rural Europe: the range of curative services

Introduction $\quad 60$

Methods $\quad 62$

Results $\quad 64$

$\begin{array}{ll}\text { Discussion } & 72\end{array}$

4 The general practitioner as the first contacted health professional by $\begin{array}{ll}\text { patients with psychosocial problems } & 77\end{array}$

$\begin{array}{ll}\text { Introduction } & 78\end{array}$

$\begin{array}{ll}\text { Methods } & 79\end{array}$

Results $\quad 83$

Discussion $\quad 86$

5 Gender-related differences in the organisation and provision of services among general practitioners in Europe $\quad 89$

Introduction 90

Methods $\quad 92$

Results 94

$\begin{array}{ll}\text { Discussion } & 100\end{array}$ 
6 Unity or diversity? Task profiles of general practitioners in central and eastern Europe

Introduction 106

$\begin{array}{ll}\text { Method and analysis } & 107\end{array}$

$\begin{array}{ll}\text { Results } & 109\end{array}$

$\begin{array}{ll}\text { Discussion } & 114\end{array}$

$\begin{array}{lll}7 & \text { GP home visiting in } 18 \text { European countries } & 117\end{array}$

$\begin{array}{ll}\text { Introduction and aim } & 118\end{array}$

$\begin{array}{ll}\text { Backgrounds } & 118\end{array}$

Hypotheses $\quad 120$

Methods and data $\quad 121$

Results $\quad 122$

$\begin{array}{ll}\text { Discussion } & 125\end{array}$

8 General Practitioners' use of time and time management 129

Introduction 130

Sources of variation in use of time 131

Patient demand consultations and home visits $\quad 132$

Managing patient demand: practice organisation 133

Individual variation: personal characteristics $\quad 135$

The country dimension: systems and cultures $\quad 136$

$\begin{array}{ll}\text { Conclusions } & 139\end{array}$

9 Variation in workload and allocation of time under different payment systems in General Practice $\quad 145$

$\begin{array}{ll}\text { Introduction } & 146\end{array}$

$\begin{array}{ll}\text { Hypotheses } & 148\end{array}$

Data and methods $\quad 149$

Results 153

$\begin{array}{ll}\text { Discussion } & 158\end{array}$

$\begin{array}{ll}10 \text { Summary and conclusions } & 161\end{array}$

Introduction $\quad 162$

Background to the study $\quad 162$

Summary of results $\quad 163$

$\begin{array}{ll}\text { Discussion } & 172\end{array}$

$\begin{array}{ll}\text { Implications } & 176\end{array}$ 
Literature

Appendix 1: Local coordinators of the study

Appendix 2: Questionnaire of the study

Acknowledgement

Dankwoord 238

Curriculum vitae (in English)

Curriculum vitae (in het Nederlands) 


\section{Problem, method and questions of the study}




\section{Introduction}

Differences in the tasks and activities of general practitioners (GPs) do not only exist between individual GPs but also, at a higher level, between countries. The diversity in patterns of provision between individual GPs within a single health care system, is a well-studied phenomenon (Wilkin and Smith, 1987; Knottnerus et al., 1990; Van de Lisdonk and Schellevis, 1994; Delnoij and Spreeuwenberg, 1997). Variation at this level is related to individual characteristics of GPs, and the circumstances and population of the practice. Sources of variation between countries lie in the features of the health care system, such as organisation and mode of financing and regulation (Anderson, 1963; Mechanic, 1972; McPherson, 1981; Fleming, 1993; Gervas et al., 1994; Van den Brink-Muinen et al., 2000). Precise information on international differences in the provision of tasks by GPs is scanty, however, and little is known about the possible influence of features of health care systems, as a consequence. The study reported in this book is an attempt to fill the need for information on the diversity in the provision of services in general practice. Task profiles, crisply typifying the GPs' supply of services, have been compiled in European countries, and the differences will be explained by relating them to relevant characteristics of the health care systems in these countries, taking individual features of GPs and their practices into account.

The need for comparative information on primary care and general practice has been fostered by developments in European health care systems during the late 1980 s and the 1990s. Western European countries were confronted with sharply rising expenditure on health care while, at the same time, the systems were experiencing difficulties in responding to the changing health care needs of the population (Saltman and Figueiras, 1997; McKee and Healy, 2002a). New needs for health care resulted from demographic, medico-technological and societal developments. A major change has been the growing prevalence of chronic conditions resulting from the ageing of populations. The coordinative capacity of many health care systems was inadequate to enable the flexible involvement of various health care services and providers and to cope with demand for different long-term care arrangements. A coherent primary care system, with general practice as its integrative core, was thought to have the potential to improve cost-effectiveness as well as coordination and responsiveness (Starfield, 1996, 1998; Boerma and Fleming, 1998; Delnoij et al., 2000; Shi et al., 2002).

The situation in the countries of central and eastern Europe was even more urgent. Freed from communism, they had no choice but to fundamentally restructure their extensive but not very effective health care systems. As 
happened in other sectors, they looked to the West for models of provision and financing of health care. Whichever models these countries chose, the choice implied a structure of health care with a firm base of primary care, including GPs in a more or less central role and a simultaneous reduction of the hospital sector (Goldstein et al., 1996; Marrée and Groenewegen, 1997; McKee et al., 2002b). The results of the European Study on GP Task Profiles will show the state of affairs in general practice in the transitional countries and the diversity in the position of GPs in Europe as it was in the years 1993/4.

The aim of this first chapter is to provide an introduction and background. The problem and research questions of the study will be stated, the relevant influences on the activities of GPs described, and details given of the study design, instruments, methods, response and analysis. Chapters 2 to 9 contain articles that resulted from the study. The book will end with a summary of the results, a discussion and the implications for science, practice and policy.

\section{Problem and research questions Lack of information}

Despite the trend towards increasing integration, the organisation and provision of health care in European countries continues to be diverse, even within the European Union. Indeed, health care is still largely a national affair in the EU, although there are indirect effects from other policy areas (the free mobility within the EU, for example). This (informal) process is not directly driven by competences in health care or initiatives on the part of the European Commission, yet it is resulting in the gradual convergence of national health policy agendas. It has become very clear in this situation how little information is available for comparison of health services in different countries - even at descriptive level. International studies on expenditure have frequently been undertaken in fact, but research on the provision of health care to the population is scarce and handicapped by lack of data.

This lack of information and evidence is particularly noticeable in the light of the health care reforms that have occurred since the early 1990s, many of which have affected primary care. Examples are the introduction of GP fund-holding and the later Primary Care Groups/Trusts in the UK, the family doctor system in Sweden, policies in Germany, France, Norway and Finland leading to voluntary patient list systems and a stronger coordinating role for GPs (Vohlonen et al., 1989; Le Grand, 1998 Aguzzoli et al., 1999; Bundesministerium, 2000; Alban and Christiansen, 1995; Vehvilaeinen, 1996; Weiner et al., 2002). Traditional boundaries between primary and secondary care are shifting as a result of 
transfer and delegation of tasks. Policymakers assume that a stronger system of primary care and general practice will contribute to realizing the aims of more efficient health care systems that are more responsive to the health needs of citizens. Coordination, a gatekeeper role for GPs and the registration of patients with a GP are important instruments, while the transfer of tasks from secondary to primary care and new tasks created in screening, health promotion and coordination result in changing task profiles in general practice. The scale of general practice tends to increase, as do the professional requirements, particularly in countries where general practice is well developed, such as the UK, Denmark and the Netherlands (Maarse et al., 1990; Olesen and Jolleys, 1994; Saltman and Figueras, 1997; Van der Linden, 1997; Olesen et al., 1998; Dixon et al., 1998; Temmink, 2000). Health care in central and eastern Europe has been subject to much more fundamental reform. New systems have been designed, based on the view that primary care and general practice should be the health system's central function and main focus to control hospital costs. Expectations about the beneficial role of primary care and general practice in improving health of the population may be plausible, but lack a firm basis of evidence (Maynard, 1995; Sheaf, 1998). In this context, the European Study of Task Profiles in General Practice was undertaken to satisfy the need for information on the provision of GP services.

\section{Research questions}

This study aims to produce comparable information on the provision of services in general practice in Europe and to relate differences in task profiles to relevant characteristics at the level of GPs, the practice and the health care system in the countries included in the study. The following questions will be answered:

1 'What is the variation between countries and within countries in the range of tasks that GPs provide to their patients? Distinctions will be made between tasks in the patients' first contact with health problems, curative tasks related to the treatment of acute and chronic conditions, and tasks in the field of prevention and health education.'

2 'To what extent can differences in task profiles be explained by relating them to the following factors:

- individual characteristics of GPS (gender, age, education and training);

- the organisation of the practice (teamwork; equipment available; staff); 
- the local context of the practice (city or rural location, availability of hospital facilities, characteristics of the practice population);

- features of the health care system (remuneration system of GPs, GP gatekeeping, registration of patients with GPS, former communist country or western European country].'

\section{Influences on the provision of GPs' services}

General practice is typified by the provision of a comprehensive set of services in a specific community setting, with collaborative relations with other providers and services. There are many conditions and influences at different levels in health care that determine the extent to which the ideal model - as defined by the international GP community - will be realised. These influences are related to characteristics of the health care system, personal characteristics of GPs and the circumstances of the practice.

\section{General practice defined}

Many definitions of general practice have been given in the past half century but the actual situation in general practice continues to be extremely heterogeneous. Historical developments have been the origins of quite different conditions for general practice in Europe. In some countries, such as the United Kingdom and the Netherlands, a clear separation between specialist and generalist doctors was established long ago, with the latter controlling patient access to secondary care through referrals. This protected position provided the generalists with opportunities for strong professional development and eventually the recognition of generalism as a specialism in itself (Digby, 1999). In countries where general practice was not given this protected position, the boundary between general and specialist medicine continued to be blurred. In these countries, GPs and specialists compete for patients who can choose whom to consult.

A synthesis of the definitions identifies the following - ideal - characteristics of general practice:

- General: refers to the full range of unselected health (-related) problems and to all categories of the population, without exclusion by age, gender or whatever.

- First contact: as the point of first contact, services are available at all times and at a close distance - in patients' homes if necessary.

- Context-oriented: treatment also takes the person of the patient into account, the social network and the living circumstances. 
- Continuity. interventions are not limited to one episode of care but cover patients' health needs longitudinally. This requires keeping detailed and complete records of patient encounters.

- Comprehensive: services comprise curative, rehabilitative and supportive care, as well as health promotion and disease prevention.

- Co-ordination: patients are referred to other health professionals if necessary; health care resources are allocated and coordinated. These tasks require teamwork and collaboration (RCGP, 1972; Leeuwenhorst, 1974; Boerma and Fleming, 1998; Van Weel, 1999; WONCA 2002; Olesen, 2002). These attributes not only contain features of the services provided in general practice (such as dealing with all problems of unselected populations, offering first contact, curative, rehabilitative and preventive care) but also conditions and requirements enabling the provision of these services (e.g. easy access, keeping medical records, teamwork and collaboration). The degree to which conditions are met may explain differences between GPs in the provision of services. Three groups of conditions or influences on the provision of services in general practice can be identified, viz. those related to the person of the GP, those related to the practice and, at national level, those determined by the features of the health care system. These are shown in figure 1.1 and elaborated thereafter.

\section{The health care system}

A major added value of this international study is to explain the variation in task profiles of GPs by differences in selected features of the health care systems in which GPs function. The features used as variables in this study are the formal position of GPs in the access to secondary care, the dominant employment status of GPs and the mode of payment, and whether or not a country used to be part of the former communist East Bloc. In itself, the last distinction referred to between 'eastern' and 'western' countries is not a feature of health care systems, but relates to the ongoing process of fundamental transition in society in these countries, including the health care systems. These selected features are related to the basic functions in a health care system, viz. regulation, financing and provision. The way in which the functions are designed largely determines the interactions between the actors in health care systems. 
Figure 1.1 Influences on the task profiles of GPs

$$
\begin{aligned}
& \text { Individual: } \\
& \text { - gender } \\
& \text { - age } \\
& \text { - education and training } \\
& \text { - allocation of time }
\end{aligned}
$$

\section{Practice}

- teamwork

- equipment/staff support

- organisation location / other health supply

\section{Health care system}

- gatekeeping / patient list system

- payment/employment

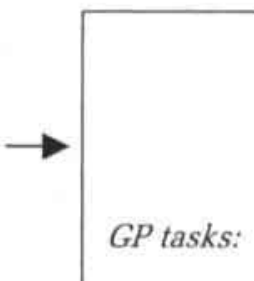

- Tasks related to patients' first contact with health care

- Curative tasks with patients presenting acute and chronic conditions

- Preventive tasks and health promotion

\section{Health care: similar actors, different interactions}

Differences between health care systems do not lie in the types of actor, but in the way these are related. The categories of actor are invariably the patients or consumers of services, the providers of services (those directly contacted by patients and those available via first level providers), the financers or insurers of health care, and governments (Evans, 1981; OECD, 1992). The interactions between the actors relate to the provision of services to patients, referrals from first level to second level providers, patients' payment of insurance premiums (or taxes), payments for services and regulation by government (see figure 1.2).

The ultimate responsibility for health care lies with the government, but the direct involvement of governments in the system may be diverse. Governance may be shared with or delegated to other actors, such as groups of professionals. 
Figure 1.2 Actors and interactions in health care (adapted from Klazinga, 1996)

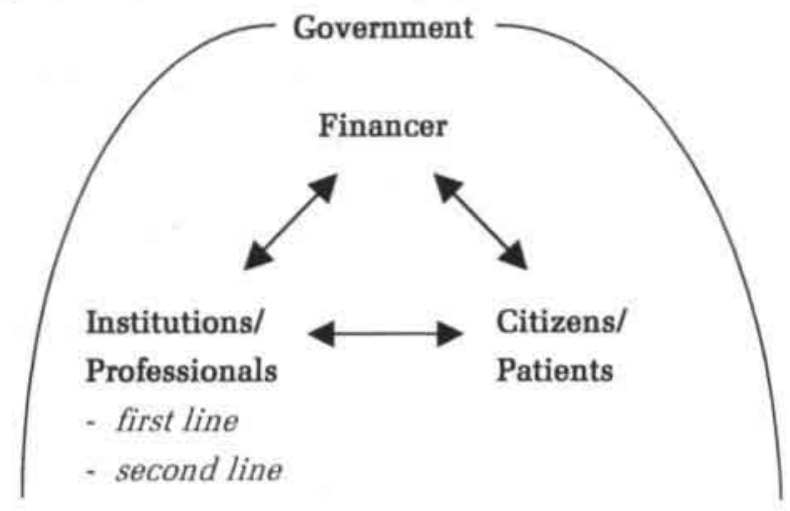

Two extreme strategies on the continuum of state involvement are comprehensive funding and provision by the state at one end, and a policy of minimum state intervention at the other, while an intermediate strategy is state harmonisation of arrangements developed among interest groups in society (labour unions, for example) (Van der Zee et al., 2003). The so-called 'Semashko systems' that used to be in place in communist countries, are examples of a dominant and comprehensive role of the state. These systems were strictly hierarchically structured with exclusive powers for authorities and the exclusion of private provision. GPs in these systems were state employed (Marrée and Groenewegen, 1997). National Health Service systems, also called 'Beveridge systems', are less extreme; funding is through taxation and services are largely provided in kind by the state. Private practitioners, such as GPs, may be contracted to the system or be allowed to work in private practice, parallel to the system. Variations of the Beveridge-type system prevail in the UK, Mediterranean countries and Scandinavia. The intermediate strategy of harmonisation applies to social security based health care systems (also known as 'Bismarck systems'), which are funded from proportional premiums earmarked for health care. In social health insurance systems, the provision of care - in general practice, for example - is mostly left to private providers and institutions (usually not-for-profit). Health care in Germany, Austria, the Netherlands, France, Belgium and Luxemburg is rooted in this type, which has recently been (re)adopted by several countries in central and eastern Europe (Marrée and Groenewegen, 1997). The strategy of minimum state intervention means that whatever possible is left to private funding and private provision, the resulting health care system usually being neither comprehensive nor equally accessible 
for all categories of the population. In Europe there are no examples of this strongly market-oriented strategy, although the American health care system resembles this scenario (Van der Zee et al., 2003).

In our study, the post-Semashko countries are examined individually and contrasted with the western countries, because the governance structure in health care changed so profoundly after the fall of communism. Most of these countries swiftly moved to capitalism and primary care was among the first sectors to be privatised in many cases, with tax funding being replaced by social insurance. Actors in health care were not prepared for their new roles; legislation was lacking, as was the professional infrastructure for maintaining the quality of care in the new situation; the newly established health insurance companies were not able to collect premiums properly and they certainly did not take up active roles as contractors or purchasers of services. Many primary care physicians went into solo practice without being able to act as entrepreneurs apart from which they were expected to transform rapidly into westernstyle GPs. Professional organisations, such as GP Colleges, were still nonexistent or just starting. This situation resulted in a vacuum of insufficient professional control, poor role setting and a general lack of direction (Preker, 2001, 2002; Boerma et al., 2003). Another important interaction is the payment of providers, which is an instrument for influencing professional activities by means of financial incentives and disincentives. The simplest method of payment is by patients, out-of-pocket, to providers. Patients may or may not be reimbursed by insurers for this expenditure, and if they are, the reimbursement received may be complete or partial. In general practice, billing schemes like this are used when GPs are paid fees per item of service. In health care systems with benefits in kind to the patients, the providers (and GPs in particular) are usually under contract to the system and paid directly by the insurers. These contractual payments are primarily lump sums per insured patient on GPs' lists, irrespective of the services provided (capitation payments). Both fee-for-service schemes and capitation payment schemes apply to self-employed GPs. This is in contrast to the third mode, viz. indirect payments made to providers who are employed by a health care organisation, such as GPs in a health centre. Insurers pay the health centre's budget, including the salaries of providers (OECD, 1992). Payment schemes and the possible effects on the provision of services in general practice will be treated in more detail later in this section.

Task profiles of GPs relate to the primary process of delivering health care in interaction with patients. At the macro level of the health care system, the 
dimension of service provision allows the classification of systems according to the degree of regulation of access and the structuring of services. Health care systems differ in the strictness of the boundaries created between primary and secondary care and the formalisation of the patients' transitions between the two levels. The distinction made between providers of the first level and those of the second level (see: Evans, 1981 and OECD, 1992) points to the option of one type of provider - usually GPs - as the entry point to health care, through which the levels of specialist services and hospital care can become available.

In terms of its function and structure, health care can be represented as a pyramid with three layers: primary, secondary and tertiary care. Primary care, the base of the pyramid, is the response to unspecified and common health problems accounting for the vast majority of the population's health needs. Problems that require more specialised medical expertise are dealt with in secondary care (which comprises outpatient and inpatient departments of general hospitals), while rare and very complex cases are treated in tertiary care in categorial hospitals. In functional terms, primary medical care is not necessarily the exclusive domain of one particular type of medical provider. In countries like Germany, France and Switzerland, no such specification has been made; services of GPs and services of ambulatory medical specialists are equally accessible and both have a role in the first contact with peoples' health problems. In other countries, such as Denmark, the United Kingdom, Portugal and the Netherlands, primary and secondary care are not only used functionally but are also organisational entities. The provision of primary care in these countries is reserved for GPs and separated from secondary care. The GP acts as the patient's agent and as the treating physician for common health problems. In 'open access' systems, with many possible points of entry, patients are supposed to be their own agents in finding the proper health care provider. Excessively strict separation between primary and secondary care, however, may threaten the overall objective of coherence and coordination in the health care system (Plochg and Klazinga, 2002; Delnoij et al., 2003). Medical information should be able to follow the patient after referral from primary to secondary care and back to primary care. New developments like shorter stays in hospitals, more complex care in the ambulatory setting and more frequent crossing of echelon borders by patients, demand a flexible management of borders.

In this study, three characteristics of the health care systems in the various countries have been selected as important influences on the practice profile of 
GPs. The first one was mentioned above and is the patients' mode of access to secondary care (the gatekeeping position of GPs); the second characteristic is the mode of payment of GPs; the third distinguishes between the former communist countries that have been transforming their health care systems profoundly since the early 1990s, and the other countries in Europe.

\section{Entry to health care and access to secondary care: patient list and GP gate- keeping}

There are a number of variants between the two extremes of patients' open access to secondary care services and a strict GP gatekeeping system. Denmark, for instance, has a GP gatekeeping system for all but a small fraction of the population, which prefers complete freedom of choice and is willing to pay for it. In the Norwegian system patients need a referral to secondary care, but several GPs may be involved in the referral process over time. In the Netherlands, where a public and a private system run parallel, not all privately insured patients need a referral. In Spain, GPs are not the only referring agents; a limited number of directly accessible specialists may also refer patients further into the specialised services (Franks et al., 1983; Boerma et al., 1993; European Observatory, 1999; 2000a,b; 2001a,b).

In addition to the diversity of referral schemes, their effectiveness is also affected by the degree to which they are observed in practice. All gatekeeping systems make an exception for emergencies that can be presented directly to hospitals or Accident and Emergency departments. The problem there is for medical staff to clearly label a problem as urgent, while it may be difficult to send non-urgent cases away without providing attention. This is a major leakage of gatekeeping systems, especially during evenings and weekends, when GP services are less available (Kulu Glasgow et al.,1998; Salisbury et al., 1999; Forrest et al., 2001).

Citizens are usually registered with a GP in GP gatekeeping systems. Whereas the aim of gatekeeping is more concerned with efficiency by avoiding unnecessary and expensive specialist treatment, the aim of patient registration is more concerned with enhancing continuity of care and GPs' responsibility for their patients' files. A system with registered patients, usually referred to as a list system, is only effective if GPs have a gatekeeping position, but patient lists are not necessarily required for a gatekeeping system. Registration is obligatory, but people are free to choose a GP on whose list they will be for a period of time; they can usually change after six months or one year. GPs need to be available to their patients and have a responsibility to offer a defined package of primary 
medical care to the patients on their list. Countries where GPs do not fulfil a gatekeeping role (such as Austria and Germany) try to reduce patients 'shopping around' from one doctor to another by means of a health insurance voucher system. Each insured is entitled to one voucher per period (usually three months), which enables him/her to visit one (contracted) doctor. Visiting more than one doctor during this period requires the permission of the health insurance fund (European Observatory, 2000c, 2001b). The methods of access affect the workload and case-mix of patients attending GPs and medical specialists, which may in its turn have implications for health care costs and the interaction between GPs and medical specialists. There is only limited evidence, however, on whether gatekeeping systems are better in terms of efficiency and coordination. Connections have been found between systems with gatekeeping GPs and better outcomes of health care in terms of costs, population satisfaction and health status of the population (Starfield, 1994, 1996; Gervas et al., 1994; Gerdtham and Jonsson, 1995; Forrest, 1996; BASYS, 1999; Doescher et al., 1999; Delnoij et al., 2000). These studies had a limited focus and the results are not unequivocal. Micro level data on the provision of services, such as those collected in our study, need to be taken into account if better insight is to be obtained into the "black box" of gatekeeping. Patients may present a wider range of health problems in countries where GPs are gatekeepers, which may result in either more comprehensive provision of services in general, or more referrals to secondary care or other professionals in primary care.

\section{Payment systems for GPs}

The mode of payment is an important incentive in influencing the professional behaviour of GPs, with respect to the services provided, coordination and teamwork, for example (Glaser, 1970; Chaix-Couturier et al., 2000; Gosden et al., 2002 , 2003). Payment schemes can be classified according to the unit of payment (Delnoij 1994). In fee-for-service systems, the items of service are the calculation unit; in capitation systems, people are the unit of payment; in a salary system, payments are made on the basis of working hours. In most countries one of these modes of payment is dominant, but elements of other methods may also exist. Apart from the three core types of system, some variants can be distinguished, viz. the integrated capitation system and mixed systems. Each mode of payment and its intended effects will be described in brief (De Maeseneer et al., 1999; Greß et al., 2003). 


\section{Fee-for-service payment}

This method, which is in place in Belgium, France and Germany, allows GPs to respond in a flexible way to the needs of patients. Financial rewards are directly related to the activities performed. Interventions by authorities or health insurers aiming at cost containment are likely to have direct effects on clinical decision-making.

\section{Capitation payment}

Payment is made per time period per patient on the GPs' list, irrespective of the number and kind of services provided to the patient. Patients usually register with an individual GP, sometimes with a group of GPs. Payment can be differentiated according to the age category of the patients and the location of the practice by way of risk adjustment (e.g. higher payments in deprived areas). Capitation payment aims to ensure equal access for all registered patients to primary medical care services, while discouraging the provision of unnecessary services and encouraging continuity over time. This system is dominant in Italy, the Netherlands and the UK. A new variant is integrated capitation payment, whereby the fee is paid for a set of services delivered by different providers who may or may not be at different levels of care (e.g. expenditure on pharmaceutical drugs and various secondary care services).

\section{Salary}

This payment is based on working hours and is not related to the volume of services provided or the number of patients cared for. In some countries with employed GPs, the GPs are allowed to have a limited private practice outside official working hours. Salary levels are usually related to qualifications and seniority, with salary payment being intended to combine income security for GPs with good access to care for patients. Salaries for GPs are becoming less popular, but are still used in several post-communist countries in transition and in Greece, Portugal, Spain, Sweden and Slovenia.

\section{Mixed systems}

Some of these are meant to put specific incentives in place for particular services. One form is the combination of a basic payment (salary or capitation) with separate payment for certain additional tasks. Payment for these tasks usually depends on whether a target has been reached (e.g. a percentage of the population at risk being screened or vaccinated). Other possibilities of "extra" earnings are function payments for tasks not included in the basic contract (e.g. 
being involved in out-of-hours services). Another variant of mixed payment is paying GPs differently for different groups of patients. In the Netherlands, for instance, GPs have a capitation payment for their publicly insured patients (about $60 \%$ of the population) and a fee-for-service for their privately insured patients (the remaining $40 \%$ ). Yet another mix, is the situation in countries where there are both salaried GPs and independent GPs (with either a fee-forservice or a capitation payment) (De Maeseneer et al., 1999; Greß et al., 2003).

The prevailing payment system will influence the activities of GPs to a certain extent. In countries where a fee-for-service scheme is in place, GPs may tend to provide more services themselves and consequently have more patient contacts and longer working days. The practice will be organised, staffed and equipped in such a way as to cope with the range and complexity of services. GPs working in a capitation system are not encouraged to provide complicated and time-consuming diagnostic services and treatments. Patients are more likely to be referred to medical specialists in these cases, increasing the importance of working relations with medical specialists as a consequence. Salaried GPs usually work in larger units with other GPs, except in remote areas, and sometimes with specialists who may provide certain primary care tasks. The available staff and equipment in the practice are decided on by the management and may place restrictions on the profile of services. If demand increases, salaried GPs will prefer to keep to the contractually agreed hours rather than to work overtime.

The actual impact of payment systems in a certain health care system depends on the context of the system and the combination with other relevant incentives. Non-financial incentives are social control mechanisms, such as performance monitoring, peer review and audits, which can be particularly effective in group practices or groups of collaborating GPs.

In our study, the combination of access to health care and payment of GPs is an important influence on the task profiles of GPs. The combination of a gatekeeping position for GPs (with registered patients) with a fee-for-service payment system may result in undesirable expanding task profiles. Salaried GPs in a gatekeeping role is a possibility, but the GPs' accountability and commitment to patients may be poor, because patients are usually registered with a health centre and not with a particular GP of their choice. In this respect, the combination of a capitation or mixed payment system with a gatekeeping role for GPs (and registered patients) may be a more favourable combination. It creates positive incentives for access, as well as the provision of first contact care and continuous and comprehensive services, although there is a threat of under-treat- 
ment, however, and a high referral rate. There are negative incentives for continuity in the case of salaried GPs, whereas incentives for first contact and coordination are absent. In a fee-for-service system there is little inclination to delegate or to share care with other providers, and there is a threat of overtreatment (Greß, 2003).

In our study, we identified the three basic systems as categories of the independent variable 'payment system'. The mixed systems have not been taken as separate categories, because that would unacceptably reduce the number of observations per category for the analysis at country level. The mixed systems were less developed at the time of data collection for the study and have been grouped under the best fitting or dominant system in the country. Table 1.1 summarizes for each country whether the GPs hold the gatekeeping position, whether patients are registered with a GP and how GPs are paid.

\section{The east-west distinction}

A distinction between the former communist countries ('central/eastern Europe') and the other countries ('western Europe') would not be justified purely on the basis of the type of health care system. Before the breakdown of the Berlin Wall, the health care systems in central and eastern Europe were of the Semashko-type, developed in the former Soviet Union and imposed on all countries under Soviet control when the Iron Curtain was erected after the Second World War. Although the system was not uniformly implemented everywhere, its general features were a strict hierarchy and exclusive powers for central, regional and local authorities. Furthermore, there was a heavy focus on specialist and hospital care and GPs, as they exist in western countries, were unknown. Health care workers were all employees and private provision was excluded (Marrée and Groenewegen, 1997; Field, 2002; McKee, 2002b; Boerma et al., 2003). The major reason for making the distinction between 'east' and 'west' is the effects of the decline of communism on health care and the developments that followed in the 1990s. The communist heritage left these countries with old-fashioned, underfunded and inefficient systems, run by poorly paid health care workers suffering from low status and morale. And last but not least, the population's health status had deteriorated and the gap with western countries had increased. The former communist countries had little choice other than to start all over again (Marrée and Groenewegen, 1997; Saltman and Figueras, 1997; McKee et al., 2002b).

In the years 1993-1994, when data were collected for the European Study of GP Task Profiles, the post-Semashko systems were dominated by this transition. 
Most countries decided to introduce a privatised primary care-based system with a core of general practice, but GPs were scarcely prepared for new tasks.

Table 1.1 Position of GPs in the health care systems in Europe: employment status, payment scheme, gatekeeping role and patient registration (situation 1993)

\begin{tabular}{|c|c|c|c|c|}
\hline Country & $\begin{array}{l}\% \text { GPs self- } \\
\text { employed }^{1}\end{array}$ & $\begin{array}{l}\text { Payment }_{2} \\
\text { system }^{2}\end{array}$ & $\begin{array}{l}\text { GPs in gate- } \\
\text { keeping role }\end{array}$ & $\begin{array}{l}\text { Registered } \\
\text { patients }\end{array}$ \\
\hline \multicolumn{5}{|c|}{ National health service: } \\
\hline Denmark & 100 & $\mathrm{Cap}+\mathrm{Ffs}$ & yes & yes \\
\hline Finland & 2 & Sal & no & no \\
\hline Greece & 30 & Sal (self: Ffs) & no & no \\
\hline Iceland & 25 & Sal + Ffs (self: Cap + Ffs) & yes & no \\
\hline Italy & 98 & Cap & yes & yes \\
\hline Norway & 58 & Ffs (emp: Sal) & yes & no \\
\hline Portugal & 1 & Sal & yes & yes \\
\hline Spain & 4 & Sal & yes & yes \\
\hline Sweden & 1 & Sal & no & no \\
\hline United Kingdom & 99 & Cap + Ffs & yes & yes \\
\hline \multicolumn{5}{|l|}{ Social insurance: } \\
\hline Austria & 99 & $\mathrm{Ffs}$ & no & no \\
\hline Belgium & 97 & $\mathrm{Ffs}$ & no & no \\
\hline France & 97 & $\mathrm{Ffs}$ & no & no \\
\hline Germany & 100 & $\mathrm{Ffs}$ & no & no \\
\hline Ireland & 91 & Cap & yes & $\begin{array}{l}\text { yes (lower } \\
\text { incomes) }\end{array}$ \\
\hline Luxembourg & 98 & Ffs & no & no \\
\hline Netherlands & 93 & $\mathrm{Cap}+\mathrm{Ffs}$ & yes & yes \\
\hline Switzerland & 99 & $\mathrm{Ffs}$ & no & no \\
\hline Turkey & 3 & Sal & no & no \\
\hline \multicolumn{5}{|c|}{ Transitional countries ${ }^{3}$ : } \\
\hline Belarus & 0 & Sal & no & no \\
\hline Bulgaria & 1 & Sal & no & no \\
\hline Croatia & 0 & Sal & yes & no \\
\hline Czech Republic & 33 & Sal (self: Ffs) & no & no \\
\hline Estonia & 1 & Sal & no & no \\
\hline Hungary & 12 & Sal (self: Cap / Ffs) & no & no \\
\hline Latvia & 3 & Sal & no & no \\
\hline Lithuania & 0 & Sal & no & no \\
\hline Poland & 0 & Sal & no & no \\
\hline
\end{tabular}


- table 1.1 continued -

\begin{tabular}{lrlll}
\hline Romania & 6 & Sal & no & no \\
Slovakia & 83 & Ffs & no & no \\
Slovenia & 1 & Sal & yes & yes \\
Ukraine & 0 & Sal & no & no \\
\hline
\end{tabular}

Sources: Boerma and Fleming, 1998; Boerma et al., 1993; 1997; Groenewegen et al., 2003

1 Percentage of self-employed GPs established in the European Study of GP Task Profiles (Boerma and Fleming, 1998)

2 Predominant payment system; if more than $25 \%$ but less than $50 \%$ has a different payment system this is noted in brackets ('self means payment system if selfemployed; 'emp' means payment system if employed)

3 There have been considerable changes in the transitional countries since the collection of these data, particularly in the Czech Republic, Hungary. Poland and The Baltic States

Many GPs had not yet been re-trained, structures for continuing medical education had failed and there were problems related to GPs' working as independent practitioners.

It was sometimes difficult to find a balance between financial objectives and pressures, and patient care. Patients, on the other hand, were not yet used to the new role of GPs. This situation affected the range of services that GPs could offer to patients.

\section{Urban or rural location of the practice}

Within health care systems, the geographical situation of the practice location is related to the provision of services in general practice. Health services are generally more widely available in conurbations than in the countryside, where GPs are often the only providers. The prevailing regulations for access and use of services may be more difficult to enforce in cities, where there is a more extensive supply of health services. Patients can take problems that would otherwise be presented to GPs to the Accident and Emergency departments of hospitals, for example. In addition, there may be differences in availability and quality of services that are related to the geographical location. There is concern about poor health services in remote rural areas in several countries (Horner et al., 1993; Lucas and Tonnelier, 1995), although this is also a problem in unattractive inner city areas (Talbott, 1991; Hastings and Rashid, 1993). In compensation, GPs working in underprivileged areas in the UK and in the Netherlands qualify for income supplements. The distance between the place where patients live and the health care facilities affects the use of these 
services, which also applies to general practice, longer distances being related to lower utilisation of services (Dopheide, 1982; Verheij, 1996). Demand for health care also differs between urban and rural populations, with urban populations making more use of certain services, such as home care and specialist care (outpatient and inpatient), than their rural equivalents, (Verheij and De Bakker, 1994). Results of studies on differences in the utilisation of GP services are equivocal. Some studies reported a higher utilisation of GP services in rural areas, while Dutch studies found more frequent contacts between patients and their GPs in cities (i.a. Haynes, 1991; Gloerich and Van der Zee, 1992). Where the scope of GP services is concerned, Fearn (1988) found British rural GPs to be more involved in minor surgery and the insertion of intrauterine contraceptive devices than their urban colleagues. Several studies have reported higher referral rates by urban GPs, although the evidence is inconclusive - at least for the UK (Wilkin and Smith, 1987). In the Netherlands, Verheij et al. (1992) reported that urban GPs initiated more laboratory investigations and undertook fewer medical procedures than their rural colleagues. Sixma (1996) monitored hospital-based emergency services following the opening of a new suburban hospital and reported substitution of services formerly provided by local GPs. It may be concluded that general practice is not similar in cities and in rural areas. Rural GPs provide a wider range of services, which seems to be related to the greater distance to other health care facilities and probably a different attitude on the part of the population.

\section{The practice}

In addition to the geographical situation of the practice and the surrounding health facilities, there are features of the practice itself that affect the workload and type of activities of GPs. These features are associated with patients' demands and the organisation, staff and other resources in place to cope with these demands. The most obvious influence, where demand is concerned, is the size of the service population (either in terms of patients on the GPs' list or the regularly attending clientele). Furthermore, morbidity and medical consumption, and the tasks of GPs by extension, are related to the age and gender of patients, while the social class of the practice population is another significant factor in the work of GPs. People with lower socio-economic status have lower scores on most indicators of health than those with higher socio-economic status (Mackenbach et al., 1997; Van der Velden 1999). In general practice, social patterns are found in the morbidity presented to and the treatment offered by the GP. The ethnicity of the practice population is related to social 
class, particularly when there are large proportions of immigrants. These categories of patients often combine lower social class with a deviant pattern of morbidity, although cultural differences which may hamper the communication with the GP are probably more important (Weide and Foets, 1998).

There may be major differences in the organisation of supply of services in general practice in response to the needs and demands of the population, a situation which is obviously related to the tasks and functions of GPs in a country and the norms and incentives created for that purpose (Okkes et al., 2002). In countries where GPs are self-employed, they are often responsible for the provision of premises, equipment and supporting staff, while health authorities bear these responsibilities in countries where GPs are employees. Whoever may be involved, arrangements must be made to facilitate patient access to the practice and an appropriate provision of services. The following topics have been considered in the study.

\section{Cooperation with other professionals}

Cooperation in primary care can take different forms. GPs may work alone, or share premises with one or more colleagues in partnerships and group practices. The size of group practices varies and may be more than 10 GPs, while medical specialists, such as internists, gynaecologists and paediatricians, may also be included in group practices. Where there is multidisciplinary cooperation, GPs may work in a team with other professions in primary care, such community nurses, physiotherapists, midwives, social workers and occupational therapists. Multidisciplinary teamwork may be difficult if the employment status and backgrounds of team members are very different, if some are self-employed for instance and others are employed by an external body. Physicians used to work in large units in central and eastern Europe, except in rural areas, but privatisation has changed this situation for GPs in several of these countries. Teamwork may increase the possibilities overall, but the range of services provided by individual team members may be reduced if specialisation occurs.

\section{Staff and equipment}

Ancillary staff include those who facilitate administrative operations within the practice, such as answering the telephone, arranging appointments, filing records and distributing information leaflets. Secretaries or receptionists may also have audit tasks, which are necessary for the monitoring of practice operations (when there are item-of-service payments, for example). Other 
professional staff may include practice nurses who are particularly involved in the application of medical techniques and health education and there are also managerial functions, especially in larger group practices and multidisciplinary health centres. The premises and the practice equipment are both part of an integrated package. The equipment should enable GPs to provide the diagnostic, treatment and preventive services included in the task package, which is why the equipment in a practice reflects the position of GPs. Where GPs are in competition with specialists in primary care, the latter will probably have more and more sophisticated equipment than GPs in gatekeeping situations. It may not be necessary for GPs to have expensive equipment, such as ECG and X-ray, if these services are readily available outside the practice with results at short notice. Lack of equipment may reduce the tasks that GPs can provide to patients (Marsh, 1991a).

\section{Keeping medical records}

High quality and systematically kept medical records are necessary for the treatment of disease. They serve as reminders for the GP and other staff, define the risk status of the patient and can be used for monitoring, auditing, research and teaching in the practice. Computer files were increasingly replacing paper records as much as ten years ago, but the computer has more to offer than faithful and comprehensive records of the results of examinations, investigations, prescriptions and referrals. It can also provide an integrated information system for (authorised) professionals in primary and secondary care and thus contribute to continuity and coordination of care. An electronic record system may also help identify and monitor patient groups at risk. Keeping comprehensive medical records allows GPs to provide screening and surveillance tasks and services where continuity is important; in the care of chronic patients for example (Hjortdahl and Borchgrevink, 1991; Metsemakers et al., 1996; Knottnerus, 1999).

\section{Organisation of the practice}

Demand and supply in general practice are related by the organisation of access: the opening hours of the practice, an appointments system, the availability of services outside office hours, by telephone and in the patient's home. The use of an appointments system (in contrast to open surgery hours) is an important instrument for allocating time efficiently and managing the GPs' workload (Groenewegen and Hutten, 1995). Out-of-hours services can be organised by reciprocal arrangements in group practices, locum practitioners are usually employed on a rota basis in solo practices. The availability of home visits is an 
important aspect of access for seriously ill or disabled patients who are unable to reach the office. Not all home visits need to be made by GPs, however, and visits for healthcare screening of the elderly can be undertaken by practice nurses. There are arguments against home visits and the frequency of these is decreasing in most countries (Hallam, 1994). Problems are the extra time involved, the difficulty of examining a patient thoroughly in the home and increasing aggression related to home visiting in some areas. Patients often appreciate having the option of consultation by telephone, in addition to vis-a-vis consultations. Some patients may perceive efficiently organized practices as a limitation to instant access, but this will generally be the best use of the available resources for prioritised tasks (Marsh, 1991b).

\section{The GPS}

Variation between GPs at the individual level is a well known phenomenon. Competence of GPs is a blend of knowledge, skills, experience and personal characteristics, partly resulting from training and (continuing) education.

\section{Age and gender}

The age and gender of GPs explain some of the differences in competence. Older GPs are usually more experienced and may have better knowledge of the (older) patients, but younger GPs may be better informed about the latest insights and skilled state-of-the-art. Older GPs seem to make more frequent home visits, but are less involved in out-of-hours care; they spend less time on diagnostics and more on advising and counselling than younger ones (Majeed et al, 1995; Salisbury et al., 2000). The influences of GPs' age and gender are hard to separate, because in many countries female GPs are younger and prefer to work in urban practice. As a result, for female GPs their training has taken place more recently and may have placed greater emphasis on preventive care and psycho-social aspects. There is evidence that female GPs are preferred by women with gynaecological, endocrinological, and psycho-social problems; that female GPs apply fewer technical procedures and that they more frequently use counselling techniques. Female physicians have higher screening rates in preventive services, especially for cervical and breast cancer, and the higher involvement of female doctors was also reported in family planning and perinatal care. Where the organisation of the practice is concerned, there is conflicting evidence of gender-based differences in working hours, length of consultation, home visits and on-call arrangements (Van den Brink-Muinen and De Bakker, 1994; Bertakis et al., 1995; Chambers and Campbell, 1996). 


\section{Education and training}

The completion of an approved postgraduate training for general practice is now mandatory in all countries of the European Union and many pre-accession countries, but the training programmes are still quite diverse, particularly in the degree to which they are rooted in general practice (Heyrman et al., 2003).The necessity and procedures for periodic re-accreditation as a means of quality assurance are being discussed in several countries. In most countries, requirements for keeping up-to-date refer to a minimum number of hours per year spent on accredited CME courses and other activities focused on keeping up-todate. Examinations, other tests of knowledge and skills, and practice visitation are considered to be more effective means of maintaining and improving the quality of GPs. The intention of education and training is to improve the GPs' performance of professional tasks. More training and more time devoted to continuing education may extend the range of diagnostic and treatment services.

\section{Study design and methods}

The study is a cross-sectional survey in a large number of countries, using a multi-level design with data collected at the level of individual GPs and practices and at the level of health care systems. This design was decided on after consideration of alternative approaches to answering the questions of this study. Data on the role of GPs in the first contact and curative and preventive services could have been collected by means of patient surveys, which would have resulted in precise information from the patients' perspective on the role of GPs in relation to various problems. It would have been difficult, however, to relate these data to the level of individual practices and GPs. Another possibility would have been a combination of practice observations and patient interviews, but that would not have been feasible for a large- scale study like this one. Contact registration by GPs, supplemented by a survey among these GPs to collect personal and practice data would have been be a third option. This would have been feasible in countries with computerised registration networks in general practice, but networks like that did not exist in most countries ten years ago, and even if they did, not all of these networks would be able to produce the comparable data needed. Given this situation of a poor infrastructure and little tradition of health service research in most European countries, a survey was the best option and the method chosen will remain useful in future in compiling an overview comprising many countries - perhaps in a replication of this study. More in-depth questions generated by general surveys can be addressed by additional studies, using appropriate methods. 


\section{Development of the instruments}

Three methods of data collection were used in this study, viz, a questionnaire, a workload diary and desk research.

The questionnaire and the workload diary were the instruments used in the survey among GPs, while the purpose of the desk research was to produce background information at country level on the position and remuneration of GPs in the health care systems.

The questionnaire, consisting of 11 pages, was in the national languages and contained sets of questions relevant to personal characteristics of the GPs', the provision of tasks, details of the practice and cooperation with other providers. The unabridged questionnaire has been attached as Appendix 2; figure 1.3 provides an overview of the sections and topics of the questionnaire.

The one-page diary was pre-structured and covered seven successive days in a normal week; one column for each day. GPs were asked to record their (main) activity in time slots of one hour, starting at 7.00 hours in the morning until 22.00 hours in the evening. For the night hours between 22.00 and 7.00 hours the next day, respondents were asked just to fill in if they were or were not in charge of emergencies and the number of calls they had answered in that period of time if they were. Filling in the diary could start on any day of the week, but it had to be kept for seven consecutive days. It was suggested to respondents that they fill in the diary retrospectively at the end of each day. For each time slot of one full hour, respondents were asked to fill in the code of the most applicable activity as listed at the bottom of the diary page. Figure 1.4 shows the activity codes that respondents could choose. The full workload diary is also included in Appendix 2.

\section{Development of the questionnaire and workload diary}

The development of the questionnaire started with the listing of topics and items from other studies, in particular the so-called Interface Study and the First Dutch National Survey of General Practice (Crombie et al., 1990; Foets and Van der Velden, 1990). A provisional version of the questionnaire was discussed and amended at a working conference in Utrecht attended by the national coordinators, prior to the implementation of the study. The general objective of the selection of items for the questionnaire was to arrive at items that were expected to show differences in task provision between GPs. Obvious GP tasks in most countries were not taken into account as a consequence. 
Figure 1.3 Sections and subjects of the questionnaire

\begin{tabular}{|c|c|c|}
\hline \multicolumn{2}{|c|}{ Section } & Subjects \\
\hline 1 & $\begin{array}{l}\text { Practice and } \\
\text { personal } \\
\text { information }\end{array}$ & $\begin{array}{l}\text { Demographic data } \\
\text { Education and training } \\
\text { Employment status; normal working hours } \\
\text { practice } \\
\text { - Working arrangement; teamwork } \\
\text { - Pverage workload; home visits; emergency services } \\
\text { Practice organisation; staff and equipment } \\
\text { Medical record keeping; use of computer }\end{array}$ \\
\hline & $\begin{array}{l}\text { Provision of } \\
\text { medical } \\
\text { technical } \\
\text { procedures }\end{array}$ & $\begin{array}{l}\text { A list of } 14 \text { medical techniques, such as: } \\
\text { - Wedge resection of ingrowing toenail } \\
\text { - Wound suturing } \\
\text { - Insertion of IUD } \\
\text { - Fundoscopy } \\
\text { - Strapping an ankle } \\
\text { - Setting up an intravenous injection etc. } \\
\text { Perceived involvement of the GP if patients in the practice } \\
\text { population need such procedures could be indicated on a five- } \\
\text { point scale ranging from '(almost) always' to 'seldom/never'. }\end{array}$ \\
\hline & $\begin{array}{l}\text { Provision of } \\
\text { first contact } \\
\text { care }\end{array}$ & $\begin{array}{l}\text { 27 Short case descriptions of patients' health problems such as: } \\
\text { - Child with a rash } \\
\text { - Woman aged } 18 \text { asking for oral contraception } \\
\text { - Man aged } 24 \text { with chest pain } \\
\text { - Woman whed } 50 \text { with a lump in her breast } \\
\text { - Woman aged } 60 \text { with acute symptoms of paralysis/paresis } \\
\text { - Man aged } 29 \text { with lower back pain } \\
\text { - Couple with relationship problems } \\
\text { - Woman aged } 50 \text { with psychosocial problems related to her } \\
\text { work } \\
\text { Perceived degree to which such cases were presented to the GP if } \\
\text { occurring in the practice population could be indicated on a five- } \\
\text { point scale ranging from '(almost) always' to 'seldom/never'. }\end{array}$ \\
\hline
\end{tabular}




\begin{tabular}{|c|c|c|}
\hline 4 & $\begin{array}{l}\text { Provision of } \\
\text { screening, } \\
\text { preventive care } \\
\text { etc. }\end{array}$ & $\begin{array}{l}\text { Questions about the GPs' routines concerning: } \\
\text { - Measuring blood pressure } \\
\text { - Measuring blood cholesterol level } \\
\text { - Taking cervical smears for cancer screening } \\
\text { - Examination for breast cancer screening. } \\
\text { Questions about involvement of GPs in: } \\
\text { - Health education clinics on smoking cessation, food } \\
\text { intake and alcohol consumption } \\
\text { - Intra-partum care } \\
\text { - Paediatric surveillance clinics } \\
\text { - Family planning / contraception } \\
\text { - Homoeopathic medicine }\end{array}$ \\
\hline 5 & $\begin{array}{l}\text { Provision of } \\
\text { disease } \\
\text { management }\end{array}$ & $\begin{array}{l}\text { A list of } 17 \text { diseases, such as: } \\
\text { - Hyperthyroidism } \\
\text { - Peptic ulcer } \\
\text { - Congestive heart failure } \\
\text { - Peritonsillar abscess } \\
\text { - Uncomplicated diabetes type } 2 \\
\text { - Depression } \\
\text { Perceived involvement of the GP in the treatment if such cases } \\
\text { occur in the practice population could be indicated on a five- } \\
\text { point scale ranging from '(almost) always' to 'seldom/never'. }\end{array}$ \\
\hline 6 & Job satisfaction & $\begin{array}{l}\text { Seven statements on aspects of GPs' work, such as: } \\
\text { - 'I feel that some parts of my work do not really make sense' } \\
\text { - 'My work still interests me as much it ever did' } \\
\text { - 'Assuming that pay and conditions were similar, I } \\
\text { would just as soon do non-medical work' } \\
\text { Agreement could be expressed on a five-point scale, varying } \\
\text { from 'agree strongly' to 'disagree strongly'. }\end{array}$ \\
\hline
\end{tabular}


Figure 1.4 Activity codes for use with the 7-days workload diary

\begin{tabular}{|c|c|}
\hline Part of the day & Activity codes \\
\hline $\begin{array}{l}\text { Daytime and evening } \\
\text { (between } 7.00-22.00 \text { hours) } \\
\text { (code for the dominant activity per time } \\
\text { slot of one hour) }\end{array}$ & $\begin{array}{ll}1 & =\text { patient contacts in the surgery } \\
2 & =\text { visiting patients at home } \\
3 & =\text { visiting patients in the hospital } \\
4 & =\text { on call duties / emergencies } \\
5 & =\text { infant welfare clinic } \\
6 & =\text { travelling (professional) } \\
7 & =\text { meeting other health professionals } \\
8 & =\text { practice administration etc. } \\
9 & =\text { teaching, research, etc. } \\
10 & =\text { private time, breaks, etc. } \\
11 & =\text { other activities }\end{array}$ \\
\hline $\begin{array}{l}\text { Night } \\
\text { (between } 22.00-7.00 \text { hours) } \\
\text { (no further subdivision) }\end{array}$ & $\begin{array}{l}\text { - either or not in charge } \\
\text { - if in charge: number of night calls }\end{array}$ \\
\hline
\end{tabular}

The workload diary was also derived from a diary previously developed for use in the First Dutch National Survey (Foets and Van der Velden, 1990; Groenewegen et al., 1992a). The adaptation for use in this international study took place in a similar way as the development of the questionnaire.

The draft versions of the questionnaire and the workload diary (in English) were piloted in a few countries, resulting in the final versions for translation into the relevant national languages. Translation took place in successive steps. First translations were produced under the responsibility of the national coordinators and these local translations were compared with independent translations made by official translators in the Netherlands, coordinated by NIVEL. These were subsequently fed back to the local coordinators, who decided on the final versions.

With two exceptions, design, final text processing and printing of the 26 language versions of the questionnaire and the workload diary were executed in the Netherlands under the responsibility of NIVEL. All questionnaires had basically the same exterior, with uniform covers on which the title of the study was printed in all languages and national coordinators could decide to have a national logo on the cover, in addition to the logos of WHO and NIVEL. The introductory text sent with the questionnaire differed from country to country. 
It was often an official letter on the first page, written and signed by a national GP organisation or GP department that supported the study.

\section{Desk research}

Information on the level of health care systems was needed to construct national variables first of all, such as the employment status and payment of GPs and the mode of patients' access to health care, but insight into differences in the context of primary and secondary care was indispensable, however, in order to understand the results of the study. This information was not readily available and was gathered from the literature, statistical yearbooks and databases by a small team at NIVEL. In order to promote the comparability of the information, a uniform structure was maintained for the description of each country, under the following headings:

- General information on the country (geography, political system, some history, economy).

- Statistical key figures on population, development, economy and health and mortality.

- Organisation of health care.

- Health financing and insurance.

- Trend in health expenditure.

- Secondary care.

- Primary care.

- General practice.

- Training and education of GPs.

National coordinators contributed from other sources when information in English was not available and, in cases where written sources were lacking, the national coordinators of the study also provided as much of the missing information as possible, sometimes after consulting experts in their own countries.

The overview of general practice in national contexts that resulted from this background study was published as a book on the occasion of the 1993 WONCA-SIMG Congress in The Hague (Boerma et al., 1993).

\section{Sampling procedure}

The aim was to include all countries belonging to the WHO European Region in the study. For practical reasons (e.g. no coordinator found who was able to implement the study; very poor infrastructure; instability due to war), most countries belonging to the former Soviet Union, as well as some countries of the 
former Yugoslavia could not be included. In some other cases (Ukraine and Slovakia) reasons of discontinuity resulted in severe delays in data collection, the worst delay being well over one year. The number of countries to be included had to be sufficient to allow the application of multi-level analysis, with the countries being the higher order units.

The sampling procedure applied within countries was intended to facilitate intra-country analyses of subgroups of GPs practising in different conditions of urbanisation. GPs working in inner cities, in towns and in rural areas would be compared. These categories were to be roughly equally represented in the sample. The preferred procedure was a random national sample of the target group of physicians identified. If the response in one of the categories was below the required number, the sample was then to be extended in that stratum. The total sample size per country depended on the expected response rate, which was often a mere guess in the absence of studies like this one. A power analysis was not possible, since we did not know enough about the size of the effects to be expected. The number of completed questionnaires required per country was fixed at $200 \mathrm{GPs}$ (and less in the smallest countries, viz. Iceland and Luxemburg).

A special problem in some countries in central and eastern Europe was to define the target population. Since GPs were virtually unknown in many of these countries, district doctors were recruited as the primary care physicians most resembling GPs.

National samples were not feasible in many countries, especially in eastern Europe. Physicians were sampled in a limited number of pre-selected regions in these cases, taking note of the degree of urbanisation of the relevant regions. Samples of polyclinics or health centres were drawn when samples of individuals were not practicable and the physicians working in these facilities were subsequently asked to participate, an approach that proved to be very effective. Other concessions to the desired recruitment procedure were also necessary in (mostly western) countries where participation was expected to be extremely low. In Belgium, for instance, GPs affiliated to the Belgian College of General Practitioners were approached to supplement a first random sample with low response. In Germany, questionnaires were distributed to a random sample in one of the Länder and to teachers in general practice all over the country. In France, recruitment was achieved by opportunistic sampling using advertisements in two popular medical journals. 


\section{Organisation and implementation}

The European GP Task Profile Study was funded by the European Commission within the framework of the BIOMED 1 programme. It was carried out by NIVEL in collaboration with a network of national co-ordinators who were involved at all stages. Two conferences of national coordinators were organised; one in the initial stage of the study to discuss and comment on the draft questionnaire and a second at a later stage, for the presentation of first results. In accordance with agreed procedures, these coordinators were responsible for the implementation of the study in their countries. After publication of the initial results, the complete study data base was placed at their disposal for their own purposes, and many presentations and publications have indeed resulted in the countries involved. The names of the national coordinators are listed as an annex to this book.

The WHO Regional Office for Europe has provided important support at all stages of the study and is also a user of its results. Many results were published in a WHO sponsored book for example, which was published in 1998 and later translated into Russian (Boerma and Fleming, 1998). This has helped with the dissemination of the results of the study.

\section{Response}

A total of 7,895 GPs and primary care physicians participated. In most countries, a random sampling procedure was achieved (see table 1.2), although selection bias may have occurred because response rates were low (below $50 \%$ ) in many countries. It is purely a matter for speculation whether bias due to selective recruitment among the random sample is different from bias due to selective recruitment for other reasons. With the exception of Turkey, there was general under-representation of urban doctors.

In the majority of the 21 countries for which data were available, the responding GPs appeared to be a fair representation of the population when age and gender distribution were compared. There were minor under-representations of females and of the youngest and oldest age groups. In three quarters of the countries involved, the mean age of respondents was within two years of the national mean and the proportion of female GPs within $5 \%$. 
Table 1.2 Response and sampling procedures

\begin{tabular}{|c|c|c|c|}
\hline Country & $\begin{array}{r}\text { Forms } \\
\text { returned }\end{array}$ & Respons rate & $\begin{array}{l}\text { Sampling } \\
\text { procedure }\end{array}$ \\
\hline Austria & 301 & $50 \%$ & B \\
\hline Belgium & 518 & $28 \%$ & D \\
\hline Bulgaria & 242 & $84 \%$ & C \\
\hline Croatia & 202 & $59 \%$ & C \\
\hline Czech Republic $^{b}$ & 132 & $51 \%$ & C \\
\hline Denmark & 196 & $56 \%$ & B \\
\hline Estonia & 165 & $70 \%$ & B \\
\hline Finland & 239 & $42 \%$ & B \\
\hline France & 235 & n.a. & E \\
\hline Germany & 169 & $44 \%$ & D \\
\hline Greece & 179 & $33 \%$ & B \\
\hline Hungary & 162 & $36 \%$ & B \\
\hline Iceland & 52 & $37 \%$ & A \\
\hline Ireland & 130 & $65 \%$ & B \\
\hline Israel & 673 & $78 \%$ & B \\
\hline Italy & 345 & $51 \%$ & D \\
\hline Latvia & 227 & $45 \%$ & C \\
\hline Lithuania ${ }^{b}$ & 333 & $87 \%$ & C \\
\hline Luxembourg & 54 & $30 \%$ & A \\
\hline Netherlands & 210 & $53 \%$ & B \\
\hline Norway & 164 & $52 \%$ & B \\
\hline Poland & 277 & $46 \%$ & C \\
\hline Portugal & 151 & $38 \%$ & B \\
\hline Romania & 232 & $52 \%$ & C \\
\hline Slovakia & 179 & $45 \%$ & D \\
\hline Slovenia & 162 & $65 \%$ & D \\
\hline Spain ${ }^{b}$ & 574 & $42 \%$ & B \\
\hline Sweden & 209 & $52 \%$ & B \\
\hline Switzerland & 200 & $50 \%$ & B \\
\hline Turkey & 199 & $50 \%$ & C \\
\hline Ukraine & 485 & $69 \%$ & C \\
\hline United Kingdom & 301 & $30 \%$ & B \\
\hline TOTAL & 7,895 & $51 \%$ & \\
\hline
\end{tabular}

Codes: $\mathrm{A}=$ (almost) entire GP population; $\mathrm{B}=$ random national sample (stratified or not); $C=$ random sample in pre-selected regions; $D=$ mixed procedure (random procedure plus selected GPs); E='opportunity sampling'/volunteers (response rate not b applicable, n.a.)

Additional samples of paediatric GPs, drawn in this country, not included 


\section{Data reduction}

Involvement of GPs in three major task areas was measured by means of questions with answers on a four-point scale, varying from '(almost) always' to 'seldom/never'. The following scale construction and analysis procedure was applied to arrive at individual scores per GP in each of these three task areas (involvement in first contact care; involvement in the provision of medical technical procedures; involvement in treatment of diseases).

- Missing value

If a respondent failed to complete $25 \%$ of the questions covering a task area, all data covering that area were excluded from the analysis. The mean score of that item in that country was applied for missing data within this limit.

- Skewness of items

Items were considered extremely skew if at least $85 \%$ of the respondents answered on one side of the four point scale (either on the positive or the negative side). These items were excluded from the averaging procedure.

- Scale reliability

The consistency of the remaining items was calculated using Cronbach's $\alpha$. A satisfactory scale should at least have a Cronbach's $\alpha=0.75$.

- Principal components analysis

This analysis made it possible to identify factors within scales. The only factors used were those that could be labelled and are relevant to this study. The outcome of this data reduction procedure is shown in table 1.3.

Table 1.3 Outcome of the data reduction procedure

\begin{tabular}{lrlr}
\hline Task area & $\begin{array}{r}\text { Number of } \\
\text { items left }\end{array}$ & Scales/factors & Cronbach's $\alpha$ \\
\hline First contact care & 22 & - all problems (total scale) & 0.94 \\
& 5 & - acute health problems & 0.86 \\
& 5 & - health problems of children & 0.91 \\
& 5 & - health problems of women & 0.87 \\
Medico-technical & 7 & - psycho-social problems & 0.90 \\
$\quad$ procedures & & & \\
Treatment of diseases & 10 & - total scale only & 0.89 \\
\hline
\end{tabular}

Sub-scales were only identified and labelled in the task area of first contact care. The reliability of all scales and sub-scales satisfies a Cronbach's $\alpha$ varying from 0.86 to 0.94 . 
The fourth task area, relating to preventive medicine and health education, was measured by means of other types of questions. The answers have been dichotomized, distinguishing between preventive approaches (with score=1) and more incidental approaches (with score $=0$ ). Answers indicating a routine approach (regardless of the reason for going to the GP) were regarded as being preventive, as was the organisation of special clinics to which people were invited. Scores for involvement in preventive care were obtained by totalling the scores per item. Answers to questions relating to involvement in immunisation of children and paediatric surveillance simply resulted in sum scores between 0 and 2 .

Involvement in health education was measured as prevention (with score $=1$ ) when special sessions were provided to deal with food intake, smoking cessation and alcohol consumption, so the maximum score here was 3 . National scores on task areas were calculated by averaging the individual scores.

\section{Data analysis}

Data entry, data processing and analyses were carried out at NIVEL, using the SPSS software for basic analyses and data reduction, and MLwiN for multilevel analyses.

Multilevel analysis (MLA) was used because of the hierarchical nature of the data with GPs hierarchically nested within countries. The use of MLA in health systems and health services research is a relatively new development (Rice and Leyland, 1996; Leyland and Groenewegen, 2003). MLA is appropriate, whenever units on which the outcome variable is measured are nested within larger units, such as patients within hospitals or indeed GPs within countries. MLA allows us to decompose the variation between GPs in a part that is common to all GPs in a given country and a part that is related to the individual GPs. As an example one could think of the working hours of GPs; the average number of hours GPs work differs systematically between countries and individual GPs in a given country deviate from the country average. MLA also allows us to analyse variables at the country level and at the GP level at the same time. In older approaches either all GP variables would have to be aggregated to country level or all country level variables would have to be distributed to GP level. By aggregating all data to country level a lot of information is thrown away. If country level data are distributed over the individual GPs, the statistical analysis does not take into acćount that the observations on GPs in the same country are not independent of each other (one of the requirements for regression analysis). Moreover, the standard errors of the coefficients of country 
level variables will be artificially small, because they are computed on the basis of the number of GPs and not on the basis of the number of countries.

In our study we have used two levels, the country and the individual GP. This is in line with the preferred sampling procedure: a random sample of GPs within countries. In some countries this was not possible and other procedures were used. In fact this introduces dependencies within the data in certain countries; in these countries either regions or health centres/ policlinics were selected and than GPs within these units. It was, however, not possible to take this into account, because it is not known from which units individual GPs were selected in these cases.

\section{Contents}

The results of the study will be reported in the following chapters. Chapter two is a general overview of the profiles of the curative and preventive tasks of GPs in European countries. The results will also be presented for groups of countries that share characteristics of the health care system that are relevant to the position of GPs. The subject of chapter three is the differences in the services delivered by GPs working in urban and rural practices, when other effects of the health care system or personal and practice characteristics are taken into account. The focus of the fourth chapter is on one specific task, viz. GPs' first contact with psycho-social problems occurring in the practice population. The question is why some GPs are more involved in this care than others and whether differences are related to the GPs' position in the health care system. Chapter five deals with differences in the task profiles of male and female GPs and examines whether these differences persist in all countries and irrespective of the type of health care system. The sixth chapter studies the diversity of task profiles of GPs within the group of post-communist countries and in comparison with task profiles in the western countries. In chapter 7 , the point of attention is the place of service delivery, in the GPs office or in the patients' homes. To what extent can home visiting practices be explained from differences in patient demand, personal characteristics of the GP and the mode of payment? Chapters eight and nine are both about the GPs' working hours, workload and use of time, and the various influences exerted by the GPs and the organisation of the practice, as well as conditions at national level. Chapter nine focuses specifically on the role of different payment systems. Results are summarised in the final chapter and implications are described for health services research, health policy and general practice. 


\section{Service profiles of general practitioners in Europe}

This chapter was published as:

Boerma WGW, Van der Zee J, Fleming DM. Service profiles of general practitioners in Europe. British Journal of General Practice, 1997; 47: p.481-486. Reproduced with permission of the British Journal of General Practice. 


\section{Introduction}

Variation in medical practice and health care utilisation is well known. Studies on hospital admissions and surgical procedures have pointed to supply factors, such as the density of medical specialists, as determinants of national and regional differences (Vayda, 1973; Kohn and White, 1976; McPherson et al., 1982; Van der Zee et al., 1990; McPherson, 1990).

In countries where access to health care is controlled by GPs, there is some evidence of better health levels and lower costs (Starfield, 1994). Although obvious demographic variables explain some of the variation, much is unexplained, perhaps because of "... a broad zone of uncertainty in which optimal treatment and the limits of efficacy have not been scientifically established" (Evans, 1984).

There have been a number of international comparative studies in primary care. Mechanic (1972) showed quite different types of practice in the United States (US) and Great Britain. Hull's (1978-1982) accounts of practice visits showed differences in the workload and tasks of GPs. Grol et al. (1990) examined referral behaviour in Belgium, the Netherlands and the United Kingdom (UK) and found significant differences in the GP's attitudes towards taking risks. The method of remunerating GPs affects the range of services offered (Groenewegen et al., 1991; Delnoij, 1994; Sandier, 1989). Crombie et al. (1990) conducted an enquiry among GPs in 15 European countries using a structured interview and concluded that the gatekeeper role and the system of remuneration influenced the tasks undertaken. Fleming (1992) reported on 44,000 referrals by 1,500 doctors, in 15 European countries. Referral patterns were associated with the density and the remuneration of both GPs and specialists, the mode of access to secondary care and the traditional vocational training scheme for general practice.

This study concerns the range of services offered by GPs in European countries and their relationship to health care systems.

\section{Method}

The study was based on a questionnaire completed by samples of GPs in each of 30 countries of Europe. The questionnaire was designed to highlight particular aspects of service provision, access to health care, and the comprehensiveness, continuity of GP services (McWhinney, 1989; WONCA, 1991). It included the GP's activity:

- as the doctor of first contact in health related matters;

- in minor surgical and investigative procedures; 
- in the management and follow-up of a broad range of acute and chronic diseases;

- in preventive medicine.

In each of these four areas, a series of health problems was presented and GPs were asked to describe their involvement on a pre-coded scale. For example, 'first contact' was measured on a four-point scale ranging from 'almost always' to 'never' in 27 health problems (e.g. a child aged eight years with a hearing problem; woman aged 50 with a breast lump). The questionnaire was drafted from a variety of sources, including the problem questionnaire used in the Interface Study (Crombie et al., 1990) and instruments used in the Dutch National Survey of General Practice (Foets et al., 1992).

The study was undertaken simultaneously in all countries. It was coordinated and analysed at the NIVEL Institute, supported by the European Regional Office of the World Health Organisation and funded by the European Commission in the BIOMED 1 programme. National coordinators in the countries of the WHO European Region (includes Turkey and Israel) were responsible for refining the questionnaire, organizing its translation, implementing the survey and reviewing the results.

Translations provided by national coordinators were checked by licensed translators. Answers were, in general, precoded. The drawing of the samples and the circulation of questionnaires was usually carried out at national level. No data were available on the expected distribution of study variables, hence power analysis could not be made. To allow for sufficient numbers of respondents in areas with different levels of urbanisation, a response target of 200 was set for all countries, excepting Iceland and Luxembourg, where there are few GPs. Sampling in each country was influenced by the expected response rate. In some countries, GPs were sampled at random, whereas in others the sampling procedure was adapted to improve recruitment. In central and eastern European countries without GPs, district doctors or general therapists were recruited instead; in some countries health centres were sampled. Finally, in a few countries doctors were recruited by personal contact or advertisement.

Respondents in each country were examined by available parameters to assess representativeness. The answers to individual questions provided on a fourpoint scale were coded numerically. Each of the four service areas was considered separately and only those respondents answering $75 \%$ of the questions were included in the analysis of each section.

The first area concerned the role of the GP in the first contact with health care. 
The data were analysed to provide an average of the results for answered questions. The distribution of the answers to each question was examined and where extreme skewness was evident $(85 \%$ or more positive or negative answers), these questions were excluded from the averaging procedure. This resulted in a total scale reliability given by Cronbach's $\alpha=0.94$. Then by principal components analysis (SPSS, 1986), four subscales were identified (health problems with children, women's health problems, psychosocial problems and acute health problems) with reliability coefficients of $0.91,0.87$, 0.90 and 0.86 respectively.

The second area concerned the application of medical techniques. Fourteen procedures were used. For this set of data, Cronbach's $\alpha$ was 0.89 and no subscales were identified.

The third area concerned management of diseases. This was measured in 17 sample cases. Using the scale procedure, Cronbach's $\alpha$ was 0.88 and no subscales were identified.

The fourth area concerned preventive medicine and health education. This was measured in an analysis of involvement in screening for hypertension, raised cholesterol and cervical cancer by cytology. GPs were asked whether they routinely screened for hypertension when adults consulted regardless of the reason and whether they organized special clinics to which people were invited. Those answering 'yes' were totalled and expressed as a percentage of the national sample. The questions concerning blood cholesterol and cervical cancer were posed similarly. Further questions were asked in relation to immunisation of children and paediatric surveillance. Involvement in these areas could be represented by an individual score of 0,1 or 2 which was averaged to provide a national score. Involvement in health education was measured when special sessions were provided to deal with diet, tobacco smoking and alcohol consumption. National results obtained in each of the four areas of activity were considered in relation to three characteristics of health care systems (Crombie et al., 1990; Fleming, 1992):

- the gatekeeper role of GPs;

- the predominant employment status of GPs (self-employed or salaried);

- location within Europe (McKee, 1991; Boerma et al., 1993; Evans, 1994).

Mean scores for each parameter were derived and differences were analysed, bivariately as well as after standardisation for the effect of the other two variables. 


\section{Results}

In 17 countries, $50 \%$ or more of the GPs sampled completed the questionnaire (table 2.1).

A random sampling procedure was used in most countries. Our initial target of 200 respondents (excluding Iceland and Luxembourg) was not achieved in nine countries. Representativeness of the respondents by age and gender was examined by comparison with national data in 21 of the countries. There were small under-representations of women and of the youngest and oldest age groups. Differences in mean age and proportions of women between the samples and the national populations are given in table 2.1. In three quarters of the countries the mean age of respondents was within two years of the national mean and the proportion of women within $5 \%$.

\section{First contact with health care}

The GP's position in the first contact is presented in table 2.2. The seven countries with the highest scores ( 3.20 and over) were all from western Europe. Lowest scores (2.39 or less) were found in the former communist countries of central and eastern Europe and in Turkey, though some of these, Croatia, Hungary, and Slovenia, had average scores or higher. Comparison of the four subscales (see table 2.A.1) showed the first contact position was generally strongest for 'acute' problems. In countries with markedly differing scores for the health problems of children and women the GP was more often doctor of first contact for children. Scores for first contact with psychosocial problems were highest in Denmark, the Netherlands and the UK.

\section{Medical technical procedures}

Application of medical techniques (second column, table 2.2) were scored highest (2.80 or more) in the Scandinavian countries, the Netherlands, Switzerland and the UK. The countries in central and eastern Europe and Italy had low scores.

\section{Disease management}

Results for treatment and follow-up of diseases (third column, table 2.2) are less variable than the previous two parameters, ranging from 3.06 in the UK and 3.03 in Norway, to 1.65 in Turkey and 2.20 in Bulgaria. Scores were, in general, higher in the west than in the east. Predominantly German-speaking countries and France had relatively high scores. Scores were comparatively low in Spain (2.43), the Netherlands (2.44) and Finland (2.46). 
Table 2.1 Response rates, sampling procedures and representativeness on age and sex per country

\begin{tabular}{|c|c|c|c|c|c|}
\hline Country & $\begin{array}{l}\text { Forms } \\
\text { returned }\end{array}$ & $\begin{array}{l}\text { Response } \\
\text { rate }(\%)\end{array}$ & $\begin{array}{l}\text { Sampling } \\
\text { procedure }^{*}\end{array}$ & $\begin{array}{l}\text { Age } \\
\text { difference } \\
P_{-} R^{\star \star \star} \text { (years) }\end{array}$ & $\begin{array}{l}\text { Gender } \\
\text { difference } \\
P-R^{\star \star \star}(\%)\end{array}$ \\
\hline Austria & 301 & 50 & B & 3.0 & 10 \\
\hline Belgium & 518 & 28 & D & 1.3 & 6 \\
\hline Bulgaria & 242 & 84 & C & na & na \\
\hline Croatia & 202 & 59 , & C & 2.3 & 1 \\
\hline Czech Republic ${ }^{\star \star}$ & 132 & 51 & C & 1.0 & -5 \\
\hline Denmark & 196 & 56 & B & 1.0 & 4 \\
\hline Estonia & 165 & 70 & B & na & na \\
\hline Finland & 239 & 42 & B & -1.5 & 2 \\
\hline France & 235 & na & E & -0.5 & 9 \\
\hline Germany & 169 & 44 & D & -3.3 & 13 \\
\hline Greece & 179 & 33 & B & na & na \\
\hline Hungary & 162 & 36 & B & na & na \\
\hline Iceland & 52 & 37 & A & na & na \\
\hline Ireland & 130 & 65 & B & 0.8 & 4 \\
\hline Israel & 673 & 78 & B & na & na \\
\hline Italy & 345 & 51 & D & -5.6 & 9 \\
\hline Latvia & 227 & 45 & C & na & na \\
\hline Lithuania ** & 333 & 87 & C & -0.1 & 2 \\
\hline Luxembourg & 54 & 30 & A & 1.9 & 7 \\
\hline Netherlands & 210 & 53 & B & -0.2 & -4 \\
\hline Norway & 164 & 52 & B & -0.8 & 1 \\
\hline Poland & 277 & 46 & C & -1.6 & 0 \\
\hline Portugal & 151 & 38 & B & 0 & 0 \\
\hline Romania & 232 & 52 & C & na & na \\
\hline Slovenia & 162 & 65 & D & -1.7 & -2 \\
\hline Spain ${ }^{\star \star}$ & 574 & 42 & B & -0.9 & 5 \\
\hline Sweden & 209 & 52 & B & -0.9 & 1 \\
\hline Switzerland & 200 & 50 & B & -0.8 & 1 \\
\hline Turkey & 199 & 50 & C & na & na \\
\hline United Kingdom & 301 & 30 & B & -1.3 & 2 \\
\hline TOTAL & 7,233 & 47 & & & \\
\hline
\end{tabular}

* Codes for sampling procedure:

$A=($ almost) entire GP population

$\mathrm{B}=$ random national sample (stratified or not)

$\mathrm{C}=$ random sample in pre-selected regions

$\mathrm{D}=$ mixed procedure (some random procedure plus selected GPs)

$\mathrm{E}=$ 'opportunity sampling'/volunteers (response rate not applicable, na)

** additional samples of (district) paediatricians not included

$\star \star \star$ population minus response ( $\mathrm{na}=$ not available) 
Table 2.2 GPs' involvement in curative and preventive services per country

\begin{tabular}{|c|c|c|c|c|c|c|c|}
\hline Country & $\begin{array}{c}\mathrm{A}^{\mathrm{a}} \\
\text { score }\end{array}$ & $\begin{array}{c}\mathrm{B}^{\mathrm{a}} \\
\text { score }\end{array}$ & $\begin{array}{c}\mathrm{C}^{\mathrm{a}} \\
\text { score }\end{array}$ & $\begin{array}{l}\text { D } \\
\%\end{array}$ & $\begin{array}{c}\mathrm{E} \\
\%\end{array}$ & $\begin{array}{c}\mathrm{F} \\
\%\end{array}$ & $\begin{array}{c}\mathrm{G}^{\mathrm{b}} \\
\text { score }\end{array}$ \\
\hline Austria & 2.95 & 2.11 & 2.88 & 87.4 & 61.1 & 27.6 & 1.80 \\
\hline Belgium & 3.01 & 2.49 & 2.78 & 91.8 & 38.7 & 71.0 & 1.56 \\
\hline Bulgaria & 1.74 & 1.12 & 2.20 & 80.6 & 31.8 & 29.8 & 0.78 \\
\hline Croatia & 3.14 & 1.77 & 2.81 & 65.0 & 25.6 & 4.4 & 0.80 \\
\hline Czech Republic & 2.28 & 1.66 & 2.39 & 88.9 & 37.8 & 0.0 & 0.09 \\
\hline Denmark & 3.49 & 2.82 & 2.88 & 70.7 & 28.8 & 99.0 & 1.95 \\
\hline Estonia & 2.06 & 1.29 & 2.55 & 87.9 & 21.8 & 24.8 & 1.13 \\
\hline Finland & 3.00 & 3.46 & 2.46 & 53.6 & 44.4 & 74.9 & 1.35 \\
\hline France & 3.08 & 2.01 & 2.99 & 99.2 & 26.7 & 75.4 & 1.95 \\
\hline Germany & 2.82 & 2.22 & 3.02 & 91.1 & 79.2 & 35.1 & 1.59 \\
\hline Greece & 2.47 & 1.99 & 2.59 & 68.2 & 39.7 & 24.6 & 1.30 \\
\hline Hungary & 2.75 & 1.38 & 2.81 & 90.7 & 29.6 & 1.9 & 0.64 \\
\hline Iceland & 3.10 & 3.19 & 2.78 & 59.6 & 32.7 & 69.2 & 1.98 \\
\hline Ireland & 3.48 & 2.49 & 2.96 & 86.9 & 44.6 & 67.7 & 1.71 \\
\hline Israel & 3.06 & 1.70 & 2.65 & 86.6 & 73.4 & 33.4 & 1.03 \\
\hline Italy & 3.08 & 1.44 & 2.61 & 82.9 & 53.6 & 76.8 & 0.58 \\
\hline Latvia & 1.96 & 1.58 & 2.57 & 92.0 & 24.3 & 78.3 & 0.60 \\
\hline Lithuania & 1.71 & 1.10 & 2.40 & 90.6 & 39.4 & & 0.36 \\
\hline Luxembourg & 2.63 & 2.16 & 2.68 & 92.6 & 25.9 & 31.5 & 1.69 \\
\hline Netherlands & 3.67 & 3.10 & 2.44 & 36.8 & 14.4 & 99.0 & 0.83 \\
\hline Norway & 3.28 & 3.05 & 3.03 & 46.3 & 31.3 & 80.5 & 0.81 \\
\hline Poland & 2.27 & 1.34 & 2.56 & 91.6 & 35.3 & 29.8 & 1.51 \\
\hline Portugal & 3.22 & 1.74 & 2.71 & 94.0 & 28.5 & 90.1 & 1.90 \\
\hline Romania & 2.36 & 1.80 & 2.34 & 68.4 & 14.7 & 35.9 & 1.10 \\
\hline Slovenia & 2.87 & 1.99 & 2.41 & 71.0 & 35.8 & 4.9 & 0.74 \\
\hline Spain & 3.20 & 1.77 & 2.43 & 86.1 & 79.5 & 18.7 & 0.98 \\
\hline Sweden & 2.83 & 2.83 & 2.75 & 40.2 & 32.5 & 34.4 & 1.82 \\
\hline Switzerland & 2.88 & 2.94 & 2.94 & 89.9 & 51.5 & 67.7 & 1.74 \\
\hline Turkey & 2.02 & 1.73 & 1.65 & 55.3 & 8.5 & 7.0 & 1.39 \\
\hline United Kingdom & 3.51 & 2.83 & 3.06 & 92.9 & 57.6 & 98.0 & 1.74 \\
\hline TOTAL & 2.80 & 2.10 & 2.64 & 78.0 & 38.3 & 48.0 & 1.25 \\
\hline
\end{tabular}

$\mathrm{A}=$ the first contact with health problems; $\mathrm{B}=$ the involvement in application of medical techniques; $\mathrm{C}=$ disease management; $\mathrm{D}=$ routinely assessing blood pressure; $\mathrm{E}=$ routinely assessing blood cholesterol levels; $\mathrm{F}=$ routinely taking cervical smears; $\mathrm{G}=$ preventive services for children (surveillance and immunisation).

possible scores range from 1 (=low involvement) to 4 (=high involvement) possible scores range from 0 (=low involvement) to 2 (=high involvement) not available 


\section{Preventive care}

Results for prevention are summarized in table 2.3. For each of three casefinding procedures, we examined the proportion of GPs reporting routine involvement. The proportions involved for the seven countries with the highest and the seven countries with the lowest values are given. Table 2.3 also gives the score (range 0-2) for involvement in routine childhood surveillance and immunisation, and information on involvement in health education about smoking, alcohol use and diet (range 0-3). The UK was in the highest quartile for the five analyses considered, and Portugal for four of them. Croatia, the Czech Republic and Turkey were in the lowest quartile for three of the analyses. There was considerable national variation in the reported provision of the preventive services. In most countries GPs were involved in screening for hypertension. This was not the case for blood cholesterol or for cervical cancer, where involvement was often less than $30 \%$. Involvement in group health education was extremely low.

\section{The gatekeeper role}

National differences were examined first in relation to the role of GPs as gatekeepers. In 12 countries (Croatia, Denmark, Iceland, Ireland, Israel, Italy, the Netherlands, Norway, Portugal, Slovenia, Spain and the UK) referrals to specialists are largely controlled by GPs. The mean score in these countries for first contact with health problems was 3.26 , which exceeds the score in the other countries. Differences in the application of medical techniques and the management of disease were not significant. The only other difference was in cervical cancer screening but this was not significant allowing for the other variables (employment status and European region).

\section{GP employment status}

In 12 countries the GPs are largely self-employed (Austria, Belgium, Denmark, France, Germany, Ireland, Italy, Luxembourg, Norway, the Netherlands, Switzerland and the UK) and they have greater involvement as doctor of first contact, in applying medical techniques and in the treatment of disease. However, after standardisation for the gatekeeping role and the region of Europe, the difference is only significant for disease management. In preventive services, self-employed doctors had greater involvement in cervical cancer screening and paediatric preventive care, although the differences were not significant after standardisation for both other variables. 


\section{Analysis by European region}

For this analysis, the countries of central and eastern Europe included Bulgaria, Croatia, the Czech Republic, Estonia, Hungary, Latvia, Lithuania, Poland, Romania, Slovenia and Turkey. By comparison with these countries, GPs in western Europe reported significantly greater involvement as doctors of first contact, in the application of medical techniques, in screening for blood cholesterol and in paediatric prevention (both before and after standardisation for the other variables) and in disease management and cervical screening (before standardisation).

Table 2.3 The involvement of GPs in five measures of preventive care

\begin{tabular}{llll}
\hline Service & Mean & \multicolumn{2}{l}{ Seven highest (H) and lowest (L) national values } \\
\hline $\begin{array}{l}\text { Hypertension } \\
\text { screening }\end{array}$ & $78 \%$ & H: & $\begin{array}{l}\text { France (99), Portugal (94), Luxembourg (93), United } \\
\text { Kingdom (93), Belgium (92), Latvia (92), Poland (92) }\end{array}$ \\
& & L: $\begin{array}{l}\text { Netherlands (37), Sweden (40), Norway (46), Finland } \\
\text { (54), Turkey (55), Iceland (60), Croatia (65) }\end{array}$
\end{tabular}

Cholesterol $\quad 38 \% \quad$ H: $\quad$ Spain (80), Germany (79), Israel (73), Austria (61), screening United Kingdom (58), Italy (54), Switzerland (52)

L: Turkey (9), Netherlands (14), Romania (15), Estonia (22), Latvia (24), Croatia (26), Luxembourg (26)

Cervical cancer $\quad 48 \% \quad$ H: Denmark (99), Netherlands (99), United Kingdom (98), screening Portugal (90), Norway (81), Latvia (78), Italy (77)

L: Czech Republic (0), Hungary (2), Croatia (4), Slovenia (5), Turkey (7), Spain (19), Greece (25)

Immunisation/ $\quad 1.3$

H: Iceland (2.0), Denmark (1.9), France (1.9), Portugal (1.9) Austria (1.8), Sweden (1.8), Switzerland (1.7), United Kingdom (1.7)

L: Czech Republic (0.1), Lithuania (0.4), Italy (0.6), Hungary (0.6), Latvia (0.6), Slovenia (0.7), Bulgaria $(0.8)$

Health educ. * ${ }^{\star} \quad 0.33 \quad$ H: Portugal (1.1), Romania (0.9), United Kingdom (0.7), Germany (0.6). Hungary (0.6), Bulgaria (0.5), Norway (0.5)

L: Czech Republic (0.1), Latvia (0.1), Luxembourg (0.1), Belgium (0.1), Denmark (0.1), Italy $(0.2)$, Spain $(0.2)$

* possible scores range from $0-2$

** possible scores range from $0-3$ 
Table 2.4 National scores on GP involvement in services, analysed by the GP gatekeeper role $^{\mathrm{a}}$

\begin{tabular}{|c|c|c|c|c|c|}
\hline \multirow{2}{*}{$\begin{array}{l}\text { Category of activity } \\
\text { First contact }\end{array}$} & \multicolumn{2}{|c|}{$\begin{array}{l}\text { GPs gate- } \\
\text { keeper } \\
(n=12)\end{array}$} & \multirow{2}{*}{$\begin{array}{l}\text { GPs non-gate- } \\
\text { keeper } \\
(\mathrm{n}=18)\end{array}$} & \multicolumn{2}{|c|}{$\begin{array}{l}\text { Level of } \\
\text { significance }\end{array}$} \\
\hline & 3.26 & $(3.15)$ & & ** & $\left({ }^{* *}\right)$ \\
\hline Medical techniques & 2.32 & (2.15) & $1.96(2.07)$ & n.s & (n.s) \\
\hline Disease management & 2.73 & $(2.67)$ & $2.59(2.62)$ & n.s & (n.s) \\
\hline \multicolumn{6}{|l|}{ Preventive services } \\
\hline - blood pressure & 0.73 & $(.74)$ & $0.81 \quad(.81)$ & n.s & (n.s) \\
\hline - blood cholesterol & 0.42 & $(.39)$ & $0.36 \quad(.38)$ & n.s & (n.s) \\
\hline - cervic.screening & 0.62 & $(.56)$ & $0.38 \quad(.42)$ & * & (n.s) \\
\hline - child immun./surveil. & 1.26 & (1.11) & $1.24(1.34)$ & n.s & (n.s) \\
\hline
\end{tabular}

In brackets: the independent effects standardized for three national variables:

'gatekeeping', 'employment status' and 'east-west' (ANOVA procedure)

* significant ( $\mathrm{p} \leq 0.05) ;{ }^{* *}$ significant $(\mathrm{p} \leq 0.01)$

Table 2.5 National scores on GP involvement in services, analysed by the GP employment status ${ }^{\mathrm{a}}$

\begin{tabular}{lllll}
\hline Category of activity & $\begin{array}{l}\text { GPs self- } \\
\text { employed } \\
(\mathrm{n}=12)\end{array}$ & $\begin{array}{l}\text { GPs } \\
\text { salaried } \\
(\mathrm{n}=18)\end{array}$ & $\begin{array}{l}\text { Level of } \\
\text { significance }^{\mathrm{b}}\end{array}$ \\
\hline First contact & $3.16(2.93)$ & $2.57(2.71)$ & $* \star$ & $(\mathrm{n} . \mathrm{s})$ \\
Medical techniques & $2.47(2.16)$ & $1.86(2.06)$ & $\star \star$ & $(\mathrm{n} . \mathrm{s})$ \\
Disease management & $2.86(2.78)$ & $2.50(2.55)$ & $* \star$ & $\left({ }^{\star}\right)$
\end{tabular}

Preventive services

- blood pressure

- blood cholesterol

$\begin{array}{lr}0.81 & (.84) \\ 0.43 & (.36) \\ 0.69 & (.60) \\ 1.50 & (1.25)\end{array}$

$0.76 \quad(.74)$

n.s (n.s)

- cervical screening

$0.35 \quad(.40)$

n.s (n.s)

child immun./surveil.

$0.33 \quad(.39)$

** (n.s)

In brackets: the independent effects standardised for three national variables:

'gatekeeping', 'employment status' and 'east-west' (ANOVA procedure)

${ }^{*}$ significant $(\mathrm{p} \leq 0.05) ;{ }^{* *}$ significant $(\mathrm{p} \leq 0.01)$ 
Table 2.6 National scores on GP involvement in services, analysed by European Region $^{\mathrm{a}}$

\begin{tabular}{|c|c|c|c|c|c|c|}
\hline \multirow{2}{*}{$\begin{array}{l}\text { Category of activity } \\
\text { First contact }\end{array}$} & \multicolumn{2}{|c|}{$\begin{array}{l}\text { 'West' } \\
(\mathrm{n}=19)\end{array}$} & \multicolumn{2}{|c|}{$\begin{array}{l}\text { 'East' } \\
(\mathrm{n}=11)\end{array}$} & \multicolumn{2}{|c|}{$\begin{array}{l}\text { Level of } \\
\text { significance }\end{array}$} \\
\hline & 3.09 & (2.97) & 2.29 & $(2.50)$ & $\star *$ & $\left({ }^{\star \star}\right)$ \\
\hline Medical techniques & 2.44 & $(2.40)$ & 1.52 & $(1.57)$ & $\star *$ & $\left({ }^{\star \star}\right)$ \\
\hline Disease management & 2.77 & (2.71) & 2.43 & $(2.53)$ & $\star \star *$ & (n.s) \\
\hline \multicolumn{7}{|l|}{ Preventive services } \\
\hline blood pressure & 0.77 & $(.75)$ & 0.80 & $(.83)$ & n.s & (n.s) \\
\hline - blood cholesterol & 0.44 & $(.45)$ & 0.28 & $(.26)$ & $\star$ & $\left({ }^{\star}\right)$ \\
\hline cervical screening & 0.62 & $(.56)$ & 0.22 & (.33) & $\star \star *$ & (n.s) \\
\hline - child immun./surveil. & 1.49 & $(1.52)$ & 0.83 & $(.78)$ & ${ }^{\star \star}$ & $\left({ }^{\star *}\right)$ \\
\hline
\end{tabular}

In brackets: the independent effects standardized for three national variables:

'gatekeeping', 'employment status' and 'east-west' (ANOVA procedure)

${ }^{*}$ significant $(\mathrm{p} \leq 0.05) ;{ }^{* *}$ significant $(\mathrm{p} \leq 0.01)$

\section{Discussion}

The main results of this study can be summarized as follows:

- In those countries where GPs exercise a gatekeeping function, they have a significantly stronger position as doctor of first contact.

- Where GPs are self-employed, they have greater involvement in disease management than in countries where they are employees.

- GPs in the countries of western Europe have a much stronger role in the first contact, the application of medical techniques, screening for blood cholesterol and paediatric prevention than those in the east.

- Individual national profiles of GPs' tasks are disclosed and these are selfevident from the results.

In discussing these results, we will consider their validity, the international differences disclosed and, finally, relate them to the future development of primary care in Europe.

\section{Validity}

A random sampling procedure was achieved in most countries. The response rate averaged $47 \%$ and although this indicates selection bias, we are considerably encouraged by this response. The nature of the questionnaire was not such 
that the selective response might introduce significant bias, although the possibility cannot be ignored. The target of $200 \mathrm{GPs}$ in each country was not always achieved, but we believe it unlikely that the results are unrepresentative of the national positions.

Considerable care was taken with the translation of the questionnaire into the 26 languages used and it is unlikely that national versions were inaccurate. Nevertheless, some connotative loss is possible and words (such as 'routine' or 'usual') could be interpreted differently.

\section{National differences}

The national picture disclosed within this study describes the position as seen by GPs. Low rates for GP involvement do not indicate national apathy. Rather, there must be alternative methods for provision, although these were not studied.

Some of the national differences perhaps relate to the way in which primary care has evolved. Primary care is strong in Scandinavia, the Netherlands and the UK and this was evident in the analyses relating to first contact, medical technical procedures and, although to a lesser extent, in disease management. Both the UK and Portugal disclosed strong results for preventive services. Health care systems involving patient registration with a specific doctor could be used for defining responsibility for preventive care.

The concept of comprehensive and family care is included in the usual definitions of general practice, but in some countries, separate provision is made for gynaecology and paediatrics. In Spain, GPs were not involved in screening for cervical cancer; in Italy, they were not involved in paediatric prevention. These differing features of primary care will inevitably have some influence on the results of this study and their interpretation. Patient registration with a defined practice favours the involvement of general practitioners in a wide range of medical services and reduces 'shopping' for practitioners with special expertise. It was a surprise, therefore, to find relatively low scores for disease management in the Netherlands and in Finland where the position of GPs in first contact is strong. It may be that some privately insured persons in these two countries use specialist services for disease management.

\section{Development of primary care}

This study identifies effective primary care in association with certain types of health care structure. It provides guidance for national authorities in the process of developing programmes of primary care. The gatekeeper role is 
obviously associated with the function of doctor of first contact. Less obviously, it implies a powerful means of controlling health care costs (Starfield, 1994), although this depends on the provision of a service with continuous responsibility at all times.

Self-employment was associated with greater involvement in some activities. This independence may encourage doctors to develop services in addition to those basic to general practice. Opportunities to experiment with new services helps to identify those most suitable for provision in primary care.

Finally, this study has outlined briefly the different national positions of general practice in Europe in 1993. The organisation of primary health care is changing in many countries and patient choice is receiving greater attention in eastern Europe (McKee, 1991; Evans, 1994). It will be interesting to examen the impact of these developments in a few years' time. 


\section{Annex}

Table 2.A.1 GPs' involvement in the first contact with patients' health problems $^{1}$

\begin{tabular}{|c|c|c|c|c|c|}
\hline $\begin{array}{l}\text { Country } \\
\text { scale }\end{array}$ & $\begin{array}{l}\text { Total } \\
\text { problems }\end{array}$ & $\begin{array}{l}\text { Child } \\
\text { problems }\end{array}$ & $\begin{array}{l}\text { Women } \\
\text { problems }\end{array}$ & $\begin{array}{l}\text { Ps.-soc. } \\
\text { problems }\end{array}$ & Acute \\
\hline Austria & 2.95 & 3.02 & 2.74 & 2.80 & 3.39 \\
\hline Belgium & 3.01 & 3.00 & 2.83 & 3.06 & 3.30 \\
\hline Bulgaria & 1.74 & 1.67 & 1.72 & 1.76 & 2.02 \\
\hline Croatia & 3.14 & 2.83 & 2.94 & 3.19 & 3.70 \\
\hline Czech Republic & 2.28 & 1.45 & 1.85 & 2.58 & 3.44 \\
\hline Denmark & 3.49 & 3.58 & 3.68 & 3.62 & 3.32 \\
\hline Estonia & 2.06 & 2.11 & 1.79 & 1.86 & 2.50 \\
\hline Finland & 3.00 & 3.23 & 3.06 & 2.67 & 3.34 \\
\hline France & 3.08 & 3.21 & 2.85 & 3.07 & 3.37 \\
\hline Germany & 2.82 & 2.75 & 2.39 & 3.04 & 3.32 \\
\hline Greece & 2.47 & 2.52 & 2.23 & 2.18 & 3.16 \\
\hline Hungary & 2.75 & 2.41 & 2.47 & 2.90 & 3.45 \\
\hline Iceland & 3.10 & 3.36 & 3.05 & 2.88 & 3.28 \\
\hline Ireland & 3,48 & 3.60 & 3.70 & 3.19 & 3.54 \\
\hline Israel & 3.06 & 3.06 & 2,98 & 2.92 & 3.37 \\
\hline Italy & 3.08 & 3.26 & 3.24 & 2.77 & 3.11 \\
\hline Latvia & 1.96 & 1.70 & 1.76 & 1.96 & 2.43 \\
\hline Lithuania & 1.71 & 1.50 & 1.64 & 1.61 & 2.30 \\
\hline Luxembourg & 2.63 & 2.74 & 2.23 & 2.59 & 3.07 \\
\hline Netherlands & 3.67 & 3.82 & 3.85 & 3.55 & 3.80 \\
\hline Norway & 3.28 & 3.33 & 3.64 & 3.04 & 3.41 \\
\hline Poland & 2.27 & 2.25 & 1.92 & 2.06 & 3.09 \\
\hline Portugal & 3.22 & 3.42 & 3.63 & 3.12 & 2.74 \\
\hline Romania & 2.36 & 2.49 & 2.31 & 2.19 & 2.69 \\
\hline Slovenia & 2.87 & 2.39 & 2.63 & 3.01 & 3.69 \\
\hline Spain & 3.20 & 2.81 & 3.44 & 2.98 & 3.46 \\
\hline Sweden & 2.83 & 3.03 & 2.66 & 2.84 & 3.03 \\
\hline Switzerland & 2.88 & 2.68 & 2.63 & 2.92 & 3.43 \\
\hline Turkey & 2.02 & 2.35 & 2.00 & 1.42 & 2.32 \\
\hline United Kingdom & 3.51 & 3.64 & 3.71 & 3.51 & 3.40 \\
\hline Total & 2.80 & 2.82 & 2.80 & 2.75 & 3.18 \\
\hline
\end{tabular}

possible scores range from 1 (=low involvement) to 4 (=high involvement) 


\section{General practice in urban and rural Europe \\ The range of curative services}

This chapter was published as:

Boerma WGW, Groenewegen PP, Van der Zee J. General practice in urban en rural Europe: the range of curative services. Social Science \& Medicine, 1998; 4: p.445-453.

Reproduced with persmission of Elsevier Science. 


\section{Introduction}

International studies have shown considerable variation between countries in the range of services offered by general practitioners (GPs). The differences have been associated with features of the health care system, such as: the mode of patient access to secondary care (direct or on referral by GPs in a gatekeeper role), remuneration method (fees for items of service, capitation fees or salary) and health care supply characteristics (density of GPs and of specialists) (Boerma et al., 1997; Crombie et al., 1990; Delnoij, 1994; Fleming and Backer, 1992; Sandier, 1989). There is evidence suggesting that the organisation and regulation of health care systems influence the outcome of health care. For instance, primary care based systems with patient choice and GPs acting as gatekeepers to secondary care are associated with lower costs, increased patient satisfaction, improved health status and decreased use of medication (Starfield, 1994; Groenewegen and Delnoij, 1997).

There are also regional differences within countries in the provision of services. In particular, concern has been expressed about acceptable health services in remote rural areas (Horner, Samsa and Ricketts, 1993; Lucas and Tonnelier, 1995; Pathman et al., 1992; Politzer et al., 1991) and in unattractive inner city areas (DHSS, 1980; Talbott, 1991; Hastings and Rashid, 1993; Cox, 1994; Hart, 1971). In the UK and in the Netherlands, indices of deprivation (Jarman, 1983; Van der Velden et al., 1997) are used to define underprivileged areas qualifying GPs for income supplements.

Compared with their rural equivalents, urban populations make more use of social services, home care and specialist care (outpatient and inpatient), even after allowing for socio-economic and demographic differences (Jeangros and Hausser, 1990; Haynes, 1991; Bowling et al.,1991; Nyman et al., 1991; Clark, 1992; Verheij and De Bakker, 1994; Ten Zijthoff et al., 1994). A number of studies has suggested higher utilisation of general practitioner services in rural areas (Dor and Holahan, 1990; Haynes, 1991; Jeangros and Hausser, 1990; Eggen et al., 1993), although Dutch studies (Gloerich and Van der Zee, 1992; Verheij et al., 1992) found more frequent contacts of patients with their GPs in cities. It has been suggested that health care utilisation is related to perceived health status, to health related behaviour and to the availability and accessibility of services (Andersen and Newman, 1973; Verheij, 1996; Inwald, 1980). The supply of hospital facilities has been shown to be a major determinant of variation in the number of patients' visits to hospitals and hospital admissions (Sanders, 1988). In the Netherlands the opening of a new hospital in a remote 
new town resulted in an increase of visits to the outpatient departments and admissions to the hospital (Dopheide et al., 1986).

As regards the scope of services, Fearn (1988) found British rural GPs to be more involved than their urban colleagues in minor surgery and the insertion of intra-uterine contraceptive devices. Several studies have reported higher referral rates by urban GPs (Posthuma and Van der Zee, 1977; Wijkel, 1986; Post et al., 1991; Blanquaert et al., 1992; Verheij et al., 1992; Fleming and Backer, 1992; Gloerich and Van der Zee, 1992), although, at least for the UK the evidence is inconclusive (Wilkin and Smith, 1987).

In the Netherlands, Verheij et al. (1992) reported urban GPs initiated more laboratory investigations and undertook less medical procedures than their rural colleagues. Sixma (1996) monitored hospital based emergency services following the opening of a new suburban hospital and reported substitution of services formerly provided by local GPs.

The study reported here, which was funded by the European Commission, concentrates on differences in profiles of services provided by GPs in 30 European countries. The major aim is to examine these profiles in urban and rural communities and to determine where differences are consistent across Europe. The study is based on material gathered in the European Study of Task Profiles of General Practitioners (Boerma et al., 1997). Briefly, participating GPs answered questionnaires detailing aspects of their activities. The questions were arranged in four task areas:

- The GPs role as doctor of first contact with health problems (First contact tasks).

- Application of minor surgery and medical techniques (Procedure tasks).

- The treatment and follow-up of diseases (Treatment tasks).

- The GP role in prevention (Preventive tasks).

In this study, we have been chiefly concerned with the first three of these task areas examining medical and therapeutic activity. More details on recruitment methods, questionnaire design, analysis and descriptive results have been published elsewhere (Boerma et al., 1997). This paper aims to describe and explain differences in the range of curative services among GPs working in urban, intermediate and rural areas in the European countries. Specific hypotheses have been formulated in Section 2. 


\section{Methods}

\section{The dependent variables}

A questionnaire was mailed to participating GPs in their own national languages covering the task areas mentioned. General practitioners indicated on a four point scale their opinion of the degree of involvement they were likely to have in dealing with specified problems. Answers ranging from (almost) never, to (almost) always were scored respectively 1-4. Average scores per GP were obtained by summing item scores after excluding:

- individual data sets with less than $75 \%$ completion;

- questions where, overall, $85 \%$ of the answers were uniformly given as '(almost) always' or '(almost) never';

- questions where item scores correlated less with total scores than were represented by a correlation coefficient of 0.40 . After these exclusions, the reliability of the remaining scored items was tested by calculating the Cronbach's $\alpha$ coefficient (First contact tasks, 0.94; Procedure tasks 0.89; Treatment tasks 0.88).

\section{The independent variables}

Independent variables included in the analysis reported here have been grouped as follows:

- Location: classified subjectively by the respondent as inner city, urban or suburban, mixed urban/rural, rural. (For some analyses, these were consolidated into urban, rural and intermediate).

- Distance to nearest hospital or outpatient facility (estimated by the respondent).

- GP characteristics: age, gender, time spent on continuing medical education, vocational training.

- Practice characteristics: solo or partnership practice, use of an appointment system, ancillary staff support, available equipment.

- Practice population adjustment for under/over representation of socially deprived or elderly persons as determined by subjective comparison with nationally available data.

- Health care systems: the GP role as gatekeeper to secondary services and his employment status (salaried or self employed) (Boerma et al., 1993).

- European region: East or West (eastern countries including the Baltic States, Poland, Czech Republic, Hungary, Slovenia, Croatia, Romania, Bulgaria and Turkey). 


\section{Analysis}

Averaged task profile scores were generated in each country and for each of the parameters examined and these are presented in tabular form. Sources of variation in the scope of services of GPs are located at two levels: the local level (the GPs and their practices) and the national level (the characteristics of the health care system). To avoid the drawbacks of both aggregation (loss of information) and disaggregation (over-estimating the effects of the higher level variables) the data were analysed using the hierarchical linear model (DiPrete and Forristal, 1994; Jones, 1993) with the MLn software (Woodhouse, 1995). Practice location was not treated as a separate level but as a practice characteristic. Analyses on each of the three identified GP task areas were carried out by introducing successively the following independent variables:

- GP characteristics and practice characteristics;

- Practice location (urban, rural, intermediate);

- Health care system characteristics (gatekeeping, employment status);

- European region (East or West).

In tables 3.1-3.6 presented, only the final regression equations are given because changes in the regression coefficients with the introduction of each new group of variables were only marginal. Finally, the analyses have been repeated for each of the health care system characteristics and in each European region. These separate analyses are presented in tables 3.4-3.6 and were carried out to identify possible interactions at national level between these particular characteristics and the other variables. The regression equations have been evaluated by the proportional reduction of variance firstly at national level and secondly, within each country at practice level.

\section{Hypotheses}

The following hypotheses were tested:

- The range of service of GPs in rural practices is wider than in urban practices (and especially in inner cities).

- The profile of GP services is more limited in practices located close to hospitals (independently from the degree of urbanisation of the practice).

- In countries where GPs have a gatekeeper role and thus patient flows are more controlled, the expected difference between urban and rural GPs is smaller. 


\section{Results}

Altogether, 7,233 general practitioners from 30 countries participated. In 17 countries more than half of the sampled GPs completed the questionnaire. The representativeness of the GPs was assessed in 21 countries where national data on age and gender were available. In general, female GPs and the youngest and oldest age groups were slightly underrepresented (Boerma et al., 1997).

\section{GP and practice characteristics}

The characteristics of GPs and practices are distributed by location in table 3.1. An evaluation of statistically significant differences is reported in the two extreme right hand columns. The number of countries is entered in which the characteristic examined differed significantly from the international average. In eight countries there were more female GPs in urban practices. The proportion of vocationally trained GPs was low in inner city practices. The proportion working in solo practice was greater in rural practices but the use of appointment systems less. More equipment was available in rural practices.

Table 3.1 GPs' personal and practice characteristics broken down to degree of urbanisation of the practice location

\begin{tabular}{|c|c|c|c|c|c|c|}
\hline \multirow[t]{2}{*}{ Characteristics } & \multicolumn{2}{|c|}{$\begin{array}{l}\text { Urban general } \\
\text { practitioners }\end{array}$} & \multicolumn{2}{|c|}{$\begin{array}{l}\text { Rural general } \\
\text { practitioners }\end{array}$} & \multicolumn{2}{|c|}{$\begin{array}{l}\text { n countries } \\
\text { with sign.diff. * }\end{array}$} \\
\hline & $\begin{array}{r}\text { inner } \\
\text { city }\end{array}$ & $\begin{array}{l}\text { suburbs } \\
\text { /towns }\end{array}$ & $\begin{array}{r}\text { mixed } \\
\text { urban/ } \\
\text { rural }\end{array}$ & rural & $\begin{array}{r}\text { urban } \\
\text { higher }\end{array}$ & $\begin{array}{r}\text { rural } \\
\text { higher }\end{array}$ \\
\hline - Age (average in yrs) & 43 & 44 & 44 & 43 & 2 & 1 \\
\hline - Gender (\% female GPs) & 51 & 41 & 30 & 26 & 8 & - \\
\hline - Vocational training (\% GPs) & 39 & 47 & 51 & 44 & 3 & 2 \\
\hline - Hours for keeping up-to-date & 23 & 18 & 18 & 19 & - & 2 \\
\hline - Mode of practice (\% solo) & 26 & 32 & 39 & 63 & - & 9 \\
\hline $\begin{array}{l}\text { Ancillary staff ( } \% \text { with } \\
\text { practice assistance) }\end{array}$ & 91 & 87 & 82 & 82 & 4 & 2 \\
\hline $\begin{array}{l}\text { Appointment system for most } \\
\text { consultations }(\%)\end{array}$ & 39 & 49 & 46 & 35 & 9 & - \\
\hline - Equipment (number; max. 25) & 9 & 10 & 11 & 10 & 4 & 11 \\
\hline - Elderly above average (\%) & 42 & 41 & 39 & 7 & 3 & 4 \\
\hline $\begin{array}{l}\text { Deprived persons above } \\
\text { average }(\%)\end{array}$ & 30 & 24 & 17 & 17 & 13 & 3 \\
\hline $\mathrm{N}$ & 1738 & 2372 & 1453 & 1657 & 30 & \\
\hline
\end{tabular}

* T test $(\mathrm{p} \leq 0.05)$ 
Social deprivation was commoner in urban practices.

In the majority of countries examined individually, there were no significant differences in the characteristics of GPs or their practices when compared in urban or rural location.

\section{Task profiles}

Task profiles in the three areas evaluated are described by location in table 3.2 using a similar format to that above. Rural general practitioners had a greater role in first contact tasks and there was evidence of a trend with lowest scores in inner city areas. Analysis of each national data set showed higher scores for rural than urban GPs in 23 countries. Rural GPs reported higher scores than their urban counterparts for the procedure tasks, though the highest scores were reported by GPs working in a mixed urban/rural location. Rural GPs also reported higher scores in treatment tasks though this was only evident in 12 of the countries considered individually.

Table 3.2 Scope of GP services in urban and rural practices in Europe

\begin{tabular}{|c|c|c|c|c|c|}
\hline \multirow[t]{2}{*}{$\begin{array}{l}\text { Task } \\
\text { dimension }\end{array}$} & \multicolumn{2}{|c|}{$\begin{array}{l}\text { Urban general } \\
\text { practitioners }\end{array}$} & \multicolumn{2}{|c|}{$\begin{array}{l}\text { Rural general } \\
\text { practitioners }\end{array}$} & \multirow{2}{*}{$\begin{array}{l}\mathrm{n} \\
\text { Countries } \\
\text { with } \\
\text { significant } \\
\text { difference }\end{array}$} \\
\hline & $\begin{array}{l}\text { inner } \\
\text { city }\end{array}$ & $\begin{array}{l}\text { suburbs/ } \\
\text { towns }\end{array}$ & $\begin{array}{l}\text { mixed } \\
\text { urban/ } \\
\text { rural }\end{array}$ & rural & \\
\hline $\begin{array}{l}\text { The first contact with } \\
\text { health problems }\end{array}$ & $\begin{array}{l}2.52 \\
(.78)\end{array}$ & $\begin{array}{l}2.79 \\
(.72)\end{array}$ & $\begin{array}{l}3.02 \\
(.61)\end{array}$ & $\begin{array}{l}3.13 \\
(.60)\end{array}$ & 23 \\
\hline $\begin{array}{l}\text { Application of medical } \\
\text { technical procedures }\end{array}$ & $\begin{array}{l}1.68 \\
(.74)\end{array}$ & $\begin{array}{l}2.02 \\
(.83)\end{array}$ & $\begin{array}{l}2.37 \\
(.86)\end{array}$ & $\begin{array}{l}2.31 \\
(.78)\end{array}$ & 21 \\
\hline $\begin{array}{l}\text { Treatment and follow-up } \\
\text { of diseases }\end{array}$ & $\begin{array}{l}2.46 \\
(.67)\end{array}$ & $\begin{array}{l}2.61 \\
(.60)\end{array}$ & $\begin{array}{l}2.72 \\
(.61)\end{array}$ & $\begin{array}{l}2.78 \\
(.60)\end{array}$ & 12 \\
\hline $\mathrm{N}$ (at least) & 1333 & 2015 & 1255 & 1456 & 30 \\
\hline
\end{tabular}

1 Possible scores for task dimensions range from 1-4 (1=(almost)never involved;

$24=$ (almost) always involved)

2 In brackets: standard deviations

3 In each row differences between average scores are significant $(p \leq 0.01)$

4 test between urban and rural GPs $(\mathrm{p} \leq 0.05)$ 
Table 3.3 Two-level regression analysis to account for variation of GPs' involvement in three task dimensions (standardised regression coefficients)

$\begin{array}{ccc}\text { Variables } & \begin{array}{c}\text { First contact } \\ \text { role Application Treatment of } \\ \text { of techniques diseases }\end{array}\end{array}$

\section{Local level}

\section{Practice location}

Distance to nearest hosp/spec. $(1=>5 \mathrm{~km})$

$\begin{array}{rrr}0.059 & 0.076 & 0.032 \\ -0.039 & -0.046 & -0.018 \\ 0.142 & 0.091 & 0.045\end{array}$

Inner city ( $1=$ inner city)

0.091

0.045

Rural area ( $1=$ rural)

Organisation/equipment

Mode of practice $(1=$ solo $)$

$\begin{array}{rrr}0.008 & -0.011 & 0.017 \\ -0.026 & 0.004 & 0.028 \\ \mathbf{0 . 0 4 7} & \mathbf{0 . 0 2 5} & 0.032 \\ \mathbf{0 . 1 3 2} & \mathbf{0 . 2 9 5} & \mathbf{0 . 1 6 6}\end{array}$

Appointment system ( $1=y e s)$

0.295

0.166

Ancillary staff (number)

0.132

$\begin{array}{rrr}0.018 & -0.003 & \mathbf{0 . 0 7 2} \\ \mathbf{0 . 0 3 0} & 0.004 & 0.020\end{array}$

Practice population

Elderly ( $1=$ above average)

Deprived persons ( $1=$ above average)

GP's background

Age

$-0.006$

0.014

$-0.103$

Gender (1=woman)

$-0.006$

$-0.097$

$-0.078$

Keeping up-to-date (hours)

0.034

0.009

0.062

Vocational training ( $1=y e s)$

0.067

0.048

0.024

\section{National level}

Health system characteristics

Usual employment status (1=self-employed)

$\begin{array}{lll}\mathbf{0 . 1 4 6} & 0.058 & \mathbf{0 . 1 8 0} \\ \mathbf{0 . 4 2 2} & 0.067 & 0.047 \\ \mathbf{0 . 2 4 7} & \mathbf{0 . 2 6 3} & \mathbf{0 . 0 2 8}\end{array}$

East or west ( $1=$ West)

0.247

0.263

0.028

Proportional reduction of variance:

Country level

$81.5 \%$

$69.2 \%$

$47.1 \%$

GP level

$10.5 \%$

$21.3 \%$

$6.0 \%$

bold: significant value $(\mathrm{p} \leq 0.05)$

\section{Analyses of the differences}

Variation between GPs was related both to the GP and practice characteristics examined and to features of the health care system. The intra-class correlations 
showed that $52 \%$ of the variance in first contact tasks and $57 \%$ in procedure tasks were located at the level of the health care system; whereas $79 \%$ of the variance in treatment tasks was located at the level of the GPs and practices (this is not entered in table 3.3). Analysis of the characteristics examined is summarised in table 3.3 for each task considered. Beta values from the analyses are presented, those significant at the $5 \%$ level are bold.

\section{First contact tasks}

First contact tasks were related to practice location with higher scores and thus a greater role for GPs in rural practices. This trend was similarly evident when the distance between practice and hospital or outpatient facility was examined: GPs more than five kilometres from the hospital reported higher scores. Scores were higher where practice based estimates of socially deprived persons exceeded the national average. The quantity of equipment and availability of ancillary staff were associated with higher and routine use of an appointment system with lower scores. The age and gender of the GP were not associated with first contact task scores but vocational training and time spent in continuing medical education were positively associated. At national level, there were strong associations between scores and the gatekeeper role for GPs. The countries of western Europe reported higher scores than those in the east. Variance at national level (which was well over half the total variance), was well explained in this analysis accounting for an $81 \%$ reduction in this variance. Variance within countries (which was $48 \%$ of the total variance) was not satisfactorily explained within the model, accounting for a reduction of variance of only $10 \%$ (see table 3.3 - the proportional reduction of variance).

\section{Procedure tasks}

Scores for procedure tasks were higher for rural GPs and for those practising at greater distance from the nearest hospital. They were lower for inner city GPs. Medical equipment and the availability of ancillary staff were positively associated. Male GPs and vocationally trained GPs reported higher scores than female GPs and those without vocational training. At national level, western but not eastern countries reported higher scores for procedure tasks. National variance ( $57 \%$ of the total variance) was well explained by the model with a $69 \%$ reduction of this variance. Within countries, the model accounted for $21 \%$ of the variance. 


\section{Treatment tasks}

Task scores on treatment of diseases varied with practice location but to a lesser extent than was evident for first contact tasks and for procedure tasks. Higher scores were found in rural areas and among doctors at greater distance from hospital. Inner city GPs reported slightly lower scores than those in other locations. Higher scores were also found where practice based estimates of the elderly were above average and where medical equipment was more plentiful. Younger GPs and female GPs reported lower scores whereas GPs who spent more time in continuing education, reported higher scores. Self-employed GPs reported higher scores than those who were salaried. Most of the variation in treatment task scores occurred at practice level $(79 \%)$ rather than at national level but the factors considered in the model did not explain the variance to a high extent.

\section{Differences between health care systems}

Analyses were also made for sub-groups of countries according to the characteristics of the health care system: the gatekeeping role, the predominant employment status of GPs, and the East/West distinction. These data are presented in tables 3.4-3.6. In all sub-groups of countries, we found that greater distance between practice or hospital outpatient facility was associated with higher scores for first contact tasks. For procedure tasks, the distance effect only occurred in western countries and where GPs were gatekeepers. The higher scores for first contact tasks were particularly apparent in countries where the GP acted as a gatekeeper and those countries where the GPs were salaried. In countries where GPs were salaried, vocationally trained GPs reported higher scores for first contact tasks and procedure tasks. Increased scores for rural GPs in treatment tasks were only found in those countries where the GPs did not have a gatekeeper function and were self-employed.

There were several differences on analysis by European region. Higher than average numbers of elderly or socially deprived persons were associated with higher scores for first contact tasks in western but not eastern countries and where GPs acted as gatekeepers. Time spent on continuing medical education was associated with higher scores for first contact in western countries where GPs acted as gatekeepers. Vocational training in western countries and countries where GPs were gatekeepers, was not related to scores for procedure tasks. The availability of medical equipment was related to scores for treatment tasks in western countries and those with a gatekeeper role for GPs. 
Table 3.4 Two-level regression analysis to account for variation of GPs' involvement as doctors of first contact (stondardised regression coefficients)

\begin{tabular}{|c|c|c|c|c|c|c|c|}
\hline & All & $\begin{array}{l}\text { Non-gate } \\
\text { keeping }\end{array}$ & $\begin{array}{l}\text { Gate- } \\
\text { keeping }\end{array}$ & East & West & Salaried & $\begin{array}{l}\text { Self- } \\
\text { employed }\end{array}$ \\
\hline \multicolumn{8}{|l|}{ I. Local level } \\
\hline \multicolumn{8}{|l|}{ Practice location } \\
\hline - Distance to nearest hosp/spec. $(1=>5 \mathrm{~km})$ & 0.059 & 0.066 & 0.067 & 0.064 & 0.074 & 0.063 & 0.074 \\
\hline - Inner city ( $1=$ inner city) & -0.039 & -0.020 & -0.077 & -0.023 & -0.047 & -0.042 & -0.012 \\
\hline - Rural area ( $1=$ rural) & 0.142 & 0.174 & 0.142 & 0.234 & 0.138 & 0.177 & 0.125 \\
\hline \multicolumn{8}{|l|}{ Organisation/equipment } \\
\hline - Mode of practice $(1=$ solo) & 0.008 & 0.020 & -0.002 & 0.033 & 0.006 & 0.010 & -0.020 \\
\hline - Appointment system ( $1=y e s)$ & -0.026 & 0.010 & .0 .055 & -0.028 & -0.028 & -0.027 & -0.018 \\
\hline - Ancillary staff (number) & 0.047 & 0.050 & 0.052 & 0.051 & 0.049 & 0.029 & 0.057 \\
\hline - Equipment ( $\#$ of items) & 0.132 & 0.147 & 0.180 & 0.119 & 0.215 & 0.137 & 0.201 \\
\hline \multicolumn{8}{|l|}{ Practice population } \\
\hline - Elderly (1=above average) & 0.018 & -0.012 & 0.071 & 0.000 & 0.040 & 0.039 & -0.008 \\
\hline - Deprived persons ( $1=$ above average) & 0.030 & 0.021 & 0.053 & -0.028 & 0.060 & 0.013 & 0.048 \\
\hline \multicolumn{8}{|l|}{ GP's background } \\
\hline - Age & -0.006 & -0.003 & -0.009 & -0.048 & 0.025 & -0.009 & 0.006 \\
\hline - Gender (1=woman) & -0.006 & -0.022 & 0.008 & -0.020 & 0.008 & -0.003 & -0.001 \\
\hline - Keeping up-to-date (hours) & 0.034 & 0.024 & 0.060 & 0.026 & 0.056 & 0.030 & 0.051 \\
\hline - Vocational training $(1=y e s)$ & 0.067 & 0.078 & 0.073 & 0.128 & 0.040 & 0.101 & 0.020 \\
\hline \multicolumn{8}{|l|}{ I. National level } \\
\hline \multicolumn{8}{|l|}{ Heallh system choracteristics } \\
\hline - Usual employment status (1=self-empl.) & 0.146 & & & & & & \\
\hline - Gatekeeping system (1=gatekeeping) & 0.422 & & & & & & \\
\hline - East or west ( $\mathbf{1}=$ West $)$ & 0.247 & & & & & & \\
\hline
\end{tabular}


Table 3.5 Two-level regression analysis to account for variation in the application of medical techniques (standardised regression coefficients)

\begin{tabular}{|c|c|c|c|c|c|c|c|}
\hline & All & $\begin{array}{l}\text { Non-gate } \\
\text { keeping }\end{array}$ & $\begin{array}{l}\text { Gate- } \\
\text { keeping }\end{array}$ & East & West & Salaried & $\begin{array}{l}\text { Self- } \\
\text { employed }\end{array}$ \\
\hline \multicolumn{8}{|l|}{ I. Local level } \\
\hline \multicolumn{8}{|l|}{ Practice location } \\
\hline - Distance to nearest hosp/spec. (1 $\Rightarrow 5 \mathrm{~km})$ & 0.076 & 0.025 & 0.035 & 0.022 & 0.037 & 0.023 & 0.048 \\
\hline - Inner city (1=innes city) & -0.046 & -0.029 & -0.013 & 0.011 & -0.030 & .0 .036 & -0.001 \\
\hline - Rural area (1=rural) & 0.091 & 0.017 & 0.0332 & 0.035 & 0.013 & 0.028 & 0.010 \\
\hline \multicolumn{8}{|l|}{ Organisationleguipment } \\
\hline - Mode of practice $(1=$ solo $)$ & -0.011 & -0.066 & -0.021 & -0.013 & -0.062 & -0.042 & -0.027 \\
\hline - Appointment system (1=yes) & 0.004 & -0.010 & -0.023 & -0.029 & -0.021 & -0.032 & 0.037 \\
\hline - Ancillary staff (number) & 0.025 & 0.002 & 0.020 & .0 .030 & 0.013 & -0.013 & 0.006 \\
\hline - Equipment (\# of items) & 0.295 & 0.096 & 0.100 & 0.074 & 0.130 & 0.069 & 0.204 \\
\hline \multicolumn{8}{|l|}{ Practice population } \\
\hline - Elderly (1=above average) & $-0,00,3$ & -0.017 & -0.001 & -0.020 & -0.002 & -0.006 & 0.005 \\
\hline - Deprived persons ( $1=$ above average) & 0.004 & 0.017 & -0.009 & -0.022 & 0.018 & -0.019 & 0.048 \\
\hline \multicolumn{8}{|l|}{ GP's background } \\
\hline - Age & 0.014 & -0.052 & -0.110 & -0.058 & -0.076 & -0.095 & 0.040 \\
\hline - Gender (1=woman) & -0.097 & -0.023 & 0.043 & .0 .019 & 0.029 & 0.011 & 0.010 \\
\hline - Keeping up-to-date (hours) & 0.009 & 0.021 & 0.023 & 0.045 & 0.007 & 0.038 & 0.020 \\
\hline - Vocational training ( $1=y e s)$ & 0.048 & 0.061 & 0.028 & 0.077 & 0.014 & 0.045 & 0.021 \\
\hline \multicolumn{8}{|l|}{ II. National level } \\
\hline \multicolumn{8}{|l|}{ Hoalth system characteristics } \\
\hline - Usual employment status ( $1=$ self-empl.) & 0.058 & & & & & & \\
\hline - Gatekeeping system (1=gatekeeping) & 0.067 & & & & & & \\
\hline East or west $(1=$ West $)$ & 0.263 & & & & & & \\
\hline
\end{tabular}


Table 3.6 Two-level regression analysis to account for variation in the follow-up and treatment of selected diseases (standardised regression coefficients)

\begin{tabular}{|c|c|c|c|c|c|c|c|}
\hline & All & $\begin{array}{l}\text { Non-gate } \\
\text { keeping }\end{array}$ & $\begin{array}{l}\text { Gate- } \\
\text { keeping }\end{array}$ & East & West & Salaried & $\begin{array}{l}\text { Self- } \\
\text { employed }\end{array}$ \\
\hline \multicolumn{8}{|l|}{ l. Local level } \\
\hline \multicolumn{8}{|l|}{ Practice location } \\
\hline - Distance to nearest hosp/spec. $(1=>5 \mathrm{~km})$ & 0.032 & .0 .026 & 0.001 & -0.031 & -0.008 & -0.011 & -0.017 \\
\hline - Inner city ( $1=$ inner city) & -0.018 & -0.007 & .0 .010 & -0.031 & -0.001 & -0.029 & 0.025 \\
\hline - Rural area (1=rural) & 0.045 & 0.058 & 0.026 & 0.050 & 0.039 & 0.030 & 0.060 \\
\hline \multicolumn{8}{|l|}{ Organisationlequipment } \\
\hline - Mode of practice ( $1=$ solo) & 0.017 & 0.025 & -0.024 & 0.019 & 0.005 & 0.009 & -0.015 \\
\hline - Appointment system (1 =yes) & 0.028 & -0.017 & -0.012 & 0.010 & 0.030 & 0.004 & -0.048 \\
\hline - Ancillary staff (number) & 0.032 & -0.017 & .0 .013 & -0.092 & 0.000 & -0.044 & 0.014 \\
\hline - Equipment ( $\#$ of items) & 0.166 & 0.037 & 0.052 & 0.033 & 0.048 & 0.037 & 0.051 \\
\hline \multicolumn{8}{|l|}{ Practice population } \\
\hline - Elderly ( $1=$ above average) & 0.072 & -0.016 & 0.051 & 0.010 & 0.027 & 0.002 & 0.037 \\
\hline - Deprived persons ( $1=$ above average) & 0.020 & -0.014 & .0 .014 & 0.028 & $\cdot 0.007$ & 0.019 & $\cdot 0.008$ \\
\hline \multicolumn{8}{|l|}{ CP's background } \\
\hline - Age & -0.103 & -0.098 & -0.098 & -0.081 & -0.091 & -0.086 & -0.099 \\
\hline - Gender (1=woman) & -0.078 & 0.021 & 0.051 & 0.027 & 0.034 & 0.041 & 0.020 \\
\hline - Keeping up-to-date (hours) & 0.062 & 0.021 & 0.027 & 0.002 & 0.042 & 0.026 & 0.025 \\
\hline - Vocational training ( $1=$ yes) & 0.024 & 0.030 & 0.008 & 0.048 & 0.004 & 0.020 & 0.013 \\
\hline \multirow{2}{*}{\multicolumn{8}{|c|}{$\begin{array}{l}\text { 11. National levol } \\
\text { Health system characteristics }\end{array}$}} \\
\hline & & & & & & & \\
\hline - Usual employment status ( $1=$ self-empl.) & 0.180 & & & & & & \\
\hline - Gatekeeping system (1=gatekeeping) & 0.047 & & & & & & \\
\hline - East or west $(1=$ West $)$ & 0.028 & & & & & & \\
\hline
\end{tabular}


Furthermore, in western countries and where GPs were gatekeepers, there was greater involvement in first contact and in treatment tasks where there was an excess of socially deprived or elderly people. There were sharp differences between GPs in East and West Europe in first contact and procedure tasks but not in treatment tasks. The national characteristics of the health care system (especially the gatekeeper role), were associated with first contact task scores but not generally with other task scores.

\section{Discussion}

The results strongly support our main hypotheses: the task profiles of GPs differed between urban and rural locations. General practitioners in rural areas have higher scores and therefore a more important role as doctor of first contact with health problems and in the application of medical technical procedures than their colleagues in inner cities. These findings were supported by the trends evident in the four sub-groups of locations considered and were confirmed in the analysis based on distance between practice and hospital or outpatient facility. The distance to the nearest hospital or outpatient clinic, which is obviously related to the urban-rural distinction, is an independent determinant of the GP's task profile. Treatment tasks were much less determined by the geographical location and more by the GP's background and the practice organisation. Our third hypothesis, stating that there is less difference in the task profiles of urban and rural doctors in gatekeeping systems than in non-gatekeeping systems, was not confirmed.

There were, however, other more obvious inter-actions between the system characteristics and the location of the practices. The reduced involvement of inner city GPs in first contact tasks occurred only in western countries where GPs were gatekeepers. The higher involvement in procedure tasks of GPs working at longer distances from a hospital was only true in western countries and where GPs are self-employed. The increased involvement of rural GPs in treatment tasks only applied where GPs were not gatekeepers and were selfemployed.

Before commenting further on the results, it is necessary to consider the definition of urban and rural practice and possible limitations in the findings inherent in the questionnaire used and recruitment bias. The concept of urbanisation and the application of defining criteria varies between countries; a feasible international reference point is not available (Pumain et al., 1992). We used a simple classification in five categories which a doctor could set within 
the context of his own national situation. The relevance of urbanisation in the context of this study is twofold: it refers to differences in both the subjective experience of space and availability of facilities and services. Concerning the subjective component we recognise that what constituted a particular type of location in one country was not necessarily matched by that in another. For this reason, we also used the additional dimension of distance between practice and hospitals.

By definition there is a selection bias where the sample is not truly random or the response imperfect. We are aware of some under-representation of female doctors and suspect we may be over-represented by doctors well-motivated to participate in this type of study. However, these are unlikely to bias substantially the findings with respect to the main topic of the study - differences between urban and rural practices. Age and gender of the GP were minor determinants of differences in task profiles. This points to a particular limitation of this study applying to countries where many GPs are working in group practices as in the UK. We have applied the person characteristics of an individual doctor to task profiles which relate both to the functioning of the practice and the individual doctor. For doctors in group practices this could lead to an under-estimation of the impact of the personal characteristics of doctors, such as age and gender, on the task profile scores. This however has been partly offset by including the type of practice (solo or partnership) in the analyses.

In a widely based study such as this, there is an inevitable skewness in many of the distributions of the variables. It was not possible always to get the ideal balance between urban and rurally located GPs. In analyses undertaken within a country, this meant that on occasions, sometimes what appeared to be a large difference between urban and rural practice, did not achieve statistical significance.

There are also some methodological difficulties when interpreting findings based on association. Does the level of practice equipment, which was almost universally associated with higher scores in all three task areas, lead to more services provided or is it the other way round? It can be difficult to decide whether a variable such as vocational training for general practice should be considered as part of the health care system or as a function of the individual GP.

Notwithstanding all these difficulties, we believe this study has clarified the relation between urban and rural practices and between countries. Differences found between countries were considerable and in our model we have gone 
some way towards explaining variation at national level. Variation at practice level within countries, however, remains largely unexplained.

\section{Implications}

Differences between urban and rural GPs exist regardless of the health care system. Does that matter? Our contention is that it does. It is first necessary to recognise the difference in respect of appropriate training for general practice. It could also be argued that those differences must be considered when contractual arrangements and the related remuneration of GPs are determined. Considered the other way round, it could be argued that the formal position of the GP, especially the role as doctor of first contact, might be more closely defined within each national setting. A coordinating position can only be assured if GPs are institutionally placed in the middle of the patient flow in primary care in a gatekeeper role and with patients registered with a GP.

With all national governments struggling to contain ever increasing health care costs, it is important to know where the boundaries lie for responsibility in first contact care nrovision. In the IIK and, to a lesser extant, in the Natherlands supplementary payments are applied to the capitation system for elderly persons, for GPs working in severely socially deprived areas and for working in remote and sparsely populated areas. Personal preferences and market forces will no doubt exert influence on a doctor to go where employment prospects are greatest and living conditions are favourable but one of the main concepts of "Health for All" (WHO, 1992) concerns the notion of equality of health care provision and access to it. Even though the role of governments in health affairs is diminishing the equal distribution of health care manpower and facilities must be secured in order to prevent a situation in which services are poorest where the need is greatest.

These results and their implications provide a particular challenge for primary care in eastern Europe where scores for first contact and medical technical procedure tasks were particularly low. A combination of inadequate resources for primary care, poor remuneration, and lack of equipment has led to particularly low morale and poor motivation amongst GPs. This study could in fact provide a method whereby an evolving situation in the development and delivery of primary care could be monitored. 
The study also provides an insight into the operation of the gatekeeping function. Our findings suggest that it is less strong in the inner city areas. If the gatekeeping role of GPs is truly associated with good outcomes and reduced health care costs (Starfield,1994), then it is unlikely that a country with such a system in place would wish to lose it. Consideration has to be given to the infrastructure of practices in the inner city areas, the generally increased mobility of the population and the ability of GPs working in inner city areas (who commonly live outside these areas) to cope with changing patient demand. The establishment of large general practitioner cooperatives and the introduction of out-of-hours primary care services in Denmark and in the UK provide one way of retaining a gatekeeper function around the clock within primary care which is likely to be particularly effective in city areas. Decisions about the gatekeeper role itself for GPs, however, have to be considered in the national context. 


\section{The general practitioner as the first contacted health professional by patients with psychosocial problems}

This chapter was published as:

Boerma WGW, Verhaak PFM. The general practitioner as the first contacted health professional by patients with psychosocial problems: a European study. Psychological Medicine, 1999; 29: p.689-696.

Reproduced with permission of Cambridge University Press. 


\section{Introduction}

General practitioners (GPs), in some countries referred to as family physicians, are often the first professional person contacted when patients experience mental and social problems. This is even more the case if mental or social problems are manifested in somatic symptoms. (Regier et al., 1982; Üstün and Sartorius, 1995; Schulberg, 1987; Goldberg and Huxley, 1992; Kirmayer et al., 1993; Kroenke et al., 1994).

Many patients receiving mental health care are treated solely by GPs (Schurman et al., 1985; Olfson, 1991; Bensing and Verhaak, 1994; Verhaak, 1995a,b) and in those countries with well developed systems of primary health care, GPs are most important sources of referral to specialist mental health care (Gater et al., 1991; Øiesvold et al., 1998). Goldberg and Huxley (1980; 1992) consider the GP as the most appropriate filter between the general public and specialist psychiatric services.

There are however, large differences between GPs in the way they fulfill this function. Within health care systems there are large individual differences, depending on local or individual circumstances (Marks et al., 1979; Verhaak, 1986; DeGruy, 1996) and between countries there is also considerable systemrelated variation (Üstün and Sartorius, 1995). On the individual level, GPs differ in 'available time', 'personal knowledge of the patient', 'skills' and 'cooperation with other (psychosocial) disciplines'. These factors are positively related to their task perception regarding mental health care (Marks et al., 1979; Verhaak, 1986). The location of the practice in urban or rural areas appeared an important correlate of the position of the GP as an access point to health care provision in general (Boerma et al., 1998) and must be included as an explanatory variable on individual level as well.

On the system-level, wide variations were found in the structure of family practice and the perceived role of GPs in various aspects of curative and preventive care (Boerma et al., 1997; Boerma and Fleming, 1998). Important differences were found in relation to the referral system and the usual employment status of the GPs. In a referral system, where the GP has a gatekeeping role, he or she is responsible for the first treatment of a circumscribed population of patients (which facilitates the existence of a continued relationship). Self-employed GPs will tend to spend more time on profitable activities instead of 'costly' time-consuming interventions. Marked differences were also found between the countries in western and eastern Europe (Boerma et al., 1998). 
These results fit well with a characterisation made by Starfield, distinguishing between the individualized care model and the collective care model. In the individualized care model patients are usually registered with the GP, which enables the development of a continued relationship, and the doctor is working in a referral system with a comprehensive task profile (Starfield, 1992). The collective care model, is dominated by the clinic or hospital. The relationship between doctor and patient is usually not personal and health care is not well integrated. Individual physician responsibility for a patient does not apply (Starfield, 1992). In an international WHO-study the recognition of mental disorder in primary care was clearly related to characteristics of the individualized care model (Üstün \& Sartorius, 1995).

The explanations that we identified on the individual level and on the system level may be interrelated. For instance, the gatekeeping role of GPs facilitates continuity of care, which we considered important in the recognition of mental disorder, but this may interfere with an urban localisation of the practice where there is a larger supply of specialized mental services.

The general question in this paper concerns to what extent the self-perceived position of GPs as the first contacted health professional for patients with psychosocial problems is related to characteristics of the country's health care system, and to characteristics at local and individual level. In particular, we have examined the hypothesis that this position is more comprehensive in health care systems aligned to the individualized care model, as described above.

At the level of the practice and individual GP we evaluate the comprehensiveness of this position in relation to characteristics indicating the GP's available time, knowledge of the patient's situation and professional skills. These are reflected in aspects of workload, practice organisation, contacts with social workers, education and training, the record system in place and the location of the practice in urban or rural areas.

\section{Methods}

This paper is based on data gathered in the European Study of Task Profiles of General Practitioners, conducted in 1993 and 1994, involving 7233 responding GPs in 30 European countries (Boerma et al., 1997). The study included questions relevant to the role of the family doctor as the first contacted health professional for patients with psychosocial problems. This role was assessed in the responses to a set of 7 concise case scenarios (see table 4.1). Answers were 
pre-coded on a 4 point scale ranging from 'almost never' to 'almost always' involved. Questionnaires were presented to GPs in their own language. Translations provided by national coordinators were checked by licensed translators. Recruitment of physicians and distributions of questionnaires was done by the national representatives; the sampling frame was the family doctors or GPs and the required procedure was a random sampling. The overall response rate was almost $50 \%$. Response rates were higher in countries with salaried GPs than in those with self employed GPs and also higher in countries in central and eastern Europe than in those in the West. A comparison with available national population parameters showed the existence of some recruitment biases. The gender distribution was available in 22 countries and comparison showed a lower than average participation of female family doctors (in 16 of these countries the deviation was no more than 5\%). Comparison on age, which was possible in 20 countries, showed lower participation rates for the oldest and youngest age groups (in 16 of these countries the difference in average age was no more than two years) (Boerma et al., 1997).

\section{Dependent variable}

The dependent variable is the GP's perception of where his or her patients will go for a first professional consultation in the seven cases described in table 4.1. The answer was a score on a 4 point-scale, varying from '(almost) always the doctor of first contact' to 'seldom/never'.

\section{Table 4.1 Seven psychosocial problems: case scenarios}

- Anxious man, aged 45

- Physically abused child, aged 13

- Couple with relationship problems

- Man with suicidal inclinations

- Woman, aged 50, with psychosocial problems related to her work

- Man, aged 32, with sexual problems

- Man, aged 52, with alcohol addiction problems

The cases were selected from a list used in the so-called Interface Study (Crombie et al., 1990) and adapted in a consensus procedure with representatives from the participating countries. Cases have been selected with two aims: firstly, they should discriminate between GPs on the skills required to deal with the problem and, secondly, task assignment should be ambiguous, cases should not be obviously a task for GPs only, but also possibly assigned to other 
professionals. Gender and age of the patients were added to the cases to make them more realistic, and not as an indication of specific skills needed.

This list of problems was checked for skewness in the answers (criterion was $85 \%$ or more positive or negative answers). No items had to be removed. The items appeared to form a scale with a Cronbach $\alpha$ reliability coefficient of 0.90 . Individual GP scores were calculated by dividing the sum of the scores per item (ranging from 1-4) by seven. The higher the score, the higher the perceived role. National scores were calculated by aggregation of the individual average scores (Boerma et al., 1997).

\section{Independent variables}

Individualized care, as conceptualised by Starfield, was operationalised in the following two variables: the requirement for patient registration with an individual doctor or a practice (the so called patient list system); and referral role of GPs with respect to control of access to secondary care. Two more relevant characteristics of a country's health care system were examined (Boerma et al., 1997). These were: the (prevailing) employment status of the GPs; and the geographical region of Europe in which the country is located. The position of the countries on these variables at national level was derived from an earlier descriptive study based on literature and information from national experts (Boerma et al., 1993).

As indicators of the local perspective (the GP/practice), indicating available time, continuing knowledge of the patient and professional skills, we used the following variables: GP's weekly patient related workload (measured as the average number of patient encounters made on practice premises, plus twice the number of home visits, plus half the number of telephone encounters; this weighing procedure was derived from the GP payment contract in the Netherlands); the establishment of an appointment system for patients; the estimated average duration of consultations by appointment (as normally booked in the agenda); the usual delay between a request for an appointment and the real encounter for persons with non-acute illness; the record system in place for the patient's medical data; the existence of regular meetings with social workers; the completion of postgraduate (vocational) training in family practice; the degree of urbanisation of the practice area (inner city, urban, suburban, mixed, rural); and the age and gender of the family doctor.

Average scores for the perceived involvement in psychosocial problems were compared for the defining characteristics and the differences were evaluated, using analysis of variance tests. However, sources of variation in the scope of 
services of GPs are located at two levels: the local level (GPs and practices) and the national level (health care system). To avoid the drawback of aggregation (loss of information) or disaggregation (over-estimating the effects of the higher level variables) the data were analysed using the hierarchical linear model (Jones, 1993; DiPrete \& Forristal, 1994) with the MLn software (Woodhouse, 1995). Although theoretically three levels can be identified, the country, the practice and the GP, only two levels have been distinguished, because the effects of the practice and the GP cannot be separated here.

Figure 4.1 Mean aggregate scores per country on the GPs' perceived position in the first contact with psychosocial problems

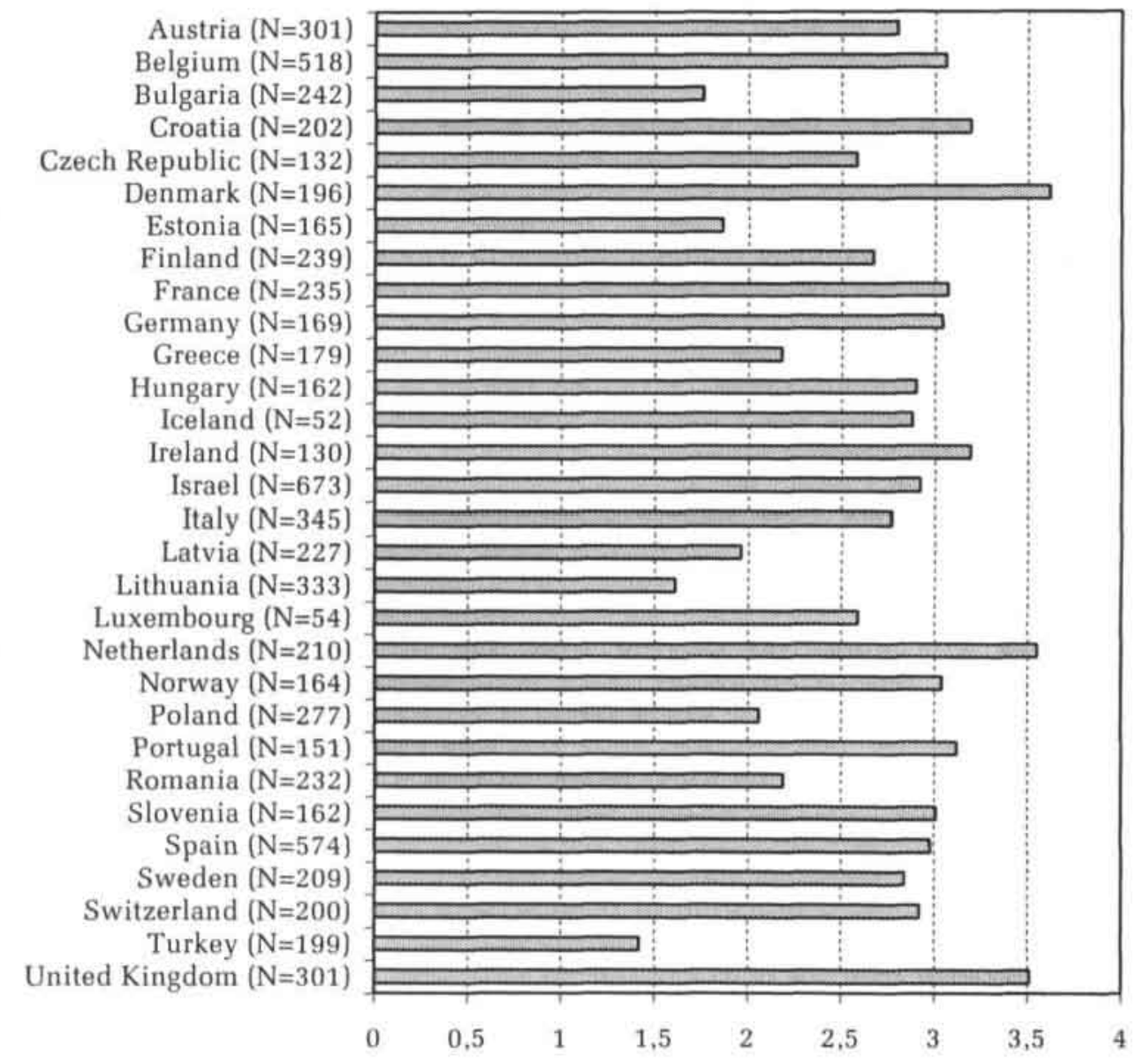




\section{Results}

\section{The GP as the first professional contact for psychosocial problems}

In the diagram presented in figure 4.1 the average national positions of GPs have been described.

Large differences were found between countries. The GP's self-perceived role as the first professional contact with psychosocial problems is most comprehendsive in Denmark, The Netherlands, United Kingdom, Croatia and Ireland and very weak in Turkey, Lithuania, Bulgaria and Estonia.

\section{Variation among health care systems}

Mean scores for the seven psychosocial problems analysed by the variables reflecting the degree of individualised care at national level are given in table 4.2.

Table 4.2 Mean scores for perceived 'first contact' with psychosocial problems by characteristics of the health care system on national level

System characteristics mean score ${ }^{1}$ (SD) $\mathrm{F}^{2}$

\section{Referral system}

GP in referral role $(\mathrm{n}=2352)$

$3.14 \quad(.70)$

$877^{\star \star}$

No referral system $(n=4258)$

$2.55 \quad(.82)$

Patients registered with GP

Personal doctor $(n=1850)$

$2.60 \quad(.82)$

Patients not listed $(n=4760)$

$628^{\star *}$

Salaried: $(\mathrm{n}=3759)$

$3.04 \quad(.68)$

Self-employed $(\mathrm{n}=2818)$

$$
(3.04-1.68)
$$

Central/east vs west

Central/eastern Europe ( $\mathrm{n}=2034)$

West $(n=4576)$

$3.00(.72)$

$655^{\star \star}$

Range 1 (=low involvement) - 4 (=high involvement)

$2 * * \quad$ significant $(\mathrm{p} \leq 0.001)$

The referral system and the requirement for patient registration (as a subset highly correlated with the referral system), the self-employed status of GPs and practising in western Europe were associated with higher mean scores than their counterparts. 


\section{Variation at local level}

The results of the examination of the practice and doctor characteristics are given in table 4.3.

Table 4.3 Mean scores for perceived 'first contact role' with psychosocial problems by variables on local level

Practice conditions

Mean $^{1}$ (SD)

F

\section{Appointment system}

None or for minority only $(n=3706)$

$2.58 \quad(.85)$

$427^{\star \star \star}$

For all or majority of patients $(n=2865)$

$3.00 \quad(.75)$

Time usually allocated per patient ${ }^{2}$

5 minutes or less $(n=159)$

$2.99 \quad(.81)$

$52^{\star \star \star}$

6-10 minutes $(\mathrm{n}=1110)$

$3.17 \quad(.74)$

11-15 minutes $(n=1049)$

$2.92 \quad(.75)$

more than 15 minutes $(\mathrm{n}=966)$

$2.77 \quad(.74)$

Usual waiting time non-acute patients ${ }^{2}$

same day: $(\mathrm{n}=2021)$

$2.83 \quad(.84)$

$21^{\star \star \star}$

next day: $(\mathrm{n}=842)$

$3.00 \quad(.73)$

2 days or more: $(n=1244)$

$2.98 \quad(.69)$

Records of patient's medical history

None or regular attendants only $(n=1091)$

$2.40 \quad(.85)$

$248^{\star \star \star}$

For all patients in the practice $(n=5437)$

$2.83 \quad(.81)$

Workload patient care

First quartile ( $n=1373$ )

$2.52(.81)$

$2.72 \quad(.85)$

Second quartile $(n=1460)$

$2.92 \quad(.78)$

Third quartile $(\mathrm{n}=1433)$

$3.02(.72)$

Regular meetings with social work

Seldom/never $(n=1735)$

$<3$ monthly $(\mathrm{n}=1257)$

$2.82 \quad(.78)$

every $1-3$ months $(n=1348)$

$2.92 \quad(.74)$

$>$ once a month $(n=1286)$

$2.99(.76)$

Vocational training

no training $(\mathrm{n}=2996)$

$2.62 \quad(.88)$

completed or in training $(\mathrm{n}=3512)$

$2.89 \quad(.76)$ 


\begin{tabular}{|c|c|c|c|}
\hline \multicolumn{4}{|l|}{ GPs' age } \\
\hline until $30(\mathrm{n}=295)$ & 2.14 & $(.89)$ & \multirow[t]{5}{*}{$64^{\star \star \star}$} \\
\hline $31-40(n=2482)$ & 2.70 & $(.83)$ & \\
\hline $41-50(n=2497)$ & 2.90 & $(.78)$ & \\
\hline $51-60(n=933)$ & 2.74 & $(.82)$ & \\
\hline over $60(n=372)$ & 2.72 & $(.84)$ & \\
\hline \multicolumn{4}{|l|}{ GPs' gender } \\
\hline Male $(n=4229)$ & 2.90 & $(.78)$ & \multirow[t]{2}{*}{$378^{\star \star *}$} \\
\hline Female $(n=2368)$ & 2.50 & $(.86)$ & \\
\hline \multicolumn{4}{|l|}{ Geographical practice location } \\
\hline urban (inner city) $(\mathrm{n}=1482)$ & 2.45 & $(.90)$ & \multirow[t]{5}{*}{$98^{\star \star \star}$} \\
\hline urban (small town) $(\mathrm{n}=1423)$ & 2.67 & $(.84)$ & \\
\hline suburban $(n=748)$ & 2.86 & $(.76)$ & \\
\hline mixed urban/rural $(\mathrm{n}=1367)$ & 2.91 & $(.74)$ & \\
\hline rural $(n=1561)$ & 2.96 & $(.77)$ & \\
\hline
\end{tabular}

Range 1 (=low involvement) - 4 (=high involvement)

2 Only applicable to GPs using an appointment system

$\star \star * \quad$ significant $(\mathrm{p} \leq 0.001)$

Higher means were reported where an appointment system was established, a comprehensive record system was in place, the family practice workload was high and meetings with social workers occurred at least once a month. Time allocated to patient encounters showed highest scores in the middle of the ranges. With delays for non-acute appointments, lowest means were found in the shortest delay category. Vocationally trained doctors had higher scores than doctors who were not. Higher scores occurred in the age group 41-50 years, and scores were low among doctors less than 30 years of age, though the sample was much smaller. Male GPs reported higher scores than female. There were strong trends in the analysis by location with lowest scores in inner city areas and highest scores in rural areas.

\section{Two-level analysis}

In a two-level multiple regression analysis, taking into account the nested structure of our data, all mentioned variables, except allocation of consultation time and the delay between appointment and consultation, have been considered. The two omitted variables only apply to a subset of the GPs. Results are given in table 4.4 . 
Table 4.4 Two-level regression analysis on GP's perceived 'first contact role' with psychosocial problems $(n=4901)$

\begin{tabular}{lcl}
\hline Variables & $\beta$ & $t$ \\
\hline National level & .35 & \\
Referral system (1=yes) & .04 & $4.08^{\star \star \star \star}$ \\
Patients registration (1=yes) & .14 & $0.43^{\mathrm{ns}}$ \\
Employment status (1=self employed) & .21 & $1.94^{\star \star}$ \\
European Region (1=West) & & $2.59^{\star \star}$ \\
Local level & .04 & \\
Appointment system (1=yes) & .07 & $2.54^{\star \star \star}$ \\
Medical records routinely (1=yes) & .13 & $5.25^{\star \star \star}$ \\
Workload & .10 & $9.21^{\star \star \star}$ \\
Meetings with soc.work (1=regular) & .05 & $8.31^{\star \star \star}$ \\
Vocationally trained (1=yes) & -.03 & $3.80^{\star \star \star}$ \\
GP's age & -.05 & $2.51^{\star \star}$ \\
GP's gender (1=female) & .08 & $4.04^{\star \star \star}$ \\
Urbanisation (1=rural) & & $6.84^{\star \star \star}$ \\
\hline
\end{tabular}

\footnotetext{
ns not significant

** significant $(\mathrm{p} \leq 0.01)$

$\star * \star *$ significant $(\mathrm{p} \leq 0.001)$
}

The intra-class correlation is 0.408 , which means that $41 \%$ of the variance is located at national level and the remaining $59 \%$ at local level. These results emphasize the importance of the role of the GP in a referral system. In countries where GPs do not hold such a position, particularly the former communist countries, the role as the first professional to be contacted by patients with psychosocial problems is perceived to be much lower than in other countries. The requirement of patient registration and the employment status of the GP have no independent effect.

On the local level GPs with a higher workload, those having regular meetings with social workers, those working in rural areas, those routinely keeping medical records, male doctors and those working with an appointment system report a more comprehensive role. In summary, health care system characteristics play a major role but individual and practice characteristics retain an influence.

\section{Discussion}

In general, our results confirm the assumptions made in the introduction. In the GP's perceived position as the first contact with mental disorder, we found clear 
differences between physicians in gatekeeping referral systems and those in more liberal health care systems. Outspoken differences were also found between the eastern European countries (heirs of a true collective care system) and the western countries, where varieties of a more individualized health care system prevail. In so far as the GP's employment status represents the possibility of a competing financial interest we found no evidence for the expected relationship. At the level of the individual GP and the practice, GPs who keep medical records routinely (hence are better informed about their patients) more often saw themselves as the first contact for mental disorder. The same was true for GPs meeting with social workers regularly and those vocationally trained; but the explanation here remains a matter of speculation. It may be the cause (improved skills) or the product (need for referral and consultation) of a more comprehensive first contact role. Furthermore GPs in rural practices more often claim to be the first contact for patients with mental problems compared with GPs who work in urban practices.

Some differences were counter-intuitive: male doctors disclosed higher scores than female, which is in contrast to evidence from other studies that female doctors are better communicators (Roter et al., 1991; Hall et al., 1994; Van den Brink-Muinen, 1996; 1997). Although the seven problems in the questionnaire were not gender specific, the description concerned more male than female patients. Further analysis of our data showed that this may have biased the results, because the only item that does not contribute significantly to the difference between male and female doctors in the multiple regression equation is the only item in which a women is the subject. Besides, GPs with the highest workload and those who have relatively short patient encounters reported a more comprehensive first contact position than doctors with lower workloads and longer patient consultations. This seems to be the working style that is usual in many British and Dutch practices.

Despite an interrelation of the variables on health care system level and individual level (e.g. a referral system more or less implies patient lists and is a good condition for comprehensive medical record keeping), effects of most variables at an individual level remained statistically significant after controlling for effects on health system level. Indeed, working in a referral system is of major importance for the GP's perceived first contact position regarding mental disorder, but within each type of health care system, the variables on individual level keep an independent impact.

The generalizability of our findings also needs to be considered. We did not measure the GP's actual position as the first contact with mental disorder but 
his or her perception of it. These two concepts are not similar, but we assume that doctors, who perceive themselves as the as the usual first contact, indeed hold such a position to a higher extent than doctors who perceive this role as small. Thus, perception is assumed to be a good indicator for the actual situation. We also believe that most GPs are well able to make the requested estimation of this position. At some time they will get to know about 'first contacts' that occurred elsewhere, either by the patient or by a report from social work or a mental health service. We do not know, however, to which extent this ability to estimate contacts with other services varies systematically between categories of GPs or countries. We recognise that a set only seven questions cannot represent the totality of psycho-social demand. The items have been selected to depict the interface between family practice and other (categorial) services. In this way they represent a good perspective of the comprehensiveness of the GP's role. We identified some response bias by age and gender, but since the study was based on such large numbers of responding doctors, we believe the effects of these under-representations are small. Finally, the implications of our results. If the involvement of GPs as the first professsional contact for patients with mental disorders is considered desirable, two approaches seem possible. On individual level, GPs should be encouraged to cooperate with social workers and mental health care professionals, to keep adequate medical records of their patients and to complete a comprehensive vocational training scheme. With respect to the structure of health care a referral system with gate keeping GPs should be strongly recommended. 


\section{Gender-related differences in the organisation and provision of services among general practitioners in Europe}

A signal to healthcare planners

This chapter was published as:

Boerma WGW, Van den Brink-Muinen A. Gender-Related differences in the Organization and Provision of Services Among General Practitioners in Europe. A Signal to Health Care Planners. Medical Care, 2000; 10: p.993-1002.

Reproduced with permission of Lippincot Williams \& Wilkins Inc. 


\section{Introduction}

Over the past decades, the number of women practicing medicine has increased considerably. Eastern Europe has a tradition of women working in medicine, but the trend is more recent in western Europe. This article examines how this emerging trend may affect the delivery of services in general practice.

Many studies have compared the activities of male and female general practitioners (GPs). Studies in Australia (Britt et al., 1996) and the Netherlands (Van den Brink-Muinen and De Bakker, 1994) have shown that more women with gynaecological, endocrine, and psycho-social problems consult female GPs than male GPs. In the Netherlands (Bensing et al., 1993) and the UK (Wilkin et al., 1987; Chambers and Campbell, 1996), female GPs apply fewer technical procedures than their male counterparts. A Canadian study found that female GPs are less involved in obstetric care (Keane et al., 1991).

Various studies have shown that female GPs are more attentive to psycho-social factors and more frequently use counselling techniques (Keane et al., 1991; Roter et al., 1991; Bertakis et al., 1995; Van den Brink-Muinen, 1997; Van den Brink-Muinen et al., 1998; Lorber, 1997; Maheux et al., 1989; Maheux et al., 1990; Lurie et al., 1997). However, an international comparison found male GPs to be more involved as the doctor of first contact for mental and social problems (Boerma and Verhaak, 1999). Regarding the organisation of the practice there is conflicting evidence of gender-based differences in office hours, length of consultation, house calls and on-call arrangements (Britt et al., 1996; Van den Brink-Muinen and De Bakker, 1994; Bensing et al., 1993; Wilkin et al., 1987; Chambers and Campbell, 1996; Cooke and Ronalds, 1985a; Hooper, 1989; Groenewegen and Hutten, 1995).

In preventive services, female physicians have higher screening rates, especially for cervical and breast cancer (Van den Brink-Muinen and De Bakker, 1994; Bertakis et al., 1995; Lurie et al., 1997; Cooke and Ronalds, 1985b; Hall et al., 1990; Osborne et al., 1991; Franks and Clancy; 1993; Kreuter et al., 1995; Andersen and Urban, 1997; Reid et al., 1997). Moreover, they feel more responsible for making sure their patients receive screening (Maheux et al., 1990; Maheux et al., 1988; Lurie et al., 1993). A higher involvement of female doctors was also reported in family planning and perinatal care (Britt et al., 1996; Chambers and Campbell, 1996; Keane et al., 1991; Cooke and Ronalds, 1985a; Hooper, 1989). Although differences appeared in specific aspects, the overall task profile does not differ between male and female physicians.

Part of the gender difference can be attributed to other factors, such as age. Female GPs are younger than male GPs (Britt et al., 1996; Wilkin et al., 1987; 
Maheux et al., 1990; Cooke and Ronalds, 1985b; Hingstman and Van der Velden, 1998). The medical training of the females is thus more recent and may therefore place greater emphasis on preventive care and psycho-social aspects. Furthermore, female GPs are more likely to work in urban areas, to be part of group practices, and to be salaried or working on a part-time basis (Britt et al., 1996; Wilkin et al., 1987; Maheux et al., 1990; Cooke and Ronalds, 1985b; Maheux et al., 1988; Hingstman and Van der Velden, 1998).

It is hard to say how significant many of these findings are because they are based on (often small-scale) research that does not control for confounding factors. Few of these studies have taken into account factors like age, of both the patient and the GP. Yet it is known that older GPs (who are often male) are consulted more frequently by older patients, because patients tend to stay with the same doctor. Besides, women usually prefer to consult a female doctor, particularly for gender-related services (Britt et al., 1996; Bensing et al., 1993; Cooke and Ronalds, 1985a; Graffy, 1990; Fennema et al., 1990). Women also consult their doctor more frequently than men and tend to present more problems (Van der Velden et al., 1992; McCormick et al., 1995).

Two other factors should be taken into account as well: the availability and proximity of services, as these may differ between cities and rural areas and between countries; and features of the health care system, such as the mode of payment, employment status, and the formal gate-keeping role of GPs. One study found evidence of an association between mode of remuneration and gender-related professional attitudes (Maheux et al., 1988).

In this article, we take advantage of the large database derived from the European Study of Task Profiles in General Practitioners (Boerma et al., 1997; Boerma et al., 1998) to answer the following two research questions:

1 Do male and female GPs in Europe differ in their personal and work related characteristics?'

2 Do male and female GPs in Europe differ in their curative and preventive service profiles? If so, how can these differences be explained?"

In line with the literature, we expect to find gender differences in work preferences, the organisation and setting of the practice, and the provision of certain services. In countries in which patients are registered with a particular GP and have access to specialist services only after referral by this 'gatekeeping' GP, we expect to find less difference in curative services. The reason is that when patients have particular problems, for which they would like to see a 
doctor of the same gender, they have less freedom of choice to do so. In countries in which GPs are self-employed we expect to find less or no difference by gender in preventive medicine and health education, because such services are rarely eligible items in these systems.

\section{Methods}

\section{Sampling and data collection}

The study is based on data collected in 1993 and 1994 in the European Study of Task Profiles of General Practitioners (Boerma et al., 1997; Boerma et al., 1998). In 32 European countries, 8,183 GPs provided answers to uniform questionnaires in their own language about themselves, their practice and their involvement in the provision of curative and preventive services. The questionnaires were translated at the national level and were subsequently checked by licensed translators. The preferred random sampling procedure could not be applied in seven countries, usually because of the lack of sampling frames. The data entry and analyses were carried out centrally at NIVEL in the Netherlands (Boerma et al., 1997).

The overall response rate was about $50 \%$, ranging from $87 \%$ to $30 \%$ among the countries. Possible bias resulting from non-response was estimated by comparing the respondents to national population parameters, when available. In general, there was some under-representation of female GPs and of younger and older physicians (Boerma et al., 1997).

\section{Measures}

\section{Dependent variables}

Concerning curative services, the role of the GP in the first contact with a patient's health problems was measured for 27 specified health problems on a four-point scale, ranging from 'almost always' to 'seldom/never'. Similarly, the involvement in technical procedures (e.g., minor surgery) was measured for 14 described procedures. The involvement in treatment and follow-up of (chronic) diseases was measured for 17 cases of specific diseases. The scores in each of these three task areas were averaged. Results were assigned to each respondent. Concerning preventive services, questions with pre-coded answers were used to measure each GP's involvement in screening for hypertension, serum cholesterol, and cervical cancer as well as the involvement in health education - i.e. clinics to stop smoking, to control alcohol abuse, and to monitor diet. Furthermore, there were questions on the involvement in pediatric surveillance and family planning/contraception. 


\section{Independent and control variables}

The key independent variable is the gender of the GP.

To study the independent effect of gender, several control variables were introduced. These concern the practitioners themselves, the practice, and the country's health care system.

Regarding the GP as a person the following variables were used: age; completion of postgraduate training in family medicine; average number of working hours in regular services per normal week (self-reported); reported average number of office-based patient encounters per day; and amount of time usually allocated per visit, as recorded in the appointment book.

At practice level, the following variables were used: working solo or in a group practice; availability of certain equipment (a list of 10 items was used); willingness to visit patients at home; provision of services outside office hours; the perceived proportion of socially deprived and elderly people among the practice population (compared with the national average); location of the practice (an inner-city, suburban/urban, or rural area); and distance to the nearest general hospital.

At the country level, the control variables were as follows: coordinating role of GPs (gatekeeping); employment status (salaried versus self-employed); and political background of the country (western Europe versus the former East Bloc countries).

\section{Statistical procedures}

Three dependent variables on curative services were measured by analyzing lists of items. After a scaling procedure, this resulted in individual scores. Items with $\geq 85 \%$ either positive or negative answers, were removed from the list. Respondents providing answers for $\leq 75 \%$ of the items of a list were not taken into account for that aspect of service. Thus, the number of respondents may vary by the kind of service considered. Reliability analyses were quite satisfactory, with a Cronbach's $\alpha$ of $\geq 0.87$. On the scale concerning the role of the GP on first contact with health problems, sub-scales were identified for the first contact with gynaecological problems and with psycho-social problems. Individual GP scores were calculated; the higher the score, the deeper the selfreported involvement (Boerma et al., 1998).

Involvement in preventive services was measured by questions with pre-coded answers per item of service. The analyses were based on the percentage of GPs being involved.

In conducting the multivariate analyses, we were aware of sources of variation 
in the scope of services to be located at the local level (GPs and practices) and the national level (system characteristics and European region). To avoid the problem of both aggregation (loss of information) and disaggregation (overestimation of the effects of the higher-level variables) the data were analyzed using the hierarchical linear model (Jones, 1993; DiPrete and Forristal, 1994) with the MLn software (Woodhouse, 1995). The multilevel analysis controlled for confounding variables on both levels. These were the following: age; postgraduate training; working hours; medical equipment; solo or group practice; degree of urbanisation of the practice location; and distance to nearest hospital. The control variables at national level were gate-keeping role, employment status and the East-West distinction. To get a specific perspective on the health care systems, gender differences were also analyzed separately with respect to countries with or without a gatekeeper role for GPs, salaried versus self-employed GPs and the former East Bloc versus western Europe.

\section{Results}

\section{Range of services of male and female GPS}

Male physicians were generally more involved in most of the services specified in table 5.1.

The exception was health education in special sessions, in which female doctors were more frequently involved. This pattern did not show up as often in distinct countries. Except for the application of technical procedures, and management of diseases, significant differences were found in only a few countries.

Regarding hypertension screening, for example, some countries had a higher involvement of male GPs whereas other countries had a higher involvement of female physicians. In five countries female doctors were more involved in the first contact with gynaecological problems. This was in contrast to the results concerning other health problems. With respect to screening for cervical cancer, there were three countries with significant differences; in all three female physicians reported higher involvement. The higher involvement of female physicians in health education, found at aggregate level, was absent in the analyses performed by country. 
Table 5.1 The provision of services by male and female GPs ${ }^{1}$

\begin{tabular}{|c|c|c|c|c|}
\hline \multirow[t]{2}{*}{ Areas of GP service } & \multirow[t]{2}{*}{$\begin{array}{l}\text { Male } \\
\text { GPs }^{2}\end{array}$} & \multirow[t]{2}{*}{$\begin{array}{l}\text { Female } \\
\mathrm{GPs}^{2}\end{array}$} & \multicolumn{2}{|c|}{$\begin{array}{r}\text { Countries with } \\
\text { sign. differences } 3 \text { (n) }\end{array}$} \\
\hline & & & $\begin{array}{c}\text { Male } \\
\text { higher }\end{array}$ & $\begin{array}{r}\text { Female } \\
\text { higher }\end{array}$ \\
\hline
\end{tabular}

\section{Curative:}

First contact with health problems

(mean score)

- all ( $n=6676)$

- gynaecological only $(n=7330)$

3.0

2.5

2.9

2.5

6

2.9

2.4

1

- psycho-social only $(n=7404)$

Application of medical techniques

(mean score) $(\mathrm{n}=6597)$

Treatment/follow-up of disease (mean score) $(n=6979)$

2.4

\section{Preventive:}

Screening (\%) for

- hypertension $(n=8045)$

- cervix cancer $(n=7307)$

- serum cholesterol $(n=7973)$

$\begin{array}{llll}80.5 & 79.1(\mathrm{~ns}) & 5 & 5 \\ 51.6 & 45.8 & - & 3 \\ 45.2 & 38.9 & 2 & 3\end{array}$

Health education sessions (\%)

( $\mathrm{n}=7828$ )

- smoking

$12.7 \quad 16.3$

- diet

12.4

16.6

10.9

16.9

1

Family planning $(\%)(n=6000)$

75.3

54.8

3

Pediatr. surveillance $(\%)(n=5998)$

65.3

54.6

2

All differences are significant ( $\mathrm{p} \leq 0.001)$ unless indicated by ns

2 Involvement scores range from 1 (low) to 4 (high)

3 Total number of countries: 32

\section{Characteristics of the person and the work situation}

Well over half of our sample ( $58 \%$ ) consisted of men. In 20 countries male GPs outnumbered female GPs; in eight (East European) countries, the proportion was the other way round; and in four countries there was no significant difference. On average, male doctors were older; this difference was found in 17 countries. 
Table 5.2 Personal and practice characteristics of male and female GPs

Characteristics

$\begin{array}{cr}\text { Male } & \text { Female } \\ \mathrm{GPs}^{1} & \mathrm{GPs}^{1}\end{array}$

$\mathrm{GPs}^{1} \quad$ significant differences ${ }^{2}$

Male Female

higher higher

\section{Personal:}

- $\operatorname{Gender}^{3}(\%)(\mathrm{n}=8137)$

58.1

41.9

20

44.9

41.6

- Postgrad. training completed (\%) $(\mathrm{n}=7956)$

46.0

34.3

3

41.5

36.1

10

29.8

25.7

32.0

34.3

14.7

15.5

45.2

27.0

6

15.2

59.9

41.5

4.0

14

- Making house calls (\%) $(n=8002)$

- Involvement in after hours services $(\%)(n=7918)$

- Socially deprived above national average $(\%)(\mathrm{n}=6996)$

20.6

17.7

5

- Elderly above national average (\%) $(\mathrm{n}=7012)$

41.8

35.1

4

27.2

14.9

18.7

33.7

58.7

8

3

2

6

3

9

- Practice location (\%) $(n=8084)$

. rural

- inner city

. hospital $>5 \mathrm{kms}$

All differences are significant $(\mathrm{p} \leq 0.001)$

2 Total number of countries: 32

3 Gender distribution in our sample

4 Excluding hours on-call services

5 Only GPs working with an appointment system

The following profile for female GPs emerged: compared with their male counterparts, a smaller proportion had completed postgraduate (specialist) 
training in family medicine; they had fewer regular working hours per week; they had fewer office contacts per day and allocated slightly more time per patient; and they had a lower total workload for patient care per week (table 5.2). When we took only full-timers into account, the workload difference diminished considerably. Moreover, the number of office contacts per day was even somewhat higher for female physicians. In many countries, female GPs worked fewer hours per week. In nine countries, female physicians allocated significantly more time to each patient. In 11 countries, the patient workload of female doctors was lower, but in most of these countries this difference disappeared if only full-timers were taken into account.

Female doctors were more likely to work in partnerships and group practices. They had less medical equipment at their disposal; they made fewer house calls; they were less involved in services outside of regular office hours; and they worked more frequently in inner cities (but less in practices with relatively large estimated numbers of socially deprived and elderly people).

Male physicians were over-represented in rural areas and in practices farther away from the hospital. Differences at the aggregate level were also found in a substantial number of individual countries, particularly in terms of medical equipment, location of the practice, and working in groups.

\section{Service profiles}

\section{Curative services}

After adjustment for the control variables, we found significant gender differences in the provision of the various curative services (table 5.3). Female GPs were more involved in the first contact with gynaecological problems, although in the separate analysis this applied only to countries in western Europe. The higher involvement of male GPs in the first contact with psycho-social problems, which was found at a general level, does not hold for countries with gate-keeping GPs, nor for countries in western Europe. Involvement in the application of technical procedures and in the treatment and follow-up of disease was also higher among male GPs than among female GPs. This was true regardless of country or type of health care system. In countries with GPs in a gate-keeping position, the standardized coefficients were generally closer to zero than in the other countries. This means that gender differences were smaller in countries with a gate-keeping system. Similarly, we found greater differences between male and female physicians in the countries of the former East Bloc than in the West. The exception was the first contact for gynaecological problems, which virtually no GP in the East European countries reported. 
Table 5.3 Standardized regression coefficients of gender (female=1) with GP involvement in five measures of curative services; controlled for personal and practice variables

\begin{tabular}{|c|c|c|c|c|c|}
\hline \multirow{2}{*}{$\begin{array}{l}\text { Type of country's } \\
\text { healthcare system/ } \\
\text { European region }\end{array}$} & \multicolumn{3}{|c|}{$\begin{array}{l}\text { Position as the doctor of first contact } \\
\text { with health (-related) problems }\end{array}$} & \multirow{2}{*}{$\begin{array}{r}\text { Applica- } \\
\text { tionof } \\
\text { technical } \\
\text { proce- } \\
\text { dures } \\
(n=6177)\end{array}$} & \multirow{2}{*}{$\begin{array}{r}\text { Treat- } \\
\text { ment and } \\
\text { follow-up } \\
\text { of disease } \\
(n=6531)\end{array}$} \\
\hline & $\begin{array}{l}\text { All health } \\
\text { problems } \\
(\mathrm{n}=7433)\end{array}$ & $\begin{array}{r}\text { Gyn. } \\
\text { problems } \\
(n=6841)\end{array}$ & $\begin{array}{r}\text { Psycho- } \\
\text { social } \\
\text { problems } \\
(\mathrm{n}=6898)\end{array}$ & & \\
\hline All systems / countries & -0.008 & $0.063^{\star}$ & $-0.047^{\star}$ & $-0.096^{\star}$ & $-0.083^{\star}$ \\
\hline With gate-keeping GPs & 0.006 & $0.034^{\star}$ & -0.024 & $-0.085^{\star}$ & $-0.065^{\star}$ \\
\hline No gate-keeping GPs & -0.018 & $0.059^{\star}$ & $-0.072^{\star}$ & $-0.101^{\star}$ & $-0.096^{\star}$ \\
\hline With self-employed GPs & 0.012 & $0.068^{\star}$ & $-0.033^{\star}$ & $-0.092^{\star}$ & $-0.065^{\star}$ \\
\hline With salaried GPS & -0.009 & $0.063^{\star}$ & $-0.049^{\star}$ & $-0.098^{\star}$ & $-0.086^{\star}$ \\
\hline Former East Bloc & $-0.034^{\star}$ & 0.031 & $-0.090^{\star}$ & $-0.150^{\star}$ & $-0.095^{\star}$ \\
\hline Western Europe & 0.018 & $0.099^{\star}$ & -0.017 & $-0.079^{\star}$ & $-0.066^{*}$ \\
\hline
\end{tabular}

* significant value $(\mathrm{p} \leq 0.05)$

\section{Preventive services}

With respect to health education, which is not central in the GP's task anywhere, female physicians were generally more involved than males in special sessions or clinics on three topics: smoking, alcohol use, and diet (table 5.4).

In the separate analyses, however, this greater involvement of female GPs did not hold for all types of health care systems, nor for all countries. The gender difference in clinics to stop smoking was not found in the countries with selfemployed GPs. Female physicians were more involved in health education on alcohol use in western countries, though not in countries with gate-keeping GPs. Involvement in health education on dietary issues was higher among female GPs in countries in which GPs are salaried and do not have a gatekeeping position as well as in former East Bloc countries. Concerning involvement in screening of populations at risk of high levels of hypertension and serum cholesterol and of cervical cancer, no gender differences were found in the countries of western Europe (table 5.4). In the countries of eastern Europe, female doctors were more involved than male GPs in screening for serum cholesterol and cervical cancer. Separate analyses including the gate-keeping role and employment status revealed no gender differences. 
Table 5.4 Standardized regression coefficients of gender (female=1) with GP involvement in health education and screening; controlled for personal and practice variables

\begin{tabular}{|c|c|c|c|c|c|c|}
\hline \multirow{2}{*}{$\begin{array}{l}\text { Type of country's } \\
\text { healthcare system / } \\
\text { European region }\end{array}$} & \multicolumn{3}{|c|}{ Health education concerning } & \multicolumn{3}{|c|}{ Screening of risk groups for } \\
\hline & $\begin{array}{l}\text { smoking } \\
(\mathrm{n}=7380) \\
B\end{array}$ & $\begin{array}{l}\text { alcohol } \\
\text { use } \\
(n=6847) \\
B\end{array}$ & $\begin{array}{l}\text { diet } \\
(n=7330) \\
B\end{array}$ & $\begin{array}{l}\text { hyper - } \\
\text { tension } \\
(n=7329) \\
B\end{array}$ & $\begin{array}{l}\text { serum } \\
\text { cholest. } \\
\text { ( } \mathrm{n}=7322 \text { ) } \\
\mathrm{B}\end{array}$ & $\begin{array}{l}\text { cervical } \\
\text { cancer } \\
(\mathrm{n}=7274) \\
B\end{array}$ \\
\hline $\begin{array}{l}\text { - All systems/ } \\
\text { countries } \\
\text { - With gatekeeping }\end{array}$ & $0.052^{\star}$ & $0.038^{\star}$ & $0.031^{\star}$ & -0.007 & 0.007 & 0.011 \\
\hline $\begin{array}{l}\text { GPs } \\
\text { - No gatekeeping }\end{array}$ & $0.073^{*}$ & 0.021 & 0.024 & -0.024 & -0.013 & -0.014 \\
\hline $\begin{array}{l}\text { GPs } \\
\text { - With self- }\end{array}$ & $0.035^{\star}$ & $0.055^{\star}$ & $0.039^{\star}$ & 0.010 & 0.024 & 0.033 \\
\hline employed GPs & 0.015 & $0.044^{*}$ & -0.019 & -0.020 & -0.028 & -0.001 \\
\hline - With salaried GPs & $0.062^{\star}$ & $0.034^{*}$ & $0.049^{\star}$ & 0.001 & 0.022 & 0.018 \\
\hline - Former East Bloc & $0.054^{\star}$ & 0.015 & $0.065^{\star}$ & 0.015 & $0.047^{\star}$ & $0.038^{\star}$ \\
\hline - Western Europe & $0.043^{\star}$ & $0.045^{\star}$ & 0.002 & -0.021 & -0.023 & -0.011 \\
\hline
\end{tabular}

* significant value $(\mathrm{p} \leq 0.05)$

Table 5.5 Standardized regression coefficients of gender (female=1) with GP involvement in paediatric surveillance and family planning; controlled for personal and practice variables

\begin{tabular}{lll}
$\begin{array}{l}\text { Type of country's healthcare } \\
\text { system / European region }\end{array}$ & $\begin{array}{l}\text { Pediatric surveillance } \\
(\mathrm{n}=5557), \mathrm{B}\end{array}$ & $\begin{array}{l}\text { Family planning } \\
(\mathrm{n}=5561), \mathrm{B}\end{array}$ \\
\hline All systems / countries & 0.016 & -0.023 \\
With gatekeeping GPs & -0.008 & $-0.053^{\star}$ \\
No gatekeeping GPs & 0.036 & -0.001 \\
With self-employed GPs & -0.007 & -0.032 \\
With salaried GPs & 0.018 & -0.021 \\
& & \\
Former East Bloc & -0.009 & 0.041 \\
Western Europe & 0.015 & $-0.062^{\star}$ \\
\hline
\end{tabular}

* significant value $(\mathrm{p} \leq 0.05)$ 
No gender differences were found for paediatric surveillance, either at the aggregate level or in the separate analyses by subgroups of countries (table 5.5). For family planning, we found that male GPs were more often involved than their female counterparts in western Europe and in countries with gate-keeping GPs.

\section{Discussion}

In countries with quite different health care systems, we found consistent gender differences in practice preferences. Compared with their male counterparts, female GPs were more often found in partnerships than in solo practices; they tended to work in urban rather than in rural areas; they made fewer house calls and were less involved in work outside regular office hours; and on average they spent more time on each consultation. With respect to the number of office contacts per day (adjusted for part-time working), however, we found no difference between male and female GPs. These findings are in accord with our expectations derived from the literature.

Our expectation to find less differences in the provision of curative services in health care systems with gate-keeping GPs, was confirmed by the results. With all distinguished services the differences were smaller in these systems. Gender differences in curative services are less obvious among gate-keeping GPs, because, by regulation, a broad range of problems are channelled through the GP into the system (Boerma et al., 1997) some of which may be referred to other practitioners.

Concerning the provision of preventive services and health education we expected to find less or no gender difference in systems with self-employed GPs. Here, the results were mixed. In these systems we indeed found smaller or no gender difference with health education on smoking and food intake and cervical cancer screening. In the other services, however, the difference was even higher among self-employed GPs. It should be kept in mind that, overall, GPs reported a very low involvement in health education clinics; health education in general practice may be practised more frequently in individual consultations. Because the overall involvement of GPs in cervical cancer screening in eastern Europe was very low, we could not detect any difference related to gender. Yet even in western Europe, we found no difference between male and female GPs, which seems to contradict the results of many studies (Hall et al., 1990; Osborne et al., 1991; Franks and Clancy, 1993; Kreuter et al., 1995; Reid et al., 1997). In western Europe, GPs have good opportunities for case finding and follow up, and that is why they are increasingly called in with 
community screening programs. This trend decreases the chance of having gender differences.

The higher involvement of male GPs in family planning in western Europe is not in line with results found by Britt et al. (1996) and Cooke and Ronalds (1985a), and further research should clarify this difference.

We also wanted to know whether the patterns of services identified in local and regional studies were confirmed in this more broadly based study. Some of the differences we identified, have particular bearing on curative services. The greater involvement of male GPs in curative services was related to their longer working hours and to the fact that male GPs predominated in rural areas. There were also differences in postgraduate training, which had been completed by relatively more male GPs. The available equipment was closely related to the range of services provided.

The greater involvement of male physicians in the application of technical procedures, was in accordance with Dutch and UK studies. This picture was generally similar, regardless of the gatekeeper role and the remuneration system of GPs, or the geographical location in the East or the West. The same result was found with respect to the treatment and follow-up of disease.

Furthermore, at least in western Europe, female GPs were more involved as the first contact for women with gynaecological problems. The absence of a difference in eastern Europe must have resulted because primary care physicians, male and female, hardly saw any women with gynaecological problems. We identified, at general level, a greater involvement of male GPs in the first contact with psycho-social problems, apparently in contrast to most other studies. However, on further analysis, this turned out not to apply to countries in western Europe or to countries with gate-keeping GPs. This restriction may help clarify this contradictory result, because the other studies did not cover countries in eastern Europe (Britt et al., 1996; Van den Brink-Muinen and De Bakker, 1994; Keane et al., 1991; Roter et al., 1991; Bertakis et al., 1995; Van den Brink-Muinen, 1997; Van den Brink-Muinen et al., 1998; Lorber, 1997; Maheux et al., 1989; Maheux et al., 1990; Lurie et al., 1997). Moreover, we asked about only the first contact with psycho-social problems, whereas Britt et al. (1996) and Bensing et al. (1993), for instance, studied all contacts for psychological and social reasons.

We should also consider some methodological issues. This study did not entail random recruitment in all participating countries, and the rate of non-response was high. Because the questionnaire covers a broad range of issues and possible 
tasks, it is not likely that we have attracted GPs with particular interests more than others. For this reason we do not think we have identified a particularly biased group of GPs with regard to service provision. Gender selection is also an issue: the gender distributions of respondents in 21 countries were compared to the populations of GPs. Male GPs were slightly over-represented in three countries, females in 15 countries. In most cases the deviation in our sample was less than five percent from the national proportion. It is quite possible that we missed some female GPs holding a small part-time job who might not have thought that the invitation to participate in this study was meant for them. We are aware that the results may have been affected by self-selection in the response. In individual countries, this may have led us to underestimate the gender differences. In the international comparison, however, we believe that the total number of female GPs was sufficient to permit generalisation.

Another concern is the methodological difference between this large-scale international study and the local and regional studies to which we have referred. The methods used in these studies, such as direct observation or registration of patient contacts, would not be feasible in our study. This divergence puts a constraint on comparability. The strengths of our approach, which is based on self-reported activities, are its uniform application in many countries, and the fact that it takes relevant confounders and other background variables into account. These features form the basis for a good international comparison.

\section{Study implications}

The importance of the study lies in its implications for the future provision of care in general practice. At this point, we would like to suggest some likely trends.

\section{Working arrangements}

Increased numbers of female GPs will encourage the establishment of group practices. For women, the flexibility of part-time work, the more limited commitment and the possibility of salaried employment will often be more attractive. Female GPs were less involved in activities outside regular office hours. That is why new arrangements will be needed to ensure the provision of these services. In countries where most GPs are still involved in evening-, nightand weekend services, such as Denmark, the United Kingdom and The Netherlands, there are experiments that point a way forward. 


\section{Education}

Training for a part-time doctor is no less rigorous than for a full-time doctor and is the same for men and women. A temporary leave of absence and a limited volume of working time because of family commitments are inevitable consequences of the increased recruitment of female GPs. This results in a reduced working lifetime. Implications for the longer term therefore start with the recognition of a need for educating more doctors.

If the reduced activity of female GPs in the application of technical procedures would point to less adequate care, which has not been proven so far, additional education could be one of the remedies. Likewise, the difference found in some countries between male and female GPs in the reported recognition of psychosocial problems could also be addressed in the educational package.

\section{Resources in general practice}

As doctors provide a smaller total volume of care in the course of their working lifetime, society will need more GPs. Otherwise, some tasks will have to be transferred to other healthcare workers. Therefore, national policies should be formulated for the future direction of the provision of primary care specifically addressing the role of GPs and their relation to other professionals. At fixed costs, one direction would be to promote more involvement of ancillary workers. If, however, the present system of access to health care by GPs is preferred, it may be necessary to increase the resources. 


\section{Unity or diversity? Task profiles of general practitioners in central and eastern Europe}

This chapter was published as:

Grielen SJ, Boerma WGW, Groenewegen PP. Unity of diversity? Task profiles of general practitioners in Central and Eastern Europe. European Journal of Public Health, 2000: 10: p.249-254.

Reproduced with permission of the European Journal of Public Health. 


\section{Introduction}

Until the fall of communism in 1989, three basic types of health care systems could be distinguished in Europe. The Beveridge (tax-based NHS) system prevailed in Northwestern Europe, i.e. in the UK, Ireland and Scandinavia and in Southern Europe, i.e. in Spain, Portugal and Italy. The Bismarck (social insurance) model was current in all other western European countries, e.g. Germany, France and The Netherlands. Finally, the Soviet Semashko model existed in the former socialist countries of central and eastern Europe (Vienonen and Wlodarczyk, 1993; Saltman and Figueras, 1997; Marrée and Groenewegen, 1997). In this paper we will focus on the countries in which until the end of the 1980s - the Semashko system prevailed.

The Semashko health care system was developed in the former Soviet Union and subsequently spread over central and eastern Europe. It is a centralized, tax-based, health care system with physicians as salaried state employees. There is a heavy focus on specialist and hospital care in this system and the western type of general practitioner (GP) who gives comprehensive and continuing care to an individual does not exist (Stephen, 1979; Raffel, 1984; Roemer, 1991; Birt et al., 1996; Davis, 1989; Farmer et al., 1993). Primary care is basically provided in out-patient clinics, known as polyclinics, by three types of doctor: the pediatrician treats children (up to an age of about 15 years), a gynaecologist takes care of women's problems and general adult care is provided by a generalist, called a therapist (Marrée and Groenewegen, 1997; Stephen, 1979; Raffel, 1984; Birt et al., 1996). The generalists, the doctors that most closely resemble the western European GP, do not have a gatekeeping function and their payment and status are relatively low (Marrée and Groenewegen, 1997; Stephen, 1979; Raffel, 1984; Ryan, 1978; Field, 1988; Albrecht and Salmon, 1992). In addition, the range of their medical tasks is limited (Boerma et al., 1997; Boerma and Fleming, 1998).

The countries of central and eastern Europe all had a highly centralized health care system with tight state control and were exposed to the 'equalizing' influence of 50 years of communism. We expected that this would have led to uniformity in health services provision. We investigated this in the task profiles of GPs, which indicate GPs' involvement in various medical tasks and activities. We expected that the professional behaviour of GPs would be more uniform in eastern Europe compared to western Europe in two senses: we anticipated less variation between eastern European countries and less variation among individual GPs within eastern European countries. The first aim of this paper was to determine whether this picture of uniformity in eastern Europe is justified. 
Within this presumed uniformity, we expected differences between the countries in central and eastern Europe as well. Around the Second World War, they all adopted the Semashko model, but modelled it according to their own needs and circumstances. As a result, none of these systems is identical and several national variations of the Semashko system have been created (Roemer, 1991). Two factors could account for these differences. Firstly, their initial situations were not similar: the pre-war health care system was a factor of influence. Secondly, the countries of central and eastern Europe were exposed to varying degrees of influence from the Soviet Union and, as a consequence, the countries differed to the extent to which they adapted their health care system to the Russian system. The geographical and cultural distance from the former Soviet Union may have well played an important role in this (Marrée and Groenewegen, 1997; Stephen, 1979; Roemer, 1991; Deacon, 1987; Parmelee, 1989). These differences between the countries will be reflected in the service profiles of the GPs. We expected to find weaker task profiles for the countries which were more heavily influenced by the former Soviet Union. The second focus of this paper is thus to examine differences between the former communist countries.

In short, the following three hypotheses were formulated.

1 The variation in the task profiles of GPs between eastern European countries is less than the variation between western European countries.

2 The variation in the task profiles of GPs within eastern European countries is less than the variation within western European countries.

3 The stronger the influence of the former Soviet Union, the weaker the task profile of GPs in that country.

\section{Method and analysis}

The data that were used for this study came from the European Survey of the Task Profiles of General Practitioners. This study was designed to describe and explain differences in the position and tasks of GPs and primary care physicians in Europe. The data were collected in 1993 and 1994 by means of a standard questionnaire, translated into national languages. In the countries of central and eastern Europe, where GPs are virtually unknown, generalists were recruited. Most national samples were random and the average response rate was $47 \%$. In total $7,233 \mathrm{GPs}$ participated in the survey.

The concept of a task profile was elaborated in questions on the four key areas of activity of GPs, namely:

- first contact with health problems; 
- performing minor surgery and medical techniques;

- management and follow-up of diseases; and

- preventive medicine.

The role of the GP in first contact with health problems, in the application of medical techniques and in the treatment and follow-up of diseases was examined in a series of questions. Respondents answered on a four-point scale, ranging from (almost) always to seldom/never, indicating the extent to which specific health problems were presented to them and the extent to which specific therapeutic interventions were made by them. The fourth area concerned prevention: involvement in screening for hypertension, blood cholesterol, cervical cancer and breast cancer, as well as in giving health education (regarding diet, tobacco smoking and alcohol consumption) was measured.

In the analysis of the data, a scaling procedure was used to identify skewness and inconsistency and this led to the exclusion of some items. This resulted in a total scale reliability given by Cronbach's $\alpha 0.94$ (Boerma et al., 1997; Boerma and Fleming, 1998). This exercise facilitated the linkage of questions which could be analyzed as a single group. In this way, in the area concerning the role of the GP in first contact, four subscales were identified:

- health problems with children;

- women's health problems;

- psychosocial problems; and

- acute health problems.

No subscales were identified in the other three areas (Boerma et al., 1997; Boerma and Fleming, 1998). For a more detailed description about sampling procedures, response rates, scoring of the questionnaires and about the reliability coefficients of the subscales, we refer to earlier publications (Boerma et al., 1997; Boerma and Fleming, 1998).

The first two hypotheses deal with differences in variation in tasks between eastern and western Europe and within eastern Europe. Variance components were estimated using the multilevel analysis software MLn (Rasbash and Woodhouse, 1995). Multilevel analysis is, in this case, particularly useful in estimating the variation between GPs within countries because of the unequal numbers of GPs per country (unbalanced design) (Bryk and Raudenbush, 1992). Differences have been tested for significance using the $\mathrm{X}^{2}$ significance test for random contrasts (Woodhouse, 1995). For hypothesis 3 on the level of task performance, the countries of central and eastern Europe were divided into four groups and mean scores were compared by performing analysis of variance, in a multilevel model. In group 1 we find the countries that formed an integral part 
of the Soviet Union for more than $\mathbf{5 0}$ years. They are likely to be most strongly influenced by the former Soviet Union. Group 2 are the countries which belonged - before 1918 - to the old Austro-Hungarian empire. These countries have always had close ties - politically and economically as well as culturally with the West and had a Bismarckian social insurance system before 1945, which was considered quite advanced (Marrée and Groenewegen, 1997; Stephen, 1979; Roemer, 1991). Group 3 consists of the countries of the former republic of Yugoslavia, which adopted a totally independent policy towards the former Soviet Union and which is probably the country least influenced by Soviet policies (Stephen, 1979; Roemer, 1991; Deacon, 1987; Parmelee, 1989). Finally, group 4 is a residual group with the countries which - on the basis of the above considerations - could not be placed in the other groups. Hence, no predictions could be made. In short, the groups are as follows:

- group 1. Former Soviet: Ukraine, Estonia, Latvia and Lithuania;

- group 2. Former Bismarck: Czech Republic, Slovakia and Hungary;

- group 3. Former Yugoslavia: Slovenia and Croatia;

- group 4. Other: Poland, Romania and Bulgaria.

\section{Results}

First, we give an overview of the task profiles in eastern and western Europe as well as in the individual countries: the mean scores on the curative and preventive tasks of GPs are presented in table 6.1. A higher score indicates more involvement of GPs. For all activities, the mean scores of western Europe are significantly higher than those of eastern Europe. The largest gap between the mean scores of eastern and western Europe is visible for GPs' role in first contact with health problems (2.24 versus 3.12$)$ and in the application of medical techniques (1.52 versus 2.41). The differences between eastern and western Europe are much smaller for preventive care.

\section{Variation between eastern European countries}

As regards curative services, we only found significantly less variation between eastern European countries in applying medical techniques. This is visible in the lower estimate of 0.07 in table 6.2, compared with 0.31 for western Europe. Variation between eastern European countries is significantly larger than between western European countries for acute health problems. For preventive tasks, significantly less variation between the countries of eastern Europe was only found for assessing blood cholesterol ( 0.00 in eastern Europe versus 0.03 in western Europe). 
Table 6.1 Mean scores of GPs' involvement in curative and preventive services ${ }^{2}$ in the western and eastern part of Europe per country

\begin{tabular}{|c|c|c|c|c|c|c|c|c|c|}
\hline & $\begin{array}{l}\text { A } \\
\text { score }\end{array}$ & $\begin{array}{l}\text { B } \\
\text { score }^{c}\end{array}$ & $\begin{array}{l}\text { C } \\
\text { score }\end{array}$ & $\begin{array}{l}\text { Dcore } \\
\text { d }\end{array}$ & score $^{\mathrm{d}}$ & $\begin{array}{l}\text { F } \\
\text { score }\end{array}$ & score $^{d}$ & $\begin{array}{l}\mathrm{H} \\
\operatorname{scor} \theta\end{array}$ & $\underset{n}{\text { Minimum }}$ \\
\hline \multicolumn{10}{|l|}{ Western Europe } \\
\hline Austria & 2.95 & 2.11 & 2.88 & 1.59 & 1.58 & 1.20 & 1.64 & 0.29 & 282 \\
\hline Belgium & 3.01 & 2.49 & 2.78 & 1.38 & 1.32 & 1.61 & 1.63 & 0.14 & 479 \\
\hline Denmark & 3.49 & 2.82 & 2.88 & 1.31 & 1.26 & 1.77 & 1.45 & 0.14 & 180 \\
\hline Finland & 3.00 & 3.46 & 2.46 & 1.56 & 1.44 & 1.95 & 1.82 & 0.40 & 226 \\
\hline France & 3.08 & 2.01 & 2.99 & 1.22 & 1.16 & 1.44 & 1.48 & 0.23 & 213 \\
\hline Germany & 2.82 & 2.22 & 3.02 & 1.77 & 1.79 & 1.26 & 1.54 & 0.62 & 156 \\
\hline Greece & 2.47 & 1.99 & 2.59 & 1.29 & 1.24 & 1.05 & 1.25 & 0.28 & 106 \\
\hline Iceland & 3.10 & 3.19 & 2.77 & 1.62 & 1.35 & 1.65 & 1.63 & 0.47 & 47 \\
\hline Ireland & 3.48 & 2.49 & 2.96 & 1.58 & 1.40 & 1.74 & 1.70 & 0.12 & 120 \\
\hline Italy & 3.08 & 1.44 & 2.61 & 1.37 & 1.35 & 1.38 & 1.47 & 0.17 & 296 \\
\hline Luxembourg & 2.63 & 2.16 & 2.68 & 1.26 & 1.17 & 1.09 & 1.24 & 0.11 & 48 \\
\hline The Netherlands & 3.67 & 3.10 & 2.44 & 1.35 & 1.15 & 2.19 & 1.31 & 0.05 & 198 \\
\hline Norway & 3.28 & 3.05 & 3.03 & 1.33 & 1.27 & 1.81 & 1.53 & 0.50 & 149 \\
\hline Portugal & 3.22 & 1.74 & 2.71 & 1.74 & 1.37 & 2.05 & 1.94 & 1.09 & 145 \\
\hline Spain & 3.20 & 1.77 & 2.43 & 1.75 & 1.69 & 1.16 & 1.43 & 0.18 & 454 \\
\hline Sweden & 2.83 & 2.83 & 2.75 & 1.39 & 1.31 & 1.41 & 1.33 & 0.27 & 189 \\
\hline Switzerland & 2.88 & 2.93 & 2.94 & 1.58 & 1.46 & 1.62 & 1.79 & 0.21 & 185 \\
\hline UK & 3.51 & 2.83 & 3.06 & 2.17 & 1.62 & 2.37 & 1.94 & 0.66 & 272 \\
\hline Mean score & $3.12^{e}$ & $2.41^{e}$ & $2.75^{\circ}$ & $1.54^{\circ}$ & $1.42^{\mathrm{E}}$ & $1.57^{\mathrm{e}}$ & $1.57^{\mathrm{E}}$ & 0.30 & \\
\hline
\end{tabular}


- table 6.1 continued -

\begin{tabular}{llllllllll}
\hline Eastern Europe & & & & & & & & \\
Bulgaria & 1.74 & 1.12 & 2.20 & 1.64 & 1.25 & 1.12 & 1.35 & 0.53 & 193 \\
Croatia & 3.14 & 1.77 & 2.81 & 1.31 & 1.15 & 0.98 & 1.26 & 0.44 & 160 \\
Czech Republic & 2.28 & 1.66 & 2.39 & 1.45 & 1.27 & 1.00 & 1.24 & 0.07 & 116 \\
Estonia & 2.06 & 1.29 & 2.55 & 1.56 & 1.21 & 1.14 & 1.36 & 0.49 & 136 \\
Hungary & 2.75 & 1.38 & 2.81 & 1.58 & 1.22 & 0.98 & 1.24 & 0.57 & 131 \\
Latvia & 1.96 & 1.58 & 2.57 & 1.58 & 1.19 & 1.56 & 1.67 & 0.11 & 135 \\
Lithuania & 1.71 & 1.10 & 2.40 & 1.37 & 1.26 & $n .2$ & 1.50 & 0.21 & 196 \\
Poland & 2.27 & 1.34 & 2.56 & 1.76 & 1.28 & 1.10 & 1.40 & 0.33 & 216 \\
Rumania & 2.36 & 1.80 & 2.34 & 1.45 & 1.16 & 1.24 & 1.27 & 0.99 & 178 \\
Slovakia & 2.14 & 1.42 & 2.30 & 1.22 & 1.20 & 0.94 & 1.09 & 0.15 & 119 \\
Slovenia & 2.87 & 1.99 & 2.41 & 1.22 & 1.17 & 1.02 & 1.17 & 0.42 & 1.80 \\
Ukraine & 2.05 & 1.76 & 2.55 & 1.32 & 1.17 & 1.16 & 1.31 & & 294 \\
Mean score & 2.24 & 1.52 & 2.49 & 1.45 & 1.21 & 0.99 & 1.34 & 0.63 & \\
\hline
\end{tabular}

3 A, first contact with health problems: B, involvement in the application of medical techniques: C. disease management; D. routinely measusing blood pressure; E, routinely assessing blood cholesterol levels; F, routinely taking cervical smears: $G$. routinely examining for breast cancer; $H$. involvement in health education.

In the survey, data were also collected from Turkey and Isreel, because these countries also form part of the European Region of WHO. In our analyses. Israel was left out of the western European group because it is not situated in Europe and, consequently, has had different influences in (the development of) its health care system. Turkey was dropped from the eastern European group because it has never been under the communist sphere of influence.

c Possible scores ranging from 1 (=low involvement) - 4 (=high involvenent).

d Possible scores ranging from 0 (=low involvement) - 3 (=high involvement).

c Significant differences with mean score of eastern Europe 


\section{Variation within eastern European countries}

For curative care, significantly less variation between GPs within eastern European countries than within western European countries was again only found in the use of medical technical procedures. For GPs' role as doctors of first contact and for disease management, significantly more variation was found within eastern European countries. Within the area of first contact, significantly more variation within eastern European countries was found for acute, women's and children's health problems, ranging from 0.44 to 0.83 for eastern Europe and from 0.30 to 0.43 for western Europe (table 6.2).

For the preventive activities, variation within eastern European countries was significantly smaller than within western European countries for assessing blood cholesterol ( 0.23 for eastern Europe and 0.30 for western Europe) and taking a cervical smear ( 0.30 and 0.43 respectively). For measuring blood pressure and giving health education, the variation within eastern European countries was significantly larger.

Table 6.2 Variation between and within the countries of eastern and western Europe for the curative and preventive services of GPs

\begin{tabular}{|c|c|c|c|c|}
\hline & \multicolumn{2}{|c|}{$\begin{array}{l}\text { Variation between } \\
\text { countries }\end{array}$} & \multicolumn{2}{|c|}{$\begin{array}{l}\text { Variation within } \\
\text { countries }\end{array}$} \\
\hline & $\begin{array}{l}\text { East } \\
(n=12)\end{array}$ & $\begin{array}{l}\text { West } \\
(n=18)\end{array}$ & $\begin{array}{l}\text { East } \\
(n=12)\end{array}$ & $\begin{array}{l}\text { West } \\
(n=18)\end{array}$ \\
\hline \multicolumn{5}{|l|}{ Curative tasks } \\
\hline First contact & 0.18 & 0.09 & $0.27^{\mathrm{a}}$ & 0.24 \\
\hline - Psychosocial problems & 0.26 & 0.11 & 0.48 & 0.47 \\
\hline - Acute problems & $0.30^{\mathrm{a}}$ & 0.05 & $0.51^{\mathrm{a}}$ & 0.38 \\
\hline - Women's problems & 0.16 & 0.28 & $0.44^{\mathrm{a}}$ & 0.30 \\
\hline - Children's problems & 0.17 & 0.13 & $0.83^{\mathrm{a}}$ & 0.43 \\
\hline Medical techniques & $0.07^{\mathrm{a}}$ & 0.31 & $0.29^{\mathrm{a}}$ & 0.34 \\
\hline Disease management & 0.03 & 0.04 & $0.34^{a}$ & 0.32 \\
\hline \multicolumn{5}{|l|}{ Preventive tasks } \\
\hline Blood pressure & 0.02 & 0.05 & $0.49^{\mathrm{a}}$ & 0.42 \\
\hline Blood cholesterol & $0.00^{\mathrm{a}}$ & 0.03 & $0.23^{\mathrm{a}}$ & 0.30 \\
\hline Cervical smear & 0.12 & 0.14 & $0.30^{\mathrm{a}}$ & 0.43 \\
\hline Breast cancer & 0.02 & 0.04 & 0.45 & 0.46 \\
\hline Health education & 0.21 & 0.06 & $1.00^{\mathrm{a}}$ & 0.60 \\
\hline Respondents (minimum $n$ ) & 3806 & 2046 & 3806 & 2046 \\
\hline
\end{tabular}

$\mathrm{X}^{2}$ test; significant difference at $\mathrm{p} \leq 0.05$ 
Table 6.3 Mean scores of GPs' involvement in curative and preventive services in four groups of eastern European countries

\begin{tabular}{lllll}
\hline & $\begin{array}{l}\text { Former } \\
\text { Soviet } \\
(n=4)\end{array}$ & $\begin{array}{l}\text { Former } \\
\text { Bismarck } \\
(n=3)\end{array}$ & $\begin{array}{l}\text { Former } \\
\text { Yugoslavian } \\
(n=2)\end{array}$ & $\begin{array}{l}\text { Other } \\
(n=3)\end{array}$ \\
\hline Curative tasks & $1.95^{\mathrm{a}, \mathrm{b}}$ & $2.39^{\mathrm{c}}$ & 3.01 & 2.12 \\
First contact & $1.80^{\mathrm{a}, \mathrm{b}}$ & $2.59^{\mathrm{c}}$ & 3.10 & 2.00 \\
- Psychosocial problems & $2.44^{\mathrm{a}, \mathrm{b}}$ & 3.28 & 3.70 & 2.60 \\
- Acute problems & $1.87^{\mathrm{b}}$ & $2.03^{\mathrm{c}}$ & 2.79 & 1.98 \\
- Women's problems & $1.75^{\mathrm{b}}$ & $1.95^{\mathrm{c}}$ & 2.61 & 2.14 \\
- Children's problems & $1.43^{\mathrm{b}}$ & 1.49 & 1.88 & 1.42 \\
Medical techniques & 2.52 & 2.50 & 2.61 & 2.37 \\
Disease management & & & & \\
& & & & \\
Preventive tasks & 1.45 & 1.42 & 1.27 & 1.62 \\
Blood pressure & 1.20 & 1.23 & 1.16 & 1.23 \\
Blood cholesterol & 0.95 & 0.98 & 1.00 & 1.16 \\
Cervical smear & $1.45^{\mathrm{a}, \mathrm{b}}$ & 1.19 & 1.22 & 1.34 \\
Breast cancer & 0.65 & 0.27 & 0.43 & 0.62 \\
Health education & & & & \\
& 778 & 366 & 294 & 594 \\
Respondents (minimum $n$ ) & & & &
\end{tabular}

significant differences at $\mathrm{p} \leq 0.05$

Forner Soviet-Former Bismarck

b Former Soviet-Former Yugoslavian

c Former Bismarck-Former Yugoslavian

\section{Differences in task profiles in eastern Europe}

For all aspects of curative tasks, GPs in the countries of former Yugoslavia were most involved (table 6.3). For example, for medical techniques, the differences ranged from 1.43 for GPs in the countries of the former Soviet Union to 1.87 for doctors in the countries of former Yugoslavia. Except for disease management, all differences between GPs in former Yugoslavia and the other three groups were significant. GPs in the Bismarck countries were significantly more involved than GPs in the former Soviet Union in the area of first contact with health problems. Within this area, significant differences were found for GPs' involvement with psychosocial and children's problems. For all curative task aspects (disease management excepted) the following pattern was observed: GPs in former Yugoslavia had the most comprehensive service profile, the lowest scores were found among doctors in the former Soviet Union and the Bismarck countries were situated in between. The position of group 4 varies: for example, 
for the GP as doctor of first contact, it ranks above the countries of the former Soviet Union and below the Bismarck countries, with a score of 2.12. For disease management, it has the lowest score of all groups (2.37).

For preventive care, the pattern is different. GPs in the countries of former Yugoslavia were not most involved; in fact, in two of the five prevention tasks, they had the lowest involvement, e.g. for measuring blood pressure. GPs in the former Soviet Union, who were relatively little involved in some curative services, did well in preventive activities: they had highest scores for preventive tasks, e.g. providing health education (0.65) and screening for breast cancer (1.45). The differences between the groups, however, were only significant for screening for breast cancer.

\section{Discussion}

Our main finding was that there is no consistent pattern of more uniformity between and within eastern European countries than between and within western European countries. Thus, in our study the presumed strict state control in eastern European countries did not result in more homogeneity of profiles. This is an interesting point of departure for further investigation of the differences in central and eastern Europe.

The strong service profile of Yugoslav doctors is a remarkable finding. Yugoslavia initially started to develop a Semashko health system, but by the beginning of the $1950 \mathrm{~s}$ had abandoned this policy. Asserting his independence from Soviet dominance, the Yugoslav leader Tito went his own way. The unique feature of the health care system in Yugoslavia was the high degree of decentralized responsibility to the communities, which also played an important role in the operation of the system (Stephen, 1979; Roemer, 1991; Deacon, 1987; Parmelee, 1989). This seems to have had a beneficial influence on the range of tasks of primary care doctors.

As we expected, the weakest task profile was found among doctors in the former Soviet Union. Compared to this group, the scores of GPs in the Bismarck countries are quite good. This could be a relic of the large influence of western medicine and the presence of a Bismarckian social insurance system before the Second World War (Marrée and Groenewegen, 1997; Stephen, 1979). The high scores of Hungary could be the result of one distinctive feature of the Hungarian system, namely the relatively strong position of the district doctor, a sort of Hungarian GP (Szatmári, 1984; Visser, 1995).

Considerable differences are visible in group 4: the relatively high scores of Romania might be related to the fact that it has departed from Soviet policies by 
deliberately minimizing trends towards specialisation, among others by reducing the number of specialties enormously. Moreover, much stress has been put on broad medical knowledge and its use in general practice. Around 1980, some $60 \%$ of all Romanian doctors were GPs, which contrasts sharply with other countries in eastern Europe (Roemer, 1991). The scores of the Bulgarian doctors on the other hand were lowest and closely resembled the Soviet scores, although Bulgaria has never been part of the Soviet Union. Of all countries in eastern Europe, Bulgaria has been most heavily influenced by the Soviets. For both economical and cultural-historical reasons, it has always been the most orthodox in its association with the former Soviet Union and this applies to its health services as well (Stephen, 1979; Deacon, 1987). A distinctive pattern is visible for preventive activities: GPs in the countries of the former Soviet Union and Bulgaria were doing relatively well in preventive services. This could result from the old relatively strong orientation on prevention in the Soviet health care system (Stephen, 1979; Raffel, 1984; Roemer, 1991; Birt et al., 1996; Davis, 1989).

In conclusion, we will also consider the validity of the data. In most of these countries health care reforms have been implemented since the beginning of the 1990s. The major changes have been the shift from a tax-based state monopoly to a decentralized social insurance system with privatisations in primary care. A common aim in the reforms is strengthening primary care and (re)introducing the GP (Saltman and Figueras, 1997; Marrée and Groenewegen, 1997; Zarkovic and Satzinger, 1997; Háva, 1996; Orosz, 1996; Mastilica, 1996; Jack et al., 1997). The data for this study were collected in 1993-1994 and this raises the question whether the data are still valid as a reflection of the situation as it existed under communism. We believe that, to a large extent, it will be for two reasons. Firstly, in the first years after 1990, the reforms concerned the financing and organisation of health care; the development of general practice started later (Saltman and Figueras, 1997; Marrée and Groenewegen, 1997; Zarkovic and Satzinger, 1997; Háva, 1996; Orosz, 1996; Mastilica, 1996; Jack et al., 1997). Moreover, professional behaviour does not change overnight. Changing attitudes and broadening the knowledge base and skills of health professionals is a time-consuming process, which takes many years. Therefore, the 'socialist legacy' will still be visible in the task profiles of primary care doctors and in our data this was visible in the fact that the vast majority of GPs were still salaried state employees, as in the old days.

This paper has outlined national differences between GPs in the countries of central and eastern Europe. The results reveal the strengths and weaknesses in 
the task profiles and can provide guidance for the development of training programmes for GPs, tailored to the needs of each of these countries: they show in which area the role of the GP is relatively weak and on which skills the emphasis needs to be placed. It can be concluded that, in general, developing skills for handling women's and children's problems as well as performing the necessary medical-technical procedures is an area of attention. Naturally, the achievement of this goal does not only depend on the skills of the physicians, but also on the availability of resources and legislative changes. Finally, repetition of this study would be useful, because it could throw light on the pace of the reforms and differences between eastern European countries in developing primary care. 


\title{
GP home visiting in 18 European countries
}

\author{
Adding the role of health system features
}

This chapter was published as:

Boerma WGW, Groenewegen PP. GP home visiting in 18 European countries. Adding the role of health system features. European Journal of General Practice, 2001; 7: p.132-137.

Reproduced with permission of Mediselect. 


\section{Introduction and aim}

To put it briefly, patients seem to like home visits more than GPs do. Indeed, there is little debate about the GP's role in providing care at home with patients who are restricted in their mobility. But there are impediments. Home visits are time consuming, less efficient and not always safe to realise, specially in the evening and night (Hallam, 1994; Hobbs, 1994; Boerma and Fleming, 1998; Jones et al., 1998; Lattimer et al., 1998; De Bakker et al., 1999; Salisbury et al., 1999). Most patients, however, do expect from a GP that he or she is willing to make home visits (Havel and Neumann-Oellerking, 1998; Jung et al., 1997; Grol et al., 1999). During the past decades the involvement of GPs and the frequency of visits have decreased (Havel and Neumann-Oellerking, 1998; Whewell et al., 1983; Bucquet et al., 1985). This decrease, however, has not been equal among all categories of patients. Most home visits are currently made to elderly and chronically ill patients (Whewell et al., 1983; Aylin et al., 1996). Although concern has existed about reducing home visits of GPs, the strong variation between individual GPs as well as between countries in the practice of home visiting suggests a lack of urgency or need for some of the visits (Hallam, 1994; Grol et al., 1999; Whewell et al., 1983; Bucquet et al., 1985; Aylin et al., 1996; Marsh, 1991b; Hannay et al., 1992; Martin and Lehmann, 1986; Sandier, 1996). The aim of this article is to describe the involvement of GPs in home visiting in European countries and explain the differences. Frequencies of home visits will be related, in a comprehensive analysis, with characteristics of the GP and the practice and with features of the health care system in the various countries. A number of hypotheses, resulting from the literature, will be tested.

\section{Backgrounds}

The GP's home visiting practice is largely influenced by aspects of demand, personal preferences and attitudes and organisational conditions. Subsequently, individual GP characteristics, type of practice and composition of the patient population and features of the health care system will be dealt with.

Although a majority of GPs agree that 'a good GP' should make home visits (Jung et al., 1997), in the literature large differences in home visiting practice are reported. In the UK an almost eightfold range in home visiting ratios was found (Bucquet et al., 1985; Aylin et al., 1996; Marsh, 1991b; Hannay et al., 1992; Calnan and Butler, 1988). The GP's decision whether or not to visit a patient may be influenced by personal needs, such as avoiding a confrontation, a complaint or a charge (Hobbs, 1994; Court et al., 1996). There are also more systematic factors. Differences seem to be related to the age of the GP (inde- 
pendent of differences in size and average age of the practice population), with older GPs making more home visits than younger GPs (Martin and Lehmann, 1986; Aguzzoli et al., 1994; Kersnik, 2000). But this age effect could not be assessed in all studies (Thies-Zajonc et al., 1993). The evidence is unequivocal concerning a gender difference: female GPs make fewer home visits than males, even if part-time working is corrected for (Sandier, 1996; Kersnik, 2000; Groenewegen and Hutten, 1995).

Relevant practice characteristics are the size, urban or rural location and affluence of the practice area. Proportionally, GPs in smaller practices make more home visits (Calnan and Butler, 1988). The type of practice also seems to make a difference. GPs working in health centres made fewer home visits than those in solo practices (Groenewegen and Hutten, 1995). There is much evidence that GPs in rural areas make more home visits than urban GPs (Calnan and Butler, 1988; Aguzzoli et al., 1994; Kersnik, 2000; Verheij et al., 1992; Boerma et al., 1998; Nakar et al., 1999). Factors found to be related to home visiting during the night are similar to those in general: size and characteristics of the practice population and the daytime home visiting frequency (Majeed et al., 1995; Whynes and Baines, 1996a).

Seriously ill and mobility impaired patients, especially the very old, are more likely to be visited at home. Since morbidity and medical consumption are age related, the age composition of a practice population is an indicator for home visits (Aylin et al., 1996; Aguzzoli et al., 1994; Kersnik, 2000). This age effect in home visiting has become distinct. A British study found a very strong decrease in visits for patients under 65, while those to over 65 (and those to chronically ill) even showed an increase (Whewell et al., 1983; Aylin et al., 1996). Furthermore, GPs seem to visit elderly men more often than women. Concerning the role of social circumstances, more frequent visits were reported with children growing up in single parent households, affluent people and socially deprived people (Hallam, 1994; Bucquet et al., 1985; Martin and Lehmann, 1986; Salisbury et al., 2000; Fleming and Charlton, 1998). At practice level, indicators of social deprivation and unemployment are associated with the frequency of home visits (Majeed et al., 1995; Whynes and Baines, 1996b).

Although few studies addressed the international comparison explicitly, different national conditions are evident. In health care systems where patients are normally not listed with a GP and where specialists also provide primary care, home visiting seems to be a way to build up and maintain a clientele (Martin and Lehmann, 1986; Aguzzoli et al., 1994). The competition may even be stronger in countries with an oversupply of physicians in ambulatory care (De 
Maeseneer et al., 1994; De Maeseneer et al., 1999, Lambert, 1998). Financial incentives appear to be effective to influence home visiting. For example, in the United Kingdom the involvement of GPs in night-time home visits was assured by the introduction of payment per (night)visit. A study in eastern Germany showed a sharp increase in the rate of home visits after the 'western' system (including a fee for service payment scheme) was introduced (Hallam, 1994; Hannay et al., 1992; Baker et al.,1994; Burkowitz et al., 1995).

\section{Hypotheses}

The question is whether correlates of home visiting, often found in studies with a limited scope and within one country, will hold in the international comparison, when a range of relevant factors is taken into account. Starting from our basic notion that GPs prefer office encounters while patients prefer home visits, a number of hypotheses are formulated. In the potential conflict between GP and patient, factors related to the GP and the organisation of the practice, the practice population and the health care system may tip the balance to one side or another.

H1. GPs who are self-employed practitioners make more home visits than salaried GPs because they have a more entrepreneurial attitude and they more strongly stress 'customer relations'.

H2. In systems with gatekeeping GPs, where patients are usually listed with a GP, less home visits are expected because there is a threshold for dissatisfied patients to change to another practice.

H3. In countries with a general higher GP density more home visits are expected, because competition among GPs and the higher need for keeping good customer relations with the patients.

H4. The inconsistent results concerning an age effect may point to opposing forces. That is why we do not expect older GPS to make more home visits, because a cohort effect (older GPs were educated to be more home visit minded') is neutralised by a 'fatigue' effect (older GPs tend to be less involved in home visiting in the evening and night).

H5. We expect lower involvement of female GPs for two reasons: female GPs are younger (so less 'home visit minded') and the risks of home visiting are estimated higher for female than for male GPs.

H6. We expect more home visits with GPs working in solo practices than those in groups, because peer support helps to resist requests for less necessary visits and provides alternatives (e.g. out of hours clinic).

H7. Over-representation of socially deprived is not expected to be related to 
more home visits. Indeed, literature on social deprivation stresses higher needs for health care, but a greater proportion of these needs are unmet (Carr-Hill and Sheldon, 1991; Talbot, 1991). If an influence were to exist, it would be counterbalanced by higher estimated safety risks for home visits in socially deprived areas.

H8.In practices with larger proportions of elderly people GPs make more home visits because these have a higher demand for care; such an effect is not expected with young children because these can be transported more easily if ill. H9. More home visits are expected in rural practices, because of larger distances to Accident and Emergency departments.

\section{Methods and data}

The empirical part is based on data from the European Study of GP Task Profiles, carried out in 1993/4. The instrument used was a uniform postal questionnaire, in the national languages, covering the practice organisation and the provision of services. In almost all countries individual GPs were recruited by a random procedure. The aim was to receive at least 200 completed questionnaires per country (except the very small ones). The overall response in the 8 countries was $43 \%$; details per country are presented in table 7.1. Comparison with available GP population parameters revealed some under-representation of female GPs and the youngest and oldest age groups in the response (Boerma et al., 1997).

The dependent variable was the number of home visits in an average week as estimated by the GP. The independent variables at GP/practice level were also self-reported: age and gender; involvement in out-of-hours care; degree of urbanisation of the practice location; mode and size of the practice; the estimated over-representation of elderly, young children and socially deprived in the practice population (as compared to the national average). The independent variables at national level resulted from a background study (Boerma et al., 1993). These were: gatekeeping position of GPs (usually with patients listed), predominant employment status (salaried or self-employed) and density of GPs (national population divided by the number of GPs). Possible interaction effects of GP and practice characteristics with the gatekeeping system and the predominant employment status will be explored.

For 12 countries we could compare our average numbers of home visits with those from another study from 1990 (Fleming and Backer, 1992). In four countries the averages differed more than three visits per week: Belgium, France, Ireland and the Netherlands. This may be due to small samples in the other 
study (45, 27 and 20 GPs respectively in the first three countries mentioned). For the Netherlands, we also compared the average (21) with the one from a registration in the Dutch National Survey of General Practice (17) (Groenewegen et al., 1992a). In the analyses we took into account that sources of variation were both at the GP level and at the national level. In this situation it is neither appropriate to distribute information on the health care system to all respondents from that country, nor to aggregate GP-related information to the national level. We used a hierarchical linear model with the MLwiN multilevel software (DiPrete and Forristal, 1994; Rasbash et al., 2000).

\section{Results}

\section{GP home visiting in Europe}

In most countries home visiting was part of the normal work of GPs. In 13 of the 18 countries more than $90 \%$ of GPs made home visits. Home visiting was clearly not part of the normal work of GPs in Greece and Finland. The number of home visits that GPs make in a normal week (calculated for GPs who made home visits), ranged from an average of 44 visits per week in Belgium to two in Portugal. GPs in Germany, Austria and France reported more than 25 home visits per week. Danish GPs made considerably fewer home visits than their British, Irish and Dutch colleagues, who are often considered to hold comparable positions. In general, GPs in Scandinavia as well as in the Mediterranean countries (except Italy) had low frequencies of home visiting. Table 7.1 also shows the GPs' active personal involvement in care outside office hours (either individually or as part of a rotation group). In most countries this involvement is high, except in the Mediterranean countries.

\section{Analyses of differences}

Results of the regression analysis (table 7.2, model 1) show the variables, both at GP level and the health care system level, which were independently related to differences in home visiting practice. More home visits were made by older GPs, male GPs, GPs in rural practices, GPs in solo practices and GPs in practices with (estimated) higher proportions of elderly. In countries with mainly salaried GPs the estimated average number of 2.1 home visits per week was much lower than the average of 19.9 in countries where GPs are usually selfemployed (other variables taken into account). Besides, the variation in home visits was much higher in countries with mainly self-employed GPs. In countries with gatekeeping GPs and usually registered patients, there were also fewer home visits, namely 11.0 on an average, than in the other countries where 
the average was 19.0 (again taking the other variables into account). And in countries with gatekeeping GPs the variation was much smaller than in the other countries. Especially in the non-gatekeeping countries the amount of variance was strongly reduced when the independent variables were taken into the analysis (table 7.3). The analysis showed an intra-class correlation of 0.37 , which means that $37 \%$ of the total variance in the number of home visits was at the country level. So, in general, within countries GPs tend to have comparable patterns of home visiting.

Table 7.1 GP involvement in home visiting and out of hours care in Europe

\begin{tabular}{|c|c|c|c|c|c|}
\hline \multirow[t]{2}{*}{ Country } & \multirow{2}{*}{$\begin{array}{r}\text { Number } \\
\text { of visits } \\
\text { per week }^{\star}\end{array}$} & \multirow[t]{2}{*}{ SD. } & \multirow{2}{*}{$\begin{array}{r}\text { GPs active in } \\
\text { out-of-hours } \\
\text { care }(\%)\end{array}$} & \multicolumn{2}{|c|}{ Response } \\
\hline & & & & $\mathrm{N}$ & $\%$ \\
\hline Austria & 28 & 16 & 85 & 301 & 50 \\
\hline Belgium & 44 & 30 & 91 & 518 & 28 \\
\hline Denmark & 6 & 4 & 68 & 196 & 56 \\
\hline Finland & 3 & 9 & 84 & 239 & 42 \\
\hline France & 27 & 18 & 75 & 235 & * * \\
\hline Germany & 34 & 21 & 65 & 169 & 44 \\
\hline Greece & 8 & 6 & 62 & 179 & 33 \\
\hline Iceland & 4 & 2 & 85 & 52 & 37 \\
\hline Ireland & 14 & 10 & 85 & 130 & 65 \\
\hline Italy & 17 & 13 & 15 & 345 & 51 \\
\hline Luxembourg & 20 & 16 & 83 & 54 & 30 \\
\hline Netherlands & 21 & 12 & 98 & 210 & 53 \\
\hline Norway & 6 & 6 & 79 & 164 & 52 \\
\hline Portugal & 2 & 2 & 39 & 151 & 38 \\
\hline Spain & 9 & 7 & 46 & 574 & 42 \\
\hline Sweden & 2 & 2 & 87 & 209 & 52 \\
\hline Switzerland & 8 & 8 & 81 & 200 & 50 \\
\hline United Kingdom & 19 & 11 & 81 & 301 & 30 \\
\hline Total & 18 & 70 & 42 & 27 & 43 \\
\hline
\end{tabular}

* Mean calculated for the number of GPs who made home visits. Proportions were higher than $90 \%$, except in: Portugal $(89 \%)$, Sweden $(86 \%)$, Norway $(84 \%)$, Greece $(68 \%)$ and Finland $(47 \%)$

** Opportunity sample 
Table 7.2 Regression coefficients (B) and standardised coefficients (Betas) of GP home visiting with personal and practice characteristics and features of the health care system (model 1 = main effects only; model 2 = with interactions $)(\mathrm{n}=3691)$

\begin{tabular}{|c|c|c|c|c|c|}
\hline & \multicolumn{2}{|c|}{ model 1} & \multicolumn{3}{|c|}{ model 2} \\
\hline & $\mathrm{B}$ & SE B & B & SE B & B \\
\hline \multicolumn{6}{|l|}{ GP level } \\
\hline \multicolumn{6}{|l|}{ Personal } \\
\hline - age & $0.21^{\star}$ & $(0.03)$ & $0.21^{\star}$ & $(0.03)$ & $0.087^{\star}$ \\
\hline gender $(1=\operatorname{man})$ & $4.08^{\star}$ & $(0.63)$ & $4.03^{\star}$ & $(0.63)$ & $0.082^{\star}$ \\
\hline - out-of-hours duties (1=involved) & 0.20 & $(0.64)$ & 0.30 & $(0.64)$ & 0.007 \\
\hline \multicolumn{6}{|l|}{ Practice } \\
\hline - rural ( $1=$ rural) & $1.79^{\star}$ & $(0.60)$ & 0.82 & $(0.76)$ & 0.020 \\
\hline - mode of practice $(1=$ solo $)$ & $2.15^{\star}$ & $(0.60)$ & 0.70 & $(0.82)$ & 0.017 \\
\hline - practice size & 1.13 & $(3.11)$ & 0.75 & $(3.14)$ & 0.033 \\
\hline - elderly (1=above nat.average) & $3.56^{\star}$ & $(0.54)$ & $3.64^{\star}$ & $(0.54)$ & $0.086^{\star}$ \\
\hline - children ( $1=$ above nat. average) & -1.11 & $(0.68)$ & -1.22 & $(0.68)$ & -0.023 \\
\hline $\begin{array}{l}\text { socially deprived (1=above } \\
\text { nat.average) }\end{array}$ & 1.18 & $(0.65)$ & 1.24 & $(0.65)$ & 0.024 \\
\hline \multicolumn{6}{|l|}{ National level } \\
\hline $\begin{array}{l}\text { usual employment ( } 1=\text { salaried }) \\
\text { gatekeeping system ( } 1=\text { not }\end{array}$ & $-11.84^{\star}$ & $(3.80)$ & $-12.0^{\star}$ & $(3.84)$ & $-0.290^{*}$ \\
\hline gatekeeping) & $8.21^{\star}$ & $(3.79)$ & 5.57 & $(3.80)$ & 0.143 \\
\hline - GP density & 4.71 & $(5.03)$ & 4.67 & (5.01) & 0.120 \\
\hline
\end{tabular}

\section{Interactions}

- rural practice and non-

gatekeeping system

$2.16^{\star}(0.99) \quad 0.048^{\star}$

- solo practice and non-

gatekeeping system

$3.15^{\star}(1.18) 0.071^{\star}$

* significant ( $\mathrm{p} \leq 05)$

high GP density (<1,300 pop/GP): Belgium, Austria, Italy, France Medium GP density (1,300-1,700): Norway, Portugal, Ireland, Finland, Denmark, Iceland, Luxemburg Low GP density (>1,700): Spain, United Kingdom, Greece, Switzerland, Germany, Netherlands, Sweden

\section{Interactions}

In order to know whether the differences in variance between GP gatekeeping and non-gatekeeping countries were due to differential effects of GP or practice characteristics, we examined the regression coefficients separately for these two 
groups of countries (not in table). The variables with coefficients that differed substantially between the two groups of countries were used to construct the interaction terms entered in model 2 (table 7.2). Age and gender of the GP were still significant, as was the estimated over-representation of elderly in the practice population. The higher home visiting rates in rural practices and in solo practices turned out to be true only in countries where GPs are not in a gatekeeping role. As measured by the difference in deviance (indicating the fit of the regression models), model 2 was a significant improvement as compared to model 1 (table 7.3).

\section{Discussion}

Although home visiting is still part of the normal services of GPs in most countries, there are important differences which are related to the position of GPs in the health care system. Where this position is stronger, as gatekeepers with registered patients, home visiting was a more general task, but the average frequency was lower, suggesting that home visits can be decided more critically by gatekeeping GPs. This conforms to our expectations (H2). The expected larger numbers of home visits in rural practices (H9) and in solo practices were only found in countries where GPs do not hold a gate keeping role (H6). Another confirmation was about the smaller number of home visits in systems with salaried GPs (H1). However, it was in contrast to our expectations that the GP density in a country was not independently related (H3). A possible explanation is that in countries with a high GP density these are usually selfemployed and also not in a gatekeeping role.

At the practice level we found, as expected, that home visiting is more extensive in practices with many elderly people (H8), but not where there is an over-representation of socially deprived people (H7). Furthermore, differences were related to the age and gender of the GP. The gender effect was expected (H5), but the age effect was not (H4). Presumably the 'cohort influence' (educated to be home visit minded) dominates the older GPs' desire to retreat from this task. 
Tabel 7.3 Variance components for two-level models of GP home visiting (in brackets: standard errors of variance estimates)

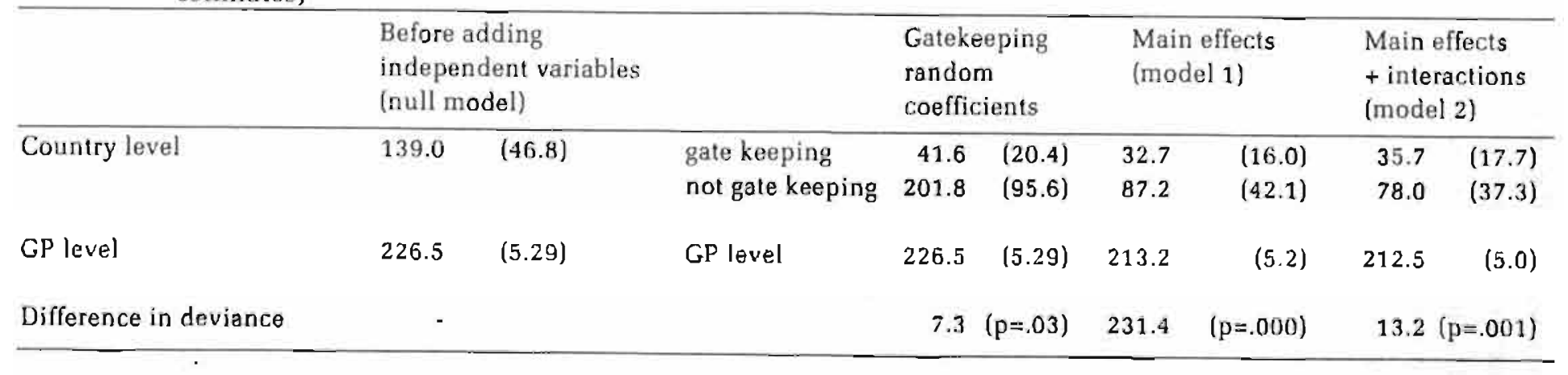


The results of this study give no reason to suppose that general practice is losing the task of home visiting. It is suggested that GPs, if their position is strong enough, are more critical in the decision whether or not to visit patients in their homes. The finding that young children no longer seem to be a category for more home visits seems to point to a more strict application of the 'need criteria'. However, this may not be enough to cope with - opposing - future trends that may foster the potential conflict between GP and patient about home visits. On the one hand, from the ageing populations demand for home visits will grow. GPs, on the other hand, will be less willing to make home visits. The older (home visit minded) generations of GPs will increasingly be replaced by young female colleagues who are less inclined to make home visits. Safeguarding necessary home visits may become a challenge which goes beyond individual creativity of GPs; it will ask for proper structural conditions. More teamwork between GPs in small groups with up-to-date facilities and that are properly staffed may be an answer. With respect to the burdensome home visits outside office hours, the Danish reform, the British GP cooperatives and Dutch experiments show that there are modern, efficient and acceptable ways of providing these services.

Overlooking Europe, however, it should be acknowledged that the situation is quite different in the countries with the highest home visiting rates and many, often competing, physicians working in primary care. In these countries making home visits is much more an economical need for GPs; treating patients in their homes is an advantage for GPs as compared to medical specialists. Cost-effectiveness and rational practice are less prominent in this context.

Finally, this study has limitations. Results are based on self-reports. Preferred methods, such as direct observation or registration, however, would not be feasible in a large scale international study. We could not distinguish between the type of patients visited, urgency and time of the day. Nevertheless, we did find relationships with home visiting at GP and practice level known from other national or local studies. The added value of this study is the international component, while controlling for the relevant local correlates. Another possible bias was in the non-response. Comparison on home visits with other studies did not reveal important deviations. The under-representation of the oldest and youngest GPs and female GPs may have resulted in more positive descriptive outcomes, in terms of frequency and involvement in home visiting. It is unlikely this has essentially influenced the explanatory results. Another point is the age of the data. It must be assumed that since 1993/4 the trend of diminishing home visits has continued and that in many countries rates are 
lower now and the way GPs are involved is changing. In order to manage the GP's burden of home visits, especially outside office hours, new larger-scale structures are being implemented, with telephone triage and advice by trained nurses (Hallam, 1994; De Bakker et al., 1999; Salisbury, 1999). After the Danish reform of out-of-hours care, GPs remained involved but the individual involvement decreased (Hansen and Munck, 1998; Christensen and Olesen, 1998). Since these new arrangements are developing in countries where GPs have a strong position, they may widen the gap that we showed with the other countries. 


\section{General Practitioners' use of time and time management}

This chapter has been accepted for publication as:

Groenewegen PP, Boerma WGW, Sawyer B. General Practitioners' use of time and time management. In: Oxford Textbook of Primary Medical Care (in press). Reproduced with permission of Oxford University Press.

Boxes from the original text, providing practical suggestions for time management and organisation of work, have not been reproduced with this chapter.

This chapter contains two appendices (tables 8.A.1 and 8.A.2) which have not been published with the original text. 


\section{Introduction}

Time is scarce and there are always competing ways of spending it. We all must make choices about the allocation of our time to private, social and professional activities, and this is no less true of general practitioners (GPs). For most of us the proportion of our time reserved for professional activities, and the flexibility to expand this proportion occasionally, is limited, and depends on the constraints of other personal and social obligations. In general practice the process of clarifying our patients problems, making accurate diagnoses and providing effective management, and giving information and reassurance to patients all need time. GPs frequently complain about lack of time and time pressures, recognizing that this may threaten the quality of care that can be provided to patients, and is likely to adversely affect their own health (Morrison and Smith, 2000).

The problem of the use of time in general practice has its roots in both the demand side and the supply side of health care. The problems presented to general practitioners tend to be increasingly complex, and patients' demands and expectations are high. Changes in other parts of health care, such as shorter hospital stays, more community-based care, longer waiting lists and a shift in the focus of care from secondary to primary care, all affect demand and the increasing range of tasks presented to primary physicians (Scott and Vale, 1998). In many countries these developments are taking place against the background of a rapidly growing proportion of female and part-time GPs, with mixed professional portfolios, and in societies with ever shortening working weeks. In seeking solutions to the conflict between workload and available time, we need to recognize that the workload of GPs consists not only of the demands of direct patient care, provided botth in the surgery and in patients' homes and which may be difficult to predict and manage, but also includes essential financial and administrative duties and activities aimed at keeping upto-date, including continuing education and professional development. GPs vary widely in the time they are able to allocate to these various professional activities, and this chapter aims to clarify the sources of this variation, which are rooted both in the characteristics of the individual GP and also in the characteristics and organisation of the practice. In examining international comparisons between GPs, the influences of different health care systems are also important.

In this chapter we present evidence on the ways in which GPs use time in a number of European countries and relate variation in the use of time to these three dimensions: characteristics of the GP, the practice population and the 
health care system. Data were collected in a Europe-wide survey in 1993/4, the European study of task profiles of GPs (Boerma et al., 1997; Boerma and Fleming, 1998). In 32 countries, 8,183 GPs completed and returned uniform questionnaires in their own language, with a response rate of almost $50 \%$.

\section{Sources of variation in use of time}

Higher patient demand requires more time to be spent in clinical care by GPs, but this patient-related workload is not related simply to the number of patients cared for, but also to the type of patients. The old and the very young have more frequent contacts with the GP, and consultations with older patients usually take more time. Less educated patients and those living in disadvantaged areas have higher needs, but the evidence about actual utilisation of services is mixed. The clinical case mix also has an important effect on workload.

GPs differ in their response to a high patient demand. Some are able to avoid being over-stretched by efficiently managing both their time and their work, often by delegating tasks and creating new skill-mixes within the primary care team. This variation is often related to the personal characteristics of the GP. Another source of variation in GPs' use of time is related to the health care system in which they work. In some countries GPs work 55 hours or more, while in others GPs follow the usual working week of 36 hours of public sector employees. These differences are related to the structure of the health care system and probably to more general cultural traits, such as patterns of work and leisure time in society in general. These influences and the groups of activities, that make up the primary care workload are summarized in figure 8.1.

Practice organisation, and to a lesser extent the personal working style of GPs, offer the best opportunities for controlling time and workload, while other factors are more difficult to change. The appropriateness of strategies to cope with pressures of time depends on whether the pressure is temporary or longstanding. One option is simply to expand the total working time, but if this is not possible the GP is likely to compensate for an expansion of time in one task area by reduction of time devoted to other tasks. Clearly this strategy may be harmful to the quality of the services provided by GPs. A third, superior, approach, is to use the available time more efficiently. There are many strategies by which surgery hours, home visiting rates, administrative tasks and other commitments can be better organized, by restructuring roles within the team or by acquiring more time-efficient working habits. 
Figure 8.1 Influences on the GPs' use of time

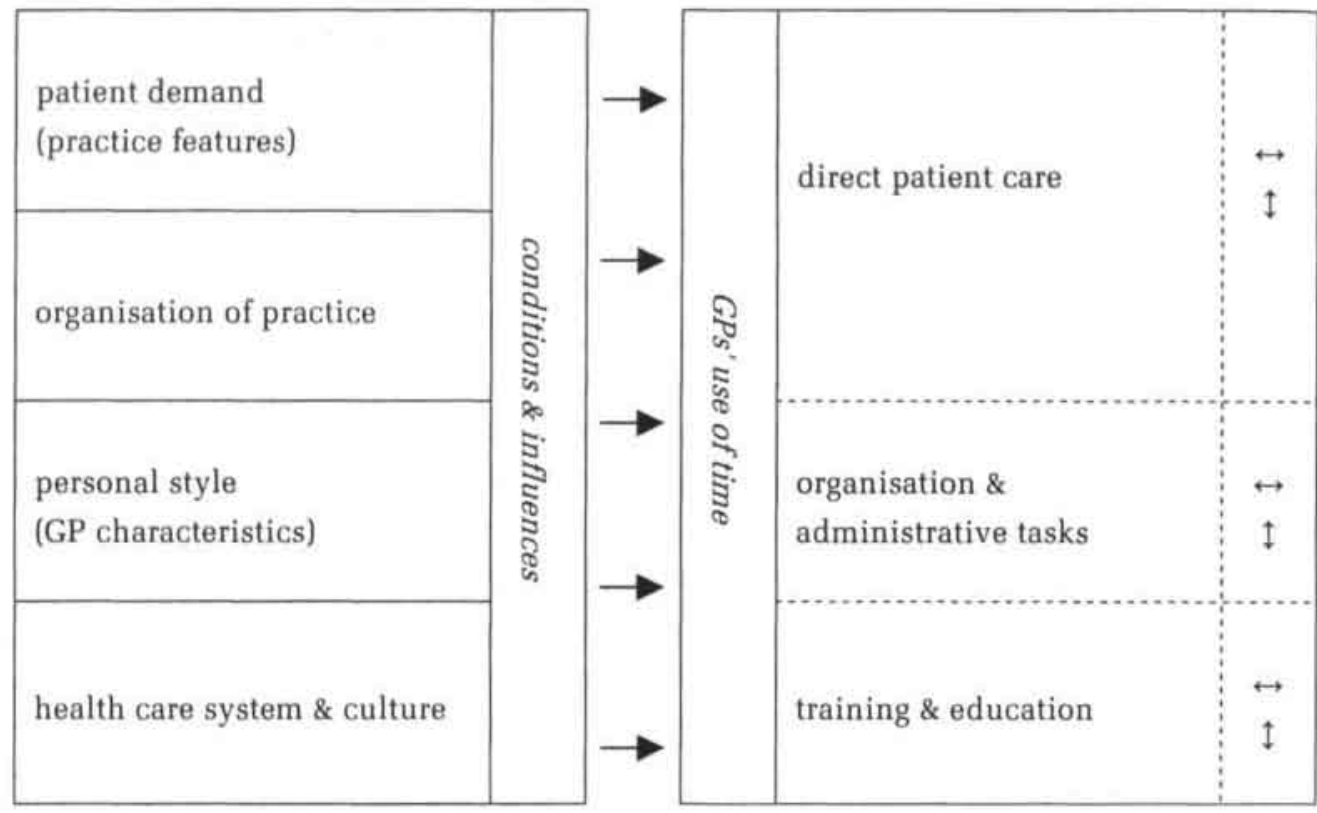

\section{Patient demand: consultations and home visits}

Larger practice sizes generate more patient contacts, and this requires more time from the GP (Calnan and Butler, 1988; Groenewegen et al., 1992b; Hutten, 1998). However, practice size alone is not the only influence on the number of patient contacts, but as described earlier the demographic characteristics of the practice are important. In some health care systems GPs or practices serve a defined, registered practice population (e.g. the list system in the United Kingdom and Norway), whilst in other systems patients are free to consult a physician of their choice. Studies in systems where patients are listed with a GP or a specific practice show that the relationship between list size and the time needed for direct patient care is not linear (Calnan et al., 1992). The average length of consultations is negatively related to list size; in other words GPs caring for larger practice populations spend less time per consultation. Furthermore, if a distinction is made between patient-initiated and doctorinitiated consultations, patient-initiated contact rates tend to be lower in larger practices, suggesting less accessibility or some form of substitution, for instance by practice staff (Groenewegen and Hutten, 1995).

According to the European Study (Boerma et al., 1997) variation in the total working time of GPs appears to be more related to direct patient care than to 
administration and education. Individual GPs and health care systems vary considerably in the number of total working hours of GPs, and the number of hours spent on direct patient care. For not-patient-related activities, however, the variation is much smaller. So it seems, therefore, that not-patient-related activities require a more or less fixed amount of time, irrespective of the size of the practice and the local situation.

Another influence on demand in general practice, and consequently on the time that needs to be spent, are the GPs' contractual obligations concerning availability outside normal office hours. Working hours will be lower if demand outside the normal office hours is diverted to special services. Recent years have seen a move away from a personal commitment of GPs to the provision of out-of-hours care to the use of deputizing services and GPs' co-operatives.

\section{Managing patient demand: practice organisation}

General practice has been described as demand-led (Calnan and Butler, 1988), meaning that aspects of demand are the main determinants of how GPs use their time. This relationship was confirmed in the European Study (Boerma et al., 1997), which showed that only a very small part of the variation in GPs' use of time is related to the organisation of practice, while a much larger part was related to aspects of demand. However, GPs may cope with their workload by adopting various timesaving habits and by organizing their practices efficiently (Marsh, 1991b). Using an appointment system instead of an open surgery system with an unplanned flow of patients is one effective way of managing workload (Gallagher et al., 2001). In appointment systems, GPs have to fix booking intervals. Booking intervals are at the same time a reflection of past experience and a constraint on the actual length of consultations. There is evidence that longer consultations give more room to patients to present their problems, especially if these are of a psycho-social nature (Howie et al., 1991; Campbell et al., 2001).

In some countries appointment systems are predominant, sometimes in combination with a short open surgery early in the morning, while in others this is much less common. Practices offering an open surgery system spend more time in direct patient care and less time in other activities than those with an appointment system (Groenewegen and Hutten, 1995).

More patients visit the practice when no appointment needs to be made. Making an appointment, even for the following day, presumably serves as a modulator of patient demand. The management of telephone calls from patients 
is also important, and Marsh has shown that by allocating a slot of time to reply to not-urgent calls from patients, time lost through interruptions of consultations can be reduced (Marsh, 1991b). The use of intra-practice email as an internal communication system is increasingly popular. Messages displayed on the computer screen give the doctor more control over time and ways of responding to demand. In the future it is possible that telephone consultations will be replaced by e-mail consultations between patients and doctors (Mechanic, 2001).

Table 8.1 Number of working hours per week (total, patient-related and notpatient related) and deviations by the influence of aspects of practice organisation

\begin{tabular}{lccc}
\hline & \multicolumn{3}{c}{ Working hours per week and deviations } \\
\cline { 2 - 4 } & total & $\begin{array}{l}\text { patient- } \\
\text { related }\end{array}$ & $\begin{array}{l}\text { not patient- } \\
\text { related }\end{array}$ \\
\hline Overall average number of hours & 51 & 45 & 6 \\
Having an appointment system & -0.5 & -1.2 & +0.7 \\
Working with other GPs & -2.9 & -2.3 & -0.6 \\
Keeping patient records & +2.7 & +1.6 & +1.1 \\
Using a computer & +0.2 & -0.6 & +0.8 \\
\hline
\end{tabular}

GPs who share accommodation in health centres with other GPs tend to work fewer hours. This may point to different ideas and preferences of those working in certain teams, but it is possible that teams can also provide better opportunities for time management, for example by levelling out peaks in workload. Additionally, the availability of ancillary staff in the practice creates the opportunity to delegate administrative or patient-related tasks, to cope better with a given workload and to keep working hours within limits. The involvement of practice nurses in acute and chronic care can permit economies in GPs' consultations and, in larger teams, the employment of a practice manager has been shown to improve overall efficiency of the use of time and resources (Bolden et al., 1992; Whynes and Baines, 1996b). However the beneficial effects of employing ancillary staff may be neutralized if new services are provided in addition to tasks already delegated from GPs (Richardson et al., 1998). This probably explains why the European study did not find an effect of the numbers of employed ancillary staff on patterns of the use of time.

Medical record keeping is usually seen as an important tool for providing continuity of care. But, in the European Study, comprehensive record keeping 
was found not to be common practice. In southern Europe especially substantial numbers of GPs do not keep comprehensive records. GPs who reported keeping routine records also reported to work more hours.

The use of computers is often seen as an opportunity to rationalize the use of resources and time and the European Study showed that using a computer in the practice had an effect on the use of time. GPs who used a computer spent, in absolute and relative terms, more time in activities unrelated to patient care, perhaps relating an individual choice in which the computer is used for other tasks, such as research and audit, that are also time-consuming. The efficient use of information technology may well prove only to be a timesaving strategy when it is fully integrated into the consulting process, and when applications go beyond administrative and financial issues (Morrison and Smith, 2001). The differences found in the European Study are likely to reflect differences between GPs in their familiarity with the use of this technology. The use of mobile telephones, laptop and hand-held computers may provide further assistance in the efficient use of time in general practice, particularly when GPs are travelling or waiting for appointments.

\section{Individual variation: personal characteristics}

Irrespective of other influences, the age and gender of GPs are related to the variations in the way time is used. Older GPs tend to work less hours, and to be less involved in providing the services from which they can opt out, such as out-of-hours care and preventive surveillance clinics for young children. On the other hand, there is still evidence that older GPs make more home visits, which is likely to be more time consuming. The gender of the GP is also a discriminating factor with respect to working hours; female GPs consistently work fewer hours than male colleagues, approximately 4 hours less each week, taking differences in health system, demand and organisation into account. This smaller number of hours is equally divided between patient-related and other practice activities. Female GPs, who are sometimes more constrained by the traditional division of labour in families, often prefer a part-time work with activities which are easier to plan. They make fewer home visits than their male colleagues, when differences in age and part-time working are controlled. Conversely they tend to be more involved in child surveillance clinics, which can easily be scheduled.

Other personal characteristics may be important. Some people are at their brightest in the morning and others at night. Early risers do best by arranging to undertake complicated tasks in the morning, when their thought processes and 
actions are likely to be quicker and more effective. Conversely, the night owls work better at night. Using quality time for important issues is an essential aspect of time management. Personal characteristics should be taken into account or used efficiently, but efficiency can also be acquired by the GP, for instance when writing a referral letter to a specialist. This can be done efficiently by dictating or typing the letter into the computer at the time of consultation. When appropriate, this may be done in the presence of the patient, thus keeping the patient fully informed. To undertake this task immediately may lengthen the consultation, but is likely to save time over all.

\section{The country dimension: systems and cultures}

Data from the European Study showed marked differences in patient loads between countries. The numbers of contacts that GPs have with patients was high in Germany, Austria, Hungary and the Czech Republic, with around 50 office contacts per day on average. The lowest averages, around 15 per day, were found in the Baltic States, France, Sweden, Iceland and Belgium. In Belgium this low number is partly compensated for by an extremely high number of home visits (averaging 44 per week per GP; this was asked per week because home visits are not always equally distributed over the days). High numbers of home visits were also made in Germany, Austria, France and Hungary, with five or fewer visits weekly in Portugal, Sweden, Finland, Iceland and Israel. Home visits are time consuming, and are not always remunerated, explaining at least in part why this service has been reduced over the last decade by GPs under pressure of time and the need to work more efficiently. In countries with relatively low GP densities and where competition is low, GPs can more easily resist the patients' pressure to make unnecessary home visits (Boerma and Groenewegen, 2001).

Data from a workload diary, kept over one working week, disclosed considerable differences in working hours. On average very long working weeks of 60 hours or more were reported by GPs in Austria, Belgium, France, Germany, Ireland, Luxembourg, Switzerland and the UK, with relatively short working weeks (40 hours or less) in Latvia, Lithuania and Sweden (see figure 8.2).

As mentioned earlier, countries differ in whether or not GPs use an appointment system, but when they do and use fixed booking intervals we are also able to look at the average length of the booking intervals (table 8.2). 
Figure 8.2 Number of working hours (total and patient-related and not-patientrelated) by country

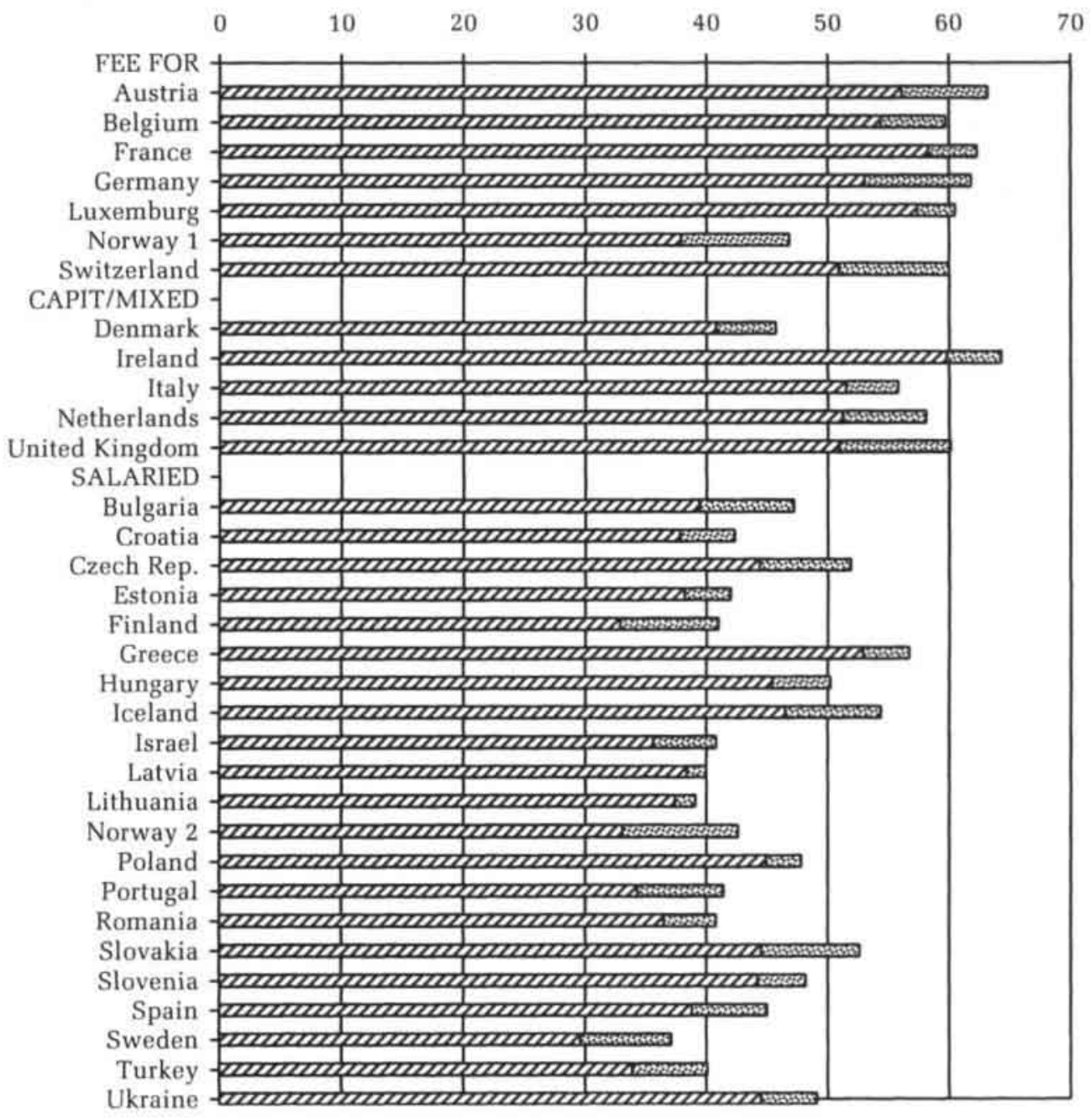

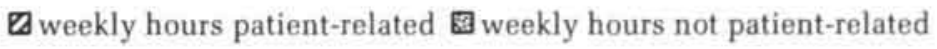


Table 8.2 Percentage of GPs having an appointment system with fixed intervals and average length of booking intervals by country

\begin{tabular}{|c|c|c|}
\hline Country & $\begin{array}{r}\% \text { of GPs using } \\
\text { fixed time intervals }\end{array}$ & $\begin{array}{r}\text { Length } \\
\text { (in minutes) }\end{array}$ \\
\hline Austria & 34 & 15 \\
\hline Belgium & 63 & 19 \\
\hline Bulgaria & 29 & 13 \\
\hline Croatia & 15 & 12 \\
\hline Czech Republic & 19 & 18 \\
\hline Denmark & 92 & 13 \\
\hline Germany & 66 & 13 \\
\hline Estonia & 27 & 16 \\
\hline Finland & 89 & 18 \\
\hline France & 69 & 20 \\
\hline Greece & 15 & 21 \\
\hline Hungary & 9 & 14 \\
\hline Iceland & 90 & 17 \\
\hline Ireland & 50 & 14 \\
\hline Israel & 63 & 11 \\
\hline Italy & 20 & 22 \\
\hline Latvia & 14 & 21 \\
\hline Lithuania & 27 & 17 \\
\hline Luxemburg & 61 & 18 \\
\hline Netherlands & 93 & 10 \\
\hline Norway & 82 & 19 \\
\hline Poland & 22 & 21 \\
\hline Portugal & 58 & 16 \\
\hline Romania & 23 & 19 \\
\hline Slovak Republic & 28 & 7 \\
\hline Slovenia & 21 & 13 \\
\hline Spain & 54 & 10 \\
\hline Sweden & 71 & 24 \\
\hline Switzerland & 78 & 15 \\
\hline Turkey & 4 & 19 \\
\hline Ukraine & 9 & 15 \\
\hline United Kingdom & 85 & 8 \\
\hline
\end{tabular}

Countries with over $80 \%$ of GPs using fixed booking intervals are to be found in the northwest of Europe. The UK and the Netherlands are countries with a high prevalence of fixed booking intervals and a short length of the intervals.

The variation in the number of working hours is not only related to individual and practice characteristics, but also to the health system or culture; more than 
one quarter of the total variation is related to this system level. Here, the influence of the GP's employment status, the position as a gatekeeper and the distinction between eastern and western Europe needs to be considered.

The employment status of GPs in a country has an important relation with time use. In countries where GPs are mainly self-employed, they work more hours in total and in patient-related activities, but not in other professional activities. Gatekeeping GPs, who usually have a defined population to care for, work fewer hours, when demand differences are taken into account. This might partly be related to efficiency; these GPs tend to know their patients better and are likely to have more complete records on them, so that their consultations are likely to be more efficient. It may also be related to more restricted opportunities for patients to switch between GPs if they are not satisfied with service provided to them (Grol et al., 2000).

There appears to be an 'East-West' distinction in the use of time by GPs. In the former Eastern Bloc countries GPs spent less time in activities unrelated to direct patient care but this only holds true when other influences on the use of time, such as practice organisation, are not taken into account. Many GPs in central and eastern Europe still work in large polyclinics, where they are not involved in most administrative duties.

\section{Conclusions}

The relevance of the use of time and time management lies in the way that they are related to professional, patient and personal outcomes (Mechanic, 1970). Time is an important asset in general practice; the length of consultations can be related to whether or not psycho-social aspects of people's health problems are identified and acted on. The use of time is related both to the content and to the quality of care (Hutten, 1998; Howie et al., 1991; Campbell et al., 2001; Howie et al., 1999). However, the relationship is not undebated and the relationship between consultation length and uptake of, for example, psycho-social problems could also be the other way around (Carr-Hill et al., 1998). Time use and time management might also be related to personal consequences, such as burn-out (Appleton et al., 1998).

The evidence in this chapter shows that demand-related variables are important in determining the use of time, and are much more important than variables related to the organisation and type of practice. This provides an important message about the characteristics of general practice. There are large differences between countries in the number of consultations people have and in the opportunities GPs have to manage this demand. In the eastern European health 
care culture doctors generally have a low professional status and are not in a position to say 'no'. They receive little support from health care managers and patients have high demands. In western European countries, patients increasingly adopt a consumerist approach, which may be difficult for some doctors to deal with, particularly in countries with a high density of doctors, were there is competition to provide patient care.

Appointment systems have been shown to be helpful in managing demand and workload. Time management techniques and organisational solutions to cope with patients' demand should, however, not reduce the accessibility of the practice to patients. Delegation of tasks from GPs to nursing and allied health personnel is seen as one solution to dealing with an increased demand for care (Iliffe, 2000). An expansion of nursing roles in general practice is altering the skill mix and distribution of time allocated to patients between team members. Two important developments include nurse triage systems and the development of nurse practitioners. In triage, a nurse makes a needs assessment with patients requesting to see a GP on the same day and, in many cases, patients' fears can readily be allayed. Triage may result in the patient seeing the GP on the same day, but in many cases advice can be given which obviates the need for an immediate consultation.

Nurse practitioners undertake a higher level of decision-making and cover more comprehensive health treatments than practice nurses. In the UK, nurse practitioners spend on average 12 minutes face to face with patients, compared with less than 8 minutes spent by doctors (Venning et al., 2000). These initiatives may save doctors' time and help to cope with increasing patient demand.

Another development affecting the allocation of time in practice is the introduction of GP specialists. Although in its infancy, this development could result in more complex cases being directed to a GP within the team who possesses expertise in a specific field. Indeed, this may save time, but could also lead to de-skilling of GPs.

The survey that produced much of the evidence on which this chapter is based, was undertaken in 1993/4. There is no empirical information available for more recent years on a Europe-wide scale. Since 1994 there have been further significant changes throughout general practice. The countries of central and eastern Europe were then at the beginning of a lengthy process of reform, moving towards independent practice with self-employed GPs. For these GPs the need for practice management and efficient use of time have become more and more important. In other countries new tasks and changing patient demands have induced GPs to pay more attention to the efficient use of time. 
The need for adaptation to these new circumstances has been reflected, during recent years, in growing feelings of frustration and lack of morale among GPs in many countries. Although it has been conjectured that GPs are working less hours and having more time to see patients (Mechanic, 2001), their subjective experience seems to divert from that trend. It is unlikely that some of the relationships discussed in this chapter, such as those between demand and the use of time have changed significantly during the past decade, but changes may have occurred in GPs' expectations and the ways in which they cope with pressure of time and competing obligations. Although subjective factors, such as workload and personal coping mechanisms, play major roles in burn-out, these can be influenced indirectly by controlling the size of the practice and the number of working hours, and the organisation of other duties, such as out-ofhours care (Van Dierendonck et al., 1992). 


\section{Annex}

Table 8.A.1 Multilevel multiple regression analyses of time use of GPs in Europe (b-coefficients)

Independent variables Total time

Patient- Not-patient

Perc. related related patient related

\section{Country characteristics}

Usual employment status ( $1=$ selfemployed)

$\begin{array}{ccrr}6.42^{\star} & 6.40^{\star} & -0.01 & 1.70 \\ -3.45^{\star} & -3.48^{\star} & 0.03 & -0.069 \\ 3.13 & 2.27 & 0.90 & -2.38\end{array}$

Geographical location (1-west)

\section{Demand variables}

Workload

Percentage children ( $1=$ above nat. average)

Percentage elderly ( $1=$ above nat. average)

Perc. socially deprived ( $1=$ above nat. average)

\section{Practice organisation variables}

Shared accommodation ( $1=\mathrm{no}$ )

Appointment system ( $1=$ no)

Routinely keeping medical records $(1=$ no)

Practice secretary (1=no)

Nurses ( $1=$ no)

Laboratory assistants $(1=$ no)

Having a computer $(1=\mathrm{no})$

$\begin{array}{llll}0.05^{*} & 0.05^{*} & -0.003^{*} & 0.02^{\star} \\ 0.25 & -0.25 & 0.50^{\star} & -0.90^{\star} \\ 1.80^{\star} & 1.72^{*} & 0.08 & 0.17 \\ -0.42 & -0.88^{*} & 0.47^{*} & -0.74^{\star}\end{array}$

\section{Age and gender of GP}

\begin{tabular}{lcccr} 
age & $-0.11^{\star}$ & $-0.09^{\star}$ & -0.02 & 0.01 \\
gender $(1=$ male $)$ & $4.13^{\star}$ & 3.58 & $0.55^{\star}$ & -0.15 \\
\hline
\end{tabular}

$\begin{array}{cccc}2.80^{\star} & 2.26^{\star} & 0.55^{\star} & -0.60 \\ 0.55 & 1.17^{\star} & -0.65^{\star} & 1.29^{\star} \\ & & & \\ -2.69^{\star} & -1.64 & -1.09^{\star} & 1.94^{*} \\ 0.02 & 0.10 & -0.07 & 0.14 \\ 0.15 & 0.25 & -0.16 & 0.46 \\ 0.62 & 0.68 & -0.05 & 0.12 \\ -0.18 & 0.64 & -0.83^{\star} & 1.68^{*}\end{array}$

* significant $(\mathrm{p} \leq 0.05)$ 
Table 8.A.2 Variance at country level and GP level; changes in variance after introducing new groups of variables; total change in variance and total fit of model (change in -2 log-likelihood)

\begin{tabular}{llrrr}
\hline Steps in the analysis & Total time & $\begin{array}{r}\text { Patient- } \\
\text { related }\end{array}$ & $\begin{array}{r}\text { Not- } \\
\text { patient } \\
\text { related }\end{array}$ & $\begin{array}{r}\text { Perc. } \\
\text { patient } \\
\text { related }\end{array}$ \\
\hline
\end{tabular}

Step 1: empty model

Country level variance

GP level variance

Intraclass correlation

Step 2: country characteristics

change in country level var

change in GP level var

Step 3: + demand variables

change in country level var change in GP level var

\section{Step 4: + practice organiz.var.}

change in country level var

change in GP level var

Step 5: + age and sex of GP

change in country level var

change in GP level var

\section{Full model}

total var, reduction country level

total var. reduction GP level

-2 log-likelihood change

significance ( $\mathrm{P}$ value)
68.8

177.3

0.28

$-44 \%$

$0 \%$

$-36 \%$

$-14 \%$

$-1 \%$

$-1 \%$

$-8 \%$

$-2 \%$

$-73 \%$

$-33 \%$

1139

.0000

64.7

177.4

0.27

$-51 \%$

$0 \%$

$-18 \%$

$-15 \%$

$-6 \%$

$-1 \%$

$-21 \%$

$-1 \%$

$-20 \%$

$-1 \%$

4.2

17.8

27.9

0.13

$-17 \%$

$0 \%$

$-8 \%$

$0 \%$

05.8

0.14

$\begin{array}{rr}+6 \% & +18 \% \\ -1 \% & -3 \%\end{array}$

$-3 \%$ 


\section{Variation in workload and allocation of time under different payment systems in General Practice}

This chapter has been submitted as an article:

Boerma WGW, Groenewegen PP, Spreeuwenberg P. Variation in workload and allocation of time under different payment systems in General Practice. A European study 


\section{Introduction}

In 1975, David Mechanic published an article on the different ways that paediatricians in capitated primary care settings and in fee-for-service practice react to differences in workload (Mechanic, 1975). The study showed that physicians working under capitated schemes treated more patients in the same time, when confronted with a larger number of patients, while physicians who were paid per item of service tended to increase their number of practice hours in the same situation. To our knowledge, this was the first analysis of the relationships between workload, allocation of time and system of remuneration. Many studies followed in the US, comparing physicians in HMO-settings to those in fee-for-service practice, however, without connecting to workload.

Mechanic's analysis provides an explanation for the finding, in health care systems where general practitioners (GPs; also referred to as family practitioners) are paid capitation fees, that the relationship between list size (i.e. the number of enrollees that a GP receives a capitation payment for) and the number of hours worked is not linear. The shape of the curve is an inverse J, indicating that the number of hours worked does not rise in proportion to increases in list size (Groenewegen \& Hutten, 1991).

The relations between workload, allocation of time and system of remuneration are important for health policy makers, particularly in Europe. Questions concerning the payment of GPs are driven from two points of view, viz. fair payment and effects on the quality of care. The issue of fair pay is especially important in capitation systems, where the amount of GPs' income is related to the number of patients on the GPs' list. In contrast, in fee-for-service schemes, on the other hand, income results from the number of services provided. A crucial factor in capitation systems is whether the amount paid per patient on the list correctly reflects the amount of work generated by patients of that category (Delnoij et al., 1994). In fee-for-service systems, where market forces usually play a stronger role, workload is not regarded as such a major problem as it is in systems with capitation fees or systems where physicians are salaried. The second point of view relates to the mode of remuneration as a general incentive system for the provision of services. Payment systems may directly affect physicians' allocation of time, and thus indirectly influence quality of care to individual patients, practice management and involvement in continuing medical education. Shorter consultations, for instance, may threaten the quality of the communication between GP and patient, leave more of the patient's problems undetected and diagnostic possibilities unused (Calnan \& Butler, 1988; Roland et al., 1986; Ridsdale et al., 1989; Howie et al., 1999; De 
Maeseneer et al., 1999; Morrison and Smith, 2000; Galagher et al., 2001; Gosden et al., 2003). Attention for these issues has been enhanced by changing patient demands and developments on the supply side of health care. Patients are more demanding nowadays and the problems they present in primary care tend to be more complex than they used to be. In addition, changes in other health sectors affect the type and volume of demand; shorter stays in hospitals are linked to a requirement for more and more day care, for example, and the existence of waiting lists for certain procedures as a result of capacity problems (Scott and Vale, 1998). Finally, a reducing effect on availability results from workforce developments, such as generally shortening working weeks and a rapidly growing proportion of female GPs in many countries who wish to work parttime (Boerma, Van den Brink-Muinen, 2000; Schneider et al., 2002; Van der Velden et. al, 2002).

It is useful in dealing with this conflict between workload and available time, to distinguish between different types of GP tasks which present different options for management (Groenewegen and Hutten, 1995). Direct patient-related activities, either in the GP's office or in the patients' homes, can only be controlled to a limited extent, because patients' demand has to be encountered for what it is. Where other activities are concerned, however, there are better options for organizing work more efficiently, by delegation for instance, or by using new information technology. Such activities are financial and administrative duties, continuing education and professional reading and other activities to keep up-to-date.

The question to be answered in this article is whether GPs working under different payment schemes react differently in the way they allocate time when work load vary. This focus on time allocation is only one of the various influences of payment on professional behaviour. Time is an important asset for GPs, however, with direct implications for quality of care. The relation between payment system, workload and management of time has not been investigated frequently, because it is difficult to achieve in national studies (Calnan et al., 1992). Only one dominant payment system for GPs prevails in most countries and comparison is difficult if there are parallel systems in place, because patients and physicians grouped under different schemes usually vary in more respects than simply the way in which GPs are paid. An international comparison is the solution to this problem. Three groups of payment systems are generally distinguished (De Maeseneer et al.,1999; Gosden et al. 2002). In feefor-service schemes, GPs are paid per single patient contact or per item of 
service. Capitation schemes pay GPs a fixed annual amount per patient on the GP's list; this amount is irrespective of the number of services rendered, but may be differentiated according to some indicator of need, such as the patients' age. The third group comprises those GPs who are on the payroll and who receive a fixed salary for an agreed number of hours of work. In this article, data from 32 European countries enable us to study the relationship between GPs' patient loads, how time is spent on different kinds of activities and the prevailing payment systems.

\section{Hypotheses}

Systems of remuneration contain different incentives that influence professional activities of GPs (Glaser, 1970; Chaix-Couturier et al.,2000; Gosden et al. 2002). Some assumptions need to be made, however, before hypotheses are formulated on the effects of mode of payment on the relationship between patient load and allocation of time. In the first place, GPs are assumed to be rational, allocating scarce resources in such a way as to enhance their personal 'utility'. Only two out of an array of utility motives are considered in this article: viz. the GP's income per unit of invested time and the amount of GP's free time, although this certainly does not exclude the existence of more influences on the GPs' use of time (De Maeseneer et al., 1999; Groenewegen et al., 2003). It is further assumed that time is a major resource of GPs; more important than in medical specialties that rely relatively more on expensive equipment. GP's actual allocation of time to work and leisure is restricted by contractual arrangements and by the physicians' anticipation of the reactions of patients. In capitation schemes patients are on the list of a GP, which makes it more difficult for a patient to change GPs than in fee-for- service systems. In systems with salaried GPs, patients may only have the choice to visit another doctor in the same centre or going private and pay for services themselves. Contractual arrangements for the allocation of time are most clear in salaried systems, where working hours are normally fixed. Contracts under capitation schemes sometimes contain separate arrangements for surgery hours and out of hours duties. Given these assumptions the following reactions of GPs to varying workloads are hypothesised:

H1: In capitation systems the number of hours worked by GPs is moderately affected by the size of the practice.

Numbers of patients treated will indeed be higher in larger practices, but this will characteristically be managed by seeing more patients in the same time period, thus by spending less time per patient. GPs are expected to increase the 
number of hours for direct patient care by less than a proportionate amount when list size increases. Time spent on indirect activities will remain constant or decrease somewhat.

H2: Under fee for service schemes GPs in larger practices will have a higher number of hours worked, while the time invested per patient remains constant. The only way for GPs to increase income is to render more services or patient contacts; thus proportionally increasing the number of hours worked. The possible response of increasing time less than proportionally is counteracted by the (expected) reactions of patients, who have encounter few obstacles to change GP. The time devoted to other, non-patient related activities is subject to contrasting influences. Administration (such as billing) will increase, but this can be compensated for by a reduction of time for education. The net result might be that the time for indirect activities is not affected.

H3: In systems with salaried GPs the number of hours worked is fixed (as is income), irrespective of the number of patients served.

A larger population to be served will not greatly affect either the number of hours worked, nor the time spent per patient. In this situation, a higher patient load will result in increasing waiting times for patients before a consultation can take place.

Real responses will deviate from these hypothetical responses for two reasons. In the first place, GPs have more (professional) aims in real life and they are subject to other restrictions (Groenewegen et al., 2003). Secondly, most health care systems do not have pure payment systems like the three described above, but represent mixtures of different kinds of payment systems. For example, in some countries, GPs receive a fee for specific services in addition to capitation payment. (Gress et al., 2003). Nevertheless, our simple model should be enough to clarify the principle and reveal the various influences.

\section{Data and methods}

\section{Sampling and data collection}

Data for this study were collected in the European Study of GP Task Profiles, funded by the BIOMED I programme of the European Commission and supported by the Regional Office of the WHO. The survey was implemented uniformly in 32 countries in the years 1993/1994 (one year later in two countries). Local co-ordinators in the relevant countries assisted in developing and translating the uniform questionnaire and in implementing the survey in their countries. The questionnaire was translated into the national languages by a double-check procedure. The preferred random sampling procedure could not be applied in 
seven countries, mostly due to the lack of sampling frames. The data entry and analyses were carried out centrally at NIVEL in the Netherlands.

The overall response was 7,895 which was approximately $50 \%$, ranging from $87 \%$ to $30 \%$ in th various countries. Possible bias due to the non-response was estimated by comparing the respondents with national population parameters, where available. In general, there was some under-representation of female GPs as well as of younger and older physicians (Boerma et al., 1997, 2000).

\section{Measurements}

The system of payment was measured at the level of individual GPs. There appeared to be one dominant system in each country except Norway, and this system was therefore taken as a feature of the country's health care system. Norway has $58 \%$ self-employed GPs and $42 \%$ salaried GPs and has been taken in the analysis as having two systems. The reason to take payment system as a country level characteristic, is that in countries where a minority of GPs do not work under the dominant payment scheme, these GPs are expected to show a tendency to conform to the usual style of practice in their country (Gosden et al., 2003). Mixed systems of capitation with fee-for-service elements have been classified as one category together with capitation systems.

Workload was measured in terms of reported list size for countries where GPs have a fixed patient list. In the countries where fee-for-service or salaried service were the dominant systems of payment, the answer to a question about the estimated population usually visiting this GP was used and an approximation of workload in terms of the number of patients usually served. Examination of the data led us to believe that some GPs had answered the question about the size of the population they served by filling in the number that applied to the whole practice (including one or more other GPs). We therefore deleted the $5 \%$ of outliers on both ends of the distribution.

The allocation of time was measured by a diary and by the questionnaire. The respondents kept an activity diary during one full week and this was used to measure the total number of hours worked and the number of hours devoted to patient-related activities and the number of hours devoted to other activities, such as practice administration and professional meetings. 'Booking interval' was measured in the questionnaire, i.e. the slot of time usually allocated in the appointments diary for a patient contact. The questionnaire finally asked the usual number of days a patient with a non-acute problem has to wait between making an appointment and the actual consultation. Both booking intervals and waiting times are only available when GPs work according to an appointment 
system. Numbers of patients treated was operationalized as the weighted sum of the reported number of office consultations, home visits and telephone consultations per week. The weights assigned were as follows: 1 for office consultations, 2 for home visits and 0.5 for telephone consultations (compare: Delnoij et al., 1994).

The gender and age of the GPs and the degree of urbanisation of the practice location were used as control variables (Boerma et al., 1998).

\section{Analysis of the data}

Sources of variation in the relationship between patient load and allocation of time are located at two levels, viz. at GP level and health care system level. To avoid the drawbacks of aggregation (loss of information) and disaggregation (over-estimating the effects of higher level variables), the data has been analysed by using multi-level analysis with the MLwiN software (Snijders and Bosker, 1999; Rasbash et al., 2000).

The relationship between list size/patient load and the dependent variables hours worked, booking intervals and numbers of patients treated, was hypothesised to be non-linear over the whole range of values of the independent variable. In order to model this curvilinear relationship and to be able to test the hypotheses, we standardised list size/patient load per country and we divided it into two halves. The slope of the relationship between list size/patient load and the dependent variables was allowed to vary for the smaller and larger half of list size/patient load values separately. We added interaction terms with list size to estimate the differences between the payment systems. In terms of a comparison between feefor-service payment and capitation payment, for example, we would expect the regression co-efficient of practice size to be positive for smaller as well as larger practices in countries with fee-for-service payment. In countries with capitation payment, however, we would expect the co-efficient of practice size to be zero (or at least smaller) for the larger practices.

Standardised values for list size/patient load were used in the analysis. There are considerable differences between countries in the average list size. We assume that the way in which individual GPs respond to smaller or larger practice populations is mainly related to the national distribution of list size. Table 9.1 gives an overview of the hypothesised relationships in terms of the analysis used. 
Table 9.1 Overview of the hypothesised relationships

Relationship between:

Relationship expected Relationship expected

\begin{tabular}{|c|c|c|c|c|c|}
\hline \multicolumn{3}{|c|}{ in smaller practices ${ }^{1}$} & \multicolumn{3}{|c|}{ in larger practices ${ }^{1}$} \\
\hline FS & Cap & Sal & FFS & Cap & Sal \\
\hline
\end{tabular}

Practice size $\leftrightarrow$ Total working time

$++\quad+$

$+0+$

$0 /+\quad 0$

Practice size $\leftrightarrow$ Time for patient care

$++\quad+$

0

$0 /+$

0

Practice size $\leftrightarrow$ Time for indirect

activities

Practice size $\leftrightarrow$ Number of patients

treated

Practice size $\leftrightarrow$ Booking time slots

Practice size $\leftrightarrow$ Delay after

appointment
0

$++\quad+\quad 0$

$0 \quad 0 \quad 0$

0

0

0

$+$

$+$

0

$0 /$ -

FFS: fee-for-service / Cap: capitation / Sal: salary

$++=$ strongly positive $/+=$ positive $/ 0=$ no relationship $/=$ negative $/ \ldots=$ strongly negative

Table 9.2 Aspects of GPs' patient load and allocation of time in European countries

\begin{tabular}{|c|c|c|c|c|c|c|c|}
\hline \multirow[t]{3}{*}{ Country } & \multirow{3}{*}{$\begin{array}{r}\text { Inhab- } \\
\text { itants } \\
\text { per GP }\end{array}$} & \multicolumn{3}{|c|}{ Number of patients treated } & \multirow{2}{*}{\multicolumn{2}{|c|}{$\begin{array}{l}\text { Appointment time } \\
\text { slots }\end{array}$}} & \multirow{3}{*}{$\begin{array}{r}\% \text { GPs } \\
\text { with } \\
\text { waiting } \\
\text { time } \\
\geq 2 \text { days }\end{array}$} \\
\hline & & \multirow{2}{*}{$\begin{array}{l}\text { Office } \\
\text { consul- } \\
\text { tations } \\
\text { (p. day) }\end{array}$} & \multirow{2}{*}{$\begin{array}{r}\text { Tele- } \\
\text { phone } \\
\text { contacts } \\
(\text { p. day) }\end{array}$} & \multirow{2}{*}{$\begin{array}{r}\text { Home } \\
\text { visits } \\
\text { (p.wk) }\end{array}$} & & & \\
\hline & & & & & $\begin{array}{c}\% \text { GP's } \\
\text { using ( } \mathrm{m} \\
\text { fixed time } \\
\text { slots }\end{array}$ & $\begin{array}{r}\text { average } \\
\text { minutes) }\end{array}$ & \\
\hline Fee for service & 1463 & 30 & 10 & 24 & 67 & 17 & \\
\hline Austria & 1532 & 48 & 12 & 28 & 34 & 15 & 15 \\
\hline Belgium & 588 & 17 & 8 & 44 & 63 & 19 & 21 \\
\hline France & 943 & 16 & 7 & 27 & 69 & 20 & 12 \\
\hline Germany (w) & 2110 & 50 & 11 & 34 & 66 & 13 & 25 \\
\hline Luxemburg & 1680 & 25 & 10 & 20 & 61 & 18 & 32 \\
\hline Norway 1 & 1360 & 21 & 12 & 5 & 98 & 18 & 90 \\
\hline Switzerland & 2030 & 31 & 7 & 8 & 78 & 15 & 37 \\
\hline Capit./Mixed & 1660 & 29 & 11 & 15 & 68 & 14 & \\
\hline Denmark & 1609 & 24 & 16 & 6 & 92 & 13 & 45 \\
\hline Ireland & 1559 & 30 & 9 & 14 & 50 & 14 & 7 \\
\hline Italy & 930 & 26 & 10 & 17 & 20 & 23 & 20 \\
\hline Netherlands & 2310 & 32 & 12 & 21 & 93 & 10 & 6 \\
\hline UK & 1892 & 34 & 6 & 19 & 85 & 8 & 31 \\
\hline
\end{tabular}


- table 9.2 continued -

\begin{tabular}{lrrrrrrr} 
Salary & $\mathbf{1 8 1 8}$ & $\mathbf{2 8}$ & $\mathbf{6}$ & $\mathbf{1 1}$ & $\mathbf{3 9}$ & $\mathbf{1 7}$ & \\
Bulgaria & $\mathrm{na}$ & $\mathbf{2 8}$ & 4 & 19 & 29 & 13 & 3 \\
Croatia & 2010 & 44 & 6 & 6 & 15 & 12 & 11 \\
Czech Rep. & $\mathbf{1 5 2 7}$ & 47 & 9 & 13 & 19 & 18 & 12 \\
Estonia & $\mathrm{na}$ & 16 & 4 & 16 & 27 & 16 & 3 \\
Finland & 1582 & 19 & 6 & 3 & 89 & 18 & 80 \\
Greece & na & 21 & 7 & 8 & 15 & 22 & 23 \\
Hungary & 1975 & 48 & 7 & 27 & 9 & 15 & 0 \\
Iceland & 1594 & 17 & 15 & 4 & 90 & 17 & 6 \\
Israel & na & 34 & 9 & 5 & 63 & 11 & 23 \\
Latvia & na & 13 & 4 & 15 & 14 & 21 & 4 \\
Lithuania & na & 17 & 3 & 15 & 27 & 17 & 0 \\
Norway 2 & 1360 & 15 & 9 & 8 & 98 & 21 & 82 \\
Poland & na & 30 & 2 & 10 & 22 & 21 & 15 \\
Portugal & 1476 & 20 & 3 & 2 & 58 & 16 & 64 \\
Romania & na & 19 & 4 & 12 & 23 & 19 & 22 \\
Slovakia & na & 49 & 9 & 8 & 28 & 7 & 16 \\
Slovenia & na & 42 & 8 & 7 & 21 & 13 & 18 \\
Spain & 1970 & 39 & 4 & 9 & 54 & 10 & 23 \\
Sweden & 2870 & 16 & 7 & 2 & 71 & 24 & 91 \\
Turkey & na & 40 & 5 & 9 & 4 & 19 & 0 \\
Ukraine & na & 15 & 5 & 26 & 9 & 15 & 6 \\
\hline
\end{tabular}

1 From: Boerma, de Jong, Mulder, 1993; no distinction made between Norway1 and 2; na $=$ not available

2 GP reported averages in a normal working day/week

3 calculated for GPs involved in home visiting

4 For majority of non-acute patient consultations

5 GP reported days between appointment and consultation (for non-acute problems)

\section{Results}

\section{The GPS' workload and allocation of time}

Direct and indirect measures of GPs' workload and the allocation of time to patient care have been listed in table 9.2.

\section{List size/patient load}

The average population per GP is a general indication of list size/patient load in a country. This average is lowest in countries with GPs working in a fee for service scheme $(1,463$ inhabitants per GP), while the number is relatively high In countries with salaried GPs (1,818 inhabitants per GP) It should be noted, however, that this information was not available for many countries in the latter 
group. The countries with a capitation or a mixed payment system occupy an intermediate position. There is also considerable variation within groups. Belgium, as a fee for service country for example, has the lowest number of inhabitants per GP, while there are substantial differences in the number of inhabitants per GP between Italy and the Netherlands, which are both in the (mixed) capitation payment group.

\section{Numbers of patients treated}

The differences in daily average numbers of office consultations between countries with fee-for-service, capitation or salaried GPs are very small, ranging from 28 to 30 office consultations per day, but the variation between individual countries is considerable. Germany, Slovakia, Austria, Hungary, Czech Republic, Croatia and Slovenia are all countries with a relatively very high number of office consultations a day (more than 40); Latvia, Norway (salaried), Estonia, France, Belgium, Lithuania, Iceland, Finland and Romania are at the other extreme, with less than 20. Countries where GPs are paid a capitation fee or receive a mixed payment are absent in the highest rank as well as in the lowest rank, so that variation in this group is relatively small, with Danish GPs with 24 office consultations a day at one end and British GPs with 34 office consultations a day at the other.

Telephone consultations are given less frequently. Countries with selfemployed GPs (whether paid a fee-for-service or receiving a capitation or mixed payment) generally reported more telephone consultations; 10 and 11 per day respectively. In countries with salaried GPs, this average is much lower, at 6 per day. Iceland, with 15 a day, has almost the highest frequency, making it an exception in this group.

In almost all countries home visiting is a normal task for a large majority of GPs, but the frequency of home visits is extremely variable. The highest averages are in the group of countries with fee-for-service schemes.

\section{Appointment time slots and waiting time}

A large proportion of GPs who work with an appointment system for the majority of consultations, use fixed time slots per patient in the appointments diary as a time management device. In countries with fee-for-service or (mixed) capitation payment schemes, about two thirds of GPs with appointment systems use fixed time slots. The figure is $39 \%$ in countries with salaried GPs. The length of the time slots varies from 7 to 10 minutes in Slovakia, the UK and The Netherlands, to 22-24 minutes in Greece, Italy and Sweden. Countries with (mixed) 
capitation systems have somewhat shorter time slots than the other two groups of countries. Finally, table 9.2 shows the proportion of GPs whose patients normally have to wait two or more days before they can see a GP in connection with a non-acute problem. This is the normal situation in Sweden, Finland and Norway, and Portugal to a lesser extent. Such delays do not occur frequently in most other countries, however. Variation within all three groups is strong.

Figure 9.1 Allocation of time in a normal working week by GPs in European countries

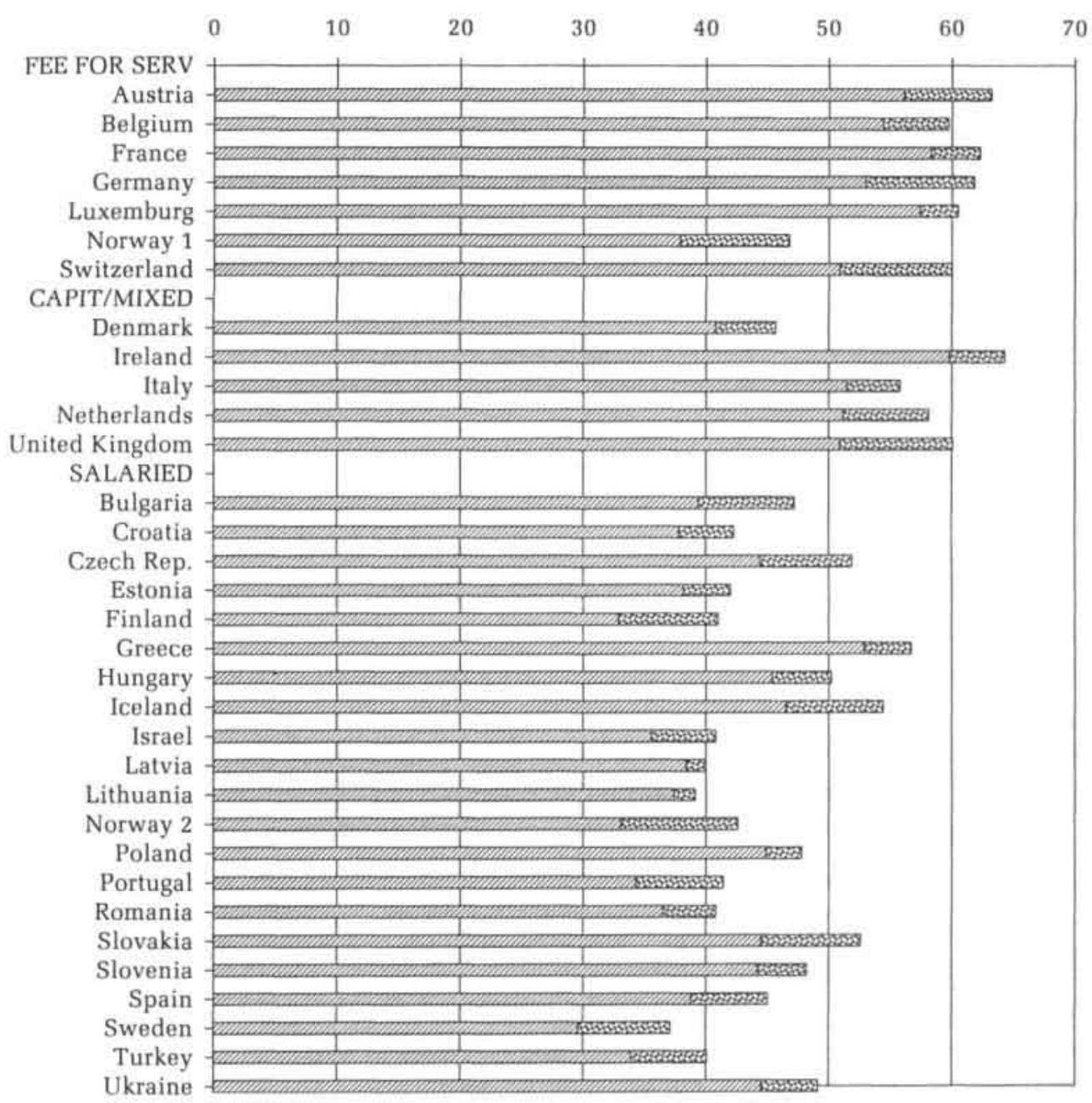

[ hours patient related 圈 hours not pat. related 


\section{GPs' working hours}

Results show great variation between countries in relation to the length of the working week (see figure 9.1). In Austria, France, Germany, Ireland and the United Kingdom, GPs reported working more than 60 hours per week. In the Baltic States, Finland, Sweden, Portugal and Romania, on the other hand, working weeks are about 40 hours.

Grouping of countries according to the dominant payment system shows that average working weeks are much shorter ( 45 hours) in countries with salaried GPs than in countries with self-employed GPs who are either paid by capitation or in a mix scheme ( 57 hours), or by an fee-for-service scheme ( 59 hours). If hours for administration and keeping up-to-date are considered separately, we again find substantial variation. GPs in the UK, Switzerland, Norway, Germany, Finland and Slovakia spend from 8 to well over 9 hours per week on such activities. In the Baltic States, Luxemburg, Greece, Slovenia and France, GPs are much less absorbed by these indirect activities, the time spent varying from less than 2 to 4 hours. Differences between the three groups of countries are small, however: 7 hours a week in fee-for-service systems, 6 hours in (mixed) capitation systems and 5.6 hours in the systems with salaried GPs. So, the differences in working hours that we find are mainly located in direct patient care.

\section{Differences in the allocation of time}

We subsequently analysed the relationship between workload and allocation of time in different payment schemes. Table 9.3 provides the results of the multilevel analysis.

Table 9.3 The relationship between GPs' allocation of time (total; patientrelated and indirect) and the relative size of the practice, controlled for GPs' age and gender and urbanisation of the practice location (unstandardised regression coefficients from a multi level analysis)

\begin{tabular}{|c|c|c|c|c|c|c|}
\hline \multirow[t]{2}{*}{ Mode of payment } & \multicolumn{2}{|c|}{$\begin{array}{c}\text { Total working } \\
\text { time }\end{array}$} & \multicolumn{2}{|c|}{$\begin{array}{l}\text { Time for patient } \\
\text { care }\end{array}$} & \multicolumn{2}{|c|}{$\begin{array}{c}\text { Time for indirect } \\
\text { activities }\end{array}$} \\
\hline & $\begin{array}{r}\text { smaller } \\
\text { practices }\end{array}$ & $\begin{array}{r}\text { larger } \\
\text { practices }\end{array}$ & $\begin{array}{r}\text { smaller } \\
\text { practices }\end{array}$ & $\begin{array}{r}\text { larger } \\
\text { practices }\end{array}$ & $\begin{array}{r}\text { smaller } \\
\text { practices }\end{array}$ & $\begin{array}{r}\text { larger } \\
\text { practices }\end{array}$ \\
\hline Fee for service & $7.84^{b}$ & 0.117 & $7.56^{b}$ & 0.889 & 0.29 & -0.755 \\
\hline Capitation /mixed & $4.10^{b}$ & -0.276 & $4.91^{b}$ & -0.807 & -0.87 & 0.540 \\
\hline Salary & 1.29 & 0.903 & $3.39^{\mathrm{b}}$ & 0.773 & -2.10 & 0.066 \\
\hline Intra-class correlation & $14 \%$ & & $15 \%$ & & $12 \%$ & \\
\hline
\end{tabular}

coefficients differ significantly between payment systems ( $\mathrm{p} \leq 0.05)$

coefficient differs significantly from zero $(\mathrm{p} \leq 0.05)$ 
The intra-class correlations of between $12 \%$ and $15 \%$ (see table 9.3) indicate that there is a reasonable amount of variance at health system level. Where total working time is concerned, regression coefficients show the absence of a relationship with practice size in countries with salaried GPs. The coefficient of practice size in countries with salaried GPs does not deviate from zero in smaller and larger practices alike. A positive relationship does exist in the smaller-practices group in countries with a fee-for-service scheme and in countries with a capitation or mixed payment scheme, but the relationship is much stronger in countries with a fee-for-service system. This means that the number of working hours initially increases with an increase of practice size in those countries where GPs are self-employed, but this increase stops when practices are larger. When time for patient care alone is taken into account, there is a relationship with practice size in all three payment conditions, but again, only for the smaller practices. The relationship is strongest for countries with a fee-for-service payment scheme and weakest in countries with salaried GPs. As was the case with total working time, no relationship was evident between time for patient care and practice size in the group of larger practices. The time for indirect activities is not related to the size of the practice in countries with fee-for-service schemes and (mixed) capitation payment schemes. In countries with salaried GPs, the negative relationship in the smaller than average practices, indicates that GPs in these practices spend more time on indirect activities than in the larger-practices group.

There are high intra-class correlation for the numbers of patients treated, length of time slots used in the appointments diary and the length of appointment delay (see table 9.4), which means that these are strongly clustered at health care system level.

Numbers of patients treated increases quite strongly with practice size in the lower half of the practices. This applied to all three payment schemes, but most strongly to fee-for-service schemes.

The length of the time slots was unrelated to size of the practice in countries with a (mixed) capitation system; which means that time slots are equal irrespective of the size of the practice. In countries with a fee-for-service scheme and in countries with salaried GPs a negative relationship was found in the smallerpractices group. The time slots in the appointment system are shorter In these countries when practices are larger (or less small). No such relationship was found for the practices which are larger than average.

The length of appointment delay is not related to practice size in capitation 
systems and salaried systems. However, in smaller practice in fee-for-services systems, appointment delay increases with practice size.

Table 9.4 The relationship between the numbers of patients treated, length of appointment time slots, and length of appointment delay and relative size of the GP practice, controlled for GPs' age and gender and urbanisation of the practice location (unstandardised regression coefficients from a multi level analysis)

\begin{tabular}{|c|c|c|c|c|c|c|}
\hline \multirow[t]{2}{*}{ Mode of payment } & \multicolumn{2}{|c|}{$\begin{array}{c}\text { Numbers of } \\
\text { patients treated }\end{array}$} & \multicolumn{2}{|c|}{$\begin{array}{l}\text { Length of time } \\
\text { slots }\end{array}$} & \multicolumn{2}{|c|}{$\begin{array}{l}\text { Length appoint- } \\
\text { ment delay }\end{array}$} \\
\hline & $\begin{array}{r}\text { smaller } \\
\text { practices }^{\mathrm{a}}\end{array}$ & $\begin{array}{r}\text { larger } \\
\text { practices }\end{array}$ & $\begin{array}{r}\text { smaller } \\
\text { practices }\end{array}$ & $\begin{array}{r}\text { larger } \\
\text { practices }\end{array}$ & $\begin{array}{r}\text { smaller } \\
\text { practices }\end{array}$ & $\begin{array}{r}\text { larger } \\
\text { practices }\end{array}$ \\
\hline Fee for service & $86.4^{b}$ & 15.01 & $-3.32^{b}$ & -0.761 & $0.256^{b}$ & 0.014 \\
\hline Capitation/mixed & $59.7^{\mathrm{b}}$ & 33.72 & -1.19 & 0.027 & 0.138 & 0.021 \\
\hline Salary & $55.5^{b}$ & 10.80 & $-2.70^{\mathrm{b}}$ & 0.627 & 0.040 & 0.040 \\
\hline Intra-class correlation & $37 \%$ & & $36 \%$ & & $43 \%$ & \\
\hline
\end{tabular}
b coefficients differ significantly between payment systems ( $\mathrm{p} \leq 0.05)$ coefficient differs significantly from zero $(\mathrm{p} \leq 0.05)$

\section{Discussion}

European countries differ strongly in terms of the indicators of GPs' workload and time allocation, such as GP density, numbers of contacts with patients, available time per patient and waiting times between an appointment and the visit. Lowest GP density is found among countries with salaried GPs, while density is highest in countries with fee-for-service systems. There is considerable variation within groups, however. There is a more than threefold differences between high-ranking and low-ranking countries in relation to the number of daily office consultations carried out by GPs. but these differences do not show up in the averages of the payment groups. Telephone consultations take place less frequently in countries with salaried GPs than in countries with GPs working independently. This also applies to home visits, but GPs in a feefor-service scheme are much more active in visiting patients in their homes than those paid a capitation fee. Another difference between countries with independent GPs and those with salaried GPs is in the use of an appointment system with fixed time slots per consultation. In the former group, a majority of two thirds uses such a system; in the latter group appointment systems are used by $39 \%$ of the GPs. Average time slots are shorter in countries where GPs work under a (mixed) capitation scheme than in both other groups. Finally, the time 
that elapses between the appointment and the consultation varies strongly. There are countries where waiting times of two or more days are normal and other countries where patients are normally seen the same day or the next. The results of hypothesis testing have been summarised in table 9.5.

Table 9.5 Results of hypothesis testing

\begin{tabular}{|c|c|c|c|c|c|c|}
\hline \multirow[t]{2}{*}{ Relationship between: } & \multicolumn{3}{|c|}{$\begin{array}{c}\text { Relationship } \\
\text { expected in } \\
\text { smaller practices }\end{array}$} & \multicolumn{3}{|c|}{$\begin{array}{c}\text { Relationship } \\
\text { expected in larger } \\
\text { practices }\end{array}$} \\
\hline & FFS & Cap & Sal & FFS & Cap & Sal \\
\hline Practice size $\leftrightarrow$ Total working time & $\mathrm{Y}$ & Y & $\mathrm{Y}$ & $\mathrm{N}$ & $\mathrm{Y}$ & $\mathrm{Y}$ \\
\hline Practice size $\leftrightarrow$ Time for patient care & $\mathrm{Y}$ & $\mathrm{Y}$ & $\mathrm{N}$ & $\mathrm{N}$ & $\mathrm{Y}$ & $\mathrm{Y}$ \\
\hline Practice size $\leftrightarrow$ Time for indirect activities & Y & Y & $\mathrm{N}$ & $\mathrm{Y}$ & Y & Y \\
\hline Practice size $\leftrightarrow$ Number of patients treated & $\mathrm{Y}$ & $\mathrm{Y}$ & $\mathrm{N}$ & $\mathrm{N}$ & $\mathrm{N}$ & $\mathrm{Y}$ \\
\hline Practice size $\leftrightarrow$ Booking time slots & $\mathrm{N}$ & $\mathrm{Y}$ & $\mathrm{N}$ & $\mathrm{Y}$ & $\mathrm{N}$ & $\mathrm{Y}$ \\
\hline Practice size $\leftrightarrow$ Delay after appointment & $\mathrm{N}$ & $\mathrm{Y}$ & $\mathrm{Y}$ & $\mathrm{Y}$ & $\mathrm{Y}$ & $\mathrm{N}$ \\
\hline
\end{tabular}

$\mathrm{Y}=\mathrm{as}$ hypothesised; $\mathrm{N}=$ not as hypothesised

The hypotheses concern the relationship between practice size and the dependent variables under different payment systems. Because of the expected non-linear shape of the relationships, we examined the relationship for smaller and larger practices separately in the statistical analysis. To evaluate whether or not the results support the hypotheses, the combination of the results for smaller and lower practices have to be taken into account. Both have to be as expected for the hypothesis to be confirmed.

The relationship between total working time and size of the practice is in accordance with expectations for countries with capitation systems and salaried service, but not for countries with fee-for-service payment. In the latter, the expected positive relationship for larger practices is absent.

When time for patient care is examined specifically, only the hypothesis for capitation systems is confirmed. The time for indirect activities shows hardly any relationship with the size of the practice, which is in line with the expectations for fee-for-service and capitation. The only departure is in countries with salaried GPs; these spend less time in indirect activities with increasing practice size.

The hypotheses about the relationship with the number of patients treated are not confirmed for any of the payment systems, as is the case for the hypotheses about the appointments time slots. In connection to delay between appointment and visit, only the hypothesis for capitation systems was confirmed. 
In general, GPs in countries with capitation or mixed systems as their dominant payment system reacted most often as expected on the basis of our hypotheses. GPs in countries with fee-for-service payment did not show the expected relationships in larger practices, while those in countries with salaried services didn't react as expected in the smaller half of practices.

The dominant curve expressing the relationship between practice size and measures of workload and allocation of time characteristically rises when smaller practices are considered and flat when the focus is on the larger practices. This implies that patients in larger practices receive relatively less care than patients in smaller practices. Apparently, the incentives of fee-forservice practice are less potent in preventing this effect than we had expected.

\section{Limitations}

In the analyses the payment system was defined at the country level. In most countries there is one dominant system. It is expected that the dominant system sets the norms, also for those GPs that work under another than the dominant payment system. Our results may have been confounded by other differences between countries. The high intra-class correlations indeed point to a high clustering within countries. This circumstance is different from the study of Mechanic, which was implemented within the USA. There was one country in our study (Norway) with two payment systems (fee-for-service and salary) covering more or less equal numbers of GPs. With Norwegian GPs under the fee-for-service scheme, the size of the practice correlated significantly (varying from 0.20 to 0.22 ) with working hours, time for patient care and time for indirect activities. Such correlations were absent with the salaried GPs in this country. This finding suggests that more support for our hypotheses could be found if confounding factors are better controlled.

A second limitation is the measurement of practice size. This variable has a very concrete meaning in systems with capitation payment. However, in fee-forservice systems patients usually have the freedom to visit the physician they want to. Practice size in this case is a virtual entity: the patients that usually visit a certain practice. It is not clear how well GPs are able to estimate their clientele. The situation of salaried GPs is somewhere in between. They usually work in health centre or clinic with a defined population, but it is not clear whether they know the size of this population. The Spearman correlation between the number of inhabitants per GP and the average reported practice size per country was 0.65 . This suggests that our measurement of practice size was sufficiently valid. 
Summary and conclusions 


\section{Introduction}

The study reported in this book fulfils the need for comparable information about the provision of primary medical care services in Europe. Individual variation in tasks delivered by general practitioners (GPs) is a well-known phenomenon, but little is known about the effect of the characteristics of health care systems on the work of GPs. In this study, the involvement of GPs in a range of curative and preventive tasks has been related to these system characteristics at national level, as well as to the possible effects of the local situation of the practices and the individual GPs. There is increasing international interest in this information, since a strong base of primary care services is considered to be a means of improving coordination and cost control in health care.

This final chapter summarises the previous nine, discusses the results and draws conclusions for the scientific community, general practice and health policy-makers.

\section{Background to the study}

The study attempts to describe and explain the variation in the range of services that GPs deliver to patients. These services may vary within countries, due to differences in GP characteristics or the organisation and circumstances of the practice, such as location in rural areas or cities, teamwork, available supporting staff and medical equipment. When countries are compared, variation is expected to be related to specific differences in the formal position of and payment systems for GPs, the mode of access for patients to health services and whether or not the country's health care system is undergoing profound changes, such as in the post-communist countries.

The design of the study is a cross-sectional survey in 32 European countries, using a multi-level design. Data on the provision of services and the situation of the practice were collected from samples of individual GPs by means of a questionnaire and a 7-day workload diary in the national languages. Information on the health care system resulted from desk research. The study was coordinated by NIVEL and implemented in collaboration with a network of contacts in the countries involved. A total of 7,895 GPs participated in the study, which is a response of $51 \%$. Data entry, data processing and analyses were carried out at NIVEL, using the SPSS and MLwiN software. The involvement of GPs in major task areas was measured by means of questions with answers on a four-point scale. Individual scores on the position of GPs in these areas were calculated using a scale construction procedure and the 
activity scores were examined in relation to characteristics of the health care systems relevant to general practice (whether or not the GPs' had a gatekeeper role, the GPs' employment status and whether or not the country was in postcommunist transition) and with characteristics of the GP and the practice situation.

\section{Summary of results}

Chapters 2 to 9 inclusive of this book comprise published work from the study. In this section, the aims, research questions and results of each chapter will be reported briefly.

\section{Overview of service profiles of GPs in Europe}

Chapter 2 provides a general description of the comprehensiveness of the services that GPs in Europe provide to their patients. It examines differences between groups of countries on the basis of the formal position (gatekeeper or parallel access to medical specialists) and payment (salaried, capitation payment or fee-for-service) of GPs. Countries differed considerably in the range of services that GPs' provide to their patients. Four broad groups of services were considered, viz. first contact with patients' health problems, the application of medico-technical procedures, the treatment of disease, and preventive care. Four sub-groups were identified within first contact care and labelled as follows: acute problems, children's health problems, women's health problems and psychosocial problems. Where the point of first contact was concerned, the GPs reported a major involvement in acute health problems and a relatively limited involvement in the first contact with psychosocial problems (patients may possibly more often contact other care providers in connection with this latter type of problems). First contact with women's health problems and children's health problems was a normal GP task in some countries, but was scarcely provided at all in other countries, where these problems are more frequently presented directly to gynaecologists and paediatricians respectively. Concerning the medico-technical procedures large differences were found, particularly between countries in northern and western Europe and those in southern and eastern Europe.

There was a greater similarity between European GPs with regard to GPs' involvement in the treatment of disease than in the other areas of service. Preventive services consisted of screening, health education and child health surveillance. Most GPs were involved in hypertension screening, while in most countries only minorities systematically screened for blood cholesterol and 
cervical cancer. The sharp contrasts found in the role of GPs in child surveillance and immunisation of children indicated different organisation of these services, in which GPs may or may not be involved. Health education in groups did not appear to be a regular task of GPs.

Groups of countries were compared on the basis of three characteristics, viz. whether or not the GPs' had a gatekeeper role, the GPs' employment status and whether or not the country was in post-communist transition. In countries where GPs were gatekeepers, they had a much more comprehensive role as the doctor of first contact than GPs in other countries. Where GPs were not gatekeepers, the first contact position was apparently shared with ambulatory medical specialists. Countries with gatekeeping GPs did not differ from the other countries in the other areas of service.

The employment status of GPs made a difference in disease management. In countries where GPs were mainly self-employed, they were more involved in the treatment of diseases than in the other countries where GPs were mainly employees. No other differences were found between countries with selfemployed and salaried GPs.

The contrast was greater when the post-communist countries were compared to 'western Europe'. GPs in western countries had a more comprehensive role in most areas of service, i.e. they had a more exclusive role in the first contact with health problems, they applied more medico-technical procedures, they screened more frequently for blood cholesterol and were more often involved in paediatric prevention than GPs in the former communist countries. No differences between east and west were found with regard to the GPs' involvement in the treatment and follow up of (chronic) diseases and the screening for hypertension and cervical cancer.

\section{Urban and rural general practice compared}

The subject of this chapter is the differences in the curative task profiles of GPs working in cities, semi-urbanised areas and the countryside. Three hypotheses were formulated on the basis of previous studies. Firstly, it was expected that GPs in rural areas would have more comprehensive service profiles than GPs in urban practices, particularly those in inner city practices. Secondly, it was hypothesised that GPs working closer to a hospital would have more limited service profiles, irrespective of the degree of urbanisation of the practice location. Thirdly, differences between urban and rural task profiles would be smaller in countries with gatekeeping GPs (where the flow of patients is more controlled). A simple comparison of urban and rural practices showed that they were differ- 
ent, as were the GPs working there. In rural areas for example, practices were more often single-handed and had more medical equipment available. Social deprivation was more common in urban practice populations. More GPs in inner city practices had not completed a postgraduate (vocational) training programme. Rural practices and practices more than 5 kilometres away from a general hospital were found to show consistent differences with other practices. Rural GPs and those working far from hospitals had more comprehensive task profiles in relation to the three task areas considered, although the differences in treatment tasks were smaller than in the other two task areas. GPs in inner city practices appeared to be less involved in technical procedure tasks than suburban and rural GPs.

The urban-rural dimension was not the only source of difference. GPs generally reported delivering a more comprehensive set of services in practices with many elderly people and many socially deprived people. Specifically favourable practice conditions for the provision of medico-technical procedures appeared to be the availability of medical equipment and allied staff, and a GP who had completed postgraduate training. In addition, male GPs provided more of these procedures. The GPs' tasks in the treatment of disease were more related to indicators of demand. There was more involvement in treatment tasks in practice populations with many elderly people (although practice equipment and time spent on keeping up-to-date played a role as well).

The comparison of groups of health care systems confirmed the earlier findings on the first contact role of gatekeeping GPs and GPs in the western countries, the contrast between eastern and western Europe in the use of medical techniques, and the greater involvement of self-employed GPs in the treatment of a range of specific (chronic) diseases. Furthermore, there was evidence of 'erosion' of the gatekeeper role in inner cities in western countries; gatekeeping GPs working in inner cities had a more limited role in the first contact with health problems than other gatekeeping GPs.

It can be concluded that GPs in rural practices and at a longer distance away from hospitals provided more comprehensive services in all health care systems, mostly in the first contact with health problems and medico-technical procedures. This strongly confirmed our first and second hypotheses, stating that rural GPs have a more comprehensive service profile than urban GPs and that GPs working close to a general hospital have a more limited service profile than those at larger distances. The third hypothesis was not confirmed; differences in service profiles between urban and rural practices occurred equally in gatekeeping systems and other systems. 


\section{The first contact with patients' psychosocial problems}

This chapter focuses on GPs as the first contacted health care professional for patients with psychosocial problems. Influences on this role as first aid in mental health care were hypothesised to be located in the health care system, in the practice and in the person of the GP. GPs in health care systems in which patients are registered with a (gatekeeping) GP were expected to be more involved in this kind of care than GPs in other health care systems, where patients have more direct access to medical specialists. The expected influences at practice level were: pressure of work and time available for patients, as well as knowledge of the patient's situation (through a comprehensive record system) and professional skills (acquired through education and from cooperation with social workers).

Large differences in GPs' first contact care with psychosocial problems were found, not only between GPs in the same country, but also between the national averages. Comparison of types of health care systems in this respect showed the effect of GPs as gatekeepers with a list of patients. In countries with a gatekeeping system, GPs' role as the first aid in mental health care is much stronger than in other countries, which was consistent with the hypothesis. Furthermore, pronounced differences were found between the post-communist countries and western Europe. GPs in the western countries were more involved in the first contact with psychosocial problems than those in central and eastern Europe.

A number of features of the organisation of the practice favoured a stronger involvement in first encounters with non-medical problems. GPs were more involved if the daily flow of patients was regulated by an appointments system and if the time allocated for a consultation was not very short when appointments were being planned. GPs with intermediate time slots per patient in the appointments diary were most involved in psychosocial first contacts. Being busy, in terms of a high patient workload, did not seem to be an obstacle however, because GPs with many patient contacts per day were even more involved in first contacts with psychosocial problems than GPs who saw fewer patients. Knowing the patients had an effect, as expected, because GPs who kept comprehensive patient medical records were more involved in this first contact care. The hypothesis on the effect of professional skills was supported by the finding that vocationally trained GPs and those who had regular meetings with social workers fulfilled a more comprehensive role in this type of care than GPs without postgraduate training and no such working relationships with social workers. Additionally, personal characteristics of GPs made a 
difference. Older GPs, in the age group of 40 to 50 years, and male GPs more often reported being the doctor of first contact for patients with psychosocial problems than the other age groups and women. The usual difference appeared when GPs were compared by location of practice, with the lowest involvement in inner city practices and the highest in rural practices.

In general, most assumptions were confirmed by the results. The GPs' position as the first contact with mental problems was more comprehensive in systems with gatekeeping GPs and registered patients than in other systems and also more comprehensive in the western countries than in the post-communist countries. More comprehensive roles in the first contact with mental problems were found among GPs who routinely keep medical records (and thus may be better informed about their patients), who had completed vocational training and who have regular meetings with social workers (which may enhance skills for dealing with mental problems).

\section{Female and male GPs compared}

This chapter described differences between male and female GPs in their personal and work-related characteristics. Their curative and preventive service profiles were related to characteristics of the health care system and the practice. As suggested by many national studies, gender differences were expected in work preferences, the organisation and setting of the practice, and the provision of services. The international comparison was expected to show less gender difference in curative services in countries with a gatekeeping system where patients are normally registered with a GP; there may be less freedom to see a doctor of the same gender in these countries. In countries with self-employed GPs, little or no difference by gender was expected in the provision of preventive medicine and health education. In these countries the overall involvement of GPs in prevention and health education is expected to be low, because such services are rarely eligible for payment in these systems. The gender distribution in general practice differed substantially across Europe. Male GPs outnumbered female GPs in most countries, but the situation was usually the other way around in the post-communist countries. Female GPs were certainly younger than male GPs and more often worked part-time in groups or partnerships, and in cities (but not in deprived areas). Female GPs had different working arrangements; they made fewer home visits and did less work outside office hours. Differences relating to the workload, that female GPs had fewer office contacts a day for example, appeared to result from female GPs' working part-time. 
No overall gender differences were found in the involvement in first contact care, but there did appear to be differences in two subgroups of problems. Female GPs in western Europe were more involved in the first contact with women's health problems. In contrast, they were less involved in the first contact with psychosocial problems (although not in countries with gatekeeping GPs). When other curative services were taken into consideration, all health care systems showed a general trend of lower involvement of female GPs in the application of medico-technical procedures and the treatment and follow up of a range of specific diseases. In most types of health care systems, however, involvement in health education (smoking cessation, alcohol consumption and diet) was higher among female GPs than among male GPs. Few differences were found where the screening of patients at risk was concerned, apart from the fact that female GPs in the former communist countries were more active in screening for serum cholesterol and cervical cancer. Finally, family planning was a service in which female GPs in western countries and in countries with gatekeeping GPs were less involved than male GPs.

As expected, the gender differences in the provision of curative services were smaller among gatekeeping GPs than in other health care systems. The expectation that little or no gender difference would be found in preventive services in countries with self-employed GPs was only confirmed for health education and cervical cancer screening.

\section{Differences within central and eastern Europe}

The health care systems of the former communist countries are often perceived as a homogeneous group. This chapter aimed to find out whether this was true or not. Variation in the task profiles of GPs in these countries were investigated and related to the different - historical - backgrounds of the health care systems. Three hypotheses were formulated, based on information on primary care in the communist era and the recent start of the transformation of health care in these countries. Firstly, that the variation between task profiles of GPs in the postcommunist countries would be less than the variation between the western countries. Secondly, that the variation in GP task profiles within the postcommunist countries would be less than the variation within western countries. Thirdly, that the stronger the influence of the former Soviet Union had been in a country, the more limited the task profile of GPs would be.

Considering all post-communist countries as a whole, there was an evident gap between them and the western countries regarding the role of GPs. Western GPs clearly delivered a much more comprehensive set of services than the GPs in 
the central and eastern countries. The greatest difference was the involvement in the first contact with health problems and the application of medical techniques. The differences were much smaller where preventive services were concerned. The supposed homogeneity among the post-communist countries was found neither in curative care nor in prevention. Despite some exceptions in both directions when specific services were considered, the general variation in GP task profiles between the central and eastern countries was no more limited than the variation between the western countries. Closer examination of the post-communist countries revealed that the variation between GPs within those countries was even greater where most curative services were concerned than it was within the western countries. The results for preventive services were mixed: with some services the variation between GPs was greater than in western countries and with other services it was the other way around.

It was possible to identify three sub-groups within the group of post-communist countries, on the basis of the comprehensiveness of GP curative tasks, viz. the former Yugoslavian countries, the countries which entered the communist sphere of influence after the second World War and the countries that used to be part of the Soviet Union. GPs' involvement in all curative tasks was highest in the former Yugoslavian countries, except in the treatment of a specified diseases. GPs occupied an intermediate position in countries of the second group, which had previously had a social health insurance system before the Soviet 'Semashko system' was introduced. GPs were less involved in curative care than in the former Yugoslavia, but they had a stronger position in first contact care (particularly relating to children's problems and psycho-social problems) than GPs in the third group, viz. countries formerly belonging to the Soviet Union.

The pattern was different for preventive care. GPs were relatively strongly involved in prevention in former Soviet countries, in contrast to the GPs in the countries of the former Yugoslavia, who were less involved in two of the five examined prevention tasks.

\section{Home visits to patients by GPS}

This chapter contains a description and comparison of the home-visiting practice of GPs in a sub-sample of 18 countries. The variation was examined in relation to relevant characteristics of the health care system, the effects of personal characteristics of the GP, and the type and organisation of the practice. The point of departure for the formulation of hypotheses was the general notion that GPs prefer office encounters while patients prefer home visits. The 
comparison of health care systems was expected to find larger numbers of home visits in countries with self-employed GPs and in countries with a relatively high number of GPs (high GP 'density'). Lower numbers of home visits were expected in countries with GPs in a gatekeeping position. Within the individual countries, more home visits were expected in rural practices, in single-handed practices and in practices with larger proportions of elderly people. It was also thought that female GPs would make fewer home visits (because these are younger and are more reluctant to make home visits in less safe situations). Opposing effects were hypothesised for the age of the GP and the presence of many socially deprived people in the practice, so that these were not expected to make a difference overall.

The results showed that, at the time of the data collection, home visits were the normal work of GPs in most countries, but that the number of home visits made varied widely from an average of 2 per week in Portugal to 44 in Belgium. In countries with self-employed GPs, the average number of home visits was much higher than in countries where GPs are usually employees. Fewer home visits were made on average in countries with gatekeeping GPs than in other countries, and the variation between GPs was smaller. These findings were in line with expectations. There was no evidence, however, for the predicted effect of the GP density in a country.

Variation in the frequency of home visiting were greater between countries than within countries. GPs in the same country tended to have comparable levels of home visiting and the differences were generally smaller than expected. The hypothesised larger number of home visits in rural practices and solo practices was only confirmed in countries where GPs were not gatekeepers. Indicators of higher patient demand in the practice population, viz. more elderly people and more socially deprived, were both related to more home visits made by GPs, while this had only been expected for the elderly. Finally, not only the gender but also the age of the GP appeared to be related to home visiting. More home visits were made by male GPs and by older GPs. The age effect had not been expected.

\section{Time use and time management by GPS}

In this chapter, results were presented on how GPs use their time and whether there were differences between countries and types of health care system. Variation in the allocation of time was also related to characteristics of the practice population (indicators of differing patient demand), the organisation of the practice and the personal characteristics of the GP. 
Contrasts were found in the number of working hours of individual GPs as well as between health care systems. When working hours were divided up into hours spent on direct patient care and hours spent on indirect activities (such as administration and education), the variation appeared to be mainly in the hours for patient care. GPs' working hours, patient load and time for patients were country-specific to a large degree. The average working hours of GPs differed between countries from over 60 to around 40 per week. The number of office contacts GPs had with patients ranged from averages of 15 to 50 per day. These large differences could be explained when the formal position of GPs in the health care system were taken into account. GPs had longer working weeks in countries where GPs were self-employed, but the excess working hours in comparison with employee GPs only referred to direct patient care and not to indirect activities. GPs in countries with gatekeeping GPs and patients who are normally registered with a GP worked fewer hours than GPs in countries where patients can visit medical specialists directly.

Differences in the time spent on indirect activities were found between the post-communist countries and the western countries. GPs in the post-communist countries devoted less time to administration and education than western GPs, although this difference may be attributable to different practice conditions. Many GPs in the post-communist countries were still working in polyclinics in the period that the data were being collected and were usually not involved in administration.

Where the effects of practice organisation were concerned, the use of appointment systems - which differed greatly from country to country - was associated with fewer working hours for direct patient care. The time slots reserved in the appointment agenda for a consultation revealed contrasts between GPs in the time available for patients. GPs in partnerships or group practices reported less working hours overall, irrespective of other arrangements. GPs who kept comprehensive medical records of patient encounters worked more hours, both in patient care and on indirect activities. GPs who used a computer, which was not yet common in 1993, spent more time on indirect activities and less time on patient care. Where personal characteristics were concerned, older GPs tended to work fewer hours than younger GPs and female GPs consistently worked fewer hours than male GPs.

\section{Influence of payment systems on GPs' workload and allocation of time}

Chapter 8 deals with the question of whether different payment systems are related to the different ways that GPs allocate their time, if their workload 
conditions (the size of the practice) vary. The hypothesis was that GPs would react as follows. The number of working hours was expected to be equal in health care systems with salaried GPs, irrespective of the number of patients served. GPs working in fee-for-service schemes would work more hours if the size of the practice increased. GPs in countries with a capitation payment system were expected to occupy an intermediate position, viz. they would work more hours, but not proportionally more, if the size of the practice increased.

The indirect measure of workload, i.e. the number of inhabitants per GP, varies by a factor of three between countries with high density and low density of GPs. Similar differences exist in direct measurements, such as the number of consultations per day and the frequency of home visits. The time that GPs reserve in the appointments diary for a consultation ranges from 7 to 24 minutes. In some countries, patients usually need to wait two or more days between making the appointment and going to see the GP. The normal working week for GPs showed national averages of between 40 and 60 hours.

The hypothesis concerning GPs working in capitation schemes was confirmed. For GPs in fee-for-service systems the hypothesis was not supported because the expected rise of working hours, time for patients and the number of patients treated was absent in the larger practices. For the salaried GPs it was not expected to find, in the group of smaller practices, an increase in time for patient care and indirect activities, the number of patients treated and shorter times in the appointments agenda with increasing size of practice. We concluded that patients in larger practices receive relatively less care of their GPs than patients in smaller practices, irrespective of the mode of GP payment. We found no evidence that fee-for service payment includes incentives to counteract this effect.

\section{Discussion}

After the review of the results of the study by the subjects, this section considers the results in a somewhat wider perspective and comments on methodological aspects. The study has succeeded in producing comparable information on services provided by GPs in European countries. The differences in task profiles between the countries were considerable in many respects. By grouping the countries according to common characteristics relating to the position and payment of GPs, we have been able to better understand the multitude of variation. The method of the study also allowed to take into account a range of characteristics of the GPs, the practice organisation and the practice location, which contributed to a better understanding of the distinct service profiles. 
More of the variation could be explained by the characteristics of the health care system than could be explained by effects related to the GPs and the practices. GPs in countries with a gatekeeping system provided more comprehensive range of services, but made fewer home visits and worked fewer hours than GPs in countries with parallel access to medical specialists. GPs in gatekeeping systems provided a more homogenous set of services than GPs in other systems where there was more variation. In countries with self-employed GPs paid per item of service, the GPs were more involved in the treatment and follow-up of disease, made more home visits and spent more working time on direct patient care than GPs in other countries. In countries with salaried GPs, the GPs provided fewer treatment services and made fewer home visits than GPs in countries with self-employed GPs. Although differences were less than expected, GPs' response to varying workloads was related to the prevailing payment system. Working hours and number of patient contacts increased more strongly with practice size in countries with GPs working in a fee-for-service system than in other countries. In general, however, patients in larger practices receive relatively less care than patients in smaller practices.

There was a consistent contrast in GP task profiles between the post-communist countries and the western European countries. In the western countries, GPs had more comprehensive service profiles than in central and eastern Europe, particularly regarding the first contact with health problems and the provision of medico-technical procedures. GPs in western countries spent more time on indirect activities, such as administration and education, than GPs in the postcommunist countries. Although the post-communist countries could be regarded as a group in comparison to the western countries, distinctions were actually found within this group - between the countries of the former Yugoslavia for instance, and the countries that had previously belonged to the Soviet Union.

Differences were found within countries, irrespective of the type of health care system. In all countries, there was a contrast between general practice in rural areas, where the profile of services was more comprehensive, and general practice in more urbanised areas and cities, where GPs were less involved in various services. Furthermore, male GPs in general had a more comprehensive task profile than female GPs. And, as might be expected, GPs in practices with more elderly people and a more socially deprived population are more involved in curative tasks (and home visits) than GPs in practices where these categories are less prominent. Finally, diverging task profiles were associated with the organisation of the practice and how GPs allocate resources, such as time. 
The implications of the study results will be explained in the sections hereafter, but some methodological reflections would be appropriate first.

The validity of the results may have been influenced by selection bias. A random sampling procedure could not be achieved in all countries. Furthermore, although the response rate was not generally low for surveys of this kind, about half of the sampled GPs did not return a completed questionnaire. Response selectivity may have been reduced, however, by the nature of the questionnaire, which covered a wide range of topics and is therefore less likely to have attracted GPs with a specific interest. Some under-representation of female GPs and GPs in the oldest and youngest age groups was established, which may have affected results in which age and gender effects were relevant, but it is unlikely that the main findings of the study, particularly where the role of the health care system is concerned, are substantially biased.

The dependent variables were based on GPs' perceptions of their involvement in services. The question is how reliable these self-reports are. More precisely, it is difficult to estimate to what extent GPs know if patients present certain health problems to other professionals as well, directly to medical specialists for example. We think that GPs are directly or indirectly confronted with patients' visits to other health professionals, enabling GPs to make a fair estimate of their position in the 'market' for a particular health problem or intervention. In fact, the estimates of gatekeeping GPs may actually be more accurate than those of GPs not in that position. This may have influenced the task profile scores to some extent, but we believe in general that the GPs' perceptions are a good indicator of the real situation.

A problem in some countries was to determine the target population of the study. GPs are easy to identify as a professional group in most countries, even if they are not a well-organised one. General practice was unknown or only starting in a number of post-communist countries and samples were drawn from district doctors instead in these countries, supplemented by a number of newly trained GPs, if available.

In the absence of a feasible international reference point, urban and rural practice have been defined subjectively. We used a simple classification into five categories, which doctors could place within the context of their own national situations. The relevance of urbanisation in the context of this study was the experience of space and environment and the availability of services. Where the subjective component was concerned, a particular type of location in one country may not necessarily be matched by that in another, which is why 
we also used the more factual dimension of distance between practice and hospital.

The translation of the questionnaire into the 26 languages was double-checked and so it is not likely that versions were inaccurate. Some connotative loss may have occurred nevertheless, and the interpretation of words may not be identical in all language versions. Our consideration of the results identified only one wrongly translated item in one of the versions of the questionnaire, which was removed from the analyses.

Low rates of GP involvement in services should not be interpreted as a lack of service provision; there will normally be an alternative method of provision when GPs are not involved. Consideration of possible alternatives was not part of this study, nor did the study cover the whole range of possible GP tasks. The focus was not on tasks that were evident GP tasks in all countries, or on very rare tasks. Some areas, such as tasks related to public health and sickness certification, were not investigated.

The associations found in this study suggest causality but do not prove it and it may be difficult to identify cause and effect. The connection between available practice equipment and the provision of services can be interpreted in two ways, and there are also two explanations for the finding that GPs who have regular meetings with social workers are more involved in the first contact with mental problems.

Then, the time that has elapsed since the data were collected should be noted. Changes have occurred in general practice in the past ten years - in the postcommunist countries in particular, but in western Europe as well. Measures have been taken to control the cost and improve the quality of health care services and these may have affected general practice to differing degrees. Although changes in professional behaviour are usually limited in scope and take years to become generally implemented, it is unlikely that today's general practice is similar to general practice a decade ago. Preliminary results from Dutch general practice clearly show that contextual changes since the early 1990s have definitively affected the way GPs' understand their job and their professional activities. Only a replication of the European GP Task Profile Study, for which our results would serve as the indispensable pre-test measurement, could reveal the degree of change in general practice in the countries. Less change is to be expected in the explanatory results of the study, compared to the descriptive results. The associations that we have found with the GPs' provision of services are assumed to be much more stable through time. 
A final limitation is in the approach of the study. By asking GPs and studying health care systems, this study took an exclusively supply-side position, which meant that patients' preferences and decisions in the use of health services (factors which also influence health care in a country) remained outside the scope of the study. This limitation may have been more significant in countries where the role and functions of health care suppliers like GPs were not yet well-defined, which was probably the case in the post-communist countries at the time of data collection.

\section{Implications}

\section{Implications for health services research}

The study has produced comparable information that shows the diversity in the organisation and provision of general practice in Europe and the influence of features of the national health care systems. This base of knowledge is a suitable starting point for elaboration in health services research. Detailed questions about the range of morbidity presented by patients to GPs and the interventions, prescriptions and referrals made by GPs, have to be answered by other methods than a survey. Practice observations or data collected by means of registration are needed to answer such questions. This highlights the importance of a research infrastructure for health services, including a health information system tailored to the needs of GPs and to the requirements of researchers, as these exist in the United Kingdom and the Netherlands, for example. In addition, capacity and resources are needed to make information out of practice data.

Further activity could also concentrate on regional, instead of national differences. Health care systems coincided with countries in our study, but variation in the organisation of health care may exist within countries as well. A regional analysis in Spain using data from our study has shown that such regional differences exist in the provision of services (Bolibar et al., 2003). Similar differences are to be expected in other decentralised or federal countries, such as Germany, Belgium and Sweden.

Our study has examined the process of care and does not answer questions on outcomes in terms of cost or the health status of the population. Evidence of the process is indispensable, however, in order to be able to understand differences in outcomes or performance of health care systems.

A major added value to this study would be its replication. It has been almost ten years since the collection of the data and many things have changed in the health care systems in Europe, particularly in the former communist countries. 
Replication would not just provide an update of the situation in general practice, but would also show trends of change in the countries involved, which can be related to the many health reforms and other health policy measures taken in these countries. The resulting information could improve understanding of the practical effects of health policy.

\section{Implications for general practice}

In general, prevention and health education are less important tasks in general practice in Europe. GPs are heavily involved in curative work and responding to individual demands from patients. An outreaching approach to people who are not ill and giving life style information to groups at risk has no tradition in general practice in most countries. In central and eastern Europe, where prevention gets much attention, the effectiveness may be questioned, however. It is to be expected, however, that the demand for prevention and health education provided by GPs will grow, since primary care is in a favourable position to foster the patients' compliance and follow-up, particularly in systems where patients are on GPs' lists. GP job descriptions could be adapted in such a way as to ensure outreaching and community-based preventive activities receive more recognition as regular tasks, while another point for discussion could be whether GPs and their routinely kept information systems could play a role in the early detection of pandemic outbreaks and environmental threats.

The differences found in the study between services provided in urban and rural practices were fundamental. Rural GPs offer a wider range of services to their patients than GPs in cities, and it may be questioned whether qualifications and job requirements are too different to keep them under the same umbrella. Making no distinction, as in the current situation (with the exception of weight factors for capitation payments in rural and deprived practices in some countries), further reduces interest in going into practice in rural areas, resulting in greater inequalities in health services provision. Identifying two strands of general practice is complicated, because of the implications for medical education and the mobility of GPs.

The proportion of female GPS is growing rapidly in many countries, particularly in western Europe. Female GPs appeared to have different preferences when going into practice and provided a somewhat different package of services to their patients than male GPs. This situation deepens the problem relating to urban and rural practice, because female GPs prefer to work in urban practice. They also prefer to work in group practices, making it likely that practice conditions need to be adapted to meet these changed preferences. Further 
research should clarify the implications of the different services provided by male and female GPs and it may be necessary for training programmes to devote more attention to 'under-served' task areas among female GPs (medico-technical procedures, for example).

There was a sharp contrast between the post-communist countries (especially those previously belonging to the former Soviet Union) and the western countries. General practice is developing in the transitional countries and it takes time to acquire an established GP position in health care systems. The poor development of tasks in first contact care indicates the inclination of the population to rely on specialist care, even for frequently occurring conditions. GPs will need more communication skills to change this exclusive medical attitude, which is an obstacle to the clarification and effective treatment of vague complaints. Furthermore, additional skills are needed for dealing with new task areas (e.g. children's problems and gynaecological problems) and running a practice efficiently. Being a gatekeeper primarily implies providing a wide range of services yourself, rather than referring patients to other care providers. National and international organisations of GPs can support GP associations in the post-communist countries with their expertise and knowledge. The very limited use of medical techniques and the poor equipment in the transitional countries demonstrates the lack of funds even for essential items. If these become available, GPs will need additional training to work with the equipment.

Results have shown the value of medical records being consistently kept by GPs, particularly in systems with registered patients. Most GPs use a computer nowadays, but its use for medical records is far from general. Computerised medical records are not just a help to GPs in providing continuous care to individual patients, a good practice data base is also indispensable for the systematic screening and following-up of chronic patients, besides being a source of information for epidemiological and health services research. Policymakers and professional organisations should strongly encourage GPs to maintain record systems appropriate for their professional tasks.

The possible conflict between increasing patient demands and changing preferences of GPs may require changes in the organisation of general practice. Our study has suggested that well-equipped and well-staffed practices, where GPs work in small teams and where the flow of patients is regulated by an appointment system are good conditions for the provision of a wide range of services. Such working conditions may also meet GPs' needs for a private life. The conflict between a GP's private life and his/her working hours, which may 
endanger the recruitment of sufficient GPs for the future, might be solved not by organisational measures alone, but by a reshuffling of tasks as well. Countries where general practice is strongly developed may point the way in finding solutions. Tasks in the care of chronic patients are increasingly being transferred from secondary care to primary care, or this care is shared by specialists and GPs. Tasks in general practice are delegated or shared with trained nurses and other staff, which requires a larger scale of practice and a good medical information system.

\section{Implications for health policy}

Recurring themes in health care reforms are access to services, equal quality, coordination and continuity of care, incentive structures and definition of professional responsibilities. The post-communist health care systems face a number of additional challenges. The results of our study suggest a number of recommendations for these aspects of health policy.

\section{Access to health care}

In countries with GPs in a strong position as gatekeepers, this system is felt to be too rigid in the care of certain categories of chronic patient, who frequently cross the border between primary and secondary care. Countries that do not have a gatekeeping system are trying to introduce one in some form, preferably on a voluntary basis, in order to improve coordination and control the costs of care. This means, in effect, that many countries are looking for flexible forms of GP gatekeeping. Our results do indeed show that gatekeeping GPs are well positioned in the patient flow at the entrance of health care, where they respond to a wide range of daily conditions - medical as well as psycho-social presented by the patients for whose care they are responsible. This position favours a coordinating role. We also found that there is more homogeneity in the GPs' package of tasks in countries with a gatekeeping system.

\section{Incentives}

The mode of employment and payment of GPs should look for a balance between meeting patients' needs and avoiding overtreatment. Self-employed GPs were found to be more active than salaried GPs, both in terms of services and working hours. Services like preventive screening, which are not demanddriven, are unlikely to be provided under simple capitation payment systems, which means that additional target payments are needed in these cases. Situations of oversupply of GPs who are not gatekeepers and are working under 
a fee-for-service payment system, often in single-handed practice, most probably contain negative incentives for cost effectiveness and good quality of care.

\section{Expanding responsibilities}

Coordination is not the only expanding task for GPs. Hospital stay is becoming shorter and can be avoided if tasks are transferred to primary care. In addition, the favourable position of GPs for case finding and promoting patient compliance with treatments has been discovered in preventive care. GPs are challenged to take up these new tasks. If payment for these services has been organised, the organisation of the practice needs to be prepared for these new tasks. We found that practices with more staff and equipment provided a wider range of services. Working in group practices made no difference in the service profile, but GPs working in groups worked fewer hours and female GPs prefer to work in group practices. Since time devoted to indirect activities is relatively constant, it seems that shortening working weeks for GPs relatively strongly affect time for patient care.

\section{Central and eastern Europe}

All post-communist countries are developing primary care and general practice and reducing the hospital sector. They have already learned the pitfalls of a feefor-service system. There is a need for more coordination and less duplication of services, and the tasks of GPs are limited. Our study would suggest that these problems can be solved by a (voluntary) patient list system, through extending the competence of GPs by additional training, and providing GPs with the equipment to provide the services.

\section{Urban and rural practices}

GPs working in rural areas provided a more varied package of services, regardless of the health care system. This situation deserves different contractual arrangements, including payment, for GPs in rural areas.

Self-employed GPs might be preferable in rural practice, because they provide the more comprehensive services that are needed in rural areas. If these conditions are absent, rural practice may lose its attractiveness and staffing problems may arise. The equal distribution of health care manpower and facilities must be secured, in order to prevent services being poorest where needs are greatest.

This also applies to inner city practices, which are becoming less attractive places for GPs to work. 


\section{Female GPs}

Many countries are seeing a sharp increase in female GPs, which has important implications for health manpower planning, as our study learned. Female GPs preferred to work part-time in group practices in urban and suburban areas and they also provided a more limited range of services than male GPs. Since there is no difference between training to become a part-time GP and training to become a full-time GP, a larger number of GPs will need to be trained in future for an equal number of posts. Practice conditions may need to be adapted to the needs of female GPs (the organisation of out of hours services, for example).

\section{Coordination and continuity of care}

Ageing populations mean more chronic patients with longer episodes of care and more complex interventions by different professionals, while continuity of care requires a coordination of various health care inputs in such cases. Our study suggested that a system in which patients are registered with a GP of his or her choice benefits coordination. There is a better chance in such systems that medical information will be stored in one place, than in systems without patient lists of this kind.

Systems with listed patients are also essential for GPs to deliver public health tasks and for researchers to collect data for primary care epidemiology and health services research. A patient list system is not sufficient, however. Individual GPs need to keep comprehensive medical records and maintain good working relations with other health professionals in primary and secondary care, conditions that can be fostered by means of proper incentives. 


\section{Samenvatting \\ (Summary in Dutch)}

\section{Huisartspraktijkprofielen in Europa:}

een internationaal onderzoek naar verschillen in de taken van huisartsen

\section{Inleiding}

Dit boek gaat over een onderzoek naar verschillen in de uitoefening van taken door huisartsen in Europa. Daarbij is vooral gekeken naar de vraag in hoeverre de wijze waarop de gezondheidszorg in een land is ingericht, invloed heeft op de betrokkenheid van huisartsen in dat land bij de verlening van curatieve en preventieve zorg. Invloeden op plaatselijk niveau, zoals praktijkomstandigheden en persoonskenmerken van huisartsen, zijn ook bij het onderzoek betrokken. Het onderzoek, dat financieel werd mogelijk gemaakt door de Europese Commissie en werd gesteund door de Wereld Gezondheids Organisatie, voorziet in een behoefte aan internationaal vergelijkbare gegevens over zorgverlening door huisartsen.

Het onderzoek heeft drie bronnen van informatie. Op grond van literatuuronderzoek en met de hulp van cntactpersonen werd de organisatie en financiering van de gezondheidszorg in de landen van Europa beschreven; deze beschrijvingen leverden de achtergrondinformatie voor het onderzoek. Verder vroegen wij in 32 landen huisartsen, via steekproeven geselecteerd, een vragenlijst (in hun eigen taal) in te vullen. De vragen gingen over de betrokkenheid van de huisarts bij de eerste opvang en behandeling van een groot aantal concreet beschreven gevallen, alsmede over de organisatie en uitrusting van de praktijk, samenwerking en kenmerken van de plaats van vestiging. Bij de vragenlijst was verder een dagboekje gevoegd, waarin de huisartsen gedurende 7 dagen de tijdsbesteding konden bijhouden. In totaal hebben 7.895 huisartsen aan het onderzoek meegedaan; dat is een respons van $51 \%$.

$\mathrm{Na}$ het eerste inleidende hoofdstuk van dit boek volgen er zeven, die eerder afzonderlijk zijn gepubliceerd en één dat nog moet verschijnen. Hoofdstuk 10 bevat een uitgebreide samenvatting en de conclusies. Hieronder volgt een bondige samenvatting van de hoofdstukken.

\section{Taakprofielen van huisartsen in Europa}

Vier groepen van taken werden onderscheiden, te weten het eerste contact met gezondheidsproblemen van patiënten, het verrichten van medisch technische 
handelingen (zoals kleine chirurgische ingrepen), het behandelen van (chronische) ziekten en preventieve zorg. In de rol van de huisarts bij het eerste contact met gezondheidsproblemen werden vooral grote verschillen gevonden waar het gaat om psycho-sociale problemen en om klachten van kinderen en vrouwen. In sommige landen blijkt de huisarts daarvoor niet de eerst aangewezen hulpverlener te zijn. Medisch-technische verrichtingen werden ook in heel verschillende mate uitgevoerd. Bij het behandelen van ziekten waren de verschillen tussen de landen kleiner dan bij de overige aspecten. De betrokkenheid van huisartsen bij systematische preventie was veel geringer dan bij de curatieve taken. Groepen van landen met gemeenschappelijke kenmerken betreffende de positie van de huisarts, werden vergeleken. In landen waar huisartsen een poortwachtersfunctie vervullen naar de specialistische zorg, hadden dezen een veel sterker ontwikkelde rol als arts-van-het-eerste-contact dan in andere landen, waar die rol wordt gedeeld met medisch specialisten. In landen met zelfstandig gevestigde huisartsen waren die meer betrokken bij het behandelen van ziekten dan in landen met huisartsen in loondienst. Tenslotte bleek dat huisartsen in de voormalige communistische landen op de meeste terreinen een beperkter rol vervullen dan hun collega's in de andere landen.

\section{Vergelijking van stads- en plattelandspraktijken}

De hypothesen werden getoetst dat bij huisartsen op het platteland een meer omvattend takenpakket zou worden gevonden, en bij huisartsen die hun praktijk vlak bij een ziekenhuis hebben juist een beperkter takenpakket. Bovendien werd verwacht dat verschillen tussen praktijken in de stad en op het platteland kleiner zouden zijn in landen waar huisartsen een poortwachtersfunctie hebben.

Praktijken op het platteland bleken anders te zijn dan die in de stad: huisartsen werken er vaker solo, er is meer apparatuur en sociale achterstand van de bevolking komt er minder voor. Huisartsen op het platteland en in praktijken op meer dan 5 kilometer van een ziekenhuis waren meer betrokken bij de zorg in de curatieve taakgebieden. Huisartsen in binnenstadspraktijken doen minder aan kleine chirurgie en andere technische verrichtingen. Overigens bleek de uitoefening van taken ook verband te houden met de aard van de praktijkpopulatie, zoals de leeftijdsopbouw, de personele bezetting en uitrusting van de praktijk, het voltooid hebben van de huisarts-beroepsopleiding en het geslacht van de huisarts (waarover zo meer). In tegenstelling tot de verwachtingen werd in landen met huisartsen in een poortwachtersfunctie wel een verschil 
gevonden in de taakprofielen van stads- en plattelandshuisartsen. Dit zou kunnen wijzen op een erosie van de poortwachtersfunctie in de stad.

De huisarts als hulpverlener in het eerste contact met psycho-sociale problemen Verondersteld werd dat in landen waar patiënten bij een huisarts staan ingeschreven, die huisartsen een meer omvattende rol vervullen in het eerste contact met psycho-sociale problematiek dan in landen waar dat niet het geval is. Daarnaast werden invloeden verwacht van de werkdruk van de huisarts en de hoeveelheid tijd die hij aan de patiënt kon besteden, kennis van de voorgeschiedenis van de patiënt (uit het medisch dossier) en de beschikbaarheid van deskundigheid (als gevolg van opleiding en door samenwerking met maatschappelijk werkers). Er werden grote verschillen gevonden in de mate waarin huisartsen de eerste opvang verzorgen bij psycho-sociale problemen, zowel binnen landen als tussen landen. Zoals verwacht waren huisartsen in landen waar zij ingeschreven patiënten hebben hierbij beduidend meer betrokken dan huisartsen in andere landen. Ook werd een uitgesproken 'oost-west' verschil gevonden. Huisartsen in de post-communistische landen waren veel minder betrokken bij de eerste opvang van psycho-sociale problematiek. Ook een aantal individuele praktijkomstandigheden was van invloed op genoemde rol van de huisarts. Huisartsen met een afspraakspreekuur en bij wie de gereserveerde tijd per patiënt niet heel kort was, en huisartsen die een goed patiëntendossier bijhouden (en daardoor beter geïnformeerd zijn over hun patiënten) waren meer betrokken bij deze eerstelijns GGZ-taken. Toch bleek een drukke praktijk, in de zin van een groot aantal patiëntencontacten per dag, geen belemmering te zijn. Zoals verwacht had de samenwerking met maatschappelijk werkers en het voltooid hebben van een beroepsopleiding tot huisarts een gunstige invloed. Hierdoor kunnen huisartsen hun vaardigheden in het omgaan met nietmedische problemen beter ontwikkelen.

\section{Vrouwelijke en mannelijke huisartsen vergeleken}

Uit de literatuur is bekend dat mannelijke en vrouwelijke huisartsen verschillen in hun voorkeur voor werktijd en werksetting. Verondersteld werd dat er ook verschillen tussen de seksen zouden zijn in de wijze van zorgverlening, maar verwacht werd dat deze verschillen in de landenvergelijking kleiner zouden zijn daar waar huisartsen een poortwachtersfunctie en ingeschreven patiënten hebben. In die landen kunnen patiënten namelijk hun eventuele voorkeur voor een huisarts van hetzelfde geslacht minder realiseren. Wat systematische preventie betreft, werd in landen met zelfstandig gevestigde huisartsen über- 
haupt weinig activiteit verwacht, omdat de honorering er daar meestal niet in voorziet. Dus worden in die landen ook geen sekseverschillen verwacht in de betrokkenheid bij preventie.

De man-vrouwverdeling onder huisartsen verschilde sterk van land tot land. Mannen waren doorgaans in de meerderheid, behalve in de landen van Midden- en Oost-Europa. Vergeleken met hun mannelijke collega's waren vrouwelijke huisartsen jonger, werkten vaker in deeltijd, in duo- of groepspraktijken en in de stad (ofschoon niet in achterstandswijken). Ze onderscheidden zich verder door een geringer aantal huisbezoeken en minder diensten buiten kantooruren. Dat vrouwelijke huisartsen minder patiënten zien, bleek geheel toe te schrijven aan deeltijdwerken. Wat de zorgtaken betreft, vonden we dat vrouwelijke huisartsen in West-Europese landen meer betrokken waren bij het eerste contact met gynaecologische problemen Voor alle overige curatieve taken was de algemene tendens dat de betrokkenheid van vrouwelijke huisartsen geringer is dan die van mannelijke collega's. Groepsgewijze gezondheidsvoorlichting, waarin huisartsen in het algemeen overigens weinig actief bleken te zijn, werd meer gedaan door vrouwen dan door mannen. Zoals verwacht bleken de sekseverschillen in de taakverlening kleiner in landen met huisartsen in een poortwachtersfunctie dan in landen met een meer open toegang tot de medischspecialistische zorg.

\section{Onderlinge verschillen tussen de landen van Midden- en Oost- Europa}

Vanuit West-Europa worden de voormalige 'oostbloklanden' vaak als een homogene groep gezien. Wij hebben, voor wat de taakuitoefening van huisartsen betreft, onderzocht in hoeverre dat zo is. In het algemeen was er een flinke kloof tussen de taakbreedte van huisartsen in 'oost' en 'west'. Voor preventie was het verschil kleiner dan voor aspecten van curatieve zorg. Binnen de groep van post-communistische landen vonden wij echter geen grotere homogeniteit in de takprofielen dan onder de overige landen. Bij de meeste curatieve taken bleek de onderlinge variatie zelfs groter dan tussen de WestEuropese landen.

Binnen de groep van Midden- en Oost-Europese landen konden op basis van het takenprofiel van de huisartsen drie subgroepen onderscheiden worden: voormalig Joegoslavië, de voormalige satellietstaten en de landen voorheen behorend tot de Sovjet Unie. Met uitzondering van het behandelspectrum van (chronische) ziekten, was de curatieve zorgverlening van huisartsen het meest omvattend in voormalig Joegoslavië, gevolgd door de satellietlanden, zoals 
Polen, Tsjechië, Slowakije, Hongarije. In laatstgenoemde landen werd het communistische zorgstelsel pas na de Tweede Wereldoorlog ingevoerd.

Joegoslavië, onder Tito, heeft door de jaren heen een betrekkelijk zelfstandige koers kunnen varen. Huisartsen in de voormalige Sovjet Unie hadden een erg beperkt pakket van curatieve zorgtaken. Bij preventie was de situatie min of meer omgekeerd. In de voormalige Sovjet Unie makte preventie een relatief groot deel uit van het takenpakket van de huisartsen (wat overigens nog niets zegt over de effectiviteit ervan).

\section{Huisbezoek door de huisarts}

Dit onderdeel ging uit van de algemene veronderstelling dat huisartsen een patiënt liever in de spreekkamer zien, terwijl patiënten meer een voorkeur hebben voor een huisbezoek. Meer huisbezoeken werden verwacht in landen met zelfstandig gevestigde huisartsen en waar een hoge 'huisartsendichtheid' bestaat. In die landen is er een sterkere prikkel voor de huisarts om de voorkeur van de patiënt te volgen, ook als de noodzaak voor een huisbezoek minder sterk is. Minder huisbezoeken werden verwacht in landen waar huisartsen een poortwachtersfunctie vervullen en ingeschreven patiënten hebben. In een dergelijk systeem is er een grotere drempel voor patiënten om van huisarts te veranderen. Op basis van de literatuur werd verder verwacht dat huisartsen op het platteland meer huisbezoeken afleggen dan hun collega's in de stad; in solopraktijken meer dan in duo- en groepspraktijken; in vergrijsde praktijken meer dan in praktijken met een jongere populatie en dat mannelijke huisartsen meer huisbezoeken afleggen dan vrouwelijke. In de meeste landen behoorde het huisbezoek tot de normale taken van de huisarts, maar de gemiddelde aantallen afgelegde bezoeken liepen zeer uiteen, van 2 tot 44 per week. In landen met zelfstandig gevestigde huisartsen lag het gemiddelde beduidend hoger dan in landen waar huisartsen in loondienst zijn. Waar huisartsen een poortwachtersfunctie vervullen met ingeschreven patiënten, legden dezen minder huisbezoeken af en waren de onderlinge verschillen in afgelegde bezoeken kleiner dan bij huisartsen in andere landen. Zo was dat ook verwacht. Het verwachte effect van huisartsendichtheid werd echter niet gevonden. Het verschil tussen stad en platteland en tussen solopraktijken en duo- en groepspraktijken werd alleen gevonden in landen waar huisartsen geen poortwachter zijn. Niet alleen in vergrijsde praktijken werd een groter aantal huisbezoeken gevonden, dit bleek ook het geval in praktijken in achterstandsgebieden. En behalve dat mannelijke huisartsen meer huisbezoeken afleggen dan vrouwelijke, vonden we ook dat oudere huisartsen er meer afleggen dan jongere. 


\section{Besteding en beheer van tijd door de huisarts}

De gemiddelde aantallen gewerkte uren van huisartsen verschilden sterk van land tot land; van 40 tot 60 uur per week. Die verschillen zaten vooral in de uren die besteed worden aan directe zorg voor patiënten, en veel minder in de uren voor indirecte activiteiten (zoals administratie en scholing). Nog groter waren de verschillen in het gemiddeld aantal patiënten dat een huisarts op een dag in zijn spreekkamer ziet: variërend van 15 tot 50 . In landen met zelfstandig gevestigde huisartsen was de gemiddelde werkweek, met name de uren voor directe patiëntenzorg, langer dan in landen met huisartsen in loondienst. In landen waar huisartsen een poortwachtersfunctie hebben en waar patiënten staan ingeschreven bij een huisarts, was de werkweek korter dan in landen waar patiënten niet staan ingeschreven (en dus makkelijker andere artsen kunnen raadplegen). In de post-communistische landen besteedden de huisartsen minder tijd aan indirecte activiteiten dan hun collega's in de overige landen. Wellicht worden in de grotere medische centra in eerstgenoemde landen bepaalde overhead-taken uitgevoerd door daarvoor aangestelde functionarissen. Huisartsen met een afspraakspreekuur, in veel landen zeker nog geen regel, werkten minder uren dan huisartsen met een open spreekuur. De gereserveerde tijd per afspraak liep sterk uiteen. Los van andere organisatorische aspecten werkten huisartsen in duo- en groepspraktijken korter dan huisartsen in solopraktijken. Huisartsen die de patiëntendossiers goed bijhouden, rapporteerden gemiddeld meer werkuren dan huisartsen bij wie dat niet het geval was.

\section{De invloed van het honoreringsstelsel op de werkbelasting en tijdsbesteding}

Verwacht werd dat huisartsen verschillend omgaan met een hogere werkbelasting al naar gelang de wijze waarop ze worden gehonoreerd. In landen waar huisartsen in loondienst zijn zouden dezen een ongeveer gelijk aantal uren werken, ongeacht de omvang van de praktijk. Waar huisartsen per verrichting worden betaald, werd verwacht dat het aantal werkuren zou toenemen met het toenemen van de praktijkgrootte. Een tussenpositie werd verwacht bij huisartsen die voornamelijk bij abonnement worden betaald. Zowel voor de indirecte maat van werkbelasting (het gemiddeld aantal inwoners per huisarts in een land) als directe maten (aantal patiëntencontacten en aantal huisbezoeken) werden zeer grote verschillen gevonden tussen de landen. De tijd die huisartsen voor een consult reserveren, varieerde van gemiddeld 7 tot 24 minuten en ook de wachttijd voor de patiënt tussen het maken van een afspraak 
en het tijdstip van het consult verschilden sterk. De gemiddelde werkweek van huisartsen in een land liep uiteen van 40 tot 60 uren per week.

Onze veronderstellingen over het verband met het betalingssysteem werden alleen bevestigd voor wat betreft huisartsen met een abonnementshonorarium. In landen met een betalingssysteem per verrichting werd weliswaar een stijging van het aantal werkuren gevonden bij huisartsen met een praktijkgrootte op of onder het gemiddelde, maar niet bij de groep huisartsen met grotere praktijken. Gesalarieerde huisartsen tenslotte lieten, tegen de verwachting in, toch een toename zien in het aantal werkuren in de groep met een gemiddelde of kleinere praktijk. We concludeerden, dat patiënten in grotere praktijken relatief minder zorg krijgen dan patiënten in kleinere praktijken, en dat er van een honorarium per verrichting geen voldoende krachtige prikkel lijkt uit te gaan die dit tegen gaat.

\section{Discussie}

Dit onderzoek heeft veel gegevens opgeleverd die de grote verscheidenheid laten zien in de organisatie en verlening van de huisartsenzorg in Europa en de invloed van kenmerken van de nationale zorgsystemen daarop. De verschillen in taakprofielen van huisartsen werden in grotere mate verklaard door die systeemverschillen dan door individuele- en praktijkkenmerken. Waar huisartsen een poortwachtersfunctie bekleden vonden we in het algemeen een breder pakket aan verleende zorgtaken en minder individuele verschillen daarin dan in landen waar medisch specialisten direct toegankelijk zijn. In landen met een betalingssysteem per verrichting zijn huisartsen meer betrokken bij het behandelen van chronische ziekten en het begeleiden van patiënten, leggen ze meer huisbezoeken af en besteden ze gemiddeld meer uren per week aan patiëntenzorg dan in landen met een ander betalingssysteem, vooral landen met gesalarieerde huisartsen. We vonden een duidelijk contrast in de verleende taken tussen de voormalige communistische landen en de overige landen in Europa. Over de hele linie was het takenpakket beperkter in de eerstgenoemde landen, al waren er ook binnen deze groep aanzienlijke verschillen tussen landen van het voormalige Joegoslavië en landen die voorheen tot de Sovjet Unie behoorden.

Naast verschillen tussen landen waren er ook de meer bekende verschillen binnen de landen. Door alle zorgsystemen heen vonden we een breder takenprofiel bij huisartsen in plattelandspraktijken vergeleken met huisartsen in de stad, en mannelijke huisartsen verleenden in het algemeen een breder pakket aan taken dan vrouwelijke huisartsen. 
Een aantal methodologische kanttekeningen dient te worden gemaakt. Niet in alle landen kon een representatieve steekproef worden getrokken en bovendien heeft slechts de helft van de aangeschreven huisartsen een vragenlijst ingevuld teruggestuurd. De invloed hiervan op de resultaten valt moeilijk vast te stellen. Voor zover het kon worden achterhaald, waren vrouwelijke huisartsen en heel jonge en oudere huisartsen enigszins ondervertegenwoordigd onder de respondenten. Resultaten waarin leeftijd en geslacht van de huisartsen van belang zijn, kunnen hierdoor zijn beïnvloed, maar in de analyses is altijd rekening gehouden met deze variabelen. De diversiteit aan onderwerpen die in de vragenlijst aan de orde werden gesteld, maakt het niet waarschijnlijk dat huisartsen op een bepaalde belangstelling zijn geselecteerd.

De afhankelijke variabelen zijn gebaseerd op eigen waarneming van de huisartsen. De vraag is in hoeverre een huisarts er weet van heeft dat zijn patiënten voor bepaalde gezondheidsproblemen ook andere artsen consulteren. Wij denken dat huisartsen dit direct of indirect te weten komen en derhalve een redelijke schatting kunnen maken van hun positie in de 'markt' voor bepaalde gezondheidsproblemen of verrichtingen.

In een aantal landen was het lastig de doelgroep van het onderzoek vast te stellen. Vooral in post-communistische landen waren huisartsen zoals wij die kennen vaak niet zo bekend als elders het geval is. In zulke situaties werden, in overleg met de lokale coördinatoren, steekproeven districtsartsen getrokken, die qua functie nog het meest lijken op de huisarts; dit werd soms aangevuld met een steekproef onder artsen die recentelijk waren omgeschoold tot huisarts.

Hoewel veel zorg is besteed aan de vertaling van de vragenlijst in 26 talen, valt het niet uit te sluiten dat sommige begrippen hierbij toch een enigszins verschillende betekenis hebben gekregen.

Hoewel in de resultaten relaties tussen oorzaak en gevolg soms zeer voor de hand liggen, moet niet worden vergeten dat slechts samenhangen zijn vastgesteld.

Waar gevonden werd dat huisartsen, vergeleken met collega's in andere landen, slechts in geringe mate betrokken zijn bij de uitoefening van bepaalde taken, moet niet geconcludeerd dat daar sprake is van een tekort. Vaak zal in die gevallen de zorgverlening door anderen dan huisartsen worden gedaan.

Een ander punt is, dat dit onderzoek zich uitsluitend heeft gericht op huisartsen, de aanbodzijde dus. Voorkeuren van patiënten bij het inroepen van hulp bij bepaalde gezondheidsproblemen, die mede de rol van huisartsen bepalen, zijn dus niet aan de orde geweest. 
Ten slotte dient opgemerkt dat nu ongeveer tien jaar zijn verstreken sinds het begin van de gegevensverzameling. In de tussenliggende jaren is er veel veranderd, vooral in Oost Europa. Hoewel professioneel handelen doorgaans langzaam verandert, zullen er veranderingen zijn opgetreden in de taakprofielen van huisartsen. Overigens is het niet waarschijnlijk dat de gevonden samenhangen tussen taakuitoefening en lokale en nationale kenmerken veel zijn veranderd. Een herhaling van deze studie biedt niet alleen de mogelijkheid de omvang van de veranderingen vast te stellen, maar ook deze in verband te brengen met het gevoerde beleid in de achter ons liggende jaren. 
Profiles of general practice in Eurc 192 


\section{Literature}

Aguzzoli F, Aligon A, Com-Ruelle L, Frerot L. Choisir d'avoir un médecin référent: une analyse réalisée à partir du premier dispositif mis en place début 1998. (Choosing to have a referring physician: an analysis made from the first implementation in the beginning of 1998.) Paris: CREDES, 1999

Aguzzoli $\mathrm{F}$, Le Fur $\mathrm{Ph}$, Sermet C. Clientèle et motifs de recours en médecine libérale; France 1992. (Clients and reasons for visits in independent practice; France 1992.) Paris: CREDES, 1994

Alban A, Christiansen T. The Nordic Lights: New Initiatives in Health Care Systems. Odense University Press, 1995

Albrecht GL, Salmon JW. Soviet health care in the Glasnost era. In: Rosenthal MM, Frenkel M (eds). Health care systems and their patients: an international perspective. Boulder: CO Westview Press, 1992: p.247-271

Allen J, Gay B, Crebolder H, Heyrman J, Svab I, Ram P. The European Definitions of the Key Features of the Discipline of General Practice: the role of the GP and core competencies. British Journal of General Practice, 2002; 52: p.526-527

Anderson OW. Medical care: its social and organisational aspects. Health services systems in the United States and other countries - critical comparisons. The New England Journal of Medicine, 1963; 16: p.839-843

Anderson R, Newman JF. Societal and individual determinants of medical care utilization in the United States. Milbank Memorial Fund Quarterly, 1973; 51: p.95124

Andersen MR, Urban N. Physician gender and screening: do patient differences account for differences in mammography use? Women \& Health, 1997; 26: p.29-39

Appleton K, House A, Dowell A. A survey of job satisfaction, sources of stress and psychological symptoms among general practitioners in Leeds. British Journal of General Practice, 1998; 48: p.1059-1063

Aylin P, Majeed FA, Cook DG. Home visiting by general practitioners in England and Wales. British Medical Journal, 1996; 313: p.207-210 
Baker B, Klein R, Carter R. Impact of the 1990 contract for general practitioners on night visiting. British Journal of General Practice, 1994; 44 : p.68-71

\section{BASYS. BASYS Informationen, March 1999. Augsburg: BASYS, 1999}

Bensing JM, Van den Brink-Muinen A, De Bakker DH. Gender differences in practice style: a Dutch study of general practitioners. Medical Care, 1993; 31: p.219-229

Bensing JM, Verhaak PFM. Psychische problemen in de huisartspraktijk veelvormiger en diffuser dan in de psychiatrie. (Psychological problems in general practice more varied and diffuse than in psychiatry.) Nederlands Tijdschrift voor Geneeskunde, 1994: 138: p.130-135

Bertakis KD, Helms LJ, Callahan EJ, Azari R, Robbins JA. The Influence of gender on physician practice style. Medical Care, 1995; 33: p.407-416

Birt CA, Kidd M, Peters G. Development of primary health care in Russia. In: Szakal G, Balogh E, Bojan F (eds). Health care reforms in central and eastern European countries. Proceedings of the Annual Meeting of the European Public Health Association (EUPHA); 1995 Dec 14-16; Budapest. Debrecen: University Medical School, 1996: p.1-7

Blancquaert IR, Zvagulis I, Gray-Donald K, Pless IB. Referral patterns for children with chronic diseases. Paediatrics, 1992; 1: p.71-74

Boerma WGW, De Jong FAJM, Mulder PH. Health care and general practice across Europe. Utrecht: NIVEL/NHG, 1993

Boerma WGW, Van der Zee J, Fleming DM. Service profiles of general practitioners in Europe. British Journal of General Practice, 1997: 47: p.481-486

Boerma WGW, Fleming DM. The role of general practice in Primary Health Care. Norwich: The Stationary Office, 1998

Boerma WGW, Groenewegen PP, Van der Zee J. General practice in urban and rural Europe; the range of curative services. Social Science \& Medicine, 1998; 47: p. $445-453$

Boerma W, Verhaak PFM. The general practitioner as the first contacted health professional by patients with psychosocial problems: a European study. Psychological Medicine, 1999; 29: p.689-69 
Boerma WGW, Van den Brink-Muinen A. Gender-Related Differences in the Organization and Provision of Services Among General Practitioners in Europe. A Signal to Health Care Planners. Medical Care, 2000; 38: p.993-1002

Boerma WGW, Groenewegen PP. GP Home visiting in 18 European countries. Adding the role of health system features. European Journal of General Practice, 2001; 7: p.132137

Bolden K, Lewis A, Sawyer B. Practice management. Oxford: Blackwell, 1992

Bowling A, Farquhar M, Browne P. Use of services in old age: data from three surveys of elderly people. Social Science \& Medicine, 1991; 6: p.689-700

Britt H, Bhasale A, Miles DA, Meza A, Sayer GP. Angelis M. The sex of the general practitioner. A comparison of characteristics, patients and medical conditions managed. Medical Care, 1996; 34: p.403-415

Bryk AS, Raudenbush SW. Hierarchical linear models. Newbury Park: Sage, 1992

Bucquet D, Jarman B, White P. Factors associated with home visiting in an inner London general practice. British Medical Journal, 1985; 290: p.1480-1483

Bundesministerium für Frauen, Jugend und Gesundheit. Gesundheitsreform 2000. (Health Care Reform 2000.) Berlin, 2000

Burkowitz J, Preissig AB, Wehner I, Fisher GC. Auswirkungen zweier Vergütungsmodelle auf Hausbesuche Allgemeinmedizinern. (Effects of two reimbursement models on house calls by GPs.) Gesundheitswesen, 1995; 57: p.782-785

Calnan M, Butler JR. The economy of time in general practice: an assessment of the influence of list size. Social Science \& Medicine, 1988; 26: p.435-441

Calnan M, Groenewegen PP, Hutten JBF. Professional reimbursement and management of time in general practice: an international comparison. Social Science \& Medicine, 1992; 35 : p. 209-216

Campbell SM, Hann M, Hacker J, Burns C, Oliver D, Thapar A, Mead N, Gelb Safran D, Roland MO. Identifying predictors of high quality care in English general practice: observational study. British Medical Journal, 2001; 323: p.784-787 
Carr-Hill RA, Sheldon T. Designing a deprivation payment for general practitioners: the UPA (8) wonderland. British Medical Journal, 1991; 302: p.393-396

Carr-Hill R, Jenkins-Clarke S, Dixon P, Pringle M. Do minutes count? Consultation lengths in general practice. Journal of Health Services Research and Policy, 1998; 3: p.207-213

Chaix-Couturier C, Durand-Zaleski I, Jolly D, Durieux P. Effects of financial incentives on medical practice: results from a systematic review of the literature and methodological issues. International Journal for Quality in Health Care, 2000; 12(2): p.133142

Chambers R, Campbell I. Gender differences in general practitioners at work. British Journal of General Practice, 1996; 46: p.291-293

Christensen MB, Olesen F. Out of hours service in Denmark: evaluation five years after reform. British Medical Journal, 1998; 316: p.1502-1505

Clark DO. Residence differences in formal and informal long-term care. Gerontologist, $1992 ; 2$ : p. $227-233$

Cooke M, Ronalds C. Women doctors in urban general practice: the patients. British Medical Journal, 1985a; 290: p.753-755

Cooke M, Ronalds C. Women doctors in urban general practice: the doctors. British Medical Journal, 1985b; 290: p.755-758

Court BV, Bradley CP, Cheng KK, Lancashire RJ. Responding to out of hours requests for visits: a survey of general practitioner opinion. British Medical Journal, 1996; 312: p.1401-1402

Cox J. Rural general practice (editorial). British Journal of General Practice, 1994; 44: p.388-389

Crombie, DL, Van der Zee J, Backer P. The Interface Study. Occasional Paper nr.48. London: Royal College of General Practitioners, 1990

Davis CM. The Soviet health system: a national health service in a socialist society. In: Field MG (ed). Success and crisis in national health systems: a comparative approach. New York/London: Routledge, 1989: p.233-262 
Deacon B. Sociopolitics or social policy: Bulgarian welfare in transition? International Journal of Health Services, 1987; 17(3): p.489-513

De Bakker D, Grielen SJ, Prins B. Werklastvermindering en tevreden patiënten; grootschalige dienstenstructuur voor huisartsen. (Workload reduction and satisfied patients; large scale service structure for GPs.) Huisarts \& Wetenschap, 1999; 54: p.1328-1331

DeGruy, F. Mental health care in the primary care setting. In: Donaldson MS, Yordy KD, Lohr KN, Vanselow NA (eds). Primary Care; America's health in a new era. Washington: National Academy Press, 1996, p.285-311

Delnoij DMJ. Physicians payment system and cost control. Utrecht: NIVEL, 1994 (thesis)

Delnoij DMJ, De Bakker DH, Groenewegen PP. Loon naar werken: vergelijking van een gedifferentieerd abonnement en een gemengde honoreringsstructuur voor huisartsen. (Getting what one deserves: a comparison of age-differentiated capitation and a mixed system of remuneration for general practitioners.) Medisch Contact, 1994; 49: p.1109-1111

Delnoij DMJ. Spreeuwenberg PMM. Variation in GPs' Referral Rates to Specialists in Internal Medicine. European Journal of Public Health, 1997; 7: p.427-435

Delnoij D, Van Merode G, Paulus A, Groenewegen P. Does general practitioner gate keeping curb health care expenditure? Journal of Health Services Research \& Policy, 2000; 5: p.22-26

Delnoij DMJ, Klazinga NS, Van der Velden J. Building integrated health systems in Central and Eastern Europe: An analysis of WHO and World Bank views and their relevance to health systems in transition. European Journal of Public Health, 2003 (in press)

De Maeseneer J, De Prins L, Heyerick JP. Het huisbezoek in België: analyse van een wereldrecord. (The home visit in Belgium: analysis of a world record.) Huisarts \& Wetenschap, 1994; 37: p.552-556

De Maeseneer J, Bogaert K, De Prins L, Groenewegen P. A literature review. In: Brown S (ed). Physician funding and health care systems - an international perspective. London: The Royal College of General Practitioners, 1999; p.17-32 
De Maeseneer J, De Prins L, Heyerick JP. Home visits in Belgium: a multivariate analysis, European Journal of General Practice, 1999; 5: p.11-14

Department of Health and Social Security. Inequalities in health. London: DHSS, 1980

Digby A. The evolution of British General Practice 1850-1948. Oxford: Oxford University Press, 1999

DiPrete DA, Forristal JD. Multilevel models: methods and substance. Annual Review of Sociology, 1994; 20: p.331-357

Dixon J, Holland P, Mays N. Developing primary care gatekeeping, commissioning and managed care. British Medical Journal, 1998; 317: p.125-128

Doescher MP, Franks P, Saver BG. Is Family Medicine Associated with Reduced Health Care Expenditures? Journal of Family Practice, 1999; 49: p.608-614

Dopheide J. Verwijzingen door de huisarts: enkele determinanten van het verwijscijfer van solohuisartsen op het verstedelijkt platteland en in forensengemeenten. (GP referrals: some determinants of referral rates of single handed GPs in rural areas and GPs in commuter communities.) Gezondheid en Samenleving, 1982; 3: p.141-151

Dopheide PP, Kersten TJ, Nijhout FP, Van der Speld GD. Een ziekenhuis op nieuw land. (A hospital on new land.) Utrecht: NIVEL, 1986

Dor A, Holahan J. Urban-rural differences in Medicare physician expenditures. Inquiry, 1990; $27:$ p. $307-318$

Eggen P, Maeland JG, Skjaerven R. Use of primary medical care: does place of residence play a role? Scandinavian Journal of Primary Health Care, 1993; 11: p.31-37

European Observatory on Health Care Systems. Health care systems in Transition.

- Portugal. Copenhagen: European Observatory, 1999

- Belgium. Copenhagen: European Observatory, 2000a

- Norway. Copenhagen: European Observatory, 2000b

- Germany, Copenhagen: European Observatory, 2000c

- Denmark. Copenhagen: European Observatory, 2001a

- Austria. Copenhagen: European Observatory, 2001b 
Evans RG. Incomplete vertical integration: the distinctive structure of the health-care industry. In: Van der Gaag J, Perlman (eds). Health, economics and health economics. Amsterdam: North Holland Publishing Company, 1981

Evans RG. Strained Mercy: The Economics of Canadian Health Care. Toronto: Butterworth,1984

Evans PR. The changing scene in general practice in Europe. British Medical Journal, 1994; 308: p.645-648

Farmer RG, Goodman RA, Baldwin RJ. Health care and public health in the former Soviet Union, 1992. Ukraine - a case study. Annals of International Medicine, 1993; 119(4): p. $324-328$

Fearn RMG. Norfolk general practice: a comparison of rural and urban doctors. Journal of the Royal College of General Practitioners, 1988; 38: p.270-273

Fennema K, Meyer DL, Owen N. Sex of physician: patients' preferences and stereotypes. Journal of Family Practice, 1990; 30: p.441-446

Field MG. The position of the Soviet physician: the bureaucratic professional. Milbank Memorial Fund Quarterly, 1988; 66(2 Suppl): p.182-201

Field MG. The Soviet legacy: the past as prologue, In: McKee M, Healy J, Falkingham J (eds). Health care in central Asia. Buckingham: Open University Press, 2002

Fleming DM, Backer P. The European Study of Referrals from Primary to Secondary Care. Occasional Paper nr. 56. London: Royal College of General Practitioners, 1992

Fleming DM. The European study of referrals from primary to secondary care. Amsterdam: Thesis Publishers, 1993 (thesis)

Fleming DM, Charlton JR. Morbidity and health care utilisation of children in households with one adult: comparative observational study. British Medical Journal, 1998; 316: p.1572-1576

Foets M, Van der Velden J. Een nationale studie van ziekten en verrichtingen in de huisartspraktijk. Basisrapport: meetinstrumenten en procedures. (A national survey of morbidity and interventions in general practice. Base report: research instruments and procedures.) Utrecht: NIVEL, 1990 
Foets M, Van der Velden J. De Bakker J. Dutch National Survey of General Practice: a summary of the survey design. Utrecht: NIVEL, 1992

Forrest CB, Starfield B. The effect of first-contact care with primary care clinicians on ambulatory health care expenditures. Journal of Family Practice, 1996; 43: p.40-48

Forrest CB, Weiner JP, Fowles J, Vogeli C, Frick KD, Lemke KW, Starfield B. Self-referral in point-of-service health plans. Journal of the American Medical Association, 2001; 285(17): p. 2223-2231

Franks P, Clancy C, Nutting P. Gatekeeping revisited - protecting patients from overtreatment. New England Journal of Medicine, 1983; 328: p.424-429

Franks P, Clancy CM. Physician gender bias in clinical decision making: screening for cancer in primary care. Medical Care, 1993; 31: p.213-218

Gallagher M, Pearson P, Drinkwater C. Managing patient demand: a qualitative study of appointment making in general practice. British Journal of General Practice, 2001; 51 : p.280-285

Gater R, De Almeida de Sousa B, Barrientos G, Caraveo J, Chandrashekar CR, Dhadphale M. The pathways to psychiatric care: a cross-cultural study. Psychological Medicine, 1991; $21:$ p.761-774

Gerdtham U, Jonsson B. Factors affecting health spending: health care policy. Health Policy Studies, 1995; Paris: OECD, 7: p.71-89

Gervas J, Perez Fernandez M, Starfield B. Primary care, financing and gatekeeping in Western Europe. Family Practice, 1994; 11: p.307-317

Glaser WA. Paying the doctor: systems of remuneration and their effects. Baltimore: Johns Hopkins University Press, 1970

Gloerich AB, Van der Zee J. Determinanten van verwijzen door de huisarts naar de tweedelijn. (Determinants of referring by GPs to secondary care.) Utrecht: NIVEL, 1992

Goldberg D, Huxley P. Mental illness in the community: the pathway to psychiatric care. London: Tavistock, 1980

Goldberg D, Huxley P, Common mental disorders. New York: Routledge, 1992 
Goldstein E, Preker A, Adeyi O, Chellaraj G. Trends in Health Status, Services, and Finance: the Transition in Central and Eastern Europe, volume 1. Washington DC: The World Bank, 1996

Gosden T, Forland F, Kristiansen IS, Sutton M, Leese B, Giffrida A, Sergison M, Pedersen L. Capitation, salary, fee-for-service and mixed systems of payment: effects on the behavior of primary care physicians (Cochrane Review). The Cochrane Library, Issue1: 2002. Oxford, Update Software

Gosden T, Sibbald B, Williams J, Petchy R, Leese B. Paying doctors by salary: controlled study of general practitioner behaviour in England. Health Policy, 2003; 64: p.415423

Graffy J. Patient choice in a practice with men and women general practitioners. British Journal of General Practice, 1990; 40: p.13-15

GreB S, Delnoij D, Groenewegen P. Managing primary care behaviour through contracts, incentives and payment systems. In: Saltman R, Rico A, Boerma W (eds). Primary care in the driver's seat? Organizational reform in European primary care. Buckingham: Open University Press, 2003 (accepted for publication)

Groenewegen PP, Van der Zee J, Van Haaften R. Remunerating General Practitioners in Western Europe. Aldershot: Avebury, 1991

Groenewegen PP, Hutten JBF. Workload and job satisfaction among general practitioners: a review of the literature. Social Science \& Medicine, 1991; 32: p.1111-1119

Groenewegen PP, De Bakker DH, Van der Velden J. Een nationale studie naar ziekten en verrichtingen in de huisartspraktijk. Basisrapport: verrichtingen in de huisartspraktijk. (A national survey of morbidity and interventions in general practice. Base report: interventions in general practice.) Utrecht: NIVEL, 1992a

Groenewegen PP, Hutten JBF, Van der Velden K. List size, composition of practice and general practitioners' workload in the Netherlands. Social Science \& Medicine, 1992b; 34: p.263-270

Groenewegen PP, Hutten JBF. The influence of supply-related characteristics on general practitioners' workload. Social Science \& Medicine, 1995; 40: p.349-358 
Groenewegen PP, Delnoij DMJ. Wat zou Nederland zijn zonder de huisarts? (What would be the Netherlands without the general practitioner?) Utrecht: Elsevier/De Tijdstroom, 1997

Groenewegen PP, Leyland A. Multilevel modelling and public health policy. Scandinavian Journal of Public Health, 2003 (in press)

Groenewegen PP, Boerma WGW, Sawyer B. General Practitioners' use of time and time management, 2003. In: The Oxford Textbook of Primary Medical Care, 2003 (in press)

Grol R, De Maeseneer J, Whitfield M, Mokkink M. Disease-centered versus patientcentered attitudes: comparison of general practitioners in Belgium, Britain and the Netherlands. Family Practice, 1990; 7(2): p.100-103

Grol R, Wensing M, Mainz J, Ferreira P, Hearnshaw H, Hjortdahl P, Olesen F, Ribacke M, Spenser T, Szecsenyi J. Patients' priorities with respect to general practice care: an international comparison. Family Practice, 1999;16: p.4-11

Grol R, Wensing M, Mainz J, Jung HP, Ferreira P, Hearnshaw H, Hjortdahl P, Olesen F, Reis S, Ribacke M. Szecsenyi J. Patients in Europe evaluate general practice care: an international comparison. British Journal of General Practice, 2000; 50, p.882-887

Hall JA, Palmer RH, Orav EJ, Hargraves JL, Wright EA, Louis TA. Performance quality, gender and professional role: a study of physicians and non-physicians in 16 ambulatory care practices. Medical Care, 1990; 28: p.489-501

Hall JA, Irish JT, Roter DL, Ehrlich,CM, Miller LH. Gender in medical encounters: An analysis of physician and patient communication in a primary care setting. Health \& Psychology, 1994; 13: p.384-392

Hallam L. Primary medical care outside normal working hours: review of published work. British Medical Journal, 1994; 308: p.249-253

Hannay D. Usherwood T, Platts M. Workload of general practitioners before and after the new contract. British Medical Journal, 1992; 304: p.615-618

Hansen BL, Munck A. Out-of-hours service in Denmark: effect of a structural change. British Journal of General Practice, 1998; 48: p.1497-1499

Hart JT. The inverse care law. Lancet, 1971; 1: p.405-412 
Hastings A, Rashid A. General practice in deprived areas: problems and solutions. British Journal of General Practice, 1993; 43: p.47-48

Háva P. Key issues of health care reform in Czech republic. In: Szakal G, Balogh E, Bojan F (eds). Health care reforms in central and eastern European countries. Proceedings of the Annual Meeting of the European Public Health Association (EUPHA); 1995 Dec 14-16; Budapest. Debrecen: University Medical School, 1996; p.37-45

Havel M, Neumann-Oellerking D. Räumliche und zeitliche Erreichbarkeit hausärztlicher Leistung durch den Patienten - Eine Befragung in Dresden/Sachsen. (Accessibility in space and time of GP services by patients - a survey in Dresden/Saxony.) Gesundheitswesen, 1998; 60, p.136-142

Haynes R. Inequalities in health and health services use: evidence from the General Household Survey. Social Science \& Medicine, 1991; 33: p.361-368

Heyrman J, Lember M, Rousovich V, Dixon A. Changing professional roles in primary care delivery: training, re-accreditation, and the role of professional groups. In: Saltman R, Rico A, Boerma W (eds). Primary care in the driver's seat? Organizational reform in European primary care. Buckingham: Open University Press, 2003 (accepted for publication)

Hingstman L, Van der Velden LFJ. Behoefteraming Huisartsen 1997-2010. (Manpower planning General Practitioners 1997-2010.) Utrecht: NIVEL, 1998

Hjortdahl P, Borchgrevink CF. Continuity of care: influence of general practitioners' knowledge about their patients on use of resources in consultations. British Medical Journal, 1991; 303: p.1181-1184

Hobbs FD. General practitioners' changes to practice due to aggression at work. Family Practice, 1994; 11: p.75-79

Hooper J. Full-time women general practitioners - an invaluable asset. Journal of the Royal College of General Practitioners, 1989; 39: p.289-291

Horner RD, Samsa GP, Ricketts TC. Preliminary Evidence on Retention Rates of Primary Care Physicians in Rural and Urban Areas. Medical Care, 1993; 31: p.640-648

Howie JGR, Porter AM, Heaney DJ, Hopton J. Long to short consultation ratio: a proxy measure of quality of care for general practice. British Journal of General Practice, 1991; 41: p.48-54 
Howie JGR, Heany DJ, Maxwell M, Walker J, Freeman GK, Rai H. Quality at general practice consultations: cross sectional survey. British Medical Journal, 1999; 319: p.738-743

Hull FM. A day with the doctor. Update, 1978-1982; vol.17-24 (long series of country reports)

Hutten JBF. Workload and provision of care in general practice: an empirical study of the relation between the workload of Dutch general practitioners and the content and quality of their care. Utrecht: NIVEL, 1998 (thesis)

Iliffe S. Nursing and the future of primary care: handmaidens or agent for managed care. British Medical Journal, 2000; 320: p.1020-1021

Inwald AC. A comparison of self-referred patients to accident and emergency departments between an urban district a rural district. Journal of the Royal College of General Practitioners, 1980; 30: p.220-223

Jack B, Nagy Z, Varga Z. Health care reform in Central and Eastern Europe. European Journal of General Practice, 1997; 3(4): p.152-158

Jarman B. Identification of underprivileged areas. British Medical Journal, 1983; 286: p.1705-1709

Jeangros C, Hausser D. La population consultante en milieu ambulatoire. (The consulting population in the ambulatory environment.) Sozial- und Praeventivmedizin, 1990; 1: p. $24-33$

Jones K. Everywhere is nowhere: multilevel perspectives on the importance of place. Portsmouth: University of Portsmouth, 1993

Jones K, Gilbert P. Little J, Wilkinson K. Nurse triage for house call requests in a Tyneside general practice: patients' views and effect on doctor workload. British Journal of General Practice, 1998; 48: p.1303-1306

Jung HP, Wensing M, Grol R. What makes a good general practitioner: do patients and doctors have different views? British Journal of General Practice, 1997; 47: p.805-809

Keane D, Woodward CA, Ferrier BM, Cohen M, Goldsmith CH. Female and male physicians: different practice profiles. Canadian Family Physician, 1991; 37: p.72-81 
Kersnik J. Observational study of home visits in Slovene general practice: patient characteristics, practice characteristics and health care utilization. Family Practice, 2000; $17:$ p.389-393

Kirmayer LJ, Robbins JM, Dworkind M, Yaffe MJ. Somatization and the recognition of depression and anxiety in primary care. American Journal of Psychiatry, 1993; 150: p.734-741

Klazinga N. A better use of existing resources: managing the Quality of Structure, Process and Outcome of Health Care Systems. Journal of International Bioethics, 1996; $7(2)$ : p.90-93

Knottnerus JA, Joosten J, Daams J. Comparing the quality of referrals of general practitioners with high and average referral rates: an independent panel review. British Journal of General Practice, 1990; 40: p.178-181

Knottnerus JA. Role of the electronic patient record in the development of general practice in The Netherlands. Methods of Information in Medicine, 1999; 38(4-5): p. $350-354$

Kohn R, White KL. Health Care An International Study. Oxford: Oxford University Press, 1976

Kreuter MW, Strecher VJ, Harris R, Kobrin SC, Skinner CS. Are patients of women physicians screened more aggressively? Journal of General International Medicine, 1995: 10: p.119-125

Kroenke K, Spitzer RL, Williams JBW. Physical symptoms in primary care: predictors of psychiatric disorders and functional impairment. Archives of Family Medicine, $1994 ; 3:$ p.774-779

Kulu-Glasgow I, Delnoij D, De Bakker D. Self-referral in a gatekeeping system: patients' reason for skipping the general practitioner. Health Policy, 1998; 45: p.221-238

Lambert ML. Les jeunes généralistes dans une zone à densité médicale élévée: une observation à Bruxelles. (Young GPs in an area with high supply of doctors: an observation in Brussels.) Cahiers de Sociologie et de Démographie Médicales, 1998; 38: p.271-296 
Lattimer V, George S, Thompson F, Thomas E, Mullee M, Turnbull J, Smith H, Moore M, Bond H, Glasper A. Safety and effectiveness of nurse telephone consultation in out of hours primary care. British Medical Journal, 1998; 317: p.1054-1059

Leeuwenhorst Working Party. The General Practitioner in Europe. A statement by the working party appointed by the second European Conference on the Teaching of General Practice. Noordwijkerhout: Leeuwenhorst Netherlands, 1974

Le Grand J, Mays N, Mulligan JA (eds). Learning from the NHS internal market: a review of the evidence, London: King's Fund, 1998

Lorber J. Gender and the Social Construction of Illness. Thousand Oaks: Sage, 1997

Lucas V, Tonnelier F. Distance d'accès aux soins en 1990. (Distance to care in 1990.) Paris: CREDES, 1995

Lurie N, Slater J, McGovern P, Ekstrum J, Quam J, Margolis K. Preventive care for women. Does the sex of the physician matter. New England Journal of Medicine, 1993; 329: p. $478-482$

Lurie N, Margolis KL, McGovern PG, Mink PJ, Slater JS. Why do patients of female physicians have higher rates of breast and cervical cancer screening? Journal of General International Medicine, 1997; 12: p.34-43

Maarse JA, Mur-Veeman IM, Tijssen IM. Changing relations between hospitals and primary health care: new challenges for hospital management. International Journal Health Planning and Management, 1990; 1: p.53-57

Mackenbach JP, Kunst AE, Cavelaars AE, Groenhof F, Geurts JJ. Socioeconomic inequalities in morbidity and mortality in western Europe. The EU Working Group on Socioeconomic Inequalities in Health. Lancet, 1997; 349: p.1655-1659

Maheux B, Dufort F, Lambert J, Berthiaume M. Do female general practitioners have a distinctive type of medical practice? Canadian Medical Association Journal, 1988; 139: p.737-740

Maheux B, Dufort F, Lambert J, Béland F, Lévesque A, Dedobbeleer N. The professional attitudes and clinical practices of men and women generalist. Canadian Family Physician, 1989: 35: p.59-63 
Maheux B, Dufort F, Béland F, Jacques A, Lévesque A. Female medical practitioners. More preventive and patient oriented? Medical Care, 1990; 28: p.87-92

Majeed FA, Cook DG, Hilton S, Poloniecki J, Hagen A. Annual night visiting rates in 129 general practices in one family health services authority: association with patient and general practice characteristics. British Journal of General Practice, 1995; 45: p.531535

Marks JN, Goldberg DP, Hillier VF. Determinants of the ability of general practitioners to detect psychiatric illness. Psychological Medicine, 1979; 9: p.337-353

Marrée J, Groenewegen PP. Back to Bismarck: Eastern European health care systems in transition. Aldershot: Avebury, 1997

Marsh GN. Efficient care in general practice, or: How to look after even more patients. Oxford: Oxford University Press, 1991a

Marsh GN. Caring for larger lists. British Medical Journal, 1991b; 303: p.1312-1316

Martin J, Lehmann P. L'effet de cohorte "médecin-patients" dans la pratique ambulatoire: les visites à domicile dans deux cantons suisses. (Cohort effect 'doctor-patient' in the ambulatory practice: the home visits in two Swiss cantons.) Cahiers de Sociologie et de Démographie Médicales, 1986; 26(3): p.237-254

Mastilica M. Health care reform in Croatia. In: Szakal G, Balogh E, Bojan F (eds). Health care reforms in central and eastern European countries. Proceedings of the Annual Meeting of the European Public Health Association (EUPHA); 1995 Dec 14-16: Budapest. Debrecen: University Medical School, 1996; p.69-81

Maynard A, Bloor K. Primary care and health care reform: the need to reflect before reforming. Health Policy, 1995; 31(3): p.171-81. Review

McCormick A, Fleming D, Charlton J. Morbidity Statistics from General Practice, Fourth National Study 1991-1992. Office of Population Censuses and Surveys, Series MB5 no.3. London: HMSO, 1995

McKee M. Health services in central and eastern Europe: past problems and future prospects. Journal of Epidemiology and Community Health, 1991; 45: p.260-265

McKee M, Healy J (eds). Hospitals in a changing Europe. Buckingham: Open University Press, 2002a 
McKee M, Healy J, Falkingham, J. Health care in central Asia. Buckingham: Open University Press, 2002b

McPherson K. Strong PM, Epstein A et al. Regional variation in the use of common surgical procedures within and between England and Wales, Canada and the United States of America. Social Science \& Medicine, 1981; 15A: p.273-288

McPherson K, Wennberg JE, Hovind OB, Clifford P. Small-area variations in the use of common surgical procedures: an international comparison of New England, England and Norway. New England Journal of Medicine, 1982; 307(21): p.1310-1314

McPherson K. International differences in medical care practices. In: Organisation for Economic Co-operation and Development. Health care systems in transition (OECD Social Policy Studies No.7). Paris: OECD,1990

McWhinney IR. A Textbook of Family Medicine. New York: Oxford University Press, 1989

Mechanic D. Correlates of frustration among British general practitioners. Journal of Health and Social Behaviour, 1970; 11: p.87-104

Mechanic D. General Medical Practice: Some Comparisons between the Work of Primary Care Physicians in the United States and England and Wales. Medical Care, 1972; 10(5): p. $402-420$

Mechanic D. The organization of medical practice and practice orientations among physicians in prepaid and non-prepaid primary care settings. Medical Care, 1975; 13: p.189-204

Mechanic D. How should hamsters run? Some observations about sufficient time in primary care. British Medical Journal, 2001; 323: p.266-268

Metsemakers JF, Knottnerus JA, van Schendel GJ, Kocken RJ, Limonard CB. Unlocking patients' records in general practice for research, medical education and quality assurance: the Registration Network Family Practices. International Journal of Biomedical Computing, 1996; 42: p.43-50

Morrison I, Smith R. Hamster health care: time to stop running faster and redesign health care. British Medical Journal, 2000; 321: p.1541-1542 
Mossialos E, Dixon A, Figueras J, Kutzin J (eds). Funding Health care: options for Europe. Buckingham: Open University Press, 2002

Nakar S, Vinker S, Weingarten M. The place of home visiting in family practice: a multicentre comparison between rural and urban physicians. British Journal of General Practice, 1999; 49: 621-625

Nyman JA, Sen A, Chan BY, Commins PP. Urban/rural differences in home health patients and services. Gerontologist, 1991; 31: p.457-466

OECD. The reform of health care: A comparative analysis of seven OECD countries. Paris: OECD, 1992

OECD. The reform of health care systems: a review of seventeen countries. Paris: OECD, 1994

Øiesvold T, Sandlund M, Hansson L, Christiansen L, Göstas G, Lindhardt A, Saarento O, Sytema S, Zandrén T. Factors associated with referral to psychiatric care by general practitioners compared with self-referrals. Psychological Medicine, 1998; 28: p.427436

Okkes IM, Polderman GO, Fryer GE, Yamada T, Bujak M, Oskam SK, Green LA, Lamberts H. The Role of Family Practice in Different Health Care Systems: a Comparison of Reasons for Encounter, Diagnoses and Interventions in Primary Care Populations in the Netherlands, Japan, Poland and the United States. The Journal of Family Practice, 2002; 51: p.72

Olesen F, Jolleys JV. Out-of-hours service: the Danish solution examined. British Medical Journal, 1994; 309: p.1624-1626

Olesen F, Jensen PB, Grinsted P. Henriksen JS. General Practitioners as advisers and coordinators in hospitals. Quality in Health Care, 1998; 7: p.42-47

Olesen F. Do we need a definition of general practice/family medicine? European Journal of General Practice, 2002; 8: p.138-139

Olfson M. Primary care patients who refuse specialized mental health services. Archives of Internal Medicine, 1991; 151: p.129-132 
Orosz E. Main challenges for health policy in a period of socio-economic transformation in Hungary. In: Szakal G, Balogh E, Bojan F (eds). Health care reforms in Central and Eastern European countries. Proceedings of the Annual Meeting of the European Public Health Association (EUPHA); 1995 Dec 14-16; Budapest. Debrecen: University Medical School, 1996; p.113-123

Osborne EH, Bird JA, McPhee SJ, Rodnick JE, Fordham D. Cancer screening by primary care physicians. Can we explain the differences? Journal of Family Practice, 1991; 32: p. $465-471$

Parmelee DE. Yugoslavia: health care under self-managing socialism. In: Field MG (ed). Success and crisis in national health systems: a comparative approach. New York/London: Routledge, 1989; p.165-191

Pathman DE, Konrad TR, Ricketts TC. The Comparative Retention of National Health Service Corps and other Rural Physicians. Journal of the American Medical Association, 1992; 268; p.1552-1558

Plogh T, Klazinga NS. Community-based integrated care: myth or must? International Journal for Quality in Health Care, 2002; 14(2): p.91-101

Politzer RM, Harris DL, Gaston MH, Mullan F. Primary Care Physician Supply and the Medically Underserved. Journal of the American Medical Association, 1991; 266: p.104-109

Post D, Mokkink HGA, Van Ree CM, Gubbels J. Verwijzen en voorschrijven in de stad en op het platteland: een onderzoek naar regionale verschillen in medische consumptie in vijf regio's. (Referring and prescribing in the city and in the countryside: a study of regional differences in medical consumption in five regions.) Tijdschrift voor Sociale Gezondheidszorg, 1991; 69: p.101-106

Posthuma BH, Van der Zee J. Tussen eerste en tweede echelon, deel I. (Between first and second echelon, part 1.) Utrecht: Nederlands Huisartsen Instituut (NHI), 1977

Preker AS. Global development challenges and health care reform. World Hospital Health Services, $2001 ; 37(3)$ : p.2-8, p.40-42

Preker AS, Jakab M, Schneider M. Health financing reforms in central and eastern Europe and the former Soviet Union. In: Mossialos E, Dixon A, Figueras J, Kutzin J (eds). Funding Health care: options for Europe. Buckingham: Open University Press, 2002 
Pumain D, Saint-Julien T, Cattan N, Rozenblatt C. The statistical concept of the town in Europe. Luxembourg: European Communities (EUROSTAT), 1992

Raffel NK. USSR. In: Raffel MW (ed). Comparative health systems: descriptive analyses of fourteen national health systems. University Park/London: Pennsylvania State University Press, 1984

Rasbash J, Woodhouse G. MLn command reference. London: Institute of Education, University of London, 1995

Rasbash J, Browne W, Goldstein H, Yang M, Plewis I, Healy M, Woodhouse G, Draper D, Langford I, Lewis T. A user's guide to MLwiN. London: University of London, 2000

Regier DA, Goldberg ID, Burns BJ, Hankin J, Hoeper EW, Nycz GR. Specialist/generalist division of responsibility for patients with mental disorders. Archives of General Psychiatry, 1982; 39: p.219-224

Reid SE, Simpson JM, Britt HC. Pap smears in general practice. A secondary analysis of the Australian Morbidity and Treatment Survey 1990 to 1993. Australian and New Zealand Journal of Pubic Health, 1997; 21: p.257-264

Rice N, Leyland A. Multilevel models: applications to health data. Journal of Health Services Research and Policy, 1996; 3: p.154-164

Richardson G, Maynard A, Cullum N, Kindig D. Skill mix changes: substitution or service development? Health Policy, 1998; 45: p.119-132

Ridsdale L, Carruthers M, Morris R, Ridsdale J. Study of the effect of time availability on the consultation. Journal of the Royal College of General Practitioners, 1989; 39 : p. $488-491$

Roemer MI. National health systems of the world. Volume I: the countries. New York/Oxford: Oxford University Press, 1991

Roland MO, Bartholomew J. Courtenay MJF et al. The 'five minute' consultation: effect of time constraint on verbal communication. British Medical Journal, 1986; 292: p. 874-876

Roter D, Lipkin S, Kortgaard A. Sex differences in patients' and physicians' communication during primary care visits. Medical Care, 1991; 29(11): p.1083-1093 
Ryan M. The organization of Soviet medical care. Oxford: Blackwell, 1978

Salisbury C, Dale J, Hallam L (eds). 24-hour primary care. Abingdon: Radcliff Medical Press, 1999

Salisbury C. Out-of-hours care: ensuring accessible high quality care for all groups of patients. British Journal of General Practice, 2000; 50: p.443-444

Salisbury C, Trivella M, Bruster S. Demand for and supply of out of hours care from general practitioners in England and Scotland: observational study based on routinely collected data. British Medical Journal, 2000; 320: p.618-621

Saltman RB, Figueras J. European health care reform: analysis of current strategies. Copenhagen: WHO Regional Office for Europe, 1997

Saltman R, Rico A, Boerma W (eds). Primary care in the driver's seat? Organizational reform in European primary care. Buckingham: Open University Press (forthcoming, 2003)

Sanders D. Variations in hospital admission rates: a review of the literature. Oxford: University of Oxford, Department of Community Medicine and general Practice, 1988

Sandier S. Health Services Utilization and Physician Income Trends. Health care Financing Review, 1989; Annual Supplement: p.33-48

Sandier S. Les quinze premières années d'activité des généralistes libéraux 1973-1993. (The first 14 years of activities of independent GPs.) Biblio no.1112. Paris: CREDES, 1996

Schneider M, Hofman U, Jumel S, Köse A. Beschäftigungsunterschiede in ausgewählten Gesundheitssystemen in der EU. (Employment differences in selected health care systems in the EU.) Augsburg: BASYS, 2002

Schrijvers AJP (ed). Health and Health Care in the Netherlands. A critical self-assessment of Dutch experts in medical and health sciences. Utrecht: De Tijdstroom, 1997

Schulberg HC. Ambulatory mental health liaison research: A review and preview. General Hospital Psychiatry, 1987; 9: p.126-134

Schurman RA, Kramer PD, Mitchell JB. The hidden mental Health Network. Archives of General Psychiatry, 1985; 42: p.89-94 
Scott A, Vale L. Increased general practice workload due to a primary care led National Health Service: the need for evidence to support rhetoric. British Journal of General Practice, 1998; 48: p.1085-1088

Sheaff R. What is 'Primary' about Primary Health Care? Health Care Analysis, 1998; 6: p. $330-340$

Shi L, Starfield B, Politzer R, Regan J. Primary care, self-rated health, and reductions in social disparities in health. Health Services Research, 2002; 37(3): p.529-550

Sixma HJ. Hospital or general practice? Results of two experiments limiting the number of self-referrals of patients with injuries to hospitals in The Netherlands. Journal of Accident and Emergency Medicine, 1996; 13: p.264-268

Snijders T, Bosker R. Multi-level analysis. An introduction to basic and advanced multilevel modeling. London: Sage Publications, 1999

Sobrequés J, Bolibar B, Unzueta L, Prados JD, Leiva F, Boerma W. Variaciones en la aplicación de técnicas médicas en atención primaria. (Variations in the application of medical techniques in primary health care.) Gaceta Sanitaria, 2002; 16(6): p.497-504

SPSS Inc. SPSS Users' Guide, 2nd edition. Chicago: SPSS, 1986

Starfield B. Primary Care: concept, evaluation and policy. New York: Oxford University Press, 1992

Starfield B. Is primary care essential? Lancet, 1994; 344: p.1129-1133

Starfield B. Is strong primary care good for health outcomes? In: Griffin J (ed). The future of primary care. London: Office of Health Economics, 1996

Starfield B. Primary Care. Balancing Health Needs, Services, and Technology. New York/Oxford: Oxford University Press, 1998

Stephen WJ. An analysis of primary medical care: an international study. Cambridge: Cambridge University Press, 1979

Szatmári M. De plaats van de huisarts in de Hongaarse gezondheidszorg. (The position of the family physician in Hungarian health care.) Medisch Contact, 1984; (4): p.117120 
Talbott RJ. Underprivileged areas and health care planning: implications of use of Jarman indicators of urban deprivation. British Medical Journal, 1991; 302: p.383-386

Temmink D. Transmural clinics: a nursing innovation explored. Utrecht: NIVEL, 2000 (thesis)

Ten Zijthoff P, Verheij RA, De Bakker DH. Urban rural variations in health and health services utilization: an annotated bibliography. Utrecht: NIVEL, Bibliography nr. 50 . 1994

Thies-Zajonc S, Sandholzer H, Szecsenyi J, Kochen M. Primärärztliche Versorgung alter Patienten; Stellenwert der Hausbesuchs- und Überweisungstätigkeit. (Primary medical care to older patients; the importance of home visiting and referrals.) Zeitschrift für Allgemeinmedizin, 1993; 69: p.187-191

Üstün TB, Sartorius N. Mental illness in general health care. An international study. Chichester: John Wiley \& sons, 1995

Van de Lisdonk EH, Schellevis FG. Interdoktervariatie en de kwaliteit van verwijzen: een literatuuronderzoek. (Interdoctor variation and the quality of referrals: a study of the literature.) Huisarts en Wetenschap, 1994; 37(13): p.573-578

Van den Brink-Muinen A, De Bakker DH. Consultations for women's health problems: factors influencing women's choice of sex of general practitioner. British Journal of General Practice, 1994; 44: p.205-210

Van den Brink-Muinen A. Gender, health and health care in general practice. Utrecht: NIVEL, 1996 (thesis)

Van den Brink-Muinen A. Women's health care: for whom and why? Social Science \& Medicine, 1997; 44(10): p.1541-1551

Van den Brink-Muinen A, Bensing JM, Kerssens JJ. Gender and communication style in general practice. Differences between women's health care and regular health care. Medical Care, 1998; 36: p.100-106

Van den Brink-Muinen A, Verhaak PF, Bensing JM, Bahrs O, Deveugele M, Gask L, Leiva F, Mead N, Messerli V, Oppizzi L, Peltenburg M, Perez A. Doctor-patient communication in different European health care systems: relevance and performance from the patients' perspective. Patient Education and Counseling, 2000; 39(1): p.115-127 
Van der Linden BA. Transmural care. Facts and future. In: Schrijvers AJP (ed). Health and Health Care in the Netherlands. A critical self-assessment of Dutch experts in medical and health sciences. Utrecht: De Tijdstroom, 1997

Van der Velden J, De Bakker DH. Claessens AAMC, Schellevis FG. Dutch National Survey of General Practice. Morbidity in general practice. Utrecht: NIVEL, 1992.

Van der Velden J, Rasch P, Reijneveld SA. Identificatie van achterstandsgebieden: een systematiek voor de verdeling van extra middelen aan huisartsen. (Identification of underprivileged areas: a method for resource allocation to general practitioners.) Nederlands Tijdschrift voor Geneeskunde, 1997; 141: p.693-697

Van der Velden J. General Practice at work. Its contribution to epidemiology and health policy. Utrecht: NIVEL, 1999 (thesis)

Van der Velden LFJ, Hingstman L, Van der Windt W, Arnold EJE. Raming benodigde instroom per medische en tandheelkundige vervolgopleiding, 2002-2012/2017/2020. (Forecasting of required influx from medical and dental postgraduate training, 20022012/2017/2020.) Utrecht: NIVEL, 2002

Van der Zee J, Groenewegen PP, Gloerich ABM, Lebrun Th, Sailly JC, Verhasselt M, Leroy X. Determinants of regional variations in hospital admission rates: the case of the Low Countries and the north of France. International Journal of Health Sciences, $1990 ; 1(4):$ p. $257-270$

Van der Zee J, Boerma WGW, Kroneman MW. An overview of health care systems and primary care systems. In: Oxford Textbook of Primary Medical Care, 2003 (in press)

Van Dierendonck D, Groenewegen PP, Sixma H. Opgebrand. Een inventariserend onderzoek naar gevoelens van motivatie en demotivatie bij huisartsen. (Burned out. An inventory of feelings of motivation and demotivation with GPs) Utrecht: NIVEL, 1992

Van Weel C. International research and the discipline of family medicine. European Journal of General Practice, 1999; 5: p.110-115

Vayda E. A comparison of surgical rates in Canada and in England and Wales. New England Journal of Medicine, 1978; 289: p.1224-1229

Vehvilaeinen AT, Kumpusalo EA, Takala JK. A list system can help to reduce the proportion of out of hours referrals for male patients. Scandinavian Journal of Primary Health Care, 1996; 14: p.148-151 
Venning P, Durie A, Roland M, Roberts C, Leese B. Randomised controlled trial comparing cost effectiveness of general practitioners and nurse practitioners in primary care. British Medical Journal, 2000; 320: p.1048-1053

Verhaak PFM. Variations in the diagnosis of psychosocial disorders: a general practice observation study. Social Science \& Medicine, 1986; 23: p.595-604

Verhaak PFM. Mental disorder in the community and primary care. Aldershot: Avebury. 1995 a

Verhaak PFM. Determinants of the help-seeking process: Goldberg and Huxley's first level and first filter. Psychological Medicine, 1995b: 25: p.95-104

Verheij RA, De Bakker DH, Van der Velden J. De huisarts in de grote stad. (The general practitioner in the big city.) Utrecht: NIVEL, 1992

Verheij RA, De Bakker D. A critical review of the literature on urban-rural differences in health and health services utilisation. In: Ten Zijthof et al. (eds). Urban and rural variations in health and health services utilisation: an annotated bibliography. Utrecht: NIVEL, 1994

Verheij RA, Explaining urban-rural variations in health: a review of interactions between individual and environment. Social Science \& Medicine, 1996; 42: p.923-935

Vienonen MA, Wlodarczyk WC. Health care reforms on the European scene: evolution, revolution or seesaw? World Health Statistics Quarterly, 1993; (46): p.166-169

Visser J. Nederlandse steun aan huisartsen in Hongarije. (Dutch support to family physicians in Hungary.) De Huisarts in Nederland, 1995; 1: p.28-30

Vohlonen I, Pekurinen M, Saltman RB. Re-organizing primary medical care in Finland: the personal doctor program. Health Policy, 1989; 18: p.65-79

Weide MG, Foets M. Migranten in de huisartspraktijk: andere klachten en diagnosen dan Nederlanders. [Migrants in family practice: their symptoms and diagnoses differ from the Dutch]. Nederlands Tijdschrift voor Geneeskunde, 1998; 142(38): p.2105-2109

Weiner J, Gillam S, Lewis R. Organization and financing of British primary care groups and trusts: observations through the prism of US managed care. Journal of Health Services Research and Policy, 2002; 1: p.43-50 
Whewell J, Marsh G, McNay RA. Changing patterns of home visiting in the North of England. British Medical Journal, 1983; 286: p.1259-1261

Whynes DK, Baines DL. Explaining variations in the frequency of night visits in general practice. Family Practice, 1996a; 13: p.174-178

Whynes D, Baines DL. Predicting activity and workload in general practice from the demographic structure of the practice population. Journal of Health Services Research and Policy, 1996b; 1: p.128-134

Wijkel D. Lower referral rates for integrated health centres in the Netherlands. Health Policy, 1986; 2: p.185-198

Wilkin D, Smith A. Explaining Variation in General Practitioner Referrals to Hospital. Family Practice, 1987; 4: p.160-169

Wilkin D, Hallam L, Leavy R, Metcalfe D. Anatomy of Urban General Practice. London/New York: Tavistock Publications, 1987

WONCA. The Role of the General Practitioner/Family Physician in Health Care Systems; A Statement from the World Organization of National Colleges, Academies and Academic Associations of General Practitioners/Family Physicians. Victoria: WONCA, 1991

WONCA. The European definition of general practice/family medicine. WONCA Europe, 2002

Woodhouse G (ed). A guide to MLn for new users. London: University of London, Institute of Education, 1995

World Health Organisation. Targets for health for all. The health policy for Europe. Summary of the updated edition, September 1991. Copenhagen: WHO Regional Office for Europe, 1992

Zarkovic G, Satzinger W. Politics and foreign involvement in reforming the health care systems of former socialist countries. In: Altenstetter C, Björkman JW (eds). Health policy reform, national variations and globalization. Basingstoke: Macmillan Press, 1997: p.255-278 


\section{Appendix 1 \\ Local coordinators of the study}

Austria, Gerhard Holler (Vienna); Belgium, Leo Pas (Berchem), Dominique-Jean Bouilliez (Nalinnes); Bulgaria, Petko Salchev (Sofia); Croatia, Zelimir Jaksic, Hrvoje Tiljak (Zagreb); Czech Republic, Jan Jaros, Jan Hartl (Prague); Denmark, Frede Olesen (Aarhus), Lone Bak (Galten); Germany, Ingbert Weber (Cologne); Estonia, Margus Lember (Tartu); Finland, Elise Kosunen (Tampere); France, Claude Diaz (Paris); Greece, Yannis Kyriopoulos (Athens); Hungary, Ivan Forgacs (Budapest); Iceland, Hjalti Kristjansson (Vestmannaeyar); Ireland, Brendan O'Shea (Newbridge, Co.Kildare); Israel, John Yaphe (D.N.Shimshon), Revital Gross, Dan Yuval (Jerusalem); Italy, Gianluigi Passerini (Sondrio), Davide Lauri (Milan); Latvia, Uldis Bruveris (Riga); Lithuania, Irena Miseviciene (Kaunas); Luxembourg, Romain Stein (Luxembourg), Guy Meisch (Esch-sur-Alzette); Netherlands, Jouke van der Zee, Peter Groenewegen (Utrecht); Norway, Knut Holtedahl (Tromso); Poland, Wlodzimierz Sapinski, Anna Salacinska (Lodz); Portugal, Zaida Azeredo (Porto); Romania, Adrian Restian, Cristian Oana (Bucharest); Slovenia, Igor Svab (Ljubljana); Spain, Bonaventura Bolibar (Barcelona), Daniel Prados Torres (Malaga), Lourdes Unzueta (Bilbao); Sweden, Christine Nerbrand (Lund), Kerstin EinevikBäckstrand (Stockholm); Switzerland, Daniel Berger, Bernhard Güntert (St.Gallen); Turkey, Niyazi Cakmak (Ankara); United Kingdom, Derek Barford, Douglas Fleming (Birmingham). 

Appendix 2
Questionnaire
(English language version; scaled down) 
1.1 In what year were you born?

1.2 Are you a man or a woman? year of birth: 19

man

woman

1.3 Are you self-employed or in salaried employment? If you have more than one paid position the one with the higher number of hours is the main position, while the other one is the additional position (other additional positions may be disregarded).

my main position is: salaried employment

self-employed with contract(s) with health service or insurance a self-employed without contract

my additional position is:

$\square$ not applicable (only one paid position)
$\square$ salaried employment
$\square$ self-employed with contract(s) to health service or insurance
$\square$ self-employed without contract

1.4 How many hours do you normally spend working in this (these) position(s) per week? (estimate averages for regular services and emergency and on-call duty)

working hours in main position:

$\square$ in regular services emergency/on call

working hours in additional position: hours per week hours per week hours per week hours per week

1.5 Please estimate the average number of hours per month spent on "keeping-up-to-date" (reading professional journals, doing post-graduate courses, scientific work, etc.):

for keeping up-to-date hours per month (average)

1.6 What is the total number of inhabitants of the city, town or village in which your (main) practice location is situated?

the number of inhabitants is (approximately)

1.7 Your (main) practice location can be characterised as:
$\square$ urban (innercity)
$\square$ urban (smaller town)
$\square$ suburban/outskirts
mixed urban-rural
rural 
1.8 Have you done vocational training in a recognised programme to become a specialist in family medicine or general practitioner in addition to your basic medical training?

no such training in this country

no, I have not had this training

yes, this training was finished in 19 and it took years (fill in)

yes, I am still in training

1.9 When did you start working as a doctor and when as a GP (not: trainee)?

I started working as a doctor in the year 19

I started working as a GP in the year 19

1.10 What is the distance by road from your (main) practice building to the nearest general practitioner (not in your partnership, health centre etc.), the nearest consultant outpatient clinic and the nearest general or university hospital (not psychiatric, convalescent etc.)

Distance to:

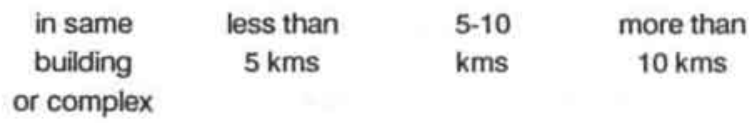

- nearest general practitioner

(not in partnership etc.)

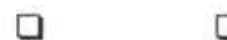

$\square$

口

口_ $\mathrm{kms}$ (fill in)

- nearest consultant outpatient

clinic (part of hospital or

independent)

ロ ロ ロ

$\square$ kms (fill in)

- nearest general/university

hospital

口 kms (fill in)

1.11 Do you work alone or in a shared accommodation with one or more other general practitioners and/or medical specialists:

alone

with other GPs in shared accommodation, namely GPs (fill in number)

with medical specialist(s) in shared accommodation, namely specialists (fill in number)

with both GPs and medical specialists in shared accommodation; their total number is:

(fill in number)

1.12 What is approximately the size of your practice population?

This may be the number on your formal patient list. If you do not have a formal list please estimate the number of people that normally rely on you for primary medical care. If your practice population is a mix of both, please fill in both lines. (in partnership or group: estimate the number that should be allocated to you)

- number of patients on the list

- number of patients not on a list 
1.13 Please estimate the average number of face-to-face contacts with patients, in the office or surgery, and during home and hospital visits:

- in your office/surgery per day (number)

- during home visits per week (number)

- during hospital visits per week (number)

1.14 What is the average number of telephone calls per day involving consultations by or advice to patients?

- telephone consultations/advice per day (number)

1.15 To what extent do you work with an appointment scheme? ('Appointment' meaning a consultation that has been arranged in advance, e.g. by telephone)

no appointments (walk-in system)

less than half of non-acute cases by appointment

more than half of non-acute cases by appointment

(almost) all non-acute cases by appointment

1.16 What is the time usually allocated per patient in your appointment system? (The actual time spent with patients may be longer or shorter):

$\square$ not applicable (no appointments)

usually minutes per patient

varies (dependent on patient's complaint, insurance mode etc.)

1.17 How long does a non-acute patient normally have to wait for the consultation after having made the appointment?

not applicable (no appointments)

consultation is usually the same day

usually the next day

usually 2 to 6 days of waiting

usually 1 to 2 weeks of waiting

usually more than 2 weeks of waiting

1.18 Please tick to what extent your practice population deviates from the average national level with respect to the following categories:

$\underset{\text { avelow }}{\text { belage }}$ average $\underset{\text { average }}{\text { above }}$ do not know

- children under 6

- elderly people (over 70 years)

- socially deprived people

- immigrants 
1.19 Are you (alone or together with some colleagues) assisted by staff working as listed below?

- receptionist/med. secretary/general assistant

- practice nurse

$\begin{array}{ll}\square \text { yes } & \square \text { no } \\ \square \text { yes } & \square \text { no } \\ \square \text { yes } & \square \text { no }\end{array}$

- any assistant for laboratory work

1.20 How often do you have face-to-face meetings/discussions with the following professions:

$\begin{array}{ccccc}\text { seldom/ } & \text { less than } & \text { every } & \text { more } & \begin{array}{c}\text { not } \\ \text { never }\end{array} \\ & 3 \text { times } & 1-3 & \text { than once } & \text { applicable } \\ & \text { a year } & \text { months } & \text { a month } & \text {. }\end{array}$

- other GPs/primary care doctor(s)

- ambulatory med. specialist(s)

- hospital med. specialist(s)

- pharmacist(s)

- primary care/home care nurse(s)

- practice nurse(s)

- social worker(s)

1.21 Who is responsible for emergency service during your off-duty hours?

no specific emergency service

$\square$ you are (almost) always on duty for emergency service

$\square$ a group of GPs on a rota basis (you are one of them)

$\square$ a group of GPs on a rota basis (you are not one of them)

$\square$ one or more doctors (not GPs); you retain overall responsibility (you are not one of them; e.g. locum service)

$\square$ emergency services are not your responsibility (seperately organised)

another arrangement

1.22 Please tick the equipment being used on site in your practice by yourself or your staff:
laboratory
$\square$ hemoglobinometer
any cholesterol meter
any blood glucose test set
imaging
ophthalmoscope
$\square$ proctoscope
$\square$ sigmoidoscope

\section{functions}
$\square$ gastroscope
ultrasound for abdomen/fetus
microscope
$\square$ otoscope
口 X-ray
$\square$ audiometer
peak flow meter
$\square$ blood pressure meter
$\square$ bicycle ergometer
spirograph
eye tonometer
- electrocardiograph
other
$\square$ urine catheter
a suture set
coagulometer
D defibrillator
set for minor surgery
disposable syringes

$\square$
$\square$
$\square$
$\square$
$\square$
$\square$
$\square$

$\square$
$\square$
$\square$
$\square$
$\square$
$\square$
$\square$ 
1.23 Do you have direct access to laboratory and X-ray facilities (not in your practice) with quick report of results (within 48 hours)?
direct access
no direct access
not applicable

- laboratory facilities

- X-ray

1.24 Are you routinely keeping medical records of patients?
no
yes, only for regularly attending patients
yes, for (almost) all patients

1.25 If a computer is at your disposal, for which purposes is it being used in your practice (more than one answer possible):

not applicable (no computer)

$\square$ administratior/billing etc.

making appointments

$\square$ recording drug prescriptions

$\square$ keeping patients records

research/audit

$\square$ other purposes 


\section{APPLICATION OF MEDICAL TECHNIQUES}

To what extent are the following activities carried out in your practice population by you (or your staff) or by a medical specialist? (Practice population means: people normally applying to you for primary medical care). For example, if wedge resections are (almost) always done by you, tick the appropriate box. If medical specialists (also) carry out this service for your practice population tick another appropriate box and list one or two relevant specialties.

Activities
Procedure carried out by me

(or my staff):

(almost) usually occasion- seldom/

always ally
Which specialties (also) do the procedure?

(list 1 or 2 of them, if applicable)

2.1 Wedge resection of ingrowing toenail

2.2 Removal of sebaceous cyst from the hairy scalp

2.3 Wound suturing

2.4 Excision of warts

2.5 Insertion of IUD

2.6 Removal of rusty spot from cornea

2.7 Fundoscopy

2.8 Joint injection

2.9 Maxillary (sinus) puncture

2.10 Myringotomy of eardrum (paracentesis)

2.11 Applying a plaster cast

2.12 Strapping an ankle

2.13 Cryotherapy (warts)

2.14 Setting up an intravenous infusion

ロ ロ ロ ロ

$\square$

$\square$

$\square$

口

$\square$

口

$\square$

$\square$

$\square$

口

$\square$

$\square$

$\square$

$\square$

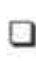

$\square$

$\square$

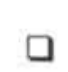

$\square$

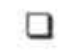

$\square$

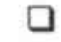

口
1

I

I

I

1

I

I

1

I

1

I

1

1

1 


\section{FIRST CONTACT WITH HEALTH PROBLEMS}

To what extent will patients in your practice population (people who normally apply to you for primary medical care) have you as the doctor of first contact for the following health problems? (exclude purely administrative contacts). This is only about the first contact, not about a possible referral for further diagnosis or treatment. If medical specialists are (also) doctors of first contact for patients in your practice population tick the appropriate box and list one or two of these specialties.

Health problems
For these problems I am the doctor of first contact:

(almost) usually occasion- seldom/ always

ally never

Which specialties (also) have the first contact (please fill in) (list 1 or 2 of them, if applicable)

\subsection{Child with a rash}

3.2 Child with severe cough

3.3 Child aged 7 with enuresis

3.4 Child aged 8 with hearing problem

3.5 Woman aged 18 asking for oral contraception

3.6 Woman aged 20 for confirmation of pregnancy

3.7 Woman aged 35 with irregular menstruation

3.8 Man aged 24 with stomach pain

3.9 Man aged 45 with chest pain

3.10 Man aged 50 who burnt his hand

3.11 Man aged 50 with acute toothache

3.12 Woman aged 50 with a lump in her breast

3.13 Woman aged 60 with deteriorating vision
1

1

1

1

I

1

I

I

I

1

1

I 
Health problems
For these problems I am the doctor of first contact:
Which specialties (also) have the first contact (please fill in) (list 1 or 2 of them, if applicable)

(almost) usually occasion- seldom/

always ally never

3.14 Woman aged 60 with polyuria

3.15 Woman aged 60 with acute symptoms of paralysis/paresis

3.16 Man aged 70 with joint pain

3.17 Woman aged 75 with moderate memory problems

3.18 Man aged 35 with sprained ankle

3.19 Man aged 29 with lower back pain

3.20 Man aged 28 with a first convulsion

3.21 Anxious man aged 45

3.22 Physically abused child aged 13

3.23 Couple with relationship problems

3.24 Man with suicidal inclinations

3.25 Woman aged 50 with psychosocial problems related to her work

3.26 Man aged 32 with sexual problems

3.27 Man aged 52 with alcohol addiction problems $\square \square$

$\square$

$\square$ 1 I I 1 I 1 I I I 1 1 1 I. 1 


\section{PREVENTIVE MEDICINE AND OTHER PROCEDURES}

4.1 When do you, or your staff, measure blood pressure? (more than one answer possible)

in connection with relevant clinical conditions or on request

$\square$ routinely in surgery contacts with adults (regardless the reason for visit)

$\square$ in adults when invited for this purpose

4.2 When do you, or your staft, measure blood cholesterol level? (more than one answer possible)

$\square$ in connection with relevant clinical conditions or on request

routinely in surgery contacts with adults (regardless the reason for visit)

in adults when invited for this purpose

no such measures

4.3 When do you, or your staft, carry out cervical smears for cancer screening? (more than one answer possible)

$\square$ in connection with relevant clinical conditions or on request

routinely in surgery contacts in at risk females

in women when invited for this purpose

$\square$ no such screening

4.4 When is manual examination for breast cancer screening performed by you or your staff? (more than one answer possible)

$\square$ in connection with relevant clinical conditions or on request

routinely in surgery contacts in at risk females

in women when invited for this purpose

no such screening

4.5 To what extent are you involved in health education as regards smoking, eating and drinking habits?

not involved

- smoking

- eating

- drinking only in connection

with normal

patient contacts also in special

group sessions or programmes

4.6 Are you involved in the following activities?

involved

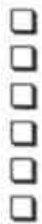

not involved

- intrapartum care

- routine antenatal care

- immunisation programme for children

- paediatric surveillance of children under 4

- family planning/contraception

- homoeopathic medicine 


\section{DISEASE MANAGEMENT}

To what extent are you involved in the treatment and follow-up of patients in your practice population with the following diagnosis ("practice population" means: people who normally apply to you for primary medical care)? For example, if you (almost) always manage chronic bronchitis in your practice population tick the appropriate box. If medical specialists are also involved tick another box and list one or two relevant specialties.

Diseases
Treatment/follow-up done by me:
Which specialties are (also) treating? (list 1 or 2 of them, if applicable)

(almost) usually occasion-
always $\begin{gathered}\text { ally } \\ \text { neldom/ } \\ \text { never }\end{gathered}$

5.1 Hyperthyroidism

5.2 Chronic bronchitis

5.3 Hordeolum (Stye)

5.4 Peptic ulcer

5.5 Herniated disc lesion

5.6 Acute cerebrovascular accident

5.7 Congestive heart failure

5.8 Pneumonia

5.9 Peritonsilar abscess

5.10 Ulcerative colitis

5.11 Salpingitis

5.12 Concussion of brain

5.13 Parkinson's disease

5.14 Uncomplicated diabetes type II

5.15 Rheumatoid arthritis

5.16 Depression

5.17 Myocardial infarction $\square$

$\square$

$\square$

$\square$

$\square$

$\square$

$\square$

$\square$

$\square$

$\square$

$\square$

$\square$

$\square$

$\square$

$\square$

$\square$

口

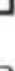

西

口

$\square$

$\square$

$\square$

$\square$

口 $\square$

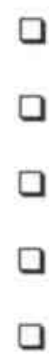

$\square$

$\square$

$\square$

口

$\square$

$\square$

$\square$

口

口

$\square$

$\square$

$\square$

$\square$

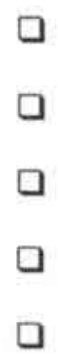

$\square$

$\square$

$\square$

$\square$

$\square$

$\square$

$\square$
曰

I

1

1

1 


\section{JOB SATISFACTION}

To what extent do you agree with the following expressions regarding your job satisfaction?

\begin{tabular}{lccc}
\hline agree & $\begin{array}{c}\text { agree } \\
\text { strongly }\end{array}$ & $\begin{array}{c}\text { nore or } \\
\text { less }\end{array}$ & $\begin{array}{c}\text { disagree } \\
\text { more or } \\
\text { less }\end{array}$ \\
\hline
\end{tabular}

6.1 I feel that some parts of my work do not really make sense

6.2 My work still interests me as much as it ever did

6.3 My work is overloaded with unnecessary administrative detail

6.4 Assuming that pay and conditions were similar I would just as soon do non-medical work

6.5 I find real enjoyment in my work

6.6 In my work there is a good correspondence between effort and reward

6.7 My work involves a great deal of wasted effort on my part

Thank you very much for your effort.

(please do not forget to keep the activities diary) 



\section{Acknowledgement}

As readers of this book will quickly have realized, this thesis is not the work of one individual. In fact, there probably would not have been a thesis at all without the help of many people and organisations. The European Commission supplied most of the funds for this international study and the WHO Regional Office gave essential support and used the results. The challenging tasks of instrument development and the implementation of this study in so many countries have been completed successfully with substantial assistance from the dedicated local coordinators. Where scientific output is concerned, I would like to express my sincere gratitude to the co-authors and other colleagues, both as researchers and in auxiliary functions, whose collaboration made it possible to establish this outcome. Looking back at the study reported in this book, I can only say that it has been a congenial and instructive period.

This book is dedicated to a collective where I have now been working for exactly 25 years. Nowadays, NIVEL by no means resembles the small, informal, pioneering organisation of 1978 , although it does continue to be a positive critical environment staffed with relatively independent professionals, who nevertheless have a positive mutual commitment. On each of the few occasions when I could have moved, I still decided to stay. NIVEL seems to offer me the right external conditions that enable me to continue to work with motivation. Among the many people who make up the institute, two must be mentioned within the context of this dissertation, and not just because of their role in this event. They are Jouke van der Zee and Peter Groenewegen. Our long shared history has proved to be a firm working basis. Peter is a keen and stimulating foreman, while it is inspirational to elaborate on the fine ideas Jouke contributes.

Finally, I am glad not to feel the need to make up to my dear family and friends for the inconveniences usually related to the writing of a thesis. It has been part of my work; no more and no less than that. Until half a year ago, they were even ignorant of this imminent $\mathrm{PhD}$. So, in the near future no drastic changes in the attention and time allocated to work and private life are to be expected.

Utrecht, 11 June 2003 


\section{Dankwoord}

Lezers van dit boek zullen snel genoeg hebben gemerkt dat dit proefschrift geen soloproductie is. Zonder de hulp van velen zou dit proefschrift er waarschijnlijk niet eens zijn geweest. De Europese Commissie heeft deze internationale studie financieel grotendeels mogelijk gemaakt en het Europese kantoor van de Wereldgezondheidsorganisatie (WHO) verleende belangrijke steun en gebruikte de resultaten. De uitdagingen van de instrumentontwikkeling en de praktische uitvoering van de studie in zo veel landen zijn tot een goed einde gebracht mede door belangrijke inbreng van de lokale coördinatoren.

Voor hun inbreng in de wetenschappelijke producten die uit deze studie zijn voortgekomen wil ik de medeauteurs en andere collega's, zowel onderzoekers als collega's in ondersteunende functies, oprecht bedanken. Terugkijkend op het onderzoek kan ik alleen maar zeggen dat het een leuke en leerzame periode was.

Dit boek is opgedragen aan een collectief waar ik nu precies 25 jaar werk. Het huidige NIVEL lijkt heel weinig op de kleine informele pionierorganisatie van 1978, maar het is nog steeds een positief kritische omgeving van betrekkelijk zelfstandig werkende, maar toch op elkaar betrokken professionals. Bij de schaarse gelegenheden dat ik van baan kon wisselen heb ik telkens besloten te blijven. Blijkbaar biedt het NIVEL mij de externe voorwaarden die nodig zijn om met plezier te blijven werken. Van alle mensen die samen het NIVEL uitmaken, wil ik er, in verband met dit proefschrift, twee met name noemen, en niet alleen vanwege hun rol in dit gebeuren: Jouke van der Zee en Peter Groenewegen. Peter is een scherpe en stimulerende voorman. Met Jouke is het inspirerend werken vanwege zijn goede ideeën.

Tot slot voel ik gelukkig niet de behoefte iets goed te maken naar mijn lieve familie en vrienden voor getob en gebrek aan aandacht waar proefschriften doorgaans mee gepaard gaan. Het was deel van mijn werk; niet meer en niet minder. Tot een half jaar geleden waren zij onwetend van deze naderende promotie. Van nu af aan hoeven geen ingrijpende veranderingen verwacht te worden in aandacht en tijd voor werk en privé-leven.

Utrecht, 11 juni 2003 


\section{Curriculum vitae}

Wienke Boerma was born in Arnhem, the Netherlands, on 12 January 1947. In 1966 he received his pre-university education diploma (HBS-a, a former Dutch type of High School) at Thomas a Kempis College in Arnhem, following which he went to study Personnel Management at the School of Higher Vocational Education (Sociale Academie) in Eindhoven, were he graduated in 1970. After completing his military service, he went to study Psychology at Utrecht University in 1971, where he took his Master's degree in Clinical Psychology in 1980.

From 1976 to 1980 he was a part-time teacher of psychology and communication for the in-service training of nurses in Zeist general hospital. In 1978 he joined the Dutch Institute of General Practitioners (Nederlands Huisartsen Instituut, NHI) as a researcher, and from 1985 until the present he has worked for its legal successor, NIVEL (the Netherlands Institute for Health Services Research), his main subject being cooperation and teamwork in Dutch primary health care, in health centres and group general practices in particular. He has been involved in the research and documentation of health care systems since 1990 and the current European research project has been part of this strand of activities. In addition, from 1992 onwards he has been involved in health care development projects in central and eastern Europe, as a project leader or technical advisor. The study reported in this book was carried out at NIVEL, in collaboration with many individuals and institutes in European countries. 


\section{Curriculum vitae}

Wienke Boerma is geboren op 12 januari 1947 in Arnhem. In 1966 haalde hij het diploma HBS-a aan het Thomas a Kempis College in Arnhem. Daarna studeerde hij Personeelswerk aan de Sociale Academie in Eindhoven, waar in 1970 het diploma werd behaald. Na het vervullen van de militaire dienstplicht ging hij in 1971 Psychologie studeren aan de Rijksuniversiteit Utrecht. De doctoraalbul Klinische Psychologie ontving hij daar in 1980.

Van 1976 tot 1980 was hij parttime leraar psychologie en communicatie aan de in-service opleiding voor verpleegkundigen in het Zeister Ziekenhuis. Vanaf 1978 werkt hij als onderzoeker bij het Nederlands Huisartsen Instituut (NHI) en vanaf 1985 bij diens rechtsopvolger NIVEL (Nederlands instituut voor onderzoek van de gezondheidszorg). Hij heeft onder meer onderzoek gedaan naar samenwerking in de Nederlandse eerstelijnsgezondheidszorg, met name in gezondheidscentra en groepspraktijken. Vanaf 1990 is hij zich gaan bezighouden met onderzoek en documentatie van stelsels van gezondheidszorg. Hiervan maakt het onderhavige Europese onderzoek deel uit. Vanaf 1992 is hij daarnaast, als projectleider of technisch adviseur, actief in projecten ter verbetering van de gezondheidszorg in de landen van midden- en oost Europa. Het onderzoek waarop dit proefschrift is gebaseerd, werd uitgevoerd door het NIVEL in samenwerking met een groot aantal personen en instellingen in Europese landen. 



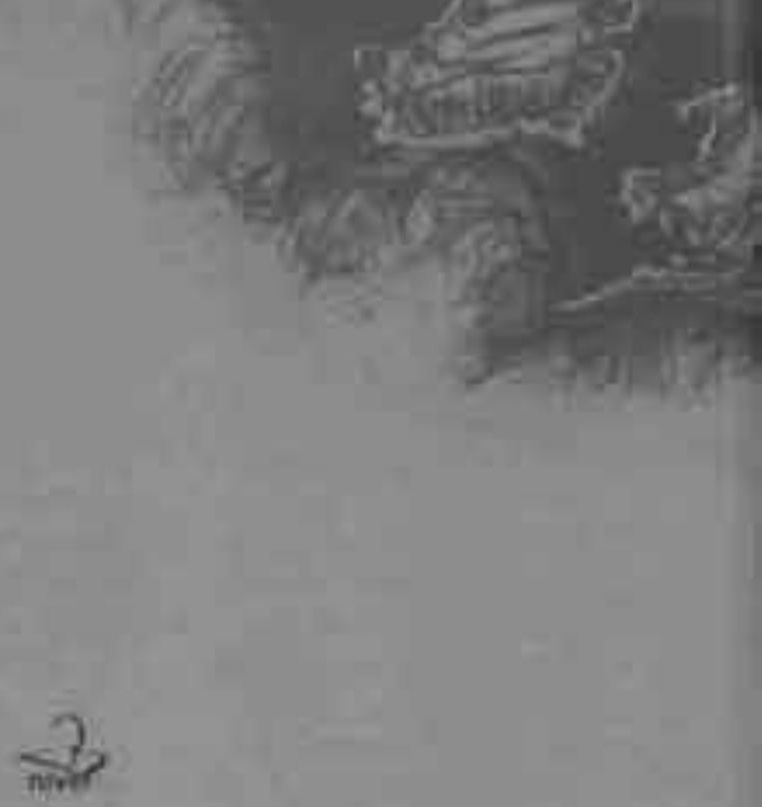

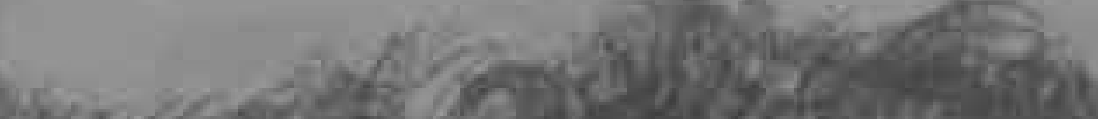

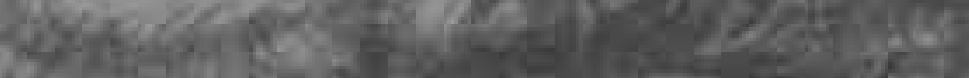

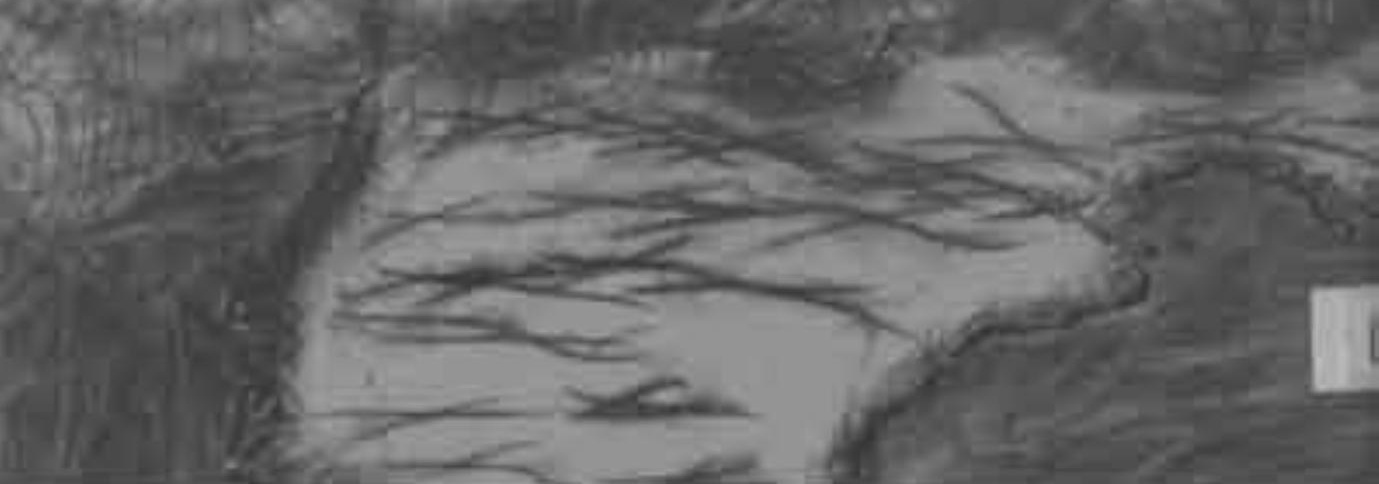

